\title{
Restabelecimento de Energia por Reconfiguração de Redes em Sistemas de Distribuição de Grande Porte com Priorização de Chaves, Consumidores e Definição de Sequência de Chaveamento ${ }^{1}$
}

\author{
Leandro Tolomeu Marques
}

Orientador: Prof. Dr. João Bosco Augusto London Junior

Dissertação de mestrado apresentada ao Departamento de Engenharia Elétrica e de Computação, da Escola de Engenharia de São Carlos, da Universidade de São Paulo, como parte dos requisitos para obtenção do título de Mestre em Ciências pelo Programa de Engenharia Elétrica. Área de concentração: Sistemas Elétricos de Potência.

USP - São Carlos

Agosto/2013

\footnotetext{
${ }^{1}$ Trata-se da versão corrigida da dissertação. A versão original encontra-se disponível na EESC/USP, que aloja o Programa de Pós-Graduação em Engenharia Elétrica.
} 
AUTORIZO A REPRODUÇÃO TOTAL OU PARCIAL DESTE TRABALHO, POR QUALQUER MEIO CONVENCIONAL OU ELETROONICO, PARA FINS DE ESTUDO E PESQUISA, DESDE QUE CITADA A FONTE.

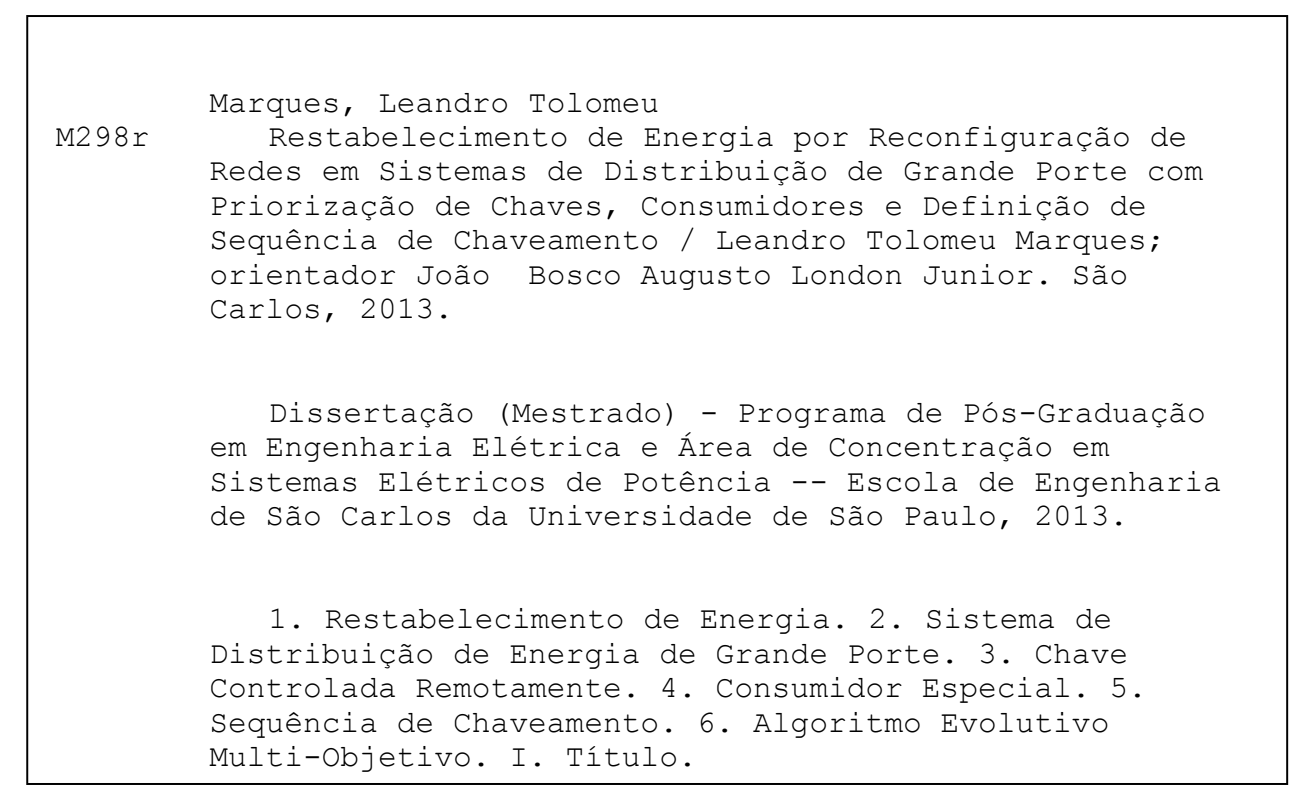




\section{FOLHA DE JULGAMENTO}

Candidato: Engenheiro LEANDRO TOLOMEU MARQUES.

Título da dissertação: "Restabelecimento de energia por reconfiguração de redes em sistemas de distribuição de grande porte com priorização de chaves, consumidores e definição de sequência de chaveamento".

Data da defesa: 29/08/2013

\section{Comissão Julgadora:}

Resultado:

Prof. Assoc. João Bosco Augusto London Júnior (Orientador) (Escola de Engenharia de São Carlos/EESC)

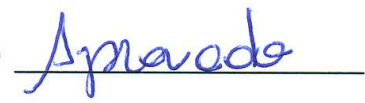

Profa. Dra. Walkyria Krysthie Arruda Gonçalves Martins (Universidade Federal de Mato Grosso/UFMT)

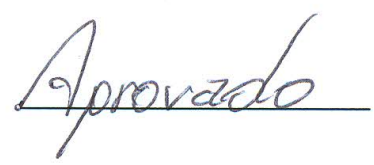

Prof. Associado Alexandre Cláudio Botazzo Delbem (Instituto de Matemática e Computação/ICMC)

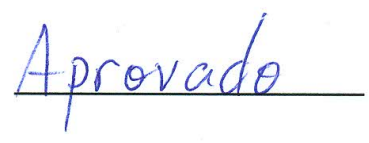

Coordenador do Programa de Pós-Graduação em Engenharia Elétrica e Presidente da Comissão de Pós-Graduação:

Prof. Titular Denis Vinicius Coury 

À minha Esposa, Joice, aos meus pais, Luiz e Ivany, à minha irmã, Laise, e a minha avó materna, Teresinha (in memoriam). 

A Deus, em primeiro lugar, por Seu amor, bondade e misericórdia que me sustentam.

À Santíssima Virgem Maria, por sua maternal intercessão, educação, condução e providência.

À minha Amada Esposa, Joice, por seu amor, carinho, companhia, dedicação, solicitude e apoio em todos os momentos.

Aos meus amados pais, Luiz e Ivany, meus primeiros professores, por seu amor, dedicação, empenho e apoio sempre constantes.

À minha querida irmã, Laise, por sua paciência, amor, companheirismo e amizade.

Ao meu orientador, professor João Bosco, pela orientação, confiança, paciência, disponibilidade e amizade.

Ao Danilo Sipoli Sanches pelas discussões, colaborações, solicitude, apoio, companhia e amizade.

Ao professor Alexandre C. B. Delbem pela colaboração e discussões durante as reuniões do grupo de pesquisa.

Ao Douglas H. Pereira pelo auxílio no desenvolvimento de parte deste trabalho.

Aos amigos do LACOSEP (Laboratório de Análise Computacional em Sistemas Elétricos de Potência) pela amizade, discussões e companhia no trabalho.

A todos os funcionários do Departamento de Engenharia Elétrica e de Computação pela atenção, profissionalismo e dedicação.

Aos amigos conquistados em São Carlos.

À Escola de Engenharia de São Carlos por todo suporte durante o desenvolvimento deste trabalho.

À FAPESP pelo apoio financeiro. 

"A fé e a razão constituem como que as duas asas pelas quais o espírito humano se eleva para a contemplação da verdade." (Beato João Paulo II) 



\section{Resumo}

Marques, L. T. Restabelecimento de Energia por Reconfiguração de Redes em Sistemas de Distribuição de Grande Porte com Priorização de Chaves, Consumidores e Definição de Sequência de Chaveamento. 129p. Dissertação de mestrado - Escola de Engenharia de São Carlos, Universidade de São Paulo, 2013.

$\mathrm{Na}$ ocorrência de uma ou de múltiplas faltas permanentes em sistemas de distribuiçâo de energia elétrica é inevitável a ausência de fornecimento à algumas cargas. Contudo, devido à presença de chaves seccionadoras, após a localização e isolação do trecho sob falta, é possível restaurar o abastecimento de energia a estas cargas fora de serviço. Para tal é necessária a obtenção de um plano de restabelecimento adequado, no menor intervalo de tempo possível, capaz de informar as chaves que devem ser operadas a fim de reconectar estas cargas à rede e sem sobrecarregar nenhum equipamento.

Neste sentido, têm sido propostas metodologias para auxiliar as atividades dos operadores de sistemas de distribuição por meio do fornecimento de planos de restabelecimento de energia em situações de contingência. Todavia, a aplicação da maioria destas técnicas restringe-se à redes pequenas, quando comparadas às redes reais que possuem milhares de barras e chaves. Em outras metodologias, na tentativa de superar esta limitação, são feitas simplificações na representação da rede, desconsiderando alguns dos seus elementos. Nestes casos, a solução fornecida para a rede simplificada pode não ter o mesmo desempenho na rede em operação, o que compromete a confiabilidade dessas metodologias. Em outros métodos, ainda, a rede é representada com todas as suas barras e chaves, no entanto, deixam de considerar a presença de consumidores especiais, que exigem prioridade de fornecimento, bem como de chaves existentes na rede que podem ser operadas remotamente.

Face ao exposto, propõe-se uma metodologia para determinação, em tempo real, de planos de restabelecimento de energia elétrica em sistemas de distribuição de grande porte em situações de uma ou de múltiplas faltas. Para lidar com os múltiplos objetivos 
deste problema, sendo alguns dele conflitantes entre si, esta será baseada em Algoritmos Evolutivos Multi-Objetivo, enquanto que a representação computacional sem simplificações da rede será proporcionada por uma codificação de dados apoiada na teoria de grafos e denominada Representação Nó-Profundidade. A fim de diminuir o tempo e o custo de implementação dos planos obtidos, será considerada e dado prioridade de manobra às chaves controladas remotamente, que podem ser alteradas do centro de operações. Será dado prioridade também ao fornecimento de energia de consumidores especiais. Por fim, para cada plano de restabelecimento fornecido será definida uma sequência factível de chaves que, quando alteradas, reconectarão as cargas sãs fora de serviço e eliminarão sobrecargas ou perfis de tensão inadequados. Para validar a metodologia proposta serão realizadas simulações computacionais no sistema de distribuição real da cidade de São Carlos-SP, em operação no ano de 1994, e nas suas versões duplicada, quadruplicada e octuplicada.

Palavras-Chaves: Restabelecimento de Energia, Sistema de Distribuição de Grande Porte, Chave Controlada Remotamente, Consumidor Especial, Sequência de Chaveamento, Algoritmo Evolutivo Multi-Objetivo. 
Marques, L. T. Service Restoration by Network Reconfiguration in Large Scale Distribution Systems with Switches and Consumers Priorization and Switching Sequence Definition. 129p. Dissertação de mestrado - Escola de Engenharia de São Carlos, Universidade de São Paulo, 2013.

The occurrence of one or multiple permanent faults in electric power distribution systems is inevitable the privation of the service to some loads. However, due to the presence of switches, after the location and isolation of the faulted section, you can restore the power supply to these out of service loads. To this it is necessary to obtain, as soon as possible, a suitable restoration plan. It must be able to inform the switches that must be operated in order to reconnect these loads without overloading on any network or equipment.

In this sense, it has been proposed methods to assist the operators' activities of the of distribution systems by providing plans to restore the service in contingency situations. However, the application of the most of these techniques is limited to small networks, when they are compared to real networks that have thousands of bars and keys. In other methodologies, in order to overcome this limitation, simplifications are made in the representation of the network, ignoring some of its elements. In these cases, the solution provided for a simplified network may not have the same performance on the network in operation, which affects the reliability of these methodologies. In other methods, the network is represented with all of its bars and switches. However, these methodologies do not consider the presence of the special consumers that require service priority neither the switches that can be operated remotely.

Given the above, we propose a methodology for determining, in real time, plans for service restoration in large-scale electric distribution systems in situations of one or multiple faults. To deal with the multiple objectives of this problem, some of them conflicting, the proposed method will be based on Multi-Objective Evolutionary Algorithms. Moreover, the computational representation without simplifications of the network will be provided by a data encoding 
based in graph theory and called Node-Depth Encoding. In order to reduce the time and cost of the implementation of the plans obtained, it will be considered and given priority to maneuvers in remotely controlled switches, which can be changed from the operation center. Priority will be given also to the power supply of special consumers. Finally, for each restoration plan provided will be gotten a feasible switching sequence that, when implemented, will reconnect the out of service loads and eliminate overloads or inadequate voltage profiles. To validate the proposed methodology it will be performed computer simulations in the real distribution system of the São Carlos-SP city, in operation in 1994, and their doubled, quadruplicate and octuplicate versions.

keywords: Service Restoration, Large-Scale Distribution System, Remotely Controlled Switch, Special Load, Switching Sequence, Multi-Objective Evolutionary Algorithm. 


\section{Lista de Abreviaturas e Siglas}

AE Algoritmo Evolutivo

AEMO Algoritmo Evolutivo Multi-Objetivo

AEMT Algoritmo Evolutivo Multi-objetivo em Tabela

AEMT ++ Algoritmo Evolutivo Multi-objetivo em Tabelas com Priorização de Chaves, Consumidores e Definição de Sequência de Chaveamento

CAO Change Ancestor Operator

CE Consumidor Especial

CCM Chave Controlada Manualmente

CCR Chave Controlada Remotamente

NA Normalmente Aberta

NF Normalmente Fechada

NSGA Non-dominated Sorting Genetic Algorithms

NSGA-II Non-dominated Sorting Genetic Algorithm-II

PAO Preserve Ancestor Operator

RNP Representação Nó-Profundidade

SDR Sistema de Distribuição Radial

SPEA2 Strength Pareto Evolutionary Algorithm 
1.1 Exemplo de restabelecimento de energia via reconfiguração de redes. . . . . 5

3.1 Ordenação por não dominância $($ Deb, 2001) . . . . . . . . . . . . . . . 23

3.2 Algoritmo de corte no modelo SPEA2 (Zitzler et al., 2001). . . . . . . . . . 25

4.1 Exemplo de SDR típico. . . . . . . . . . . . . . . . . . . . . 28

4.2 Representação em grafo do SDR da Figura 4.1. . . . . . . . . . . . . . . . 29

4.3 RNPs da floresta de grafo da Figura 4.2. . . . . . . . . . . . . . . . . . . 29

4.4 As três RNPs possíveis para o setor E. . . . . . . . . . . . . . . . . . . . . . . . . . . . . . . . . . . .

4.5 Configuração pré-falta. . . . . . . . . . . . . . . . . . . 41

4.6 Configuração inicial, que corresponde também a primeira configuração factível obtida. . . . . . . . . . . . . . . . . . . . . . 41

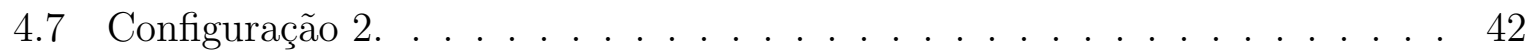

4.8 Configuração $3 \ldots \ldots \ldots a n$

4.9 Configuração $4 \ldots \ldots$. . . . . . . . . . . . . . . . . . . . 43

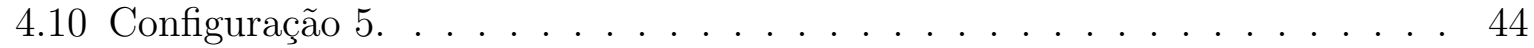

5.1 Exemplo do procedimento de obtenção da primeira configuração factível pelo AEMT++. . . . . . . . . . . . . . . . . . . . . . . . . . 49

5.2 Configuração pré-falta do SDR da Figura 5.1. . . . . . . . . . . . . . . 50

5.3 Configuração 2. . . . . . . . . . . . . . . . . . . . 56

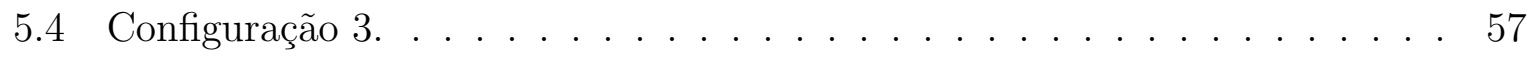

5.5 Configuração $4 \ldots \ldots \ldots \ldots \ldots \ldots \ldots$

5.6 Configuração 5. . . . . . . . . . . . . . . . . . . . . . . . 60

5.7 Reprodução da primeira configuração factível obtida no exemplo da Seção 5.2.1. . . . . . . . . . . . . . . . . . . . . . . 72

5.8 Configuração intermediária 1 de $P M_{5}^{1}$. . . . . . . . . . . . . . . . . . 74

5.9 Configuração da rede obtida por meio da aplicação da sequência de chaveamento presente em $P M_{5}^{1}$. . . . . . . . . . . . . . . . . 75

5.10 Configuração da rede obtida pela aplicação da sequência de chaveamento presente em $P M_{5}^{1}$. . . . . . . . . . . . . . . . . . . . . . . 78

6.1 Alimentador 23 do Sistema 1, com destaque para o setor 504 sob falta (Santos, 2009). 
6.2 Número percentual de vezes em que o percentual de manobras em CCRs da solução final, em relação ao número total de manobras em chaves, foi igual ou superior a 15\% (aproximadamente o dobro da quantidade percentual de CCRs existentes nos Sistemas 1, 2, 3 e 4).

6.3 Número percentual de vezes em que foi definida uma sequência de chaveamento sem a presença de chaves que retornaram ao seu estado anterior, considerando-se a ocorrência de uma única falta. . . . . . . . . . .

6.4 Número percentual de vezes em que a solução final definida não exigiu a transferência de CEs, considerando-se a ocorrência de uma única falta nos Sistemas $1,2,3$ e $4 \ldots \ldots \ldots$. . . . . . . . . . . . . 95

6.5 Alimentador 22 do Sistema 1, com destaque para o setor 464 sob falta (Modificado de Santos (2009)) . . . . . . . . . . . . . . . . . 96

6.6 Alimentador 6 do Sistema 1, com destaque para o setor 189 sob falta (Modificado de Santos (2009)) . . . . . . . . . . . . . . 96

6.7 Número percentual de vezes em que o percentual de CCRs presentes na solução final, em relação ao número de total de manobras em chaves, foi igual ou superior a 15\% (aproximadamente o dobro da quantidade percentual de CCRs existentes nos Sistemas 1, 2, 3 e 4).

6.8 Número percentual de vezes em que foi definida uma sequência de chaveamento sem a presença de chaves que retornaram ao seu estado anterior, considerando-se a ocorrência de múltiplas faltas. . . . . . . . . . . 101

6.9 Número percentual de vezes em que a solução final definida não exigiu a transferência de CEs, considerando-se a ocorrência de múltiplas faltas nos Sistemas 1, 2, 3 e 4. . . . . . . . . . . . . . . . . 103

6.10 Evolução da média da aptidão dos indivíduos que compõem a subpopulação armazenada na tabela $P_{6} \ldots \ldots$. . . . . . . . . . . . . . . . . . 103

6.11 Evolução da média da aptidão dos indivíduos que compõem a subpopulação armazenada na tabela $P_{7}$.

6.12 Evolução da média da aptidão dos indivíduos que compõem a subpopulação armazenada na tabela $P_{8}$.

6.13 Evolução da média da aptidão dos indivíduos que compõem a subpopulação armazenada na tabela $P_{9} \ldots \ldots$. . . . . . . . . . . . . . 105

6.14 Evolução da média da aptidão dos indivíduos que compõem a subpopulação

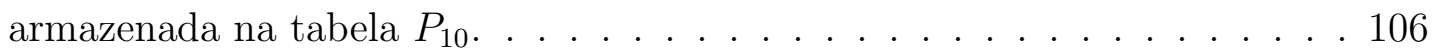

6.15 Evolução da média da aptidão dos indivíduos que compõem a subpopulação armazenada na tabela $P_{11} \ldots \ldots$. . . . . . . . . . . . 107

6.16 Evolução da média da aptidão dos indivíduos que compõem a subpopulação armazenada na tabela $P_{12} \ldots \ldots$. . . . . . . . . . . . . . 107

6.17 Evolução da média da aptidão dos indivíduos que compõem a subpopulação armazenada na tabela $P_{13} \ldots \ldots \ldots$. . . . . . . . . . . . . . . . . . . . .

A.1 Exemplo de um grafo. . . . . . . . . . . . . . . . . . . 118

A.2 Grafo representando um SDR com três alimentadores (Santos et al., 2010). 119

A.3 RNP das três árvores da Figura A.2 (Santos et al., 2010). . . . . . . . . . . 119

A.4 Árvore $T_{d e}$ e sua RNP, para aplicação do operador PAO. . . . . . . . . . . . 123

A.5 Árvore $T_{\text {para }}$ e sua RNP, para aplicação do operador PAO. . . . . . . . . . 123

A.6 Subárvore podada $T_{t m p}$ e sua RNP, na aplicação do operador PAO. . . . . . 124 
A.7 Árvore $T_{\text {para }}^{\prime}$ e sua RNP após a aplicação do operador PAO. . . . . . . . 124

A.8 Árvore $T_{d e}^{\prime}$ e sua RNP após a aplicação do operador PAO. . . . . . . 125

A.9 RNP da floresta $F^{\prime}$ obtida pela aplicação do operador PAO. . . . . . . 125

A.10 Árvore $T_{d e}$ e sua RNP, para aplicação do operador CAO. . . . . . . . . 127

A.11 Árvore $T_{\text {para }}$ e sua RNP, para aplicação do operador CAO . . . . . . . 127

A.12 Subárvores enraizadas nos nós do caminho de $r$ a $p \ldots \ldots \ldots \ldots . . .128$

A.13 Subárvore $T_{t m p}$ e sua RNP na aplicação do operador CAO . . . . . . . 128

A.14 Árvore $T_{\text {para }}^{\prime}$ e sua RNP após a aplicação do operador CAO. . . . . . . . 128

A.15 RNP da floresta $F^{\prime}$ gerado pela a aplicação do operador CAO . . . . . . 129 


\section{Lista de Tabelas}

4.1 Manobras de chaves: Caso 1. . . . . . . . . . . . . . . . . . . . . . . . . . 39

4.2 Manobras de chaves: Caso 2. . . . . . . . . . . . . . . . . . . . . . . . . 39

4.3 Manobras de chaves: Caso 3. . . . . . . . . . . . . . . . . . . . 40

4.4 Vetor com o estado das chaves na configuração pré-falta, em que 1 representa chave fechada e 0 chave aberta. . . . . . . . . . . . . . . . 41

4.5 Vetor com o número de manobras para cada configuração. . . . . . . . . . 42

4.6 Vetor com o número de manobras, atualizado com a configuração 2. . . . . 42

4.7 Vetor com o número de manobras, atualizado com a configuração 3. . . . . 42

4.8 Vetor com o número de manobras, atualizado com a configuração 4. . . . . 43

4.9 Vetor com o número de manobras, atualizado com a configuração 5. . . . . 43

5.1 Estado das chaves em $G^{i}$, onde 0 representa chave aberta e 1 corresponde a chave fechada. . . . . . . . . . . . . . . . . . . 55

5.2 Tipo de cada chave, onde 0 representa CCM e 1 corresponde a CCR. . . . 55

5.3 Matriz que salva o número de manobras em CCRs e em CCMs para cada configuração. . . . . . . . . . . . . . . . . . . . 55

5.4 Matriz que salva o número de manobras, atualizada com a configuração $2 . \quad 57$

5.5 Matriz que salva o número de manobras, atualizada com a configuração $3 . \quad 57$

5.6 Matriz que salva o número de manobras, atualizada com a configuração $4 . \quad 59$

5.7 Matriz que salva o número de manobras, atualizada com a configuração $5 . \quad 59$

5.8 Conjunto de pares de chaves alteradas de $G^{3}$. . . . . . . . . . . . . . . . 69

5.9 Conjunto de pares de chaves alteradas de $G^{5}$. . . . . . . . . . . . . . . . 71

5.10 Conjunto de chaves alteradas de $G^{5}$ atualizado pela exclusão da chave 17. . 71

5.11 Sequência de chaveamento na qual o par rearranjado encontra-se na primeira das duas linhas nas quais encontrava-se a chave 17. . . . . . . . . 73

5.12 Sequência de chaveamento na qual o par rearranjado encontra-se na segunda das duas linhas nas quais encontrava-se a chave 17. . . . . . . . . 73

5.13 Conjunto de pares de chaves alteradas de $G^{4}$. . . . . . . . . . . . . . . 76

5.14 Conjunto de pares de chaves alteradas de $G^{4}$, atualizado pela exclusão das chaves 17 e 20. . . . . . . . . . . . . . . . . . . . 77

5.15 Conjunto de pares de chaves alteradas de $G^{15}$. . . . . . . . . . . . . . 78

5.16 Conjunto de pares de chaves alteradas de $G^{15}$, atualizado pela retiradas das chaves 2 e 3. . . . . . . . . . . . . . . . . . . . . 79 
5.17 Sequência de chaveamento na qual o par rearranjado [25, 4] encontra-se inserido na primeira das três linhas nas quais haviam chaves repetidas. . . 80

5.18 Sequência de chaveamento na qual o par rearranjado $[25,4]$ encontra-se inserido na segunda das três linhas nas quais haviam chaves repetidas. . . . 80

5.19 Sequência de chaveamento na qual o par rearranjado [25, 4] encontra-se inserido na terceira das três linhas nas quais haviam chaves repetidas. . . . 80

6.1 Valores das restrições operacionais e perdas ôhmicas totais para a primeira configuração factível obtida para os Sistemas 1, 2, 3 e 4 considerando-se a ocorrência de uma única falta. . . . . . . . . . . . . . . . . . . . . . 87

6.2 Valores das restrições operacionais e das perdas ôhmicas totais para as soluções finais obtidas e tempo de processamento considerando-se a ocorrência de uma única falta nos Sistemas 1, 2, 3 e 4 . . . . . . . . . . 88

6.3 Número de manobras em chaves obtidas pelo AEMT++ para a solução final considerando-se a ocorrência de uma única falta nos Sistemas 1, 2, 3 e 4. . . . . . . . . . . . . . . . . . . . . 89

6.4 Percentual de manobras em CCRs presentes na solução final, em relação ao número total de manobras em chaves. . . . . . . . . . . . . . . . . 90

6.5 Número de CEs desligados pela ocorrência da falta e de CEs transferidos para implementação das soluções finais obtidas para os Sistemas 1, 2, 3 e 4 na ocorrência de uma única falta. . . . . . . . . . . . . . . . . . . . . . 94

6.6 Valores das restrições operacionais e das perdas ôhmicas totais para a primeira configuração factível obtida para os Sistemas 1, 2, 3 e 4 considerando-se a ocorrência de múltiplas faltas simultâneas. . . . . . . . . 97

6.7 Valores das restrições operacionais e das perdas ôhmicas totais para as soluções finais obtidas e tempo de processamento considerando-se a ocorrência de múltiplas faltas simultâneas nos Sistemas 1, 2, 3 e 4. . . . . 98

6.8 Número de manobras em chaves obtidas pelo AEMT++ para a solução final considerando-se a ocorrência de múltiplas faltas nos Sistemas 1, 2, 3 e 4. . . . . . . . . . . . . . . . . . . . . . 99

6.9 Percentual de CCRs presentes na solução final, em relação ao número total de manobras em chaves. . . . . . . . . . . . . . . . . . . . 99

6.10 Número de CEs desligados pela ocorrência de múltiplas faltas e de CEs transferidos para implementação das soluções finais obtidas para os Sistemas 1, 2, 3 e 4 na ocorrência de múltiplas faltas. . . . . . . . . . . . . 102

A.1 Lista de adjacências para os nós do grafo da Figura A.2 (Santos, 2009). 121 
1 Introdução 1

1.1 Motivação . . . . . . . . . . . . . . . . . . . . . . 1

1.2 O Problema . . . . . . . . . . . . . . . . . . 2

1.2.1 Restabelecimento de Energia em Sistemas de Distribuição . . . . . 2

1.2.2 Restabelecimento de Energia via Reconfiguração de Redes . . . . . 3

1.3 Justificativas . . . . . . . . . . . . . . . . . . . . . . 6

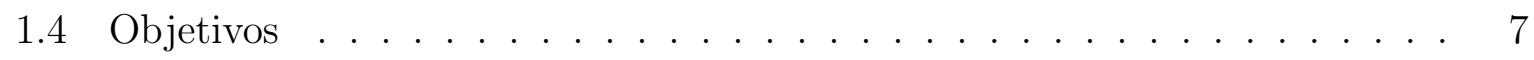

1.5 Organização do Documento . . . . . . . . . . . . . . . 8

2 Revisão Bibliográfica $\quad 11$

2.1 Considerações Iniciais . . . . . . . . . . . . . . . . . . . . . . . . 11

2.2 Revisão Bibliográfica . . . . . . . . . . . . . . . . . . . . . . 11

2.3 Considerações Finais . . . . . . . . . . . . . . . . . . 15

3 Algoritmos Evolutivos e Otimização Multi-Objetivo 17

3.1 Considerações Iniciais . . . . . . . . . . . . . . . . . . . 17

3.2 Algoritmos Evolutivos . . . . . . . . . . . . . . . . . . . . . . . . . . . . . . . . .

3.3 Otimização Multi-objetivo . . . . . . . . . . . . . . . . . . . 19

3.4 Algoritmos Evolutivos para Otimização Multi-objetivo . . . . . . . . . . . . 21

3.4.1 Non-Dominated Sorting Genetic Algorithm (NSGA) . . . . . . . . . 22

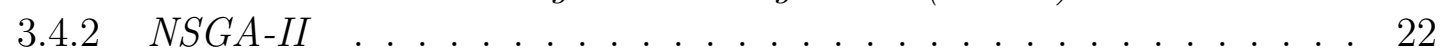

3.4.3 Strength Pareto Evolutionary Algorithm (SPEA2) . . . . . . . . 24

3.4.4 Método de Tabelas . . . . . . . . . . . . . . . 26

3.5 Considerações Finais . . . . . . . . . . . . . . . . 26

4 Medodologia Base: Algoritmo Evolutivo Multi-Objetivo em Tabela 27

4.1 Considerações Iniciais . . . . . . . . . . . . . . . . . . . 27

4.2 Estrutura de Dados . . . . . . . . . . . . . . . . . . . . . 28

4.2.1 Representação de SDRs por meio de Grafos . . . . . . . . . . . . . . 28

4.2 .2 Representação Nó-Profundidade . . . . . . . . . . . . . . . . . . . . . . . . . . . . . . 39

4.2 .3 RNP de Setor . . . . . . . . . . . . . . . . . 30

4.3 Algoritmo e Funcionamento . . . . . . . . . . . . . . . . . . . . . 32

4.4 Cálculo do Número de Manobras . . . . . . . . . . . . . . . 38 
4.4.1 Exemplo do cálculo do número de manobras . . . . . . . . . . . . . 40

4.5 Heurística para Priorização de Manobras . . . . . . . . . . . . . . . . . . . 44

4.6 Considerações Finais . . . . . . . . . . . . . . . . . . . . . . . . . . . 45

5 Metodologia Proposta $\quad 47$

5.1 Considerações Iniciais . . . . . . . . . . . . . . . . . . . . . 47

5.2 Priorização de Chaves Controladas Remotamente . . . . . . . . . . . . . 47

5.2.1 Priorização de Chaves Controladas Remotamente na Obtenção da Primeira Configuração Factível . . . . . . . . . . . . . . . . 48

5.2.2 Priorização de Chaves Controladas Remotamente ao Longo do Processo Evolutivo . . . . . . . . . . . . . . . 51

5.2.2.1 Novo Algoritmo para Cálculo do Número de Manobras em Chaves ................... 51

5.2.2.2 Novas Subpopulações em Tabelas . . . . . . . . . . . . . 60

5.3 Priorização de Fornecimento aos Consumidores Especiais . . . . . . . . . . 64

5.4 Definição de Uma Solução Final . . . . . . . . . . . . . . . . . . . . . . . 66

5.5 Definição de Sequência de Chaveamento Factível . . . . . . . . . . . . . 68

5.6 Considerações Finais . . . . . . . . . . . . . . . . . . . . . . 81

6 Resultados Experimentais $\quad 83$

6.1 Considerações Iniciais . . . . . . . . . . . . . . . . . . . . . . . . 83

6.2 Simulações para Uma Única Falta . . . . . . . . . . . . . . . . . . . . . . . . . . . . . . . . . . . . . . . . . .

6.3 Simulações para Múltiplas Faltas . . . . . . . . . . . . . . . . . . . 95

6.4 Evolução das Subpopulações Armazenadas nas Tabelas Propostas . . . . . 102

6.5 Considerações Finais . . . . . . . . . . . . . . . . . . 107

7 Conclusões, Contribuições e Trabalhos Futuros 109

7.1 Conclusões . . . . . . . . . . . . . . . . . . . . . . . . . . 109

7.2 Contribuições . . . . . . . . . . . . . . . . . . . . . . 111

7.3 Trabalhos Futuros . . . . . . . . . . . . . . . . . . . . . . 112

7.4 Publicações Originadas desta Pesquisa . . . . . . . . . . . . . . . 112

$\begin{array}{ll}\text { A Representação Nó-Profundidade e Seus Operadores } & 117\end{array}$

A.1 Considerações Iniciais . . . . . . . . . . . . . . . . . . . . 117

A.2 Conceitos Básicos da Teoria de Grafos . . . . . . . . . . . . 117

A.3 RNP Aplicada a Problemas de Reconfiguração de Redes . . . . . . . . . . 118

A.3.1 Localização de um nó na RNP . . . . . . . . . . . . . . . . . . . . . 120

A.3.2 Aplicação do Operador PAO . . . . . . . . . . . . . . . . . . . . . . . . . . . . . . 122

A.3.3 Aplicação do Operador CAO . . . . . . . . . . . . . . . . . 125

A.4 Considerações Finais ～. . . . . . . . . . . . . . . . . . . . . . . . . 129 


\section{Introdução}

\subsection{Motivação}

As atividades dos engenheiros e operadores de sistemas de distribuição de energia têm necessitado cada vez mais de ferramentas computacionais que garantam agilidade e flexibilidade no projeto e operação dessas redes (Ferreira, 2010). No contexto da operação de sistemas de distribuição, um dos problemas mais críticos com os quais esses profissionais lidam constantemente é o de restabelecimento do fornecimento de energia elétrica em situações de contingência.

Apesar disso, esse problema é atualmente solucionado essencialmente por meio da experiência dos operadores e da sua familiaridade com as características específicas da rede que gerenciam, uma vez que as ferramentas computacionais de que dispõem como auxílio são limitadas e impróprias ao fornecimento de planos de restabelecimento. Dificuldades semelhantes são encontradas em situações de manutenção preventiva, nas quais é necessário determinar uma área do sistema, em entorno do trecho a sofrer manutenção, que seja a mínima possível, a fim de que a ausência temporária de fornecimento restrinja-se à menor parte possível da rede. Vale lembrar que, para ambas as situações citadas, o tempo é também um fator crítico, pois, quanto maior o tempo sem fornecimento, pior será o desempenho dos indicadores de qualidade e de continuidade da empresa de distribuição de energia elétrica. 
Nesse sentido, para diminuir os gastos por descumprimento desses indicadores e aumentar a satisfação dos consumidores, essas empresas têm empreendido, sistematicamente, esforços para diminuir o número e o tempo de desligamentos. Como exemplos desses esforços pode-se citar a substituição que tem ocorrido dos cabos "nus" por cabos protegidos ou, em algumas situações, por cabos isolados; a instalação de chaves com capacidade de serem operadas remotamente, de equipamentos microprocessados que permitem o religamento automático das linhas e de outros capazes de isolar automaticamente um menor trecho possível com falta.

Da mesma forma, técnicas recentes de inteligência computacional, relacionadas ao restabelecimento de energia, têm sido propostas na literatura e têm se mostrado promissoras para auxiliar os operadores de sistemas de distribuição de energia, bem como capazes de melhorar o uso de recursos e de garantir economias. Entretanto, para redes reais com milhares de barras e chaves, essas técnicas podem atingir a capacidade máxima de processamento dos computadores ou não conseguem respostas em tempos compatíveis com a necessidade do problema. Outras ainda, para contornar esses problemas, simplificam a representação da rede, o que concorre para diminuir a confiabilidade da solução fornecida.

Assim sendo, propõe-se por meio desta dissertação uma nova metodologia para restabelecimento de energia em situações de contingência em sistemas de distribuição radiais (SDRs), que não exija simplificações na representação da rede. Ademais, a fim de auxiliar o trabalho dos operadores de SDRs e fornecer a estes planos adequados de restabelecimento, o grande diferencial dessa metodologia deverá ser a sua capacidade de priorizar o atendimento de consumidores especiais (CEs) (grandes indústrias e supermercados, hospitais, etc), a operação de chaves controladas remotamente (CCRs), bem como de informar ao operador uma sequência de manobra das chaves presentes no plano de restabelecimento.

\subsection{O Problema}

\subsubsection{Restabelecimento de Energia em Sistemas de Distribuição}

Os sistemas de distribuição de energia elétrica devem operar de forma contínua, confiável, econômica e em acordo com as restrições de carga e de operação. Estas restrições dizem respeito, respectivamente, ao fornecimento de energia com qualidade e continuidade ao maior número possível de consumidores e a necessidade de que os equipamentos presentes na rede operem de forma segura, sem exceder os seus limites operacionais. 
Todavia, as interrupções no fornecimento de energia são inevitáveis e, na maioria das vezes, imprevisíveis, causadas, por exemplo, por descargas atmosféricas e consequente atuação dos equipamentos de proteção. Nesse sentido, uma solução encontrada para melhorar a confiabilidade sem incorrer em gastos excessivos foi o agrupamento de vários pontos de carga em blocos, chamados setores, separados por chaves que operam no estado normalmente aberta (NA) ou normalmente fechada (NF). Assim sendo, é possível isolar trechos da rede e realizar a troca de cargas entre alimentadores e subestações.

Quando acontecem eventos que provocam a interrupção no fornecimento, as cargas atingidas são aquelas localizadas no setor sob falta e nos setores localizados à jusante deste, uma vez que essas redes são radiais, isto é, possuem fluxo de energia unidirecional. Mas, nem todas estas cargas afetadas precisam, necessariamente, permanecer sem energia elétrica durante o período de recuperação da falha. Isto porque, é possível restabelecer o fornecimento aos setores sãos desabastecidos, por meio da operação de chaves NAs e consequente transferência dos mesmos para outros alimentadores. Além disso, por meio de manobras em chaves NFs é possível também restringir a interrupção apenas ao setor sob falta, que deverá passar por manutenção.

Entretanto, dependendo da quantidade de cargas transferidas para um novo alimentador, do nível de tensão desse alimentador, do seu carregamento e do carregamento da subestação na qual este está conectado, é possível que as restrições operacionais e os critérios de qualidade da energia não sejam atendidos por essa nova configuração da rede. Assim sendo, serão necessárias manobras adicionais em chaves NFs e NAs para que seja implantada uma configuração da rede na qual as restrições de operação também sejam satisfeitas.

\subsubsection{Restabelecimento de Energia via Reconfiguração de Redes}

Devido a definição e as características do problema de restabelecimento de energia, descritas anteriormente, este é por natureza um problema de reconfiguração de redes. Reconfiguração de redes é uma ferramenta importante na operação de SDRs, uma vez que é um dos principais recursos para manutenção da qualidade e da confiabilidade do fornecimento de energia elétrica, ao passo que pode ser aplicada a diversos problemas em SDRs, tais como: redução de perdas elétricas por efeito joule (Gomes et al., 2005), planejamento de redes (Delbem et al., 2004), balanceamento de carga entre os alimentadores (Prasad et al., 2008), melhoria do perfil de tensão (Fantin et al., 2011) e, numa situação mais extrema, na ocorrência de faltas permanentes, a fim de determinar um plano de restabelecimento de energia (Kumar et al., 2008; Santos et al., 2010). 
Desse modo, com a finalidade de ilustrar como o problema de restabelecimento de energia pode ser tratado via reconfiguração de redes, considere a Figura 1.1(a), na qual é apresentada a rede primária de um SDR com dois alimentadores, seis chaves NFs, três chaves NAs, duas subestações e diversas barras de passagem e de carga, nas quais estão conectados transformadores de distribuição. Perceba que este SDR, apesar de pequeno e ilustrativo, possui características semelhantes àquelas presentes nas redes reais de grande porte. Considere também a ocorrência de uma falta na barra 7 do alimentador conectado à subestação SE1 (ver Figura 1.1(a)). Observe na Figura 1.1(b) que, com a isolação do setor sob falta, por meio da abertura das chaves NFs C3 e C4, as cargas do setor que possui as barras 11, 12 e 13 também terão o seu fornecimento de energia interrompido, mesmo sendo cargas sãs e não pertencentes ao setor sob falta. Assim sendo, deverá ser elaborado um plano de restabelecimento adequado para restabelecê-las o suprimento de energia. Neste caso, o fornecimento de energia ao setor são poderá ser realizado por meio do fechamento das chaves NAs C6 ou C9. A título de exemplo fora escolhida a chave C9, que restabeleceu o fornecimento a esses consumidores através do alimentador conectado à subestação SE2.

Um plano adequado de restabelecimento de energia, via reconfiguração de redes, envolve os seguintes objetivos (Santos, 2009):

1. Minimização do número de consumidores fora de serviço (isto é, sem fornecimento) com priorização de CEs;

2. Minimização do número de operações de chaveamento com priorização de CCRs;

3. Minimização do total de perdas resistivas por efeito Joule.

Todavia, esses objetivos estão sujeitos às seguintes restrições:

1. Ausência de sobrecarga na rede e nas subestações;

2. Manutenção dos níveis de tensão dentro dos intervalos exigidos pela legislação, equipamentos e cargas elétricas;

3. Manutenção da radialidade da rede;

4. Determinação em tempo real.

Tendo em vista essas necessidades, observa-se que a obtenção de planos de restabelecimento de energia, via reconfiguração de redes, pode ser classificada como um problema de otimização multi-objetivo com múltiplas restrições, sendo alguns destes objetivos conflitantes entre si. Contudo, um plano adequado de restabelecimento de 


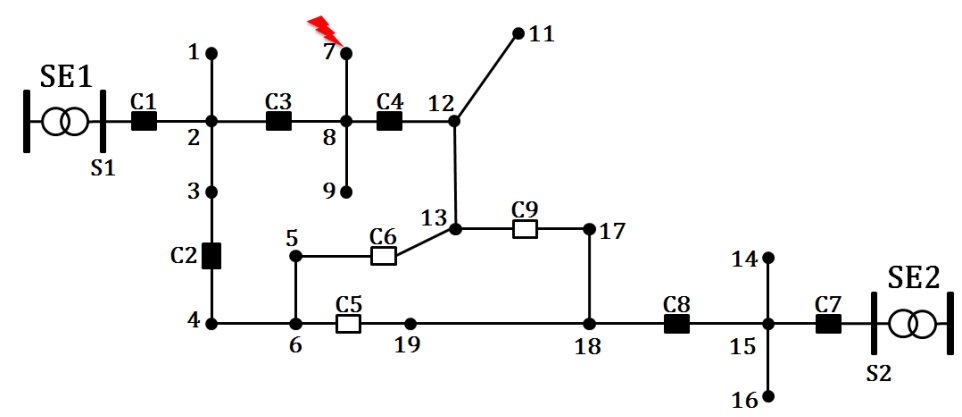

(a) Configuração anterior à ocorrência da falta.

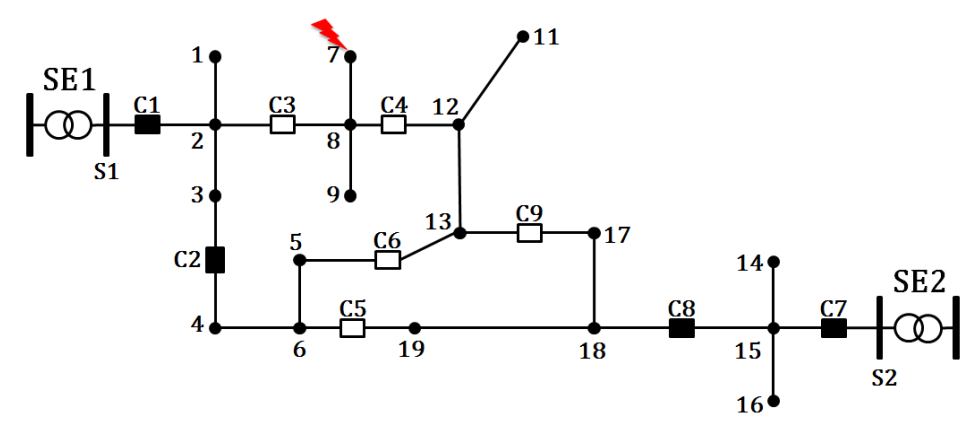

(b) Configuração posterior a ocorrência da falta e com o setor faltoso isolado.

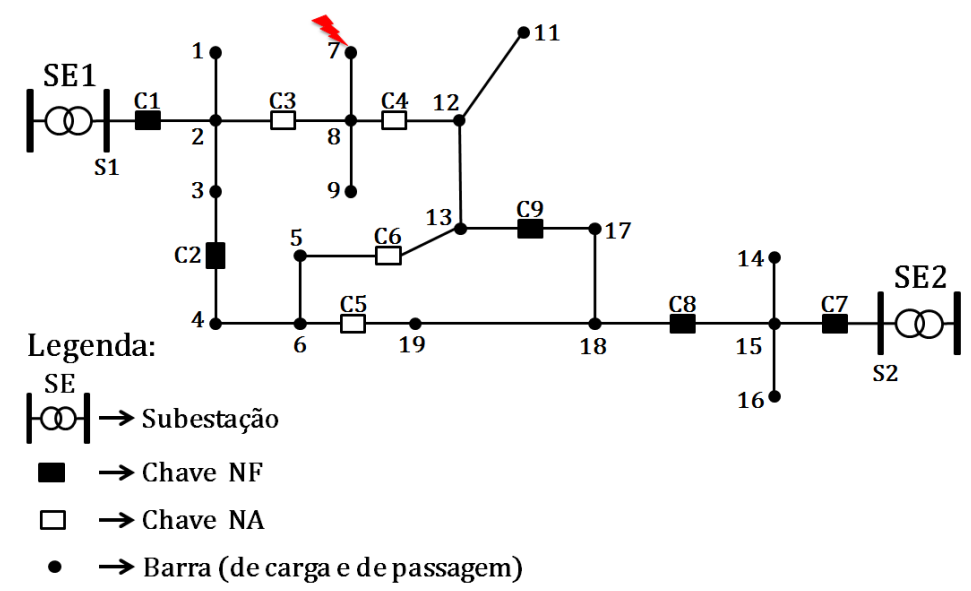

(c) Configuração final, com o setor em falta isolado e as cargas à jusante restabelecidas.

Figura 1.1: Exemplo de restabelecimento de energia via reconfiguração de redes. 
energia deve possuir também uma lista das chaves que devem ser operadas e a sequência de operação das mesmas, a fim de que o operador tenha condições de executar o plano de restabelecimento obtido.

\subsection{Justificativas}

Para lidar com o problema apresentado, diversos métodos de otimização têm sido utilizados, com destaque para aqueles baseados em meta-heurísticas, como, por exemplo, os Algoritmos Evolutivos (AEs). Estes, quando comparados com outras técnicas de otimização, como, por exemplo, aquelas baseadas em programação matemática, são mais flexíveis, mais simples de serem compreendidos e implementados, possuem diversas variações para problemas multi-objetivos e têm mostrado resultados satisfatórios.

Contudo, os AEs são conhecidos por apresentarem dificuldades para a rápida obtenção de planos de restabelecimento em SDRs de tamanho real (Delbem, 2002). De acordo com a literatura, nesse caso o desempenho de um AE é afetado principalmente pelos fatores descritos a seguir.

- A utilização de uma estrutura de dados inadequada, para representar computacionalmente a topologia elétrica dos SDRs, reduz de forma significativa o desempenho do algoritmo (Delbem et al., 2005; Santos et al., 2010);

- Os operadores genéticos normalmente utilizados não geram configurações factíveis, isto é, redes radiais capazes de fornecer energia a todas as partes do sistema possíveis de serem reconectadas por meio de chaves após a ocorrência de uma falta ${ }^{1}$ (Carreno et al., 2008);

- A conversão de um problema multi-objetivo em um mono-objetivo através da utilização de fatores de ponderação que penalizam a violação das restrições do problema (Kumar et al., 2008; Pelikan et al., 2002).

A fim de superar essas dificuldades e melhorar o desempenho de AEs para o problema de restabelecimento de energia, e também de minimização de perdas resistivas, em SDRs de grande porte, foi proposto por Santos et al. (2010) uma metodologia que utiliza uma nova estrutura de dados, denominada Representação Nó-Profundidade (RNP) (Delbem et al., 2004), e os seus operadores. De acordo com os resultados apresentados por essa metodologia, denominada AE Multi-objetivo em Tabela (AEMT), a RNP melhora o

\footnotetext{
${ }^{1}$ Em algumas situações pode não haver chaves que permitam a reconexão de um trecho do sistema sem fornecimento.
} 
desempenho dos AEs porque (Santos et al., 2010): (i) os seus operadores produzem exclusivamente configurações factíveis; (ii) em comparação com outras estruturas de dados, possui maior eficiência computacional (tem complexidade computacional de tempo médio de $\mathrm{O} \sqrt{n}$, em que $n$ é o número de nós do grafo que representa o SDR); (iii) possui capacidade para lidar com florestas formadas por um grande número de nós. Devido a essas vantagens e a outras características, que serão apresentadas no Capítulo 4, a RNP permite ainda representar computacionalmente SDRs de grande porte sem que sejam necessárias simplificações na representação da rede.

Embora o AEMT tenha tido sua eficiência computacional comprovada no tratamento do problema de restabelecimento de energia em SDRs de grande porte, este não considera alguns aspectos práticos do problema, necessários para determinação de planos adequados de restabelecimento, como por exemplo: (i) distinção entre chaves controladas manualmente (CCMs) e CCRs, que possuem tempo e custo de operação diferentes; (ii) distinção entre consumidores que possuem prioridades de fornecimento diferentes; (iii) informação do nome e da sequência das chaves que devem ser operadas para implantar o plano obtido; (iv) consideração da localização em campo das equipes de manutenção a fim de priorizar a operação de chaves que estejam próximas destas; (v) consideração de rejeição de cargas em situações de carregamento elevado da rede ou de subestações, etc. A eficiência computacional do AEMT foi comprovada em Santos et al. (2010) por meio de diversas simulações computacionais realizadas em sistemas de testes presentes na literatura e no SDR real da cidade de São Carlos - SP, em operação em 1994, que possui 3.860 barras, 632 chaves, 23 alimentadores e 3 subestações, bem como nas suas versões duplicada, e octuplicada.

\subsection{Objetivos}

Embora já tenha sido alvo de inúmeros trabalhos, o problema de restabelecimento de energia, via reconfiguração de redes, ainda representa um desafio para os pesquisadores e profissionais da área. Isto ocorre porque, devido a grande quantidade de variáveis, aos múltiplos objetivos e as necessidades práticas, as metodologias desenvolvidas, em geral, ou não são aptas para serem aplicadas em SDRs reais, ou exigem simplificações na representação da rede, ou não consideram aspectos práticos do problema.

Assim, esta dissertação tem como objetivo principal a obtenção de uma metodologia de restabelecimento de energia em SDRs de grande porte que considere todos os objetivos, restrições e necessidades do problema, apresentados na Seção 1.2.2, que não exija simplificações na modelagem da rede, considerando todas as variáveis envolvidas no problema. Para aplicação em tempo real, esta metodologia deverá permitir a obtenção 
de planos de restabelecimento de energia em situações de uma ou múltiplas faltas permanentes.

Para atingir este objetivo serão utilizadas como base para esta pesquisa a RNP (Delbem et al., 2004) e a metodologia proposta em Santos et al. (2010). No entanto, para permitir a obtenção da metodologia proposta, diversas melhorias e modificações deverão ser realizadas naquela proposta em Santos et al. (2010), a fim de que a metodologia proposta seja mais robusta e permita a obtenção de planos de restabelecimento que considerem:

- As potencialidades das redes inteligentes, dando prioridade ao chaveamento de CCRs, para que os planos de restabelecimento obtidos possam ser parcial ou integralmente implementados do centro de operação, pelo próprio operador, concorrendo para a diminuição de custos relativos ao deslocamento de equipes de manutenção e do tempo em que as cargas atingidas ficarão sem fornecimento;

- A priorização do atendimento aos consumidores chamados especiais, como, por exemplo, hospitais, centros de transfusão de sangue, grandes indústrias, grandes supermercados, etc;

- A definição de uma sequência de chaveamento ou de operação das chaves. Observe que se a sequência de chaveamento não for adequada, durante o processo de operação das chaves podem ocorrer faltas momentâneas de energia em consumidores não afetados pela falta ou ainda a formação de laços na rede, conectando, por exemplo, alimentadores e subestações diferentes.

\subsection{Organização do Documento}

Antes de apresentar a metodologia proposta, o Capítulo 2 faz uma revisão de alguns dos principais trabalhos já desenvolvidos nessa área. Noções básicas de AEs e de otimização multi-objetivo são fornecidas no Capítulo 3, que apresenta também alguns dos AEs multi-objetivos (AEMOs) mais difundidos na literatura.

No Capítulo 4 é apresentada, em detalhes, a metodologia tomada como base para o desenvolvido desta pesquisa, isto é, o AEMT. Neste capítulo, além de uma descrição dos principais passos de execução do AEMT, é apresentada também a RNP e um algoritmo eficiente para cálculo do número de manobras em chaves, que também fora proposto por Santos et al. (2010) e que fora modificado para obtenção da metodologia proposta. Esta, por sua vez, é descrita na sequência, no Capítulo 5. 
Para validar a proposta desta pesquisa, diversos testes foram realizados no SDR de grande porte da cidade de São Carlos - SP, descrito na Seção 1.3, e também nas suas versões duplicada e octuplicada. Estes testes experimentais, juntamente com os seus resultados, são mostrados no Capítulo 6

Por fim, o Capítulo 7 dá uma visão geral deste documento, resumindo os principais tópicos, e apresenta as principais contribuições desta dissertação, as publicações relacionadas a ela e os trabalhos futuros. Este documento possui ainda um apêndice (Apêndice A), no qual a RNP e seus operadores são apresentados com maiores detalhes. 
CAPÍTULO 1. INTRODUÇÃO 


\subsection{Considerações Iniciais}

Com objetivo de extrair ideias que possam ajudar no desenvolvimento da metodologia proposta, bem como analisar o estado da arte na área de restabelecimento de energia via reconfiguração de redes, realizou-se a revisão de alguns dos principais trabalhos publicados em periódicos nacionais e internacionais. Esses trabalhos são sucintamente apresentados neste capítulo.

\subsection{Revisão Bibliográfica}

O problema de restabelecimento de energia tem despertado, nas últimas décadas, o interesse de diversos pesquisadores em todo o mundo. Além disso, este é um problema de grande interesse também por parte das empresas de distribuição de energia que, por sua vez, têm investido em pesquisas tratando desse tema. Como resultado, diversas pesquisas têm sido realizadas nessa área.

Um dos primeiros trabalhos relacionados à problemas que exigem reconfiguração de redes em SDRs foi desenvolvido em Merlin e Back (1975). Nesse trabalho, a fim de minimizar as perdas resistivas em uma rede urbana, é apresentada uma variação da técnica de programação matemática inteira branch-and-bound. A metodologia proposta considera 
inicialmente todas as chaves como fechadas, e então, uma de cada vez, as chaves vão sendo abertas até que a rede torne-se radial. Para selecionar a chave que deverá ser aberta é executado, antes de cada abertura, um fluxo de carga para rede em malha, e então a chave que possuir a menor potência passando por ela e que não deixe a rede desconexa é então aberta. Nesse trabalho não são consideradas outras restrições como carregamento da rede e queda de tensão.

Em Curcic et al. (1995) é apresentada uma revisão detalhada de 19 artigos, publicados entre os anos de 1987 a 1994, e que tratam do problema de restabelecimento de energia em sistemas de distribuição. Vários aspectos do problema foram analisados pelos autores, tais como: modelagem dos objetivos e restrições; metodologia aplicada na construção dos algoritmos de restabelecimento; tipos de faltas tratadas; nível de tensão; priorização de cargas importantes; modelagem das cargas; tempo para encontrar a solução restauradora e para implementá-la; e priorização de chaves comandadas remotamente. Além disso, este trabalho possui uma seção na qual o problema de restabelecimento é detalhadamente apresentado, dando atenção aos passos principais do processo (detecção de uma falta, localização e isolação do elemento faltoso, elaboração de um plano de restabelecimento e por último a sua implementação), aos seus dois objetivos gerais (prover o restabelecimento de energia ao maior número possível de consumidores e o mais rápido possível) e aos quatro estados gerais de operação de sistemas de distribuição (normal, pré-falta, sob falta e restaurativo) e como pode-se mudar de um para o outro. Segundo os autores no estado normal de funcionamento, a reconfiguração da rede pode ser realizada para prover eficiência à operação, minimização de perdas e balanceamento de carga entre fases e alimentadores. Estando o sistema sob falta, se o elemento ou trecho faltoso da rede puder ser devolvido rapidamente para operação, o sistema retorna diretamente ao estado normal. Caso contrário, tenta-se restaurar à operação na maior parte possível da rede, e assim o sistema entrará no estado restaurativo.

O problema de restabelecimento de energia é tratado em Augugliaro et al. (2000) utilizando estratégias evolutivas com definição fuzzy dos objetivos. A motivação de tal abordagem foi (i) tratar separadamente dois objetivos conflitantes (minimização das cargas fora de serviço e minimização das perdas ôhmicas) e (ii) diminuir o tempo computacional em relação à metodologia apresentada em Augugliaro et al. (1998). Para tal, foi simulada uma falta que gerou a perda completa de um alimentador de um sistema composto por 6 alimentadores, 98 chaves, 24 bancos de capacitor comutáveis e 81 barras de carga. Considerou-se o controle remoto das chaves seccionadores, de bancos de capacitores e conexões de cargas. O algoritmo foi implementado em um computador com processador Pentium $166 \mathrm{MHz}$, em Delphi, e obteve tempo de execução menor que 50s. 
Por Kumar et al. (2008) foi proposto um algoritmo baseado no NSGA-II (do inglês, "Nondominated Sorting Genetic Algorithm-II") (ver Seção 3.4.2) para resolver o problema de restabelecimento de energia. Essa técnica possui a característica especial de manter a natureza multi-objetiva do problema sem a necessidade de quaisquer pesos ou parâmetros ajustáveis. Isso é feito tratando separadamente cada função objetivo e definindo um grau de prioridade para cada uma no momento da escolha da melhor solução. Para avaliar a eficácia da abordagem proposta foram realizadas simulações em quatro SDRs diferentes, com 10 a 75 chaves e 13 a 173 barras, utilizando três métodos diferentes (NSGA-II Básico, NSGA-II com a complexidade de tempo de execução reduzida e AG Tradicional) e considerando tanto falta única quanto múltiplas faltas. Comparando os resultados obtidos concluiu-se que a abordagem baseada no NSGA-II é capaz de encontrar boas soluções para o problema de restabelecimento de energia em tempos considerados pelos autores como sendo aplicáveis à operação em tempo real. Além disso, essa abordagem demonstrou que possui melhor desempenho que a técnica baseada em AG Tradicional. Nesse trabalho foram considerados vários aspectos práticos, tais como: presença de CEs com prioridade no restabelecimento e de chaves operadas remotamente e manualmente. No entanto, o trabalho não informa como essas questões são consideradas e tratadas pelo algoritmo apresentado.

Em Mansour et al. (2010) é apresentada uma comparação entre os algoritmos AENP (AE Convencional com RNP) (Santos et al., 2008) e NSNP (NSGA-II com RNP) (Mansour et al., 2009), que possuem em comum a utilização da RNP, a fim de determinar qual tem melhor desempenho com essa nova estrutura de dados quando aplicados ao problema de restabelecimento de energia. Para tal, foram realizadas diversas simulações computacionais com o sistema real da cidade de São Carlos-SP que possui 3860 barras, 632 chaves, 3 subestações e 23 alimentadores, considerando uma falta única na qual é perdido o maior alimentador. Conclui-se que o NSNP é melhor que o AENP para tratamento do problema de restabelecimento de energia, uma vez que ambos restabeleceram todos os consumidores interrompidos, porém, o NSNP foi capaz de fazê-lo exigindo um número menor de operações de chaveamento. Todavia, para o tratamento de problemas de reconfiguração de redes de uma forma geral, os autores constataram que não é possível afirmar que o NSNP é melhor que o AENP, pois este último obteve melhor desempenho para outros objetivos, tais como, redução de perdas resistivas, carregamento da rede e tempo de execução.

Em Sanches et al. (2012) é proposto um AEMO, chamado AEMO com RNP e Soluções Não Dominadas (AEMT-SND), que integra as principais qualidades do AEMT (Santos et al., 2010) e do NSGA-II com RNP (Mansour et al., 2010), a fim de lidar com o problema de restabelecimento de energia em SDRs de grande porte. Esse algoritmo armazena soluções 
não dominadas da fronteira de Pareto, determinadas como no NSGA-II com RNP, em três tabelas de subpopulação adicionais, como no AEMT. Segundo os autores essa técnica insere maior diversidade entre as soluções no processo de busca do AEMT, cujo resultado direto é a descoberta de melhores soluções. Para avaliar o AEMT-SND foram realizados testes no SDR da cidade de São Carlos-SP e na sua versão duplicada, considerando uma única falta.

Enquanto isso, no trabalho de Botea et al. (2012) é proposto o uso de algoritmos de busca informada da família A* para tratar o problema de restabelecimento de energia. Segundo Hart e Raphael (1968), tais algoritmos possuem duas propriedades importantes: (i) eles dão a garantia de que será encontrada a melhor solução possível toda vez que ela existir; e (ii) eles garantem fazer o menor número possível de passos no espaço de busca. Botea et al. (2012) restringiram a atenção aos planos de restabelecimento onde não há troca de cargas de um alimentador saudável para outro alimentador. Ou seja, considerou-se mover apenas blocos de cargas que estejam sem suprimento de energia. Além disso, foram considerados dois critérios, custos de comutação de chaves e a área afetada pela falta, além das restrições que dizem respeito a capacidade dos equipamentos. Para o estudo apresentado foram ignorados outros critérios, como por exemplo minimização das perdas resistivas, pois, segundo os autores, nos casos de aplicação de reconfiguração de redes para manutenção ou recuperação em uma interrupção a configuração temporária será utilizada apenas para um período de tempo relativamente curto.

Para avaliar esta proposta foram realizadas simulações computacionais em dois SDRs de tamanhos diferentes, um com 139 chaves e outro com 210, considerando um cenário com múltiplas faltas, com um máximo de 20 faltas para cada rede. Para tal, foi utilizado um computador com processador Intel Dual Core 2,4 GHz, 1,5 GB de memória RAM, sistema operacional Linux e linguagem Java 1.6. Em ambos os SDRs os resultados demostraram que o $A^{*}$ foi capaz de encontrar planos de restabelecimento em um tempo médio menor que 2 segundos, até mesmo para cenários com mais de 10 falhas. Vale ressaltar que esse trabalho considera a presença de chaves remotamente controláveis (que podem ser operadas simultaneamente e quase instantaneamente) e o custo real total (da implantação do plano de restabelecimento) como sendo a soma dos custos das operações individuais de comutação. Segundo os autores, na presença de chaves controladas manualmente a agregação dos custos individuais não é tão simples, pois chaves manuais exigem tempos de operação diferentes e maiores do que as chaves remotamente controláveis, implicando em custos diferentes. Além disso, a operação de chaves controladas manualmente pode ser realizada por uma ou mais equipes de campo, e uma otimização mais complexa pode ser necessária, envolvendo o planejamento de rotas para as equipes, as decisões sobre quantas equipes enviar e de como atribuir tarefas para cada uma delas. 
É importante dizer que o AEMT, proposto por Santos et al. (2010), por ser utilizado como base para o desenvolvimento desta pesquisa, será detalhadamente apresentado mais adiante, no Capítulo 4, conforme dito anteriormente,.

\subsection{Considerações Finais}

Neste capítulo foi apresentada uma sucinta revisão de alguns dos principais trabalhos relacionados ao problema de restabelecimento de energia em SDRs. A existência tanto de trabalhos antigos, quanto de trabalhos recentes na área de restabelecimento de energia demonstra a importância desse problema no contexto da operação de sistemas de distribuição de energia, já que tem despertado, desde há muitos anos, o interesse de diversos pesquisadores. Além disso, os trabalhos recentes demonstram ainda que este problema continua sendo um desafio de pesquisa, isto é, que ainda não possui uma solução adequada e satisfatória. Nesse sentido, o surgimento de técnicas de inteligência artificial, como os AEs, por exemplo, têm contribuído para proporcionar novas maneiras de abordar o problema, com métodos de otimização conceitualmente mais simples e ao mesmo tempo eficientes. Tais AEs serão associados, no presente trabalho, a RNP e utilizados para lidar com o problema em questão. Assim, para facilitar a compreensão da metodologia proposta, que será apresentada mais adiante, no próximo capítulo serão apresentados os conceitos básicos de AEs, bem como alguns dos AEMOs presentes na literatura que têm sido mais utilizados para o tratamento de problemas de otimização multi-objetivo. 
CAPÍTULO 2. REVISÃO BIBLIOGRÁFICA 


\section{Algoritmos Evolutivos e Otimização Multi-Objetivo}

\subsection{Considerações Iniciais}

Os AEs são algoritmos computacionais pertencentes a uma classe de métodos regidos por princípios evolutivos oriundos do mundo biológico. Baseados na teoria da evolução darwiniana, eles tentam simular o processo de evolução natural (Deb, 2001) a fim de obterem a solução para um determinado problema. Nesse capítulo serão apresentados os princípios básicos e o mecanismo típico de busca dos AEs. Tendo em vista que o problema a ser solucionado por essa pesquisa é classificado como multi-objetivo, será mostrado também nesse capítulo um enunciado geral para esses problemas juntamente com alguns AEMOs importantes da literatura.

\subsection{Algoritmos Evolutivos}

Os primeiros trabalhos envolvendo AEs são datados da década de 1930. Entretanto, foi a partir da década de 1960 que se intensificaram o seu desenvolvimento (Jong, 2006), com a realização de diversos estudos teóricos e empíricos (Gabriel e Delbem, 2008).

Nesse contexto, três abordagens de AEs foram desenvolvidas de forma independente (Jong, 2006): a programação evolutiva (PE), as estratégias evolutivas 
(EEs) e os algoritmos genéticos (AGs) . O princípio básico destas técnicas é, no entanto, a mesma (Eiben e Smith, 2003): dada uma população de indivíduos (isto é, um conjunto de possíveis soluções), pressões do ambiente desencadeiam um processos de seleção natural, ou seja, um processo que privilegia as melhores soluções até então encontradas, causando assim um incremento na adequação das soluções. Dada uma função a ser otimizada, inicialmente, gera-se aleatoriamente um conjunto de soluções, isto é, elementos pertencentes ao domínio da função, e aplica-se a função para medir a qualidade dessas soluções candidatas, atribuindo-lhes um valor que mede sua adequação, o chamado fitness (Gabriel e Delbem, 2008).

Com base no fitness, algumas das melhores soluções são selecionadas para darem origem a uma nova população pela aplicação de operadores de recombinação e/ou mutação. A recombinação é um operador aplicado a duas ou mais soluções candidatas (chamadas pais) e resulta em duas ou mais novas soluções (chamadas descendentes ou filhos). A mutação é aplicada em uma solução candidata a fim de gerar outra. Ao final desse processo, as novas soluções candidatas (descendentes) competem com as candidatas da geração anterior, com base no fitness, para assumir um lugar na nova população. Esse processo é iterativo até que uma solução candidata seja suficientemente qualificada ou até que um número máximo de iterações, também chamadas gerações, seja obtido (Gabriel e Delbem, 2008). Um pseudocódigo geral de um AE típico é apresentado no Algoritmo 1.

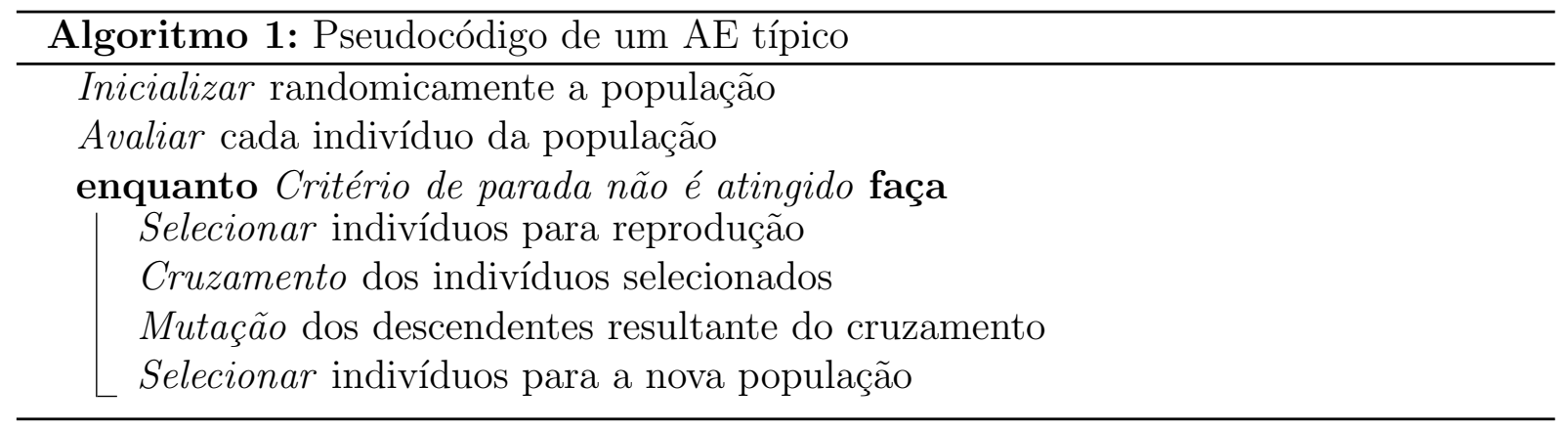

Os AEs apresentam algumas vantagens em relação a outras técnicas de busca e otimização, a saber (Santos, 2009): (i) trabalham em paralelo com um conjunto de soluções, em contraste com vários outros métodos de busca e otimização que analisam apenas uma solução para o problema a cada iteração; (ii) não requerem o conhecimento prévio das características do problema e não dependem de certas propriedades da função objetivo tais como convexidade ou diferenciabilidade; (iii) são guiados pela aptidão dos indivíduos, avaliados por uma função adequação; (iv) a estrutura do AE possui certa independência do tipo de problema que está sendo resolvido; (v) possuem maior capacidade de escapar de ótimos locais; (vi) resolvem problemas com modelos matemáticos complexos de modo simples; (vii) apresentam fácil acoplamento com outras técnicas 
(hibridização) ou aplicações. Por esses motivos, os AEs são aptos a resolver um amplo campo de problemas, dentre estes, não lineares, descontínuos, discretos, multivariáveis e de otimização combinatorial de grande escala, como é o caso dos problemas de reconfiguração de redes (Santos, 2009).

\subsection{Otimização Multi-objetivo}

Para escrever esta seção utilizou-se como referência o texto de dissertação de Moussa Reda Mansour (Mansour, 2009).

Os problemas de otimização multi-objetivo, de uma forma geral, são assim classificados pois possuem um conjunto de funções objetivo a serem otimizadas (minimizadas ou maximizadas). Além disso, possuem restrições que devem ser satisfeitas pelas soluções candidatas para que estas sejam factíveis ao problema. O enunciado geral de um problema de otimização multi-objetivo pode ser ilustrado da seguinte forma (Deb, 2001):

$\begin{array}{rcl}\text { Minimizar/Maximizar } & f_{m}(x) & m=1,2, \ldots, N_{\text {obj }} ; \\ \text { sujeito a: } & g_{j}(x) \leq 0, & j=1,2, \ldots, N R_{\text {des }} ; \\ & h_{k}(x)=0, & k=1,2, \ldots, N R_{\text {igu }} ; \\ x_{i}^{(\text {inf })} \leq x_{i} \leq x_{i}^{(\text {sup })} & i=1,2, \ldots, N_{\text {var }} ;\end{array}$

em que $x$ é um vetor de $N_{v a r}$ variáveis de decisão, $x=\left(x_{1}, x_{2}, \ldots, x_{N_{v a r}}\right)^{T}$, também denominado de solução. Os valores $x_{i}^{(i n f)}$ e $x_{i}^{(s u p)}$ representam os limites inferior e superior, respectivamente, para a variável $x_{i}$. Esses limites definem o espaço de variáveis de decisão ou espaço de decisão $S_{d e c}$. As $N R_{\text {des }}$ desigualdades $\left(g_{j}\right)$ e as $N R_{\text {igu }}$ igualdades $\left(h_{k}\right)$ são chamadas de funções de restrição. Uma solução $x$ factível satisfaz as $N R_{\text {igu }}+N R_{\text {des }}$ funções de restrição e os $2 N_{v a r}$ limites. Caso contrário, a solução não será factível. O conjunto de todas as soluções factíveis formam a região factível ou espaço de busca $S_{\text {fact }}$. Cada função $f_{m}(x)$ pode ser maximizada ou minimizada. Porém, para trabalhar com os algoritmos de otimização é necessário converter todas as funções para serem apenas de maximização ou de minimização.

As funções objetivo empregadas nos problemas de otimização multi-objetivo são, em geral, conflitantes entre si. Sabe-se que uma função objetivo $f_{1}$ é conflitante com uma outra função $f_{2}$ quando não é possível melhorar o valor de $f_{1}$ sem piorar o valor da função $f_{2}$. Um exemplo prático de objetivos conflitantes são preço e desempenho na compra de equipamentos, como por exemplo, computadores. Os equipamentos de maior 
custo apresentam usualmente um melhor desempenho e vice-versa. Assim, em uma compra devem ser considerados vários modelos de computadores com diversos valores nos objetivos de preço e desempenho. Se ambos os objetivos possuem a mesma importância (ou prioridade), não há como afirmar, por exemplo, que certa redução do preço compensa determinada perda do desempenho.

Em problemas de otimização multi-objetivo é comum empregar-se o conceito de Dominância de Pareto a fim de comparar duas soluções factíveis de um problema. Dadas duas soluções $x$ e $y$, diz-se que $x$ domina $y$ se as seguintes condição forem satisfeitas (Mansour, 2009):

1. A solução $x$ é no mínimo igual a $y$ em todas as funções objetivo;

2. A solução $x$ é melhor que $y$ em pelo menos uma função objetivo.

Desta forma, existe um conjunto de soluções que possuem vantagens em desempenho mas que não são melhores em custo e vice-versa. Ou seja, existe um conjunto de alternativas ótimas que são não dominadas entre si nos objetivos de custo e desempenho. Em um problema de otimização multi-objetivo, o conjunto de soluções não dominadas é chamado de conjunto Pareto-ótimo, que representa as soluções ótimas do problema. A fronteira de Pareto é o conjunto dos valores das funções objetivo das soluções do conjunto Pareto-ótimo.

Em (Deb, 2001) são destacadas três importantes metas em otimização multi-objetivo:

1. Encontrar um conjunto de soluções que esteja o mais próximo possível da fronteira de Pareto;

2. Encontrar um conjunto de soluções com a maior diversidade possível;

3. Realizar as duas metas anteriores com a maior eficiência computacional possível.

A primeira meta é comum a qualquer processo de otimização, pois soluções muito distantes da fronteira de Pareto não são desejáveis. Por outro lado, encontrar a maior diversidade dentro das soluções é a meta específica para otimização multi-objetivo, e que consiste em assegurar a maior cobertura possível da fronteira com as soluções o mais uniformemente distribuídas possível, ao longo da fronteira.

No entanto, encontrar um conjunto de soluções uniformemente distribuídas é uma tarefa que pode consumir consideráveis recursos computacionais (Deb, 2001), motivo pelo qual deve-se considerar a meta de obter tais soluções com a maior eficiência computacional possível.

Em relação aos aspectos que diferenciam a otimização multi-objetivo da otimização mono-objetivo identificam-se três (Deb, 2001): 
1. Nos problemas de otimização com um único objetivo (mono-objetivo) tem-se como meta encontrar uma solução ótima global (máximo ou mínimo). Se a função objetivo desses problemas for multimodal, poderá existir mais de um ótimo global. Neste caso, todos os ótimos são equivalentes. Por outro lado, em problemas de otimização com vários objetivos (multi-objetivo) a determinação do conjunto de soluções da fronteira de Pareto é tão importante quanto preservar a diversidade neste conjunto. Assim sendo, um algoritmo eficiente para otimização multi-objetivo deve considerar ambos os aspectos;

2. Nos problemas de otimização multi-objetivo trabalha-se com dois espaços, o espaço das variáveis e o dos objetivos. Por outro lado, os problemas de otimização mono-objetivo trabalham unicamente no espaço de variáveis, uma vez que procuram apenas uma solução no espaço dos objetivos. Manter a diversidade em ambos espaços complica mais o problema, dado que a proximidade de duas soluções no espaço de variáveis não implica proximidade no espaço de objetivos;

3. Os métodos tradicionais de otimização multi-objetivo reduzem o conjunto de funções objetivo a uma função simples com uma ponderação para cada objetivo. Estes métodos podem também tratar cada objetivo separadamente, utilizando os demais objetivos como restrições. Portanto, um problema de otimização multi-objetivo pode ser convertido, por meio de algumas técnicas, em um problema de otimização simples.

Conforme fora dito no final da Seção 3.2, os AEs apresentam algumas vantagens em relação a outras técnicas de busca e otimização. Desse modo, serão apresentados na próxima seção alguns métodos baseados em AEs para problemas de otimização multi-objetivo, isto é, alguns dos AEMOs mais difundidos na literatura.

\subsection{Algoritmos Evolutivos para Otimização Multi-objetivo}

A primeira implementação de AEs para problemas de otimização multi-objetivo foi proposta por Schaffer (1985). Desde então uma diversidade de AEMOs têm sido propostos baseando-se naquelas ideias iniciais. A principal diferença dos AEMOs em relação aos AEs tradicionais é o operador de seleção, dado que a comparação entre duas soluções é efetuada com base no conceito de dominância de Pareto (Mansour, 2009).

De acordo com Deb (2001), os AEMOs podem ser classificados em: 
- Elitistas: a melhor solução ou o conjunto com as melhores soluções é guardado de uma geração para outra;

- Não elitistas: a melhor solução ou o conjunto com as melhores soluções não é necessariamente preservado de uma geração para outra.

A seguir são apresentados alguns AEMOs difundidos e disponíveis na literatura.

\subsubsection{Non-Dominated Sorting Genetic Algorithm (NSGA)}

Proposto por Srinivas e Deb (1994) o "Non-dominated Sorting Genetic Algorithms" (NSGA) foi um dos primeiros AEMOs a tratar separadamente cada objetivo sem a necessidade de utilização de uma função ponderação. Porém, esse método possuía algumas características que o levou a receber várias críticas, a saber: (i) alta complexidade computacional $\mathrm{O}\left(N_{o b j} N^{3}\right)$ ao ordenar as soluções não dominadas ( $N_{o b j}$ é o número de objetivos e N é o tamanho da população); (ii) ausência de um método de elitismo; (iii) necessidade da especificação pelo usuário de um parâmetro externo. Devido a essas limitações, Deb et al. (2000) apresentaram uma versão melhorada do NSGA, onde as dificuldades do primeiro método foram amenizadas. Esse método foi denominado NSGA-II (Santos, 2009).

\subsubsection{NSGA-II}

O NSGA-II baseia-se na ordenação elitista por dominância chamada de Pareto ranking. Esse procedimento consiste em classificar as soluções de um conjunto $M$ em diversas fronteiras $\left(\mathcal{F}_{1}, \mathcal{F}_{2}, \ldots, \mathcal{F}_{k}\right.$, onde $k$ é o número de fronteiras) conforme o grau de dominância de cada solução. Deste modo, a fronteira $\mathcal{F}_{1}$ contém as soluções não dominadas de todo o conjunto de soluções $\mathrm{M}, \mathcal{F}_{2}$ contêm as soluções não dominadas de $M-\mathcal{F}_{1}, \mathcal{F}_{3}$ contêm as soluções não dominadas de $M-\left(\mathcal{F}_{1} \cup \mathcal{F}_{2}\right)$ e assim sucessivamente. A Figura 3.1 ilustra as soluções nas fronteiras $\mathcal{F}_{1}, \mathcal{F}_{2}$ e $\mathcal{F}_{3}$ que minimizam dois objetivos quaisquer $f_{1}$ e $f_{2}$.

No processo de ordenação por não dominância para cada solução $i$, contida em uma população $P$, são calculados dois valores:

- $n d_{i}$, o número de soluções que dominam a solução $i$;

- $U_{i}$, o conjunto de soluções que são dominadas pela solução $i$.

As soluções com $n d_{i}=0$ são aquelas que estão contidas na fronteira $\mathcal{F}_{1}$. Em seguida, para determinar as soluções contidas na fronteira $\mathcal{F}_{2}$, um algoritmo percorre o conjunto 


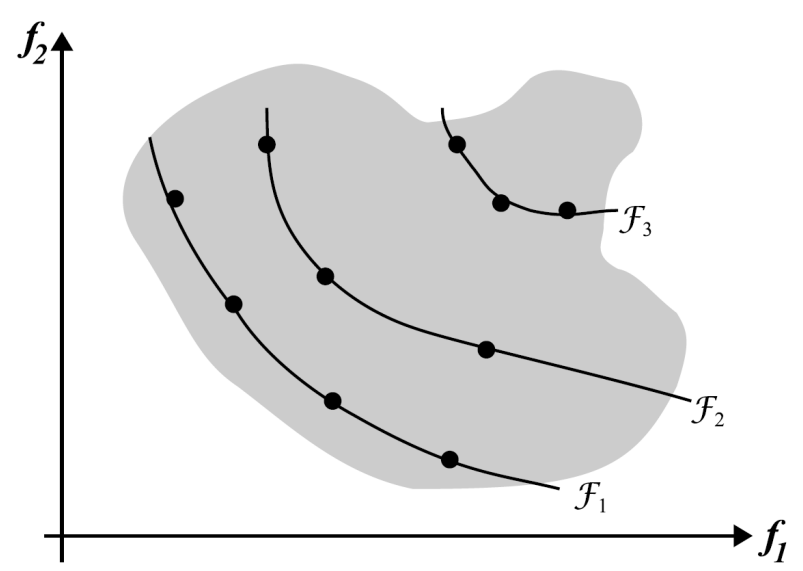

Figura 3.1: Ordenação por não dominância (Deb, 2001).

de soluções dominadas $U_{i}$ (ou seja, as soluções que são dominadas pelas soluções contidas em $\mathcal{F}_{1}$ ), e cada solução $j$ não contida em $\mathcal{F}_{1}$ tem seu contador $n d_{j}$ decrementado em 1 . Assim, ao final desse processo, as soluções $j$ que possuírem $n d_{j}=0$ são então aquelas que pertencerão a fronteira $\mathcal{F}_{2}$. O mesmo procedimento é feito para encontrar as soluções contidas em $\mathcal{F}_{3}, \ldots, \mathcal{F}_{k}$.

O algoritmo NSGA-II trabalha com duas populações, denotadas por $P$ e $Q$, ambas de tamanho $N_{\text {ind }}$. As populações $P$ e $Q$ em cada iteração $t=1,2, \ldots, N_{\text {iter }}$ são denotadas por $P_{t}$ e $Q_{t}$, respectivamente. Na primeira geração, os indivíduos iniciais da população $P_{1}$, que são gerados aleatoriamente, geram as soluções em $Q_{1}$, através da aplicação dos operadores genéticos. Em seguida, estabelece-se um processo competitivo para preencher $N_{\text {ind }}$ vagas para a solução $P_{t+1}$, entre $2 * N_{\text {ind }}$ indivíduos contido em $R_{t}=P_{t} \cup Q_{t}$. Esta operação é realizada utilizando a ordenação por não dominância em $R_{t}$, encaminhando as soluções não dominadas contidas nas fronteiras diretamente para a próxima geração (elitismo) (Mansour, 2009).

Para garantir a diversidade na fronteira, o NSGA-II emprega uma estimativa de densidade das soluções que rodeiam cada indivíduo da população. Assim, calcula-se a média da distância das duas soluções adjacentes a cada indivíduo para todos os objetivos. Esse valor é denominado distância de multidão (Mansour, 2009).

O fitness de cada solução i é determinado pelos seguintes valores:

1. $\operatorname{rank}_{i}=k$, o valor de ranking $i$ é igual ao número da fronteira $\mathcal{F}_{k}$ à qual $i$ pertence;

2. crowdist $_{i}$, o valor de distância de multidão de $i$.

O cálculo da distância de multidão permite que as soluções melhores espalhadas passem a ocupar as últimas vagas disponíveis de $P_{t+1}$, garantindo a diversidade das soluções. A população $Q_{t+1}$ é gerada utilizando os operadores de seleção por torneio, 
recombinação e mutação em $P_{t+1}$. O NSGA-II continua por $N_{\text {iter }}$ iterações e as soluções finais encontram-se em $P_{N_{\text {iter }}} \cup Q_{N_{\text {iter }}}$.

\subsubsection{Strength Pareto Evolutionary Algorithm (SPEA2)}

Para escrever esta subseção utilizou-se como referência o texto de qualificação de doutorado de Danilo Sipoli Sanches (Sanches, 2012).

Proposto por Zitzler et al. (2001), o SPEA2 emprega também duas populações $P$ e $Q$. Na população $Q$, chamada de população externa, são armazenadas apenas as soluções não-dominadas encontradas pelo algoritmo. O tamanho da população $Q$, denotado como $N_{\text {ext }}$, é fornecido como parâmetro. As populações $P$ e $Q$, em cada iteração $t=1,2, \ldots N_{\text {iter }}$, são denotadas como $P_{t}$ e $Q_{t}$, respectivamente.

No SPEA2 inicialmente é criado uma população aleatória $P_{1}$ e uma população externa $Q_{1}$ inicialmente vazia. Em cada iteração, a função de aptidão é calculada para cada solução $i$ em $R_{t}=P_{t} \cup Q_{t}$. No cálculo da função de aptidão, são usados os conceitos de dominância e de densidade, que serão definidos a seguir. O objetivo é minimizar o valor da função de aptidão. Quanto menor o valor da função de aptidão de um indivíduo, melhor é a adaptação do mesmo. A força do indivíduo $i$ (denotado por strength ${ }_{i}$ ) é dada pelo número de soluções que ele domina, determinado por:

$$
\text { strength }_{i}=\left|\left\{j \mid j \in R_{t} \wedge i \succ j\right\}\right|
$$

em que, $|\bullet|$ denota a cardinalidade do conjunto $R_{t}$, $t$ é a geração atual, e $i \succ j$ indica que a solução $i$ domina a solução $j$. Desse modo, o valor strength $h_{i}$ representa o número de soluções em $R_{t}$ que são dominadas pela solução $i$. Assim, soluções que não-dominam nenhuma outra possui o valor de strength $h_{i}$ igual a zero. Calcula-se também o valor de aptidão bruto do indivíduo, denotado por $\operatorname{raw}_{i}$, que é a soma das forças de todos os indivíduos que o dominam:

$$
\operatorname{raw}_{i}=
$$

O valor rawi $_{i}$ representa o somatório dos valores strenght $t_{j}$ das soluções $j \in R_{t}$ que dominam $i$. Assim, as soluções não-dominadas tem um valor rawi igual a zero; enquanto que as soluções com um rawi alto são dominadas por muitas soluções em $R_{t}$.

A densidade do indivíduo é uma função decrescente em relação ao k-ésimo vizinho mais próximo. A inclusão de um fator de densidade se deve ao fato de que, nos casos em 
que existem muitas soluções não-dominadas, strenght $t_{i}$ se aproxima de zero para todas as soluções. Nesse caso, é necessário haver um mecanismo para privilegiar soluções dentre as não-dominadas.

Para cada indivíduo $i$, as distâncias (no espaço dos objetivos) entre $i$ e todos os indivíduos $j$ da população $P$ e da população externa $Q$ são calculadas pela equação 3.4 e armazenadas em uma lista.

$$
\operatorname{dens}_{i}=\frac{1}{\operatorname{dist}_{i j}^{k}+2} .
$$

Depois de ordenada a lista em ordem crescente, o k-ésimo elemento representa o termo $d i s t_{i j}^{k}$. É sugerido para $k$ o valor $\sqrt{\left|R_{t}\right|}$. Finalmente, a aptidão final para cada solução $i$ em $R_{t}$, denotada por $F_{i}$, é dada por:

$$
F_{i}=\operatorname{raw}_{i}+\text { dens }_{i}
$$

O SPEA2 possui um algoritmo de corte cujo objetivo é restringir o tamanho de $Q_{t+1}$ a $N_{e x t}$ soluções. Em cada iteração, é removida a solução cuja distância para seu vizinho mais próximo seja a menor dentre as distâncias existentes. No caso de empate, calcula-se a segunda menor distância, e assim sucessivamente. Formalmente, uma solução $i^{\prime}$ é eliminada de $Q_{t+1}$ se as seguintes condições forem satisfeitas:

1. dist $_{i^{\prime} j^{\prime}}^{1}<d i s t_{i j}^{1}$ para $i^{\prime}, j^{\prime}, i \neq i^{\prime}, j \in Q_{t+1}$ ou;

2. dist $_{i^{\prime} j^{\prime}}^{l}=d i s t_{i j}^{l}$ e dist $t_{i^{\prime} j^{\prime}}^{k}<d i s t_{i j}^{k}$ para $i^{\prime}, j^{\prime}, i \neq i^{\prime}, j \in Q_{t+1}, l<k<N_{e x t}, 1<l<k$. onde $\operatorname{dist}_{i^{\prime} j^{\prime}}^{1}$, dist ${ }_{i^{\prime} j^{\prime}}^{k}$ e dist $_{i^{\prime} j^{\prime}}^{l}$ representam as distâncias de $i^{\prime}$ em relação a seu primeiro, $k$-ésimo e l-ésimo vizinho mais próximo (denotado por $j^{\prime}$ ). Com isso, são eliminadas soluções em $Q_{t+1}$ até reduzir o seu tamanho para $N_{\text {ext }}$.

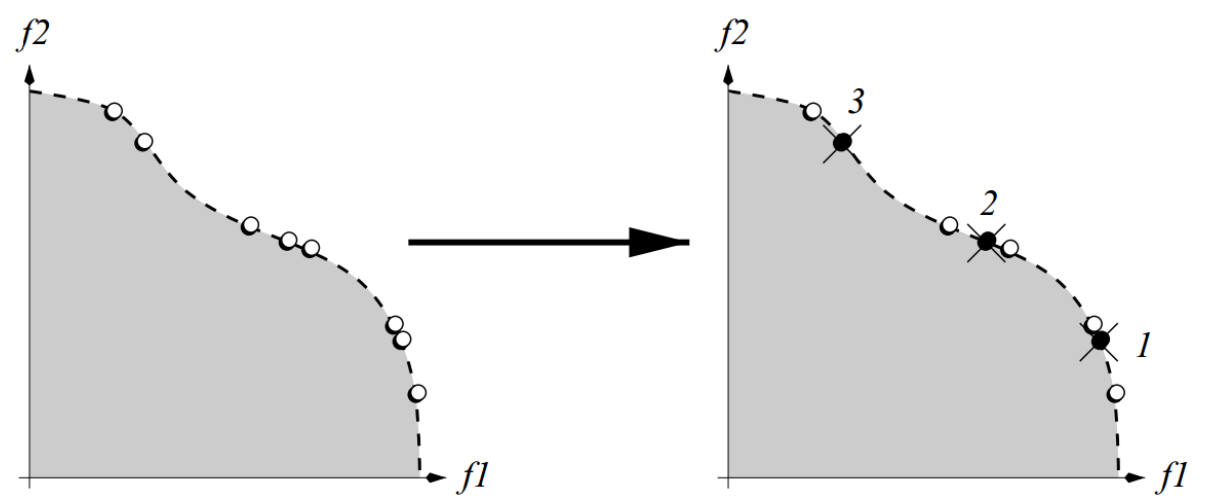

Figura 3.2: Algoritmo de corte no modelo SPEA2 (Zitzler et al., 2001).

A Figura 3.2 ilustra um conjunto de soluções pertencentes à população externa $Q_{t+1}$, para um problema com dois objetivos $f_{1}$ e $f_{2}$, e a aplicação do algoritmo de corte, por 
meio do qual três soluções são eliminadas. Além disso, o algoritmo de corte garante que as soluções extremas para cada objetivo sejam mantidas.

\subsubsection{Método de Tabelas}

Conforme dito na Seção 3.3, as funções objetivo dos problemas de otimização multi-objetivo são, em geral, conflitantes entre si. Nesse caso, torna-se difícil definir uma prioridade entre elas e, consequentemente, dizer qual das soluções candidatas possui a melhor adequação considerando concomitantemente todos os objetivos. Por esse motivo, é difícil também definir pesos que ponderem os objetivos a fim de converter o problema multi-objetivo em um mono-objetivo e penalizar soluções que violem as restrições do problema.

Nesse sentido, foi proposto por Benayoun et al. (1971) um AEMO que otimiza paralelamente todos os objetivos de um problema, sem a necessidade de definição de pesos. Para tal, em todas as gerações, a população é dividida em $N_{o b j}$ subpopulações, formadas pelos indivíduos que possuem a melhor adequação para cada objetivo em específico do problema. Essas subpopulações são armazenadas em tabelas, conhecidas como tabelas de subpopulações, e por isso essa técnica é conhecida como "Método de Tabelas". Para exemplificar como essa estratégia de otimização funciona, considere o AEMT (Santos et al., 2010), que é baseado nesse Método de Tabelas, bem como um problema de otimização com três objetivos $f_{1}, f_{2}$ e $f_{3}$. Assim, para solucionar esse problema deverão haver três tabelas $P O P_{f_{1}}, P O P_{f_{2}}$ e $P O P_{f_{3}}$ que armazenarão, respectivamente, os melhores indivíduos para os objetivos $f_{1}, f_{2}$ e $f_{3}$. Em relação a escolha de um indivíduo para reprodução, este pode ser selecionado em qualquer uma das tabelas.

Segundo Santos et al. (2010), essa estratégia aumenta a diversidade entre as soluções. Consequentemente, diminui-se a possibilidade do processo de busca ficar preso em ótimos locais.

\subsection{Considerações Finais}

Este capítulo apresentou os principais conceitos e o funcionamento de um AE típico, que lida com problemas de otimização com um objetivo. Foi apresentada também uma explanação sobre problemas de otimização com múltiplos objetivos bem como alguns dos principais AEs presentes na literatura para esse tipo de problema. Dentre os AEMOs apresentados encontra-se o Método de Tabelas, no qual se baseia o AEMT que será apresentado no próximo capítulo. 


\section{Medodologia Base: Algoritmo Evolutivo Multi-Objetivo em Tabela}

\subsection{Considerações Iniciais}

Para atingir os objetivos desta pesquisa, apresentados na Seção 1.4, utilizar-se-á como base para o seu desenvolvimento o AEMT, proposto por Santos et al. (2010). Esta metodologia faz uso da RNP para representar computacionalmente os SDRs sem simplificações, e foi desenvolvida com base no Método de Tabelas (Seção 3.4.4) para tratar os problemas de redução de perdas resistivas e de restabelecimento de energia em SDRs de grande porte via reconfiguração de redes. Essa metodologia base e a RNP serão apresentadas nesse capítulo. Por se tratar de uma estrutura de dados baseada na Teoria de Grafos, a compreensão da RNP exige o conhecimento de alguns conceitos básicos desta teoria. Portanto, caso o leitor não seja familiarizado com esses termos, sugere-se a leitura do Apêndice A, especialmente da Seção A.2, para melhorar o entendimento do que será apresentado a seguir.. 


\subsection{Estrutura de Dados}

\subsubsection{Representação de SDRs por meio de Grafos}

Uma diversidade de problemas pode ter dados representados por meio de grafos. Um exemplo conveniente são os problemas relacionados às redes elétricas de distribuição de energia (Mansour, 2009), cuja rede primária ${ }^{1}$ é constituída essencialmente por um conjunto de barras (de carga e de passagem), de chaves seccionadoras, de linhas que conduzem a energia elétrica e de subestações, conforme ilustrado na Figura 4.1. Esta figura apresenta um SDR com características semelhantes àqueles presentes nas redes reais de energia elétrica, e que possui 17 barras (incluindo as barras S1 e S2 em subestação), 5 chaves NF, 3 chaves NA, 2 alimentadores e 2 subestações.

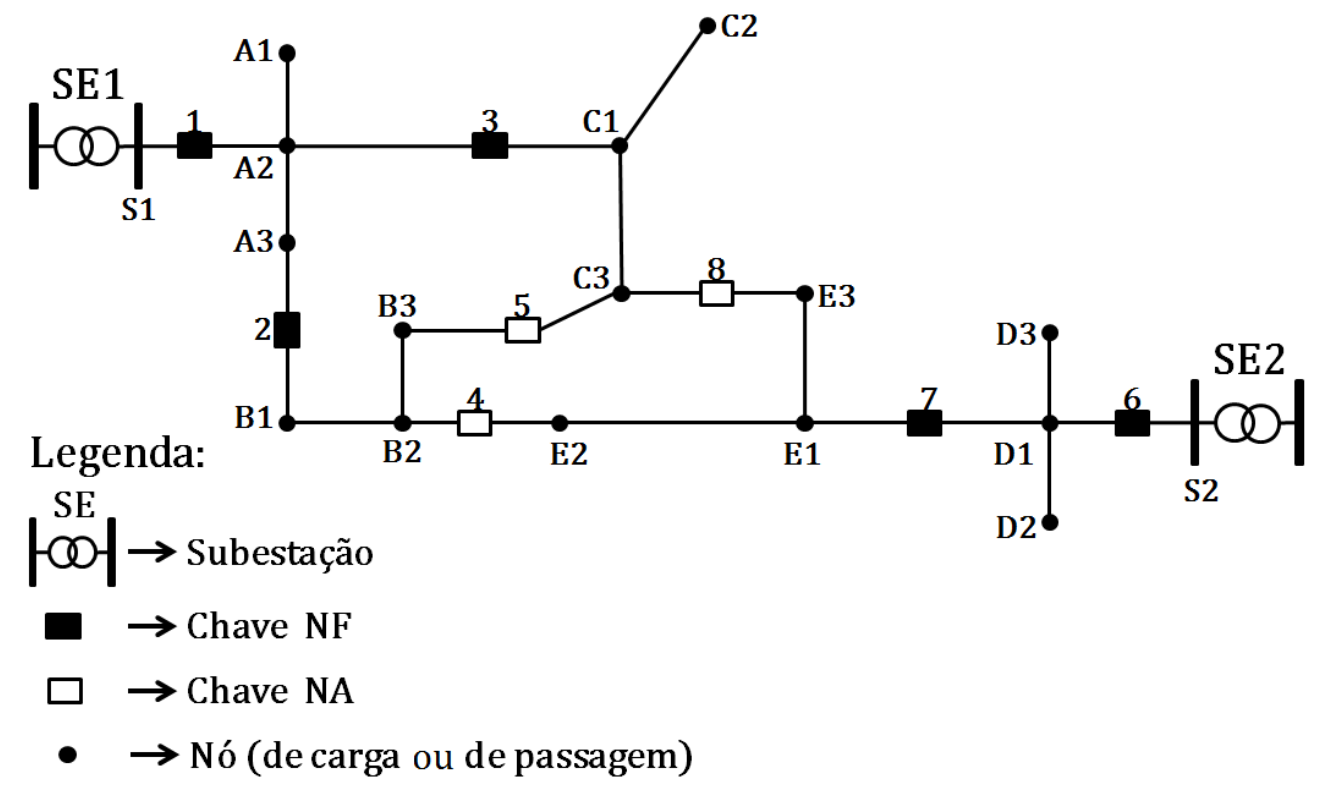

Figura 4.1: Exemplo de SDR típico.

Para representar um SDR qualquer por meio de grafos, os alimentadores devem ser considerados como sendo as árvores, os setores como os nós, as chaves seccionadoras como as arestas e as barras das subestações como nós raízes das árvores. Desse modo, um SDR composto por vários alimentadores pode ser representado como uma floresta de grafo, formada por várias árvores. Na Figura 4.2 é ilustrada a representação em grafo do SDR da Figura 4.1, na qual as arestas em linha cheia e em linha tracejada representam, respectivamente, as chaves NFs e as chaves NAs, enquanto que os nós representam os

\footnotetext{
${ }^{1}$ As redes elétricas de distribuição de energia são constituídas pelas redes primária e secundária. Entretanto, na rede secundária é incomum a presença de chaves seccionadoras, o que dificulta a reconfiguração de redes nessa parte dos SDRs.
} 
setores daquele SDR. Por exemplo, o nó A, do grafo da Figura 4.2, representa o setor A da Figura 4.1, que é formado pelas barras A1, A2 e A3.

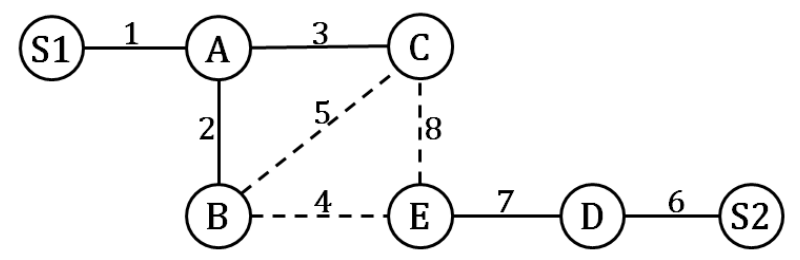

Figura 4.2: Representação em grafo do SDR da Figura 4.1.

\subsubsection{Representação Nó-Profundidade}

A fim de representar computacionalmente árvores de grafo, foi desenvolvida por Delbem et al. (2004) a codificação de dados abstrata denominada RNP. A RNP baseia-se nos conceitos de caminho e profundidade de nó em uma árvore de grafo (definidos na Seção A.2 do Apêndice A), e consiste, basicamente, de uma lista linear contendo os nós da árvore e suas respectivas profundidades, formando pares do tipo $(n x ; p x)$, sendo $n x$ o nó da árvore e $p x$ a profundidade do nó (Delbem et al., 2004; Mansour, 2009). Para ilustrar como uma árvore de grafo pode ser armazenada na RNP, considere a Figura 4.3 na qual é apresentada a RNP de cada árvore da floresta de grafo da Figura 4.2, sendo $T_{1}$ e $T_{2}$ as árvores que possuem como nó raiz, respectivamente, os nós S1 e S2.

$$
\begin{aligned}
& \boldsymbol{T}_{1}=\left|\begin{array}{c}
\text { nó } \\
\text { prof. }
\end{array}\right|=\left|\begin{array}{cccc}
\mathrm{S} 1 & \mathrm{~A} & \mathrm{~B} & \mathrm{C} \\
0 & 1 & 2 & 2
\end{array}\right| \\
& \boldsymbol{T}_{2}=\left|\begin{array}{c}
\text { nó } \\
\text { prof. }
\end{array}\right|=\left|\begin{array}{ccc}
\mathrm{S} 2 & \mathrm{D} & \mathrm{E} \\
0 & 1 & 2
\end{array}\right|
\end{aligned}
$$

Figura 4.3: RNPs da floresta de grafo da Figura 4.2.

Inicialmente, essa codificação foi desenvolvida para ser utilizada em AEs que visam solucionar o problema de projeto de redes. Isto porque as representações tradicionais tem mostrado-se ineficientes e limitadas para esse tipo de problema, especialmente quando são aplicadas à redes de grande porte (Lima e Delbem, 2007). Entretanto, a RNP tem sido amplamente aplicada também ao problema de restabelecimento de energia (Mansour et al., 2009; Sanches et al., 2012; Santos et al., 2010) e a outros problemas de reconfiguração de redes, como, por exemplo, redução de perdas elétricas (Sanches et al., 2011) e melhoria do perfil de tensão (Fantin et al., 2011).

Computacionalmente, a lista contendo os pares $(n x ; p x)$ é representada por uma matriz de dimensão $2 \times n$, onde $n$ é o número de nós da árvore, de tal forma que cada par $(n x ; p x)$ 
é armazenado em uma determinada coluna dessa matriz, sendo $n x$ e $p x$ armazenados, respectivamente, na primeira e na segunda linha, (ver Figura 4.3). A ordem em que os pares $(n x ; p x)$ são disposto é importante (Mansour, 2009) e deve ser determinada por um algoritmo de busca em profundidade (Cormen, 2002), utilizando o nó raiz da árvore como referência. Esse procedimento pode ser executado off-line.

Para facilitar a manipulação da floresta armazenada em RNPs, com baixo tempo de processamento computacional, foram criados dois operadores: o PAO (do inglês, Preserve Ancestor Operator) e o CAO (do inglês, Change Ancestor Operator) (Delbem et al., 2004). Estes operadores produzem novas florestas geradoras $G$ quando aplicados a uma floresta $G^{x}$, qualquer, armazenada em RNPs. Para tal, ambos transferem uma subárvore de uma árvore $T_{d e}$ (árvore origem) para uma árvore $T_{\text {para }}$ (árvore destino). Entretanto, no operador PAO a raiz da subárvore podada será a raiz da mesma na nova árvore $T_{\text {para }}$, enquanto que no operador CAO um novo nó, diferente da raiz da subárvore podada, é escolhido para ser a nova raiz da subárvore transferida para $T_{\text {para }}$ (Delbem e de Carvalho, 2003).

O operador PAO requer a definição prévia de dois nós: o nó de poda $p$, que indica a raiz da subárvore que será podada, e o nó adjacente $a$, que indica onde a subárvore podada será inserida na árvore $T_{\text {para }}$. Já o operador CAO requer, além desses dois nós, um terceiro nó chamado de nó $r$, que será a nova raiz da subárvore que será transferida (Delbem et al., 2004; Mansour, 2009). É importante destacar que a característica da RNP de gerar exclusivamente configurações factíveis é garantida pela maneira como esses operadores realizam poda e transferência de subárvores.

\subsubsection{RNP de Setor}

Em muitos trabalhos relacionados ao processo de restabelecimento de energia em SDRs de tamanho real são feitas simplificações na modelagem da rede, como, por exemplo, considerar todas as barras de carga e linhas de um setor como se estivessem concentradas em um único ponto. Esse tipo de procedimento, conforme dito anteriormente, reduz o grau de confiabilidade da resposta fornecida, uma vez que o modelo utilizado não corresponde diretamente à rede em operação.

Desse modo, a fim de superar essa limitação e garantir que as redes reais sejam representadas sem simplificações, nesse trabalho, assim como em (Santos et al., 2010), foi utilizada a RNP em dois níveis: a RNP de alimentador (apresentada na seção anterior) e a RNP de setor. Conforme mostrado anteriormente, na RNP de alimentador representa-se computacionalmente uma árvore de grafo na qual os nós representam os setores e as arestas como sendo chaves seccionadoras. Enquanto isso, na RNP de setor codifica-se 
uma árvore de grafo na qual os nós representam barras de carga e de passagem e as arestas representam trechos de linha não separados por chave (a exceção da aresta que conecta o nó raiz à árvore).

No contexto de AEs para problemas relacionados a SDRs, a RNP de alimentador permite melhorar o desempenho de AEs no que tange à representação computacional e manipulação da rede. Por outro lado, a RNP de setor permite a execução de um fluxo de potência de Varredura Direta/Inversa (Baran e Wu, 1989; Shirmohammadi et al., 1988) considerando-se todas as barras de carga e de passagem e todos os trechos de linha, isto é, sem simplificações. Além disso, segundo (Santos et al., 2010), a representação de SDRs por meio da RNP de setor permite também a ordenação e o armazenamento das barras, de forma natural, segundo uma relação conhecida como "Modelo Pai-Filho"(MPF) (Kagan et al., 2005). No MPF todas as barras estão ordenadas segundo o sentido do fluxo de potência através do SDR, possibilitando a execução de um algoritmo de fluxo de potência de Varredura Direta/Inversa. Quando outras estruturas de dados são utilizadas faz-se necessário a execução de um algoritmo específico para ordenar as barras segundo essa relação toda vez que uma nova configuração for gerada pelo AE (Santos et al., 2010).

A representação de um setor por meio da RNP é feita de forma semelhante a da RNP de alimentador, onde cada árvore $i$ é armazenada em uma RNP denotada por $T_{i}$. Já a RNP de setor denotar-se-á por $B_{s r}$, onde $s$ representa o setor em análise (setor filho) e $r$ refere-se ao setor pelo qual a energia elétrica chega ao setor $s$ (setor pai) (Santos, 2009). Por exemplo, considere o setor E do SDR apresentado na Figura 4.1, separado pelas chaves 4, 7 e 8 e constituído pelas barras E1, E2, E3 e pelos trechos de linha entre essas barras. Ademais, nessa configuração da rede, mostrada pela Figura 4.1, o setor pelo qual a energia elétrica chega até setor E é o setor D, através da barra D1. Assim, a codificação do setor E por meio da RNP, ou seja, $B_{E D}$, é dada conforme ilustrado pela Figura 4.4(a), que apresenta também a representação em grafo desse setor. Observe que na representação de um setor por meio da RNP acrescenta-se a barra por meio da qual a energia elétrica chega a esse setor. Essa barra tornar-se, então, o nó raiz desse setor.

No entanto, alguns setores podem ser alimentados com energia por mais de um caminho, ou seja, podem ter mais de um nó raiz e, consequentemente, mais de uma RNP associada. No caso do setor E, do exemplo anterior, este pode receber energia também dos setores B e C, caso as chaves 4 ou 8, respectivamente, sejam fechadas e a chave 7 aberta. Assim, as outras duas RNPs relacionadas ao setor E serão, $B_{E B}$ e $B_{E C}$, que terão como nó raiz, respectivamente, os nós B2 e C3. Ambas podem ser vistas, respectivamente, nas Figuras 4.4(b) e 4.4(c), juntamente com os respectivos grafos associados. 


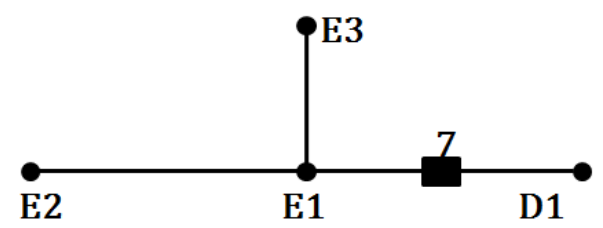

$$
B_{E D}=\left|\begin{array}{c}
\text { nó } \\
\text { prof. }
\end{array}\right|=\left|\begin{array}{cccc}
\mathrm{D} 1 & \mathrm{E} 1 & \mathrm{E} 2 & \mathrm{E} 3 \\
0 & 1 & 2 & 2
\end{array}\right|
$$

(a) RNP do setor E do SDR da Figura 4.1, tendo como raiz o nó D1.

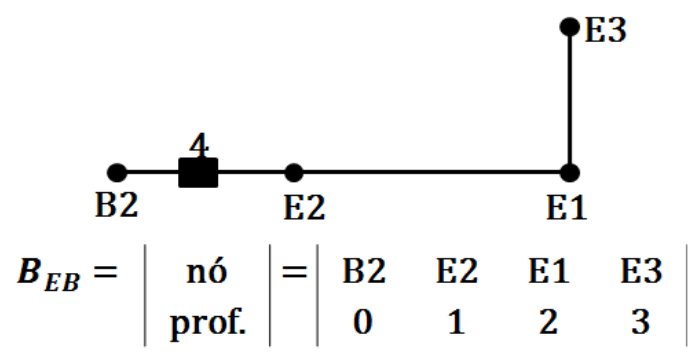

(b) RNP do setor E do SDR da Figura 4.1, tendo como raiz o nó $\mathrm{B} 2$.

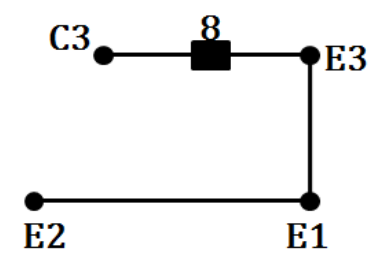

$$
B_{E C}=\left|\begin{array}{c}
\text { nó } \\
\text { prof. }
\end{array}\right|=\left|\begin{array}{cccc}
\mathrm{C} 3 & \mathrm{E} 3 & \mathrm{E} 1 & \mathrm{E} 2 \\
0 & 1 & 2 & 3
\end{array}\right|
$$

(c) RNP do setor E do SDR da Figura 4.1, tendo como raiz o nó $\mathrm{C} 3$.

Figura 4.4: As três RNPs possíveis para o setor E.

Maiores informações sobre a RNP, os seus operadores e a aplicação de ambos na representação computacional de SRDs, podem ser obtidas em (Santos et al., 2010) e no Apêndice A.

\subsection{Algoritmo e Funcionamento}

Ao lidar com o problema de restabelecimento de energia ou de redução de perdas resistivas via reconfiguração de redes, o AEMT considera como indivíduo ${ }^{2}$ toda floresta de grafo

\footnotetext{
${ }^{2}$ Ao longo deste texto de dissertação um indivíduo poderá ser referido também pelas palavras 'configuração' e 'solução', sendo, neste contexto, todas elas sinônimas.
} 

MULTI-OBJETIVO EM TABELA

modelada em RNP, correspondente a uma configuração do SDR na qual o setor em falta encontra-se isolado e a(s) área(s) sã(s) fora de serviço reconectada(s) a algum setor da rede com fornecimento (Santos, 2009). Ademais, uma subpopulação é definida como um conjunto formado por alguns dos indivíduos de uma população.

Nesse contexto, o AEMT trabalha com várias subpopulações em paralelo, armazenadas em tabelas (Benayoun et al., 1971; Santos et al., 2010). Estas tabelas guardam os melhores indivíduos para: carregamento da rede, carregamento de subestação, queda de tensão, perdas resistivas, função agregação e número de operações de manobra. A função agregação é uma equação que reuni as restrições operacionais e as perdas resistivas para cada configuração $G$ gerada pelo AEMT, conforme apresentado pela Equação 4.1.

$$
f(G)=\gamma(G)+w_{x} X(G)+w_{s} B(G)+w_{v} V(G)
$$

em que:

- $G$ é uma floresta de grafo representando uma configuração do sistema;

- $\gamma(G)$ são as perdas resistivas totais, em kW, na configuração $G$;

- $\mathrm{X}(\mathrm{G})$ é o maior valor de carregamento da rede na configuração $G$;

- $\mathrm{B}(\mathrm{G})$ é o maior valor de carregamento da subestação na configuração $G$;

- $\mathrm{V}(\mathrm{G})$ é a maior queda de tensão da configuração $G$;

- $w_{x}, w_{s}$ e $w_{v}$ são pesos definidos da seguinte forma:

$$
\begin{aligned}
& w_{x}=\left\{\begin{array}{l}
A, \text { se } X(G)>1 \\
0, \text { caso contrário; }
\end{array}\right. \\
& w_{b}=\left\{\begin{array}{l}
B, \text { se } B(G)>1 \\
0, \text { caso contrário; }
\end{array}\right. \\
& w_{v}=\left\{\begin{array}{l}
C, \text { se } V(G)>0,1 \\
0, \text { caso contrário. }
\end{array}\right.
\end{aligned}
$$

em que A, B e C são valores maiores do que zero. Os valores de $X(G), B(G)$ e $V(G)$ são determinados da seguinte forma:

- $X(G)=M A ́ X I M O\left(x_{j} / \bar{x}_{j}\right)$, em que $\bar{x}_{j}$ é um limitante superior de corrente para cada corrente de linha $x_{j}$ em uma linha $j$; 
- $B(G)=M A ́ A X I M O\left(b_{s} / \bar{b}_{s}\right)$, onde $\bar{b}_{s}$ é um limitante superior para cada injeção de corrente $b_{s}$ provida por uma subestação $s$;

- $V(G)=M A ́ X I M O\left(1-\left(v_{k} / v_{b}\right)\right)$, onde $v_{k}$ é a magnitude de tensão na barra $k$ e $v_{b}$ é a magnitude da tensão base do sistema.

O pseudocódigo do AEMT é apresentado no Algoritmo 2 (Santos et al., 2010). A fim de facilitar ao leitor a compreensão do funcionamento desta metodologia tomada como base para o desenvolvimento do presente trabalho, a seguir serão explicados os principais passos de execução desse algoritmo.

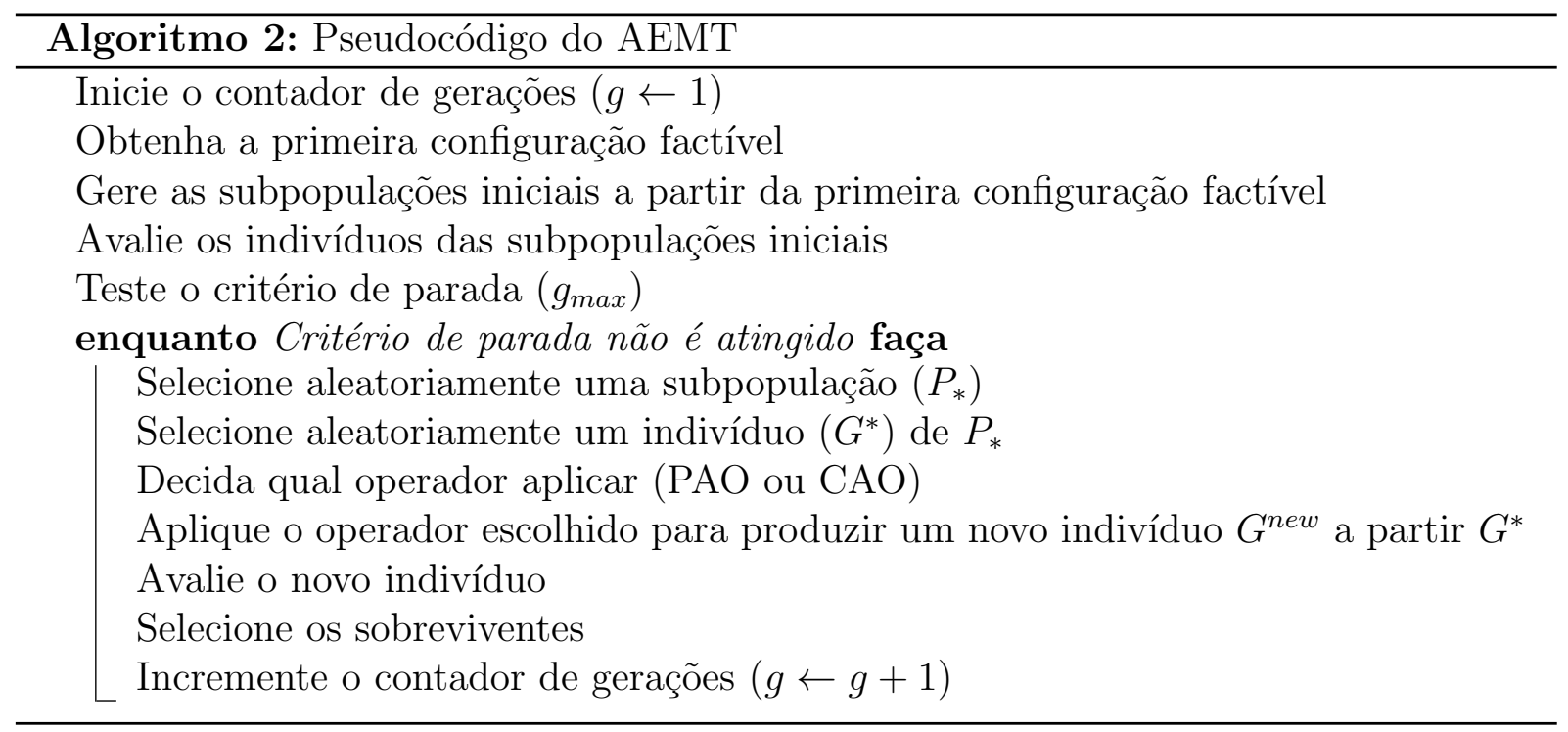

\section{Obtenção da Primeira Configuração Factível}

O funcionamento do AEMT começa com a obtenção da primeira configuração factível, chamada em (Santos et al., 2010) de "Starting Solution", a partir da configuração inicial. Uma configuração é considera factível se esta puder ser representada por meio de um grafo acíclico e conexo. Em outras palavras, é uma configuração que é radial (sem formação de laços) e que garante fornecimento de energia a todos os setores, a exceção do setor sob falta. Já a configuração inicial é definida nesta dissertação como sendo aquela na qual o setor sob falta encontra-se isolado e os setores sãos, localizados à jusante da falta, encontram-se desconectados da rede e sem fornecimento. Um exemplo de configuração inicial e de configuração factível pode ser visto, respectivamente, nas Figuras 1.1(b) e 1.1(c), na página 5.

Dada uma configuração inicial qualquer, a primeira configuração factível é obtida no AEMT por meio da reconexão dos setores fora de serviço em setores adjacentes a estes, 
escolhidos aleatoriamente dentre todos os setores adjacentes que possuem fornecimento de energia e conexão com os setores fora de serviço. Existe ainda a possibilidade de que a falta ocorra em um setor que não possuir setores à jusante. Nestes casos, a primeira configuração factível obtida será a própria configuração inicial. A primeira configuração factível é o primeiro indivíduo do AEMT e servirá como ponto de partida para a geração da população inicial (dividida em subpopulações) e para o processo evolutivo das subpopulações armazenadas em tabelas.

\section{Geração das Subpopulações Iniciais}

A partir da primeira configuração factível, gerar-se-ão novos indivíduos a fim de preencher todas as tabelas de subpopulação, que juntas formarão a primeira população. Para tal, aplica-se exclusivamente o operador PAO da RNP, na primeira configuração factível ou em uma das configurações já geradas a partir dela, até que todas as tabelas de subpopulações estejam completas.

As tabelas presentes no AEMT são dez, e as subpopulações que armazenam são aquelas formadas por:

- $P_{1}$ - soluções com os menores valores de função agregação (Equação 4.1);

- $P_{2}$ - soluções com os menores valores de perdas resistivas;

- $P_{3}$ - soluções com os menores valores de carregamento da rede;

- $P_{4}$ - soluções com os menores valores de carregamento de subestação;

- $P_{5}$ - soluções com os menores valores de queda máxima de tensão;

- $P_{5+i}$ - soluções com os menores valores de perdas resistivas e com $i$ pares de manobras após a isolação da falta e reconexão das cargas sãs sem fornecimento, sendo $i=1, \ldots, 5$.

\section{Avaliação dos Indivíduos das Subpopulações Iniciais}

A avaliação dos indivíduos no AEMT é realizada por meio da aplicação de um algoritmo de fluxo de potência de Varredura Direta Inversa do tipo Soma de Correntes (Shirmohammadi et al., 1988) com RNP (ver na Seção 4.2.3 as vantagens da RNP no contexto de fluxo de potência). Para tal as cargas elétricas são representadas segundo o Modelo de Corrente Constante com a Tensão (Kagan et al., 2005) e o trecho de linha entre duas barras $a$ e $b$ é representado por uma impedância $Z_{a b}$. Os indivíduo são avaliados também em relação ao 
número de operações de manobras em chaves necessárias para obtê-lo (maiores detalhes a seguir).

Os algoritmos de fluxo de potência de Varredura Direta Inversa são métodos desenvolvidos para determinação das tensões complexa nas barras, dos fluxos de potências nas linhas e das perdas especificamente em SDRs. Eles são assim chamados por apresentarem um processo de cálculo que percorre, a cada iteração, as barras e linhas do SDR em dois sentidos: $(i)$ das barras terminais ou periféricas em direção à barra da subestação (varredura inversa) e (ii) da barra da subestação em direção às barras terminais ou periféricas (varredura direta). Esse processo é iterativo, terminando quando o critério de convergência adotado é atingido.

\section{Critério de Parada}

O critério de parada adotado pelo AEMT é um número máximo de indivíduos gerados $\left(g_{\max }\right)$, sendo este um parâmetro a ser informado no início da sua execução

\section{Seleção Aleatória de uma Subpopulação}

Criadas as subpopulações iniciais, que preencheram todas as tabelas, o AEMT iniciará, então, o processo de evolução da população por meio da competição entre as soluções (ou indivíduos) armazenadas nas tabelas e soluções que serão geradas a partir de agora. A seleção de um novo indivíduo para reprodução inicia-se pela escolha randômica de uma tabela de subpopulação $P_{*}$.

\section{Seleção Aleatória de um Indivíduo na Subpopulação Escolhida}

Em seguida, um indivíduo $G^{*}$, pertencente a tabela de subpopulação $P_{*}$, é também escolhido randomicamente. Assim, uma nova solução $G^{\text {new }}$ poderá ser gerada por meio da aplicação de um dos operadores da RNP (PAO ou CAO) em $G^{*}$. Desse modo, o indivíduo selecionado para reprodução pode ser proveniente de qualquer subpopulação. Segundo Santos et al. (2010), essa estratégia de seleção aumenta a diversidade entre os indivíduos que se reproduzem, de forma que as características de um indivíduo de uma subpopulação possam migrar para as demais subpopulações. Consequentemente, aumentam-se as possibilidades do algoritmo escapar de ótimos locais, aproximando-se de soluções com avaliações mais próximas de um ótimo global. 


\section{Decisão de Aplicação de um dos Operadores da RNP (PAO ou CAO)}

Uma vez iniciado o processo de evolução da população, dividida em subpopulações armazenadas em tabelas, a seleção de um dos operadores da RNP que será aplicado um uma configuração $G^{*}$, a fim de gerar uma nova configuração $G^{\text {new }}$, é feita seguindo um ajuste dinâmico, que funciona da seguinte forma: no início do processo de busca, o algoritmo utiliza a mesma taxa de probabilidade de escolha para ambos operadores $\left(P B_{P A O}=P B_{C A O}=0,50\right)$. Suponha que o operador PAO tenha sido escolhido para gerar um novo indivíduo. Se o indivíduo gerado tiver sucesso, ou seja, for acrescentado a uma ou mais subpopulações, aumenta-se $P B_{P A O}$ para 0,51 e, como consequência, $P B_{C A O}$ é reduzido para 0,49, e assim sucessivamente. Esse ajuste dinâmico do processo de escolha dos operadores melhora consideravelmente o desempenho do algoritmo, conforme mostrado nos testes apresentados em (Santos et al., 2010).

\section{Aplicação do Operador Escolhido e Geração de um Novo Indivíduo}

Esse passo consiste na aplicação, em $G^{*}$, do operador escolhido, a fim de gerar $G^{\text {new }}$. Maiores informações sobre os operadores da RNP, utilizados no AEMT como operadores de mutação, podem ser adquiridas no Apêndice A deste documento.

\section{Avaliação do Novo Indivíduo}

A avaliação do novo indivíduo gerado é feita da mesma forma que a dos indivíduos das subpopulações iniciais, apresentada anteriormente. Em outras palavras, utiliza-se também aqui um algoritmo de fluxo de potência de Varredura Direta Inversa do tipo Soma de Correntes com RNP. Esse algoritmo irá determinar para esse novo indivíduo, isto é, $G^{\text {new }}$, os valores de perdas resistivas totais, da maior queda de tensão, do maior carregamento da rede e do maior carregamento de subestação, ou seja, os valores de $\gamma\left(G^{\text {new }}\right), \mathrm{V}\left(G^{\text {new }}\right)$, $\mathrm{X}\left(G^{\text {new }}\right)$ e B $\left(G^{\text {new }}\right)$ (ver Seção 1.2.2). Com base nesses dados calcula-se também o valor da função agregação $f\left(G^{n e w}\right)$ para $G^{\text {new }}$, conforme a Equação 4.1. Nesse etapa é determinado ainda o número de operações de chaveamento ou número de manobras necessários para se obter $G^{\text {new }}$ a partir da configuração pré-falta (denotada por $\left.G^{p f}\right)$, isto é, $\psi\left(G^{\text {new }}, G^{p f}\right)$. Para tal, utiliza-se de um algoritmo eficiente proposto em (Santos et al., 2010) e que será apresentado a seguir na Seção 4.4. É importante destacar que a cada novo indivíduo gerado, a rotina de fluxo de potência é executada somente para o par de alimentadores que sofreram modificações, uma vez que a topologia dos demais alimentadores do SDR não sofreu nenhuma alteração, e, portanto, as variáveis de estado nestes permanecem iguais. Essa estratégia contribui para a eficiência computacional dessa metodologia. 


\section{Seleção dos Sobreviventes nas Tabelas de Subpopulações}

Determinadas as características de $G^{\text {new }}$ este é, então, comparado com o pior indivíduo presente em cada uma das tabelas de subpopulação e será incluído em uma tabela $P_{q}$, qualquer, se $G^{\text {new }}$ for melhor que a pior solução presente em $P_{q}$. Assim, dependendo da adequação de $G^{\text {new }}$ aos objetivos do problema, este poderá ser armazenado em uma ou mais tabelas ou ainda descartado. Tendo em vista que o tamanho das tabelas é fixo, se $G^{\text {new }}$ entrar em uma tabela $P_{q}$, o pior indivíduo em $P_{q}$ deverá ser descartado.

\subsection{Cálculo do Número de Manobras}

Normalmente, o número de manobras é determinado por meio da comparação entre vetores que armazenam, de forma binária, os estados das chaves. De tal forma que, para cada nova configuração gerada é criado um vetor com os estados de todas as chaves nessa nova configuração. Então, para se determinar o número de operações requeridas para implantar essa configuração, faz-se uma comparação daquele vetor de estado das chaves com o vetor que armazena o estado das chaves na configuração pré-falta (Santos, 2009).

Entretanto, esse procedimento envolve custo computacionalmente elevado, ao passo que requer a comparação dos estados de todas as chaves, mesmo que somente algumas poucas tenham sido alteradas de uma configuração para outra. Além disso, esse custo computacional é proporcional ao número de chaves presentes no SDR. Assim, quanto maior for o número de chaves maior será o custo computacional para determinação do número de manobras necessário para se obter uma certa configuração da rede. Logo, para SDRs de grande porte, foco deste trabalho, esse procedimento pode tornar-se inviável dada a necessidade do problema de obtenção de soluções em tempo real.

Assim sendo, para garantir ao AEMT eficiência computacional no cálculo do número de manobras, foi proposto em (Santos et al., 2010) um novo algoritmo que requer apenas dois vetores: um vetor com o estado das chaves na configuração pré-falta e outro vetor, de tamanho $g_{\text {max }}$, para armazenar o número de operações de manobras requerido para obter de cada configuração $G$ (Santos et al., 2010) a partir da configuração pré-falta.

Além disso, esse algoritmo baseia-se na informação de que, após a isolação do setor sob falta e a reconexão das cargas fora de serviço, as alterações em chaves ocorrerão sempre em pares. Em outras palavras, depois da execução das manobras em chaves necessárias para restabelecer o fornecimento aos setores fora de serviço, todas as operações em chaves ocorrem para transferência de cargas entre alimentadores e correção de possíveis sobrecargas e/ou melhoria do perfil de tensão. Logo, para cada chave que for aberta outra deverá ser fechada. Assim, para determinar o número de manobras 
necessárias para implementar uma dada configuração, considere o estado das chaves em três configurações específicas: configuração pré-falta $\left(G^{p f}\right)$, configuração alterada $\left(G^{x}\right)$ e configuração final $\left(G^{y}\right)$. Dessa forma, considerando que uma configuração $G^{y}$ originou-se de uma configuração $G^{x}$, há três possibilidades para computar o número de manobras da configuração $G^{y}$ (Santos et al., 2010; Santos, 2009):

Caso 1: os estados em $G^{y}$, das duas chaves alteradas em $G^{x}$, são diferentes dos estados dessas chaves em $G^{p f}$. Portanto, o número de chaves alteradas de $G^{y}$, em relação a $G^{p f}$, será o número de chaves alteradas de $G^{x}$ mais 2. Por exemplo, na Tabela 4.1, considere que as chaves 2 e 5 foram alteradas em $G^{x}$ para gerar $G^{y}$, e ainda que a notação $G_{k}^{w}$ representa o estado de uma chave $k$ qualquer em uma configuração $G^{w}$ também qualquer. Como $G_{2}^{y} \neq G_{2}^{p f}$ e $G_{5}^{y} \neq G_{5}^{p f}$, para implementar $G^{y}$ são necessárias duas manobras a mais que para implementar $G^{x}$. Como de $G^{p f}$ para $G^{x}$ foram realizadas 2 alterações, então, de $G^{p f}$ para $G^{y}$ são necessárias 4 alterações.

Tabela 4.1: Manobras de chaves: Caso 1.

\begin{tabular}{|c|c|c|c|c|c|c|}
\hline & & \multicolumn{5}{|c|}{ Configurações } \\
\hline & & $G^{p f}$ & $\ldots$ & $G^{x}$ & $\ldots$ & $G^{y}$ \\
\hline$\stackrel{0}{0}$ & 1 & 1 & $\longrightarrow$ & 0 & & 0 \\
\hline$\widetilde{\pi}$ & 2 & 0 & & 0 & $\longrightarrow$ & 1 \\
\hline v & 3 & 0 & $\longrightarrow$ & 1 & & 1 \\
\hline क & 4 & 1 & & 1 & & 1 \\
\hline$\underset{\mathbb{G}}{\vec{I}}$ & 5 & 1 & & 1 & $\longrightarrow$ & 0 \\
\hline$\circlearrowright$ & 6 & 0 & & 0 & & 0 \\
\hline
\end{tabular}

Caso 2: os estados em $G^{y}$, das duas chaves alteradas em $G^{x}$, são iguais aos estados dessas chaves em $G^{p f}$. Portanto, o número de chaves alteradas de $G^{y}$ será o número de chaves alteradas de $G^{x}$ menos 2. Por exemplo, na Tabela 4.2, considere que as chaves $1 \mathrm{e}$ 3 foram alteradas em $G^{x}$ para gerar $G^{y}$. Como $G_{1}^{y}=G_{1}^{p f}$ e $G_{3}^{y}=G_{3}^{p f}$, para implementar $G^{y}$ são necessárias duas manobras a menos que para implementar $G^{x}$.

Tabela 4.2: Manobras de chaves: Caso 2.

\begin{tabular}{|c|c|c|c|c|c|c|}
\hline & & \multicolumn{5}{|c|}{ Configurações } \\
\hline & & $G^{p f}$ & $\ldots$ & $G^{x}$ & $\ldots$ & $G^{y}$ \\
\hline ? & 1 & 1 & $\longrightarrow$ & 0 & $\longrightarrow$ & 1 \\
\hline$\pi$ & 2 & 0 & & 0 & & 0 \\
\hline है & 3 & 0 & $\longrightarrow$ & 1 & $\longrightarrow$ & 0 \\
\hline के & 4 & 1 & & 1 & & 1 \\
\hline$\tilde{\sigma}$ & 5 & 1 & & 1 & & 1 \\
\hline U & 6 & 0 & & 0 & & 0 \\
\hline
\end{tabular}

Caso 3: o estado em $G^{y}$, de uma chave alterada em $G^{x}$, é igual ao estado dessa chave em $G^{p f}$, e o estado em $G^{y}$ da outra chave alterada em $G^{x}$ é diferente do estado dessa 
chave em $G^{p f}$. Portanto, o número de chaves alteradas de $G^{y}$ será igual ao número de chaves alteradas de $G^{x}$. Por exemplo, na Tabela 4.3, considere que as chaves 3 e 6 foram alteradas em $G^{x}$ para gerar $G^{y}$. Como $G_{3}^{y}=G_{3}^{p f}$ e $G_{6}^{y} \neq G_{6}^{p f}$, para implementar $G^{y}$ é necessário o mesmo número de manobras para implementar $G^{x}$.

Tabela 4.3: Manobras de chaves: Caso 3.

\begin{tabular}{|c|c|c|c|c|c|c|}
\hline & & \multicolumn{5}{|c|}{ Configurações } \\
\hline & & $G^{p f}$ & $\ldots$ & $G^{x}$ & $\ldots$ & $G^{y}$ \\
\hline of & 1 & 1 & $\longrightarrow$ & 0 & & 0 \\
\hline$\widetilde{\pi}$ & 2 & 0 & & 0 & & 0 \\
\hline की & 3 & 0 & $\longrightarrow$ & 1 & $\longrightarrow$ & 0 \\
\hline है & 4 & 1 & & 1 & & 1 \\
\hline$\underset{\widetilde{J}}{\overparen{\Xi}}$ & 5 & 1 & & 1 & & 1 \\
\hline$\circlearrowright$ & 6 & 0 & & 0 & $\longrightarrow$ & 1 \\
\hline
\end{tabular}

O pseudocódigo desse contador de manobras eficiente é apresentado no Algoritmo 3. A seguir será apresentado um exemplo da aplicação do mesmo em um SDR sob falta.

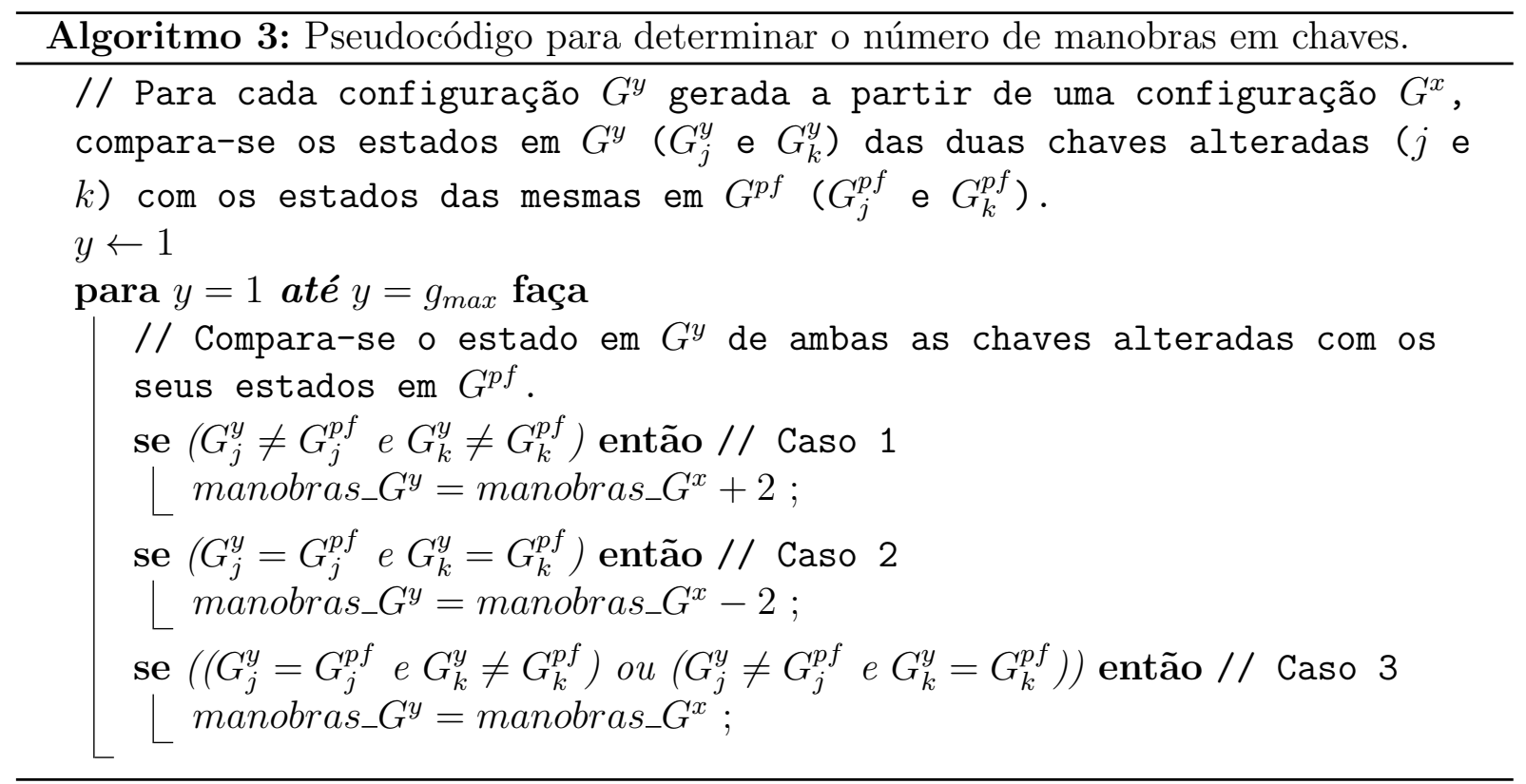

\subsubsection{Exemplo do cálculo do número de manobras}

Com a finalidade de ilustrar o funcionamento do Algoritmo 3, considere o SDR representado pelo grafo da Figura 4.2 e reproduzido na Figura 4.5, bem como a ocorrência de uma falta no setor $\mathrm{C}$ desse SDR. No grafo da Figura 4.5 a árvore em azul representa o alimentador 1, a árvore em preto destaca o alimentador 2, o setor em vermelho, 
pertencente ao alimentador 1, corresponde ao setor sob falta, as arestas tracejadas em verde são as chaves NAs e as arestas contínuas em preto e em azul são chaves NFs.

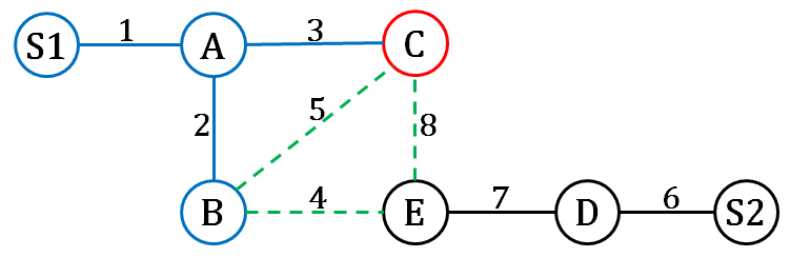

Figura 4.5: Configuração pré-falta.

Analisando a configuração $G^{p f}$, apresentada na Figura 4.5, observa-se que o procedimento de isolar a falta pode ser executado pela abertura da chave 3. Como consequência, obter-se-á a configuração inicial ilustrada pela Figura 4.6. Como, para esse exemplo não existem setores localizados à jusante do setor sob falta para serem reconectados, logo, a configuração inicial da Figura 4.6 representa também a primeira configuração factível obtida, a partir da qual as manobras em chaves ocorrerão sempre em pares. Conforme dito anteriormente, o algoritmo para cálculo do número de manobras proposto em Santos et al. (2010) exige apenas dois vetores. O primeiro deles tem a função de armazenar o estado das chaves em $G^{p f}$, e pode ser visto na Tabela 4.4 .

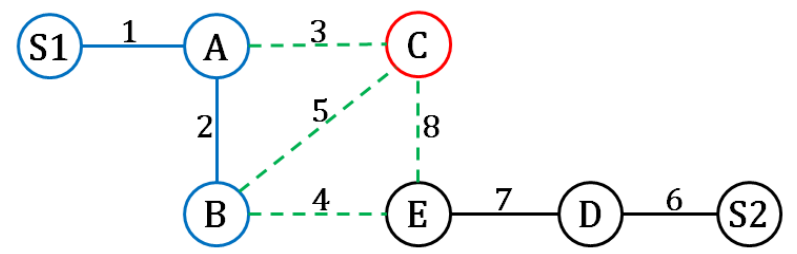

Figura 4.6: Configuração inicial, que corresponde também a primeira configuração factível obtida.

Tabela 4.4: Vetor com o estado das chaves na configuração pré-falta, em que 1 representa chave fechada e 0 chave aberta.

\begin{tabular}{lllllllll}
\hline Chaves & 1 & 2 & 3 & 4 & 5 & 6 & 7 & 8 \\
Estado Inicial & 1 & 1 & 1 & 0 & 0 & 1 & 1 & 0 \\
\hline
\end{tabular}

Além desse vetor, o algoritmo AEMT cria também outro, de tamanho $g_{\max }$, para armazenar o número de manobras necessárias para implementar cada configuração a partir de $G^{p f}$. Esse vetor é mostrado na Tabela 4.5, e está informando que até o momento há apenas uma única configuração obtida, isto é, a primeira configuração factível (configuração 1), e que esta foi obtida a partir de $G^{p f}$ por meio da operação de 1 chave.

Para gerar a segunda configuração factível (configuração 2), considere na configuração 1 a abertura da chave 1 e o fechamento da chave 4. Em seguida, de acordo com o 
Tabela 4.5: Vetor com o número de manobras para cada configuração.

\begin{tabular}{llllllll}
\hline Configuração & 1 & 2 & 3 & 4 & 5 & $\ldots$ & $g_{\max }$ \\
Número de manobras & 1 & & & & & $\ldots$ & \\
\hline
\end{tabular}

Algoritmo 3, deve-se comparar os estados dessas duas chaves na configuração 2 com os estados das mesmas em $G^{p f}$, por meio da Tabela 4.4. Como a chave 1 foi aberta, seu estado passou para 0, enquanto que o estado da chave 4, que foi fechada, passou a ser 1. Portanto, o estado de ambas as chaves na configuração 2 é diferente dos estados das mesmas em $G^{p f}$, caracterizando um Caso 1. Logo, para implementar a configuração 2 a partir de $G^{p f}$ são necessárias 2 manobras. A Figura 4.7 mostra a topologia desse SDR para a configuração 2 .

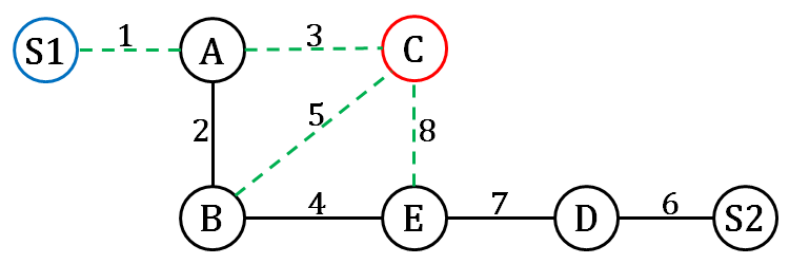

Figura 4.7: Configuração 2.

Com a aplicação do Algoritmo 3 e a constatação de que $G_{1}^{y} \neq G_{1}^{p f}$ e $G_{4}^{y} \neq G_{4}^{p f}$, o vetor que armazena as manobras necessárias para implantar cada nova configuração é, então, atualizado para aquele mostrado na Tabela 4.6.

Tabela 4.6: Vetor com o número de manobras, atualizado com a configuração 2.

\begin{tabular}{llllllll}
\hline Configuração & 1 & 2 & 3 & 4 & 5 & $\ldots$ & $g_{\max }$ \\
Número de manobras & 1 & 3 & & & & $\ldots$ & \\
\hline
\end{tabular}

Para obter a configuração 3 utilizou-se também da configuração 1. Para tal, suponha que a chave 2 foi aberta e a chave 4 foi fechada. Ao comparar-se os estados dessas duas chaves na configuração 3 , com os estados das mesmas em $G^{p f}$, observa-se que o estado de ambas as chaves na configuração 3 é diferente do estado das mesmas em $G^{p f}$ (Caso 1). Logo, para implementar a configuração 3 é necessário o número de manobras para implementar a configuração 1 mais 2 alterações. A Figura 4.8 mostra a topologia do SDR para a configuração 3 e a Tabela 4.7 apresenta o vetor de manobras atualizado para esta última configuração.

Tabela 4.7: Vetor com o número de manobras, atualizado com a configuração 3.

\begin{tabular}{llllllll}
\hline Configuração & 1 & 2 & 3 & 4 & 5 & $\ldots$ & $g_{\max }$ \\
Número de manobras & 1 & 3 & 3 & & & $\ldots$ & \\
\hline
\end{tabular}

Para gerar a configuração 4 foi escolhida a configuração 3. Considere que nessa configuração a chave 7 foi aberta e a chave 2 foi fechada. Ao comparar-se os estados 


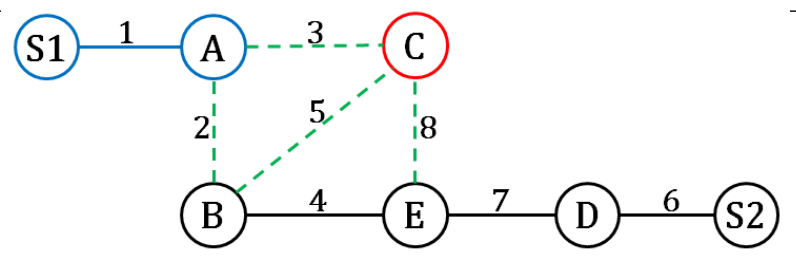

Figura 4.8: Configuração 3.

dessas duas chaves na configuração 4 com os estados das mesmas em $G^{p f}$, observa-se que o estado da chave 2 é igual, porém, o da chave 7 é diferente. Logo, o número de manobras para implementar a configuração 4 é igual ao número de manobras para implementar a configuração que a gerou, ou seja, a configuração 3 , uma vez que $G_{7}^{y}=G_{7}^{p f}$ e $G_{2}^{y} \neq G_{2}^{p f}$, (Caso 3). A Figura 4.9 mostra a topologia do SDR para a configuração 4 e a Tabela 4.8 apresentada o vetor de manobras atualizado para esta última configuração obtida.

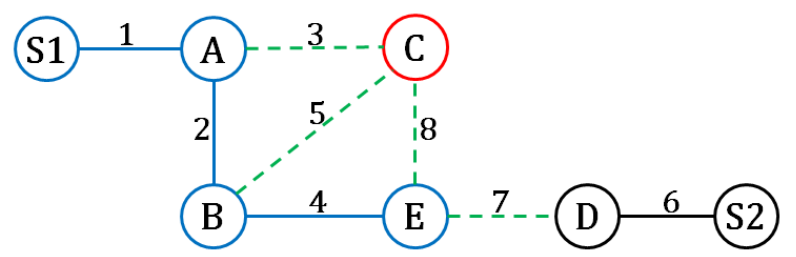

Figura 4.9: Configuração 4 .

Tabela 4.8: Vetor com o número de manobras, atualizado com a configuração 4.

\begin{tabular}{llllllll}
\hline Configuração & 1 & 2 & 3 & 4 & 5 & $\ldots$ & $g_{\max }$ \\
Número de manobras & 1 & 3 & 3 & 3 & & $\ldots$ & \\
\hline
\end{tabular}

Outra possibilidade ocorre quando os estados das duas chaves alteradas se tornam iguais aos seus estados em $G^{p f}$. Considere, então, que para gerar a configuração 5 foi utilizada a configuração 2, e que para tal foi aberta a chave 4 e fechada a chave 1 . Comparando-se os estados dessas duas chaves alteradas em configuração 5, com o seu estado das mesmas em $G^{p f}$, vê-se que ambos são iguais, ou seja, ambas retornaram ao estado que possuíam em $G^{p f}$. Logo, para implementar a configuração 5 são necessárias 2 alterações a menos que o necessário para implementar a configuração 2. Desse modo, o vetor com o número de manobras atualizado após a geração da configuração 5 pode ser visto na Tabela 4.9, enquanto que a configuração 5 é ilustrada pela Figura 4.10.

Tabela 4.9: Vetor com o número de manobras, atualizado com a configuração 5.

\begin{tabular}{lccccccc}
\hline Configuração & 1 & 2 & 3 & 4 & 5 & $\ldots$ & $g_{\max }$ \\
Número de manobras & 1 & 3 & 3 & 3 & 1 & $\ldots$ & \\
\hline
\end{tabular}

Por meio do exemplo ilustrativo apresentado nesta seção pode-se observar que o algoritmo proposto em (Santos et al., 2010), para calcular o número de manobras 


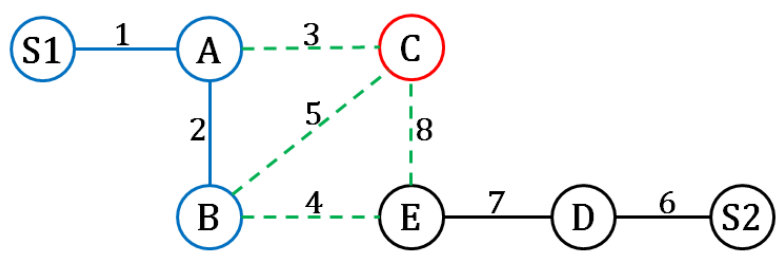

Figura 4.10: Configuração 5 .

necessárias para implementar cada configuração gerada, é claramente mais simples que a metodologia tradicional, descrita no início desta seção. Além disso, ele requer pouco esforço computacional, uma vez que realiza apenas duas comparações a cada nova configuração gerada, ao invés de efetuar $N_{C H}$ comparações como comumente é feito em outras abordagens (sendo $N_{C H}$ o número de chaves presentes no SDR). Por outro lado, observe que essa metodologia utiliza a configuração pré-falta como referência para a comparação dos estados das chaves alteradas, e que por isso ela efetua desnecessariamente a contagem também das manobras exigidas para isolar a falta, ação esta que relacionada ao problema de localização e isolação de faltas em sistemas elétricos, e não de restabelecimento de energia.

\subsection{Heurística para Priorização de Manobras}

Conforme dito anteriormente, a geração de novos indivíduos, isto é, configurações da rede, é feita no AEMT pela aplicação dos operadores PAO e CAO da RNP, e nos quais a escolha dos alimentadores para transferência de cargas é feita de forma aleatória. Todavia, no trabalho de Sanches (2013), observou-se que definir aleatoriamente o alimentador que perderá cargas pode permitir a execução de operações de chaveamento desnecessárias, uma vez que esse mecanismo de escolha não impede que sejam retiradas cargas de um alimentador no qual todas restrições são satisfeitas.

Assim, foi proposto em Sanches (2013) uma heurística para priorizar a aplicação dos operadores da RNP às regiões do SDR com os maiores valores de queda de tensão e carregamento da rede. A ideia é priorizar a execução de manobras de chaves em regiões do SDR nas quais as restrições de queda de tensão e carregamento da rede são violadas após a ocorrência de uma falta. Para tal a escolha do alimentador que perderá cargas, dentro do processo de geração de novos indivíduos, deixa de ser aleatória e passa a ser definida da seguinte forma: (i) na configuração escolhida pelo AEMT para aplicação do PAO ou do CAO, verifica-se a queda máxima de tensão de todos os alimentadores e aqueles com os maiores valores são ranqueados em ordem decrescente de seu valor de queda máxima de tensão; (ii) caso dois alimentadores empatem nesse critério (precisão de $10^{2}$ ), define-se que o pior é aquele com maior valor de carregamento da rede; (iii) 
finalmente, o alimentador em primeiro no ranking é escolhido para perder cargas, isto é, é escolhido como árvore de poda para o PAO ou CAO (ver as Seções A.3.2 e A.3.3 do Apêndice A). Caso dois alimentadores empatem em queda máxima de tensão e em carregamento máximo da rede, a definição de um, dentre ambos, será aleatória.

Devido as vantagens proporcionadas por essa heurística e comprovadas em Sanches (2013), decidiu-se por inseri-la na metodologia base para esse trabalho. Assim, tomou-se como ponto de partida para o desenvolvimento da metodologia proposta uma versão do AEMT modificada pela adição da heurística apresentada.

\subsection{Considerações Finais}

Neste capítulo foi apresentada a metodologia tomada como base para o desenvolvimento deste trabalho de mestrado. Como pode ser visto, o AEMT é capaz de lidar com o problema de restabelecimento de energia sem simplificações na representação da rede e com uma eficiência computacional que lhe permite ser aplicado em tempo real. Todavia, ele é limitado em relação a alguns aspectos e necessidades práticas do problema. A fim de obter uma metodologia mais adequada para a determinação de planos de restabelecimento em situações de contingência, o AEMT foi modificado e melhorado pela inclusão de uma heurística e dos objetivos desta pesquisa, o que resultou na metodologia proposta nesse documento e que será apresentada no Capítulo 5, a seguir. 
CAPÍTULO 4. MEDODOLOGIA BASE: ALGORITMO EVOLUTIVO MULTI-OBJETIVO EM TABELA 


\section{Metodologia Proposta}

\subsection{Considerações Iniciais}

Neste capítulo será apresentada a metodologia proposta neste trabalho a fim de solucionar o problema de restabelecimento de energia em SDRs de grande porte sem simplificações na representação da rede e em tempo real. Destaca-se que o grande diferencial desta metodologia, em relação àquelas presentes na literatura, será a sua capacidade de, em SDRs de grande porte, considerar e priorizar a operação de CCRs e o fornecimento de CEs, bem como de fornecer planos de restabelecimento com uma sequência factível para operação das chaves e consequente implementação do mesmo. Por ter sido desenvolvida tendo como base o AEMT, a metodologia proposta será, deste ponto em diante, denominada por AEMT++, isto é, Algoritmo Evolutivo Multi-objetivo em Tabelas com Priorização de Chaves, Consumidores e Definição de Sequência de Chaveamento.

\subsection{Priorização de Chaves Controladas Remotamente}

A fim de diminuir o tempo de ausência de fornecimento de energia às cargas sãs fora de serviço, bem como diminuir ou extinguir os custos relativos ao deslocamento de equipes de manutenção para operação de chaves em campo, o AEMT++ foi desenvolvido para priorizar a operação de CCRs. Ao contrário das CCMs, esse tipo de chave é telecomandada e pode ser manobrada, pelo próprio operador, do centro de operação. Desse modo, para obtenção de planos que possam ser parcial ou inteiramente implementados remotamente, o AEMT++ considera não apenas o objetivo de minimizar o número total de operações de 
chaveamento, mas também o de proporcionar, dentro deste conjunto mínimo de manobras, o máximo possível de operações em CCRs. Para tal, esta metodologia considera a priorização de CCRs em duas ocasiões durante a execução do algoritmo: na obtenção da primeira configuração factível e ao longo do processo de evolução da adequação das subpopulações de indivíduos armazenadas em tabelas.

\subsubsection{Priorização de Chaves Controladas Remotamente na Obtenção da Primeira Configuração Factível}

O AEMT++, assim como o AEMT (ver Seção 4.3), inicia a sua execução pela obtenção da primeira configuração factível, que servirá como ponto de partida para a geração de novas configurações e a formação da primeira população.Nesse sentido, a fim de garantir a essa primeira configuração factível uma boa aptidão, em relação ao objetivo de priorizar a operação de CCRs, proporcionando ao AEMT++ um bom ponto de partida para o seu processo de evolução, optou-se por modificar, em relação ao AEMT, o modo como este primeiro indivíduo é determinado. Dessa forma, obteve-se no AEMT++ um novo procedimento para obtenção da primeira configuração factível que dá prioridade à operação de CCRs.

Conforme dito anteriormente na Seção 4.3, a obtenção da primeira configuração factível, pelo AEMT, é feita pela reconexão dos setores sãos sem fornecimento a setores da rede com fornecimento definidos de forma inteiramente aleatória. Destaca-se que no $\mathrm{AEMT}++$ esta reconexão deixa de ser aleatória e passa a ser feita por meio de CCRs, sempre que isso for possível. Assim, se houver no mínimo uma CCR que permita a reconexão de setores sãos desabastecidos, esta chave deverá ser determinada e a sua operação requerida. Já nos casos em que há apenas CCMs dando esse possibilidade, a escolha da chave NA para efetuar essa reconexão é feita de forma aleatória.

Para ilustrar esse procedimento proposto, considere o grafo da Figura 5.1(a) (Kagan, 1999), que representa um SDR formado por 8 alimentadores, 23 setores e 28 chaves, e no qual os nós, independentemente da cor, representam setores (a exceção dos nós raízes, ilustrados por retângulos, que representam barras em subestações), as arestas pontilhadas são chaves NAs, as arestas contínuas são chaves NFs, as arestas em azul correspondem a CCRs e as arestas em preto representam CCMs. Os setores encontram-se identificados por números em negrito, enquanto que as chaves encontram-se designadas por números em itálico. Considere também a ocorrência de uma falta no setor 2 em destaque, que, após isolado, como na figura, gerou um desabastecimento de energia às cargas dos setores sãos 3 e 15, 4 e 5, e também 6, localizados à jusante do setor faltoso (antes da ocorrência da falta, o setor 2 encontrava-se conectado ao nó raiz 17 e aos setores 3, 4 e 6, respectivamente, por meio das chaves 9, 5, 6 e 7, como pode ser visto na Figura 5.2). 


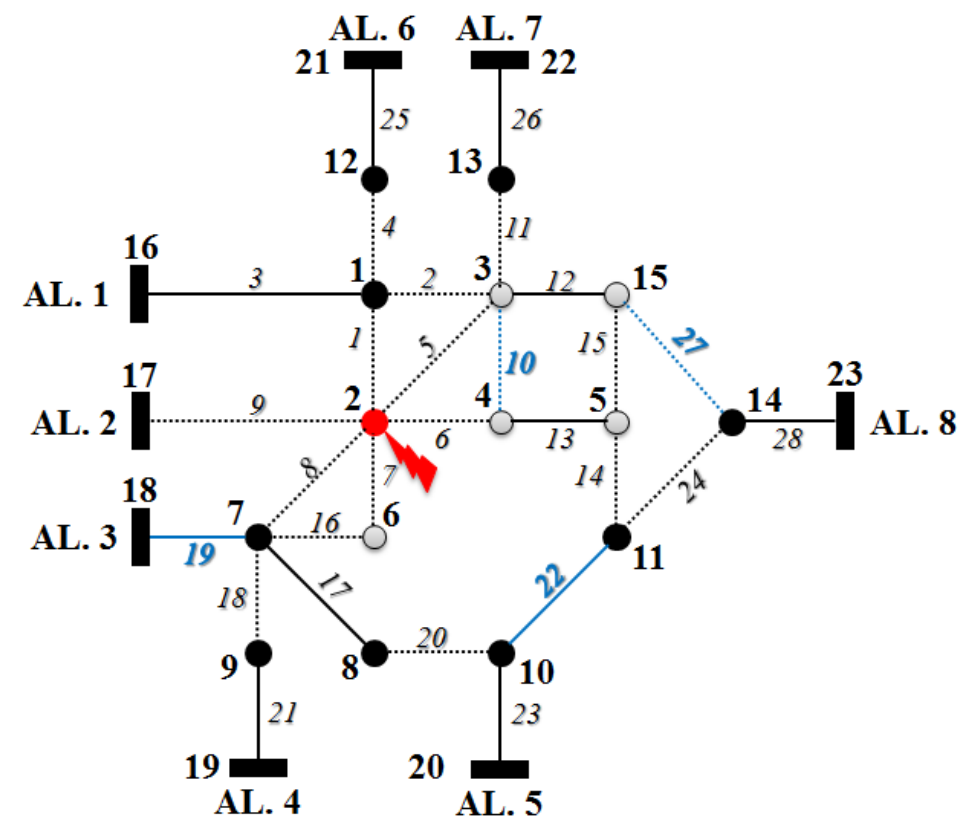

(a) Configuração inicial: setor 2 sob falta isolado e setores sãos à jusante sem fornecimento.

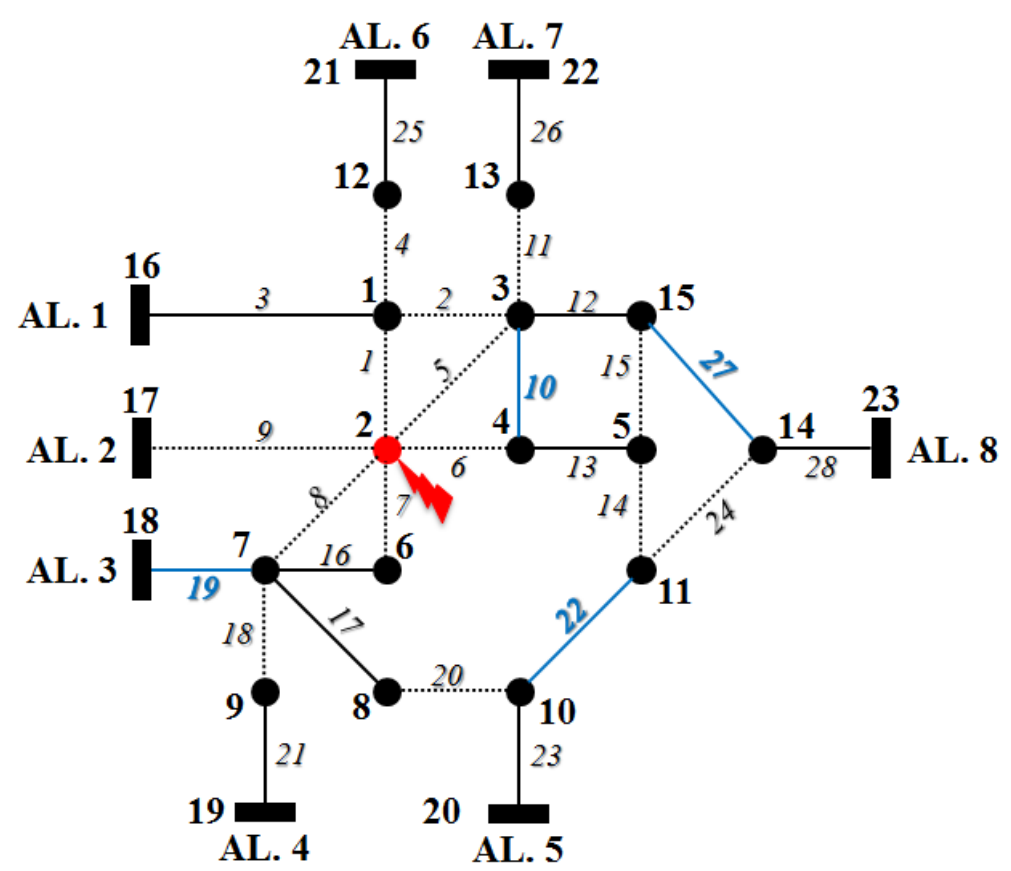

(b) Primeira configuração factível obtida: setor 2 sob falta isolado e setores sãos à jusante reconectados.

Figura 5.1: Exemplo do procedimento de obtenção da primeira configuração factível pelo AEMT++.

Nesse caso, a obtenção da primeira configuração factível pelo AEMT++, tendo em vista a configuração inicial apresentada na Figura 5.1(a), dar-se-á da seguinte forma: primeiro será verificada, para o setor 3, a existência de uma chave CCR NA que permita reconectá-lo, juntamente com o setor 15 , a um outro setor da rede com fornecimento. 


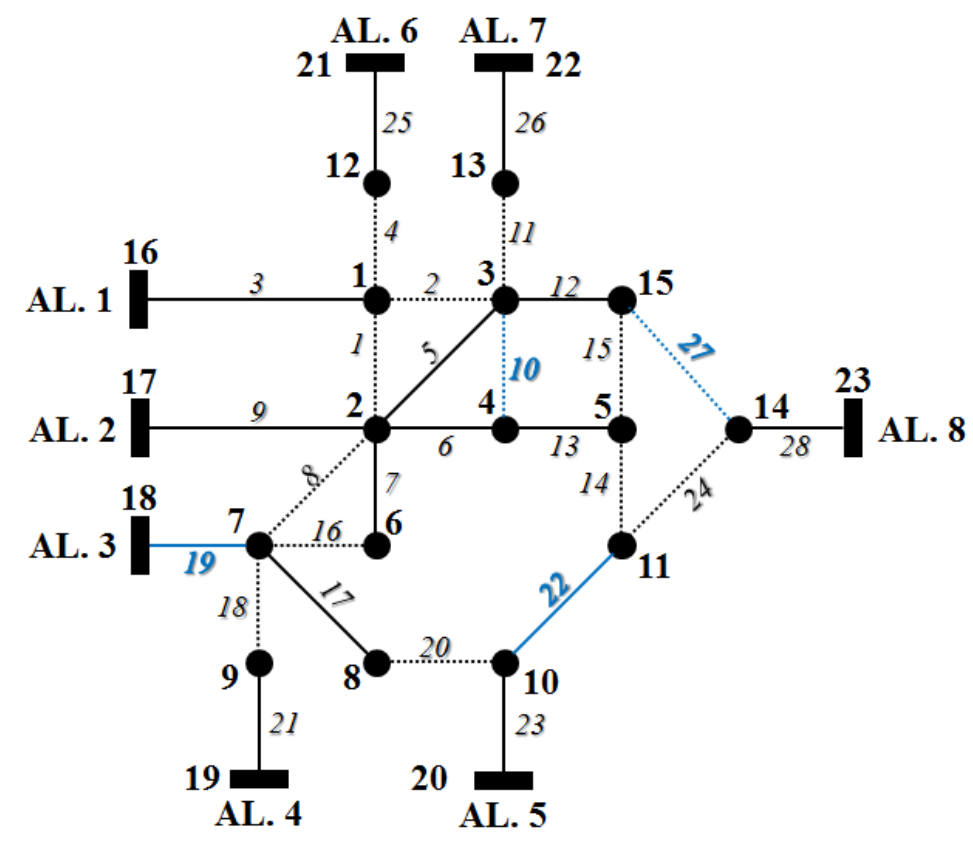

Figura 5.2: Configuração pré-falta do SDR da Figura 5.1.

Observe que as únicas possibilidade são as chaves 2 e 11. No entanto, ambas são do tipo CCM. Logo, passa-se a verificação do próximo setor à jusante deste, isto é, do setor 15. Para o setor 15 faz-se novamente a verificação: há alguma CCR NA que permita reconectá-lo, juntamente com o setor 3, a outro setor da rede com fornecimento? Nesse caso, observe que há uma possibilidade: a chave 27. Então o primeiro grupo de setores fora de serviço, formado pelos setores 3 e 15, será reconectados à rede por meio do fechamento da CCR NA 27, localizada entre os setores 15 e 14 (ver Figura 5.1(b)).

O mesmo procedimento deverá ser feito também para o grupo formado pelos setores 4 e 5 , e também para o setor 6 . No caso dos setores 4 e 5 observe que a CCR NA 10 permite reconectá-los à rede por meio do setor 3 , já com fornecimento. No entanto, no caso do setor 6 o mesmo não é possível, pois, não há qualquer CCR que possibilite conectá-lo a um setor adjacente com fornecimento. Nesse caso, deve-se definir uma CCM qualquer de forma aleatória. Como para esse setor existe apenas uma chave com a capacidade de reconectá-lo, isto é, a chave CCM 16, a mesma será escolhida para ligá-lo ao setor 7 . Desse modo, obter-se-á, para o exemplo em questão, a configuração ilustrada pela Figura 5.1(b) como a primeira configuração factível determinada.

De forma genérica, o procedimento de determinação da primeira configuração factível com priorização de CCR por meio do AEMT++ pode ser descrito da seguinte forma: na configuração inicial, dada uma subárvore qualquer $t$, localizada à jusante de um setor sob falta e, portanto, sem fornecimento, a mesma deverá ter todos os seus nós (isto é, setores) verificados a fim de determinar se pelo menos um setor $s 1$, pertencente a $t$, possui uma CCR NA incidente que permita reconectar $t$ a um setor $s 2$ qualquer da rede com 
fornecimento. Se sim, essa CCR NA entre $s 1$ e $s 2$ deverá ser operada para que $t$ seja reconectada à rede. Senão, o setor $s 1$ deverá ser definido aleatoriamente e, em seguida, também de forma aleatória, deverá ser definido um setor $s 2$ adjacente a $s 1$ e que esteja com fornecimento. A chave entre $s 1$ e $s 2$ deverá, então, ser operada para que $t$ seja reconectada à rede por meio de uma CCM. No primeiro caso, se houver mais de uma possibilidade de reconectar $t$ por meio de uma CCR, será escolhida aquela que foi encontrada primeiro.

\subsubsection{Priorização de Chaves Controladas Remotamente ao Longo do Processo Evolutivo}

A fim de priorizar a operação de CCRs durante o processo de evolução da adaptação das subpopulações em tabelas aos objetivos do problema, a estratégia utilizada foi de minimizar prioritariamente a operação em CCMs. Em outras palavras, dados dois indivíduos com igual número total de operações de manobras em chaves e diferente número de operações de manobra em CCMs, dar-se-á prioridade para aquele que requer menos manobras em CCMs, pois, como consequência, este indivíduo exigirá mais manobras em CCRs que o outro para um mesmo número total de manobras.

Para implementar essa estratégia e auxiliar o seu funcionamento, algumas alterações e inserções foram realizadas naquela metodologia base, tais como: modificação dos critérios de inserção de indivíduos nas tabelas $P_{6}, P_{7}, P_{8}, P_{9}, P_{10}$ e dos objetivos considerados por cada uma, apresentadas no Capítulo 4; inserção de uma nova tabela; inserção de uma nova estrutura para guardar o número de chaves alteradas em cada configuração; inserção de um novo vetor auxiliar para armazenar o tipo de cada chave; modificação do algoritmo para cálculo de número de manobras em chaves.

É importante destacar que estas três últimas alterações são utilizadas e executadas no AEMT++ não somente a partir do início do processo evolutivo, com a formação da subpopulação inicial em cada tabela, mas também na geração dos primeiros indivíduos que irão compô-la. Isto porque, estas alterações estão associadas ao algoritmo proposto para cálculo de número de manobras em chaves que será apresentado a seguir e que é executado também na determinação do número de chaves alteradas dos indivíduos gerados para formar a subpopulação inicial de cada tabela. Estas modificações e inserções tornarão a metodologia proposta apta para considerar e priorizar a operação de CCRs, conforme será apresentado a seguir.

\subsubsection{Novo Algoritmo para Cálculo do Número de Manobras em Chaves}

Para priorizar a operação de CCRs deve-se, primeiramente, considerar concomitantemente a presença desse tipo de chave e de CCMs no SDR em situação de contingência, e, a cada nova configuração gerada, efetuar separadamente o cálculo do número de manobras em 
CCMs e em CCRs, necessárias para implantar esta configuração. Desse modo, propõe-se um novo algoritmo para determinação, de forma eficiente, do número de manobras em chaves, cujo pseudocódigo é apresentado no Algoritmo 4. Este algoritmo foi desenvolvido com base naquele apresentado por Santos et al. (2010), mostrado na Seção 4.4, e por isso também considera que, após a isolação do setor sob falta e a reconexão dos setores sãos fora de serviço, as manobras ocorrerão sempre em pares, ou seja, para cada chave que for aberta outra deverá ser fechada. Considera também o estado das chaves em três configurações: $G^{i}, G^{x}$ e $G^{y}$, isto é, configuração inicial, configuração alterada e configuração final, respectivamente. Conforme pode ser visto no exemplo da Figura 5.1(a), a configuração inicial não é uma configuração factível.

Para auxiliar o algoritmo proposto e armazenar separadamente o número de manobras em CCMs e em CCRs, são necessários dois vetores e uma matriz. O primeiro vetor possui tamanho $N_{C H}$ (parâmetro definido ao final da Seção 4.4.1, na página 40) e armazena o estado das chaves em $G^{i}$, ao contrário daquele utilizado por Santos et al. (2010) (Tabela 4.4 para o exemplo da Seção 4.4.1), que armazena o estado das chaves em $G^{p f}$ (configuração pré-falta). Isto ocorre porque este algoritmo proposto para cálculo de número de manobras considera $G^{i}$, e não $G^{p f}$, como a configuração de referência para comparação dos estados das chaves alteradas para gerar um novo indivíduo. Este procedimento foi adotado para que seja efetuada a contagem exclusivamente das chaves necessárias para restabelecer o fornecimento às cargas sãs fora de serviço, presentes em $G^{i}$, e também das manobras para troca de cargas entre alimentadores. Assim, desconsiderar-se-á as manobras requeridas para a isolar o setor sob falta, uma vez que estas estão associadas à ações que são próprias do problema de proteção de redes elétricas, e não de restabelecimento de energia.

O segundo vetor auxiliar também possui tamanho igual a $N_{C H}$, mas é responsável por guardar a informação do tipo de cada chave existente no SDR, ou seja, ele informa se uma chave $j$ qualquer é do tipo CCM ou CCR. Já a matriz auxiliar proposta têm dimensão $3 \times g_{\max }$ e armazena, em relação a $G^{i}$, o número de CCMs, de CCRs e total de chaves alteradas em cada configuração existente. Por exemplo, para uma configuração $G^{y}$, qualquer, na primeira linha dessa matriz na ípsilon-ésima coluna estará salvo o número de CCRs alteradas em $G^{y}$ em relação $G^{i}$ (manobras_ $G_{C C R}^{y}$ ), calculado pelo algoritmo que será apresentado a seguir; na segunda linha na ípsilon-ésima coluna estará armazenado o número de CCMs alteradas em $G^{y}$ em relação a $G^{i}$ (manobras_G $G_{C C M}^{y}$ ), calculado pelo algoritmo que será apresentado a seguir; e na terceira linha na ípsilon-ésima coluna estará o número total de chaves alteradas em $G^{y}$ em relação à $G^{i}$, isto é, manobras_G $G_{C C R}^{y}+$ manobras_G $G_{C C M}^{y}$.

A fim de demostrar o funcionamento do Algoritmo 4, proposto no AEMT++ para efetuar o cálculo de número de manobras na presença de CCMs e CCRs, considere como $G^{i}$ 


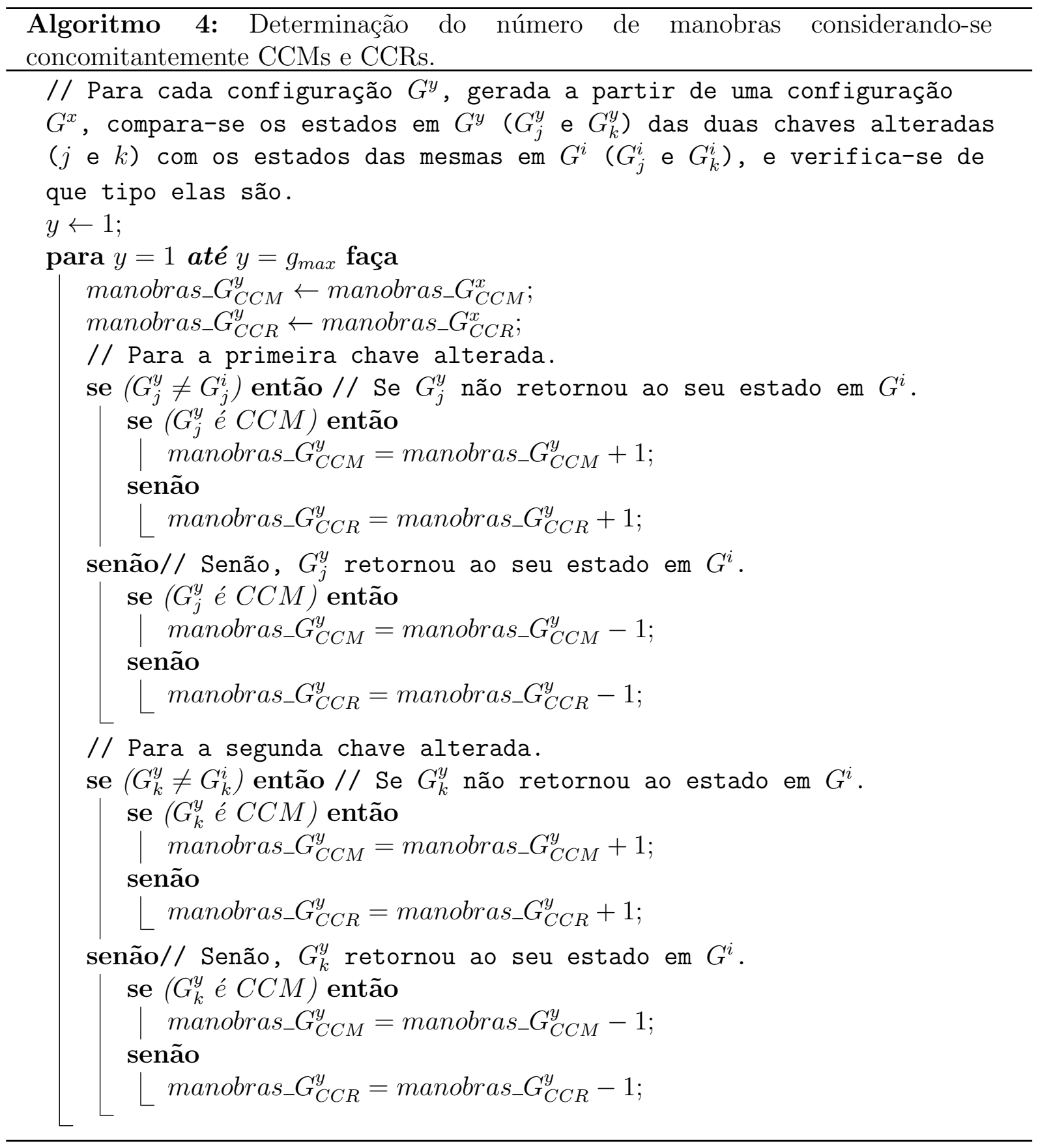

a configuração apresentada pela Figura 5.1(a). Desse modo, os vetores que armazenam o estado das chaves em $G^{i}$ e o tipo de cada chave podem ser representados, respectivamente, pelas Tabelas 5.1 e 5.2. Considere também a primeira configuração factível obtida para aquele exemplo, ilustrada na Figura 5.1(b). Assim, a matriz que armazena o número de manobras em CCMs e em CCRs pode ser vista na Tabela 5.3. Observe que a primeira coluna desta matriz já se encontra preenchida com o número de manobras em CCRs (duas) e em CCMs (uma) que foram necessárias para se obter a primeira configuração factível (configuração 1) a partir de $G^{i}$, por meio do procedimento descrito na Seção 5.2.1 
que prioriza a operação em CCRs. Dado que, a partir da isolação do setor sob falta e a reconexão dos setores sãos fora de serviço, as manobras em chaves ocorrem sempre em pares, então, da mesma forma que no Algoritmo $3^{1}$, há três possibilidades de se computar o número de chaves alteradas, em relação a $G^{i}$, de uma configuração $G^{y}$ gerada a partir de uma configuração $G^{x}$ :

Caso 1: o estado em $G^{y}$, das duas chaves alteradas em $G^{x}$, é diferente do estado de ambas em $G^{i}$. Logo, o número total de chaves alteradas de $G^{y}$, em relação a $G^{i}$, será o número total de chaves alteradas de $G^{x}$ mais 2, como no Algoritmo 3. Todavia, como no Algoritmo 4 proposto há dois contadores de manobras para $G^{y}$ (manobras_G $G_{C C M}^{y}$ e manobras_ $\left.G_{C C R}^{y}\right)$, sendo um para cada tipo de chave, então, antes de computar-se o número de chaves alteradas de $G^{y}$, deve-se verificar de que tipo elas são, para que assim seja incrementado o contador específico. Em outras palavras, para o Caso 1, se as duas chaves alteradas ( $j$ e $k$ ) forem do tipo CCM, então haverão dois incrementos em manobras_ $G_{C C M}^{y}$, um para a chave $j$ e outro para a chave $k$. Caso contrário, se ambas foram do tipo CCR, haverão dois incrementos em manobras_ $G_{C C R}^{y}$. Ou, se as chaves alteradas forem uma CCM e uma CCR, então haverá um incremento em manobras_G $G_{C C M}^{y}$ e outro em manobras_ $G_{C C R}^{y}$. Observe no Algoritmo 4 que no início, antes de serem incrementados, os contadores de manobras de $G^{y}$ recebem o valor de manobras em CCR e em CCM da configuração selecionada para gerá-la, isto é, da configuração $G^{x}$ ( $m a n o b r a s_{-} G_{C C M}^{x}$ e manobras_ $G_{C C R}^{x}$ ).

Por exemplo, considere a escolha da configuração 1 (Figura 5.1(b)) para gerar uma segunda configuração factível (configuração 2). Considere também que, para tal, a chave 17 foi aberta e a chave 20 foi fechada na configuração 1. Assim, a configuração 2 gerada pode ser vista na Figura 5.3.

Para efetuar o cálculo do número de manobras de $G^{2}$, em relação a $G^{i}$, inicialmente o Algoritmo 4 proposto busca pelo número de manobras em CCR e em CCM da configuração que gerou $G^{2}$, isto é, de $G^{1}$ (primeira configuração factível), e salva-o em manobras_ $G_{C C R}^{2}$ e manobras_ $G_{C C R}^{2}$, respectivamente. Observe na Tabela 5.3 que estes valores de $G^{1}$ estão armazenados na primeira coluna dessa matriz. Logo, inicialmente esses contadores assumirão os seguintes valores: manobras_ $G_{C C R}^{2}=2$ e manobras_G $G_{C C M}^{2}=1$. A partir disso, o Algoritmo 4 comparará, separadamente, o estado em $G^{2}$ das chaves alteradas $\left(G_{17}^{2}\right.$ e $\left.G_{20}^{2}\right)$ com o estado de ambas em $G^{i}\left(G_{17}^{i}\right.$ e $\left.G_{20}^{i}\right)$, armazenados no vetor apresentado pela Tabela 5.1. Para a chave 17 , que foi aberta e cujo estado passou para 0 , observe que $G_{17}^{2} \neq G_{17}^{i}$. Logo um dos contadores deverá ter o primeiro incremento.

\footnotetext{
${ }^{1}$ Lembrando que no Algoritmo 3, diferentemente deste proposto, o número de chaves alteradas é determinado em relação a $G^{p f}$.
} 
Tabela 5.1: Estado das chaves em $G^{i}$, onde 0 representa chave aberta e 1 corresponde a chave fechada.

\begin{tabular}{|c|c|c|c|c|c|c|c|c|c|c|c|c|c|c|c|c|c|c|c|c|c|c|c|c|c|c|c|c|}
\hline Chave & 1 & 2 & 3 & 4 & 5 & 6 & 7 & 8 & 9 & 10 & 11 & 12 & 13 & 14 & 15 & 16 & $\mathbf{1 7}$ & 18 & 19 & $\mathbf{2 0}$ & 21 & $\mathbf{2 2}$ & $\mathbf{2 3}$ & $\mathbf{2 4}$ & 25 & 26 & 27 & 28 \\
\hline Estado & 0 & 0 & 1 & 0 & 0 & 0 & 0 & 0 & 0 & 1 & 0 & 1 & 1 & 0 & 0 & 1 & $\mathbf{1}$ & 0 & 1 & $\mathbf{0}$ & 1 & $\mathbf{1}$ & $\mathbf{1}$ & $\mathbf{0}$ & 1 & 1 & 1 & 1 \\
\hline
\end{tabular}

Tabela 5.2: Tipo de cada chave, onde 0 representa CCM e 1 corresponde a CCR.

\begin{tabular}{|c|c|c|c|c|c|c|c|c|c|c|c|c|c|c|c|c|c|c|c|c|c|c|c|c|c|c|c|c|}
\hline Chave & 1 & 2 & 3 & 4 & 5 & 6 & 7 & 8 & 9 & 10 & 11 & 12 & 13 & 14 & 15 & 16 & $\mathbf{1 7}$ & 18 & 19 & $\mathbf{2 0}$ & 21 & $\mathbf{2 2}$ & $\mathbf{2 3}$ & $\mathbf{2 4}$ & 25 & 26 & 27 & 28 \\
\hline Tipo & 0 & 0 & 0 & 0 & 0 & 0 & 0 & 0 & 0 & 1 & 0 & 0 & 0 & 0 & 0 & 0 & $\mathbf{0}$ & 0 & 1 & $\mathbf{0}$ & 0 & $\mathbf{1}$ & $\mathbf{0}$ & $\mathbf{0}$ & 0 & 0 & 1 & 0 \\
\hline
\end{tabular}

Tabela 5.3: Matriz que salva o número de manobras em CCRs e em CCMs para cada configuração.

\begin{tabular}{llllllll}
\hline Configuração & 1 & 2 & 3 & 4 & 5 & $\ldots$ & $g_{\max }$ \\
\hline Manobras em CCRs & 2 & & & & & $\ldots$ & \\
Manobras em CCMs & 1 & & & & & $\ldots$ & \\
Manobras totais & 3 & & & & & $\ldots$ & \\
\hline
\end{tabular}

Manobras em CCMs

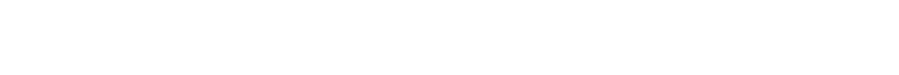


No entanto, para definir entre manobras_ $G_{C C R}^{2}$ e manobras_ $G_{C C M}^{2}$ aquele que será incrementado, deve-se primeiramente buscar no vetor da Tabela 5.2, na $17^{\text {a }}$ coluna, o tipo da chave 17. Ao fazê-lo, obtêm-se a informação de que esta se trata de uma CCM. Portanto, manobras_ $G_{C C M}^{2}$ é o contador que deverá ser incrementado, e passará a armazenar manobras_ $G_{C C M}^{2}=2$. O mesmo precedimento deve ser feito para a segunda chave alterada (chave 20). Primeiro, observe que $G_{20}^{2} \neq G_{20}^{i}$, e em seguida, no vetor da Tabela 5.2, que a chave 20 é do tipo CCM. Assim, o contador manobras_G $G_{C C M}^{2}$ deverá ser incrementado novamente, guardando manobras_ $G_{C C M}^{2}=3$.

Ao final dessa última verificação termina-se a execução do Algoritmo 4 para a configuração 2 e os valores de manobras_ $G_{C C R}^{2}$ e de manobras_ $G_{C C M}^{2}$ serão salvos na segunda coluna da matriz da Tabela 5.3, respectivamente, na primeira e na segunda linha. Com a inserção desses dados essa matriz é atualizada para aquela apresentada na Tabela 5.4. Observe na terceira linha da segunda coluna dessa tabela que o número de total de manobras de $G^{2}$ é exatamente o número de manobras da configuração que a gerou (configuração 1) mais 2. Isto comprova que o Algoritmo 4 proposto é capaz de obter os mesmos valores totais de manobras em chaves que seriam obtidos por aquele algoritmo proposto por Santos et al. (2010), caso este último pudesse ser aplicado ao exemplo em questão, já que não distingue entre CCRs e CCMs.

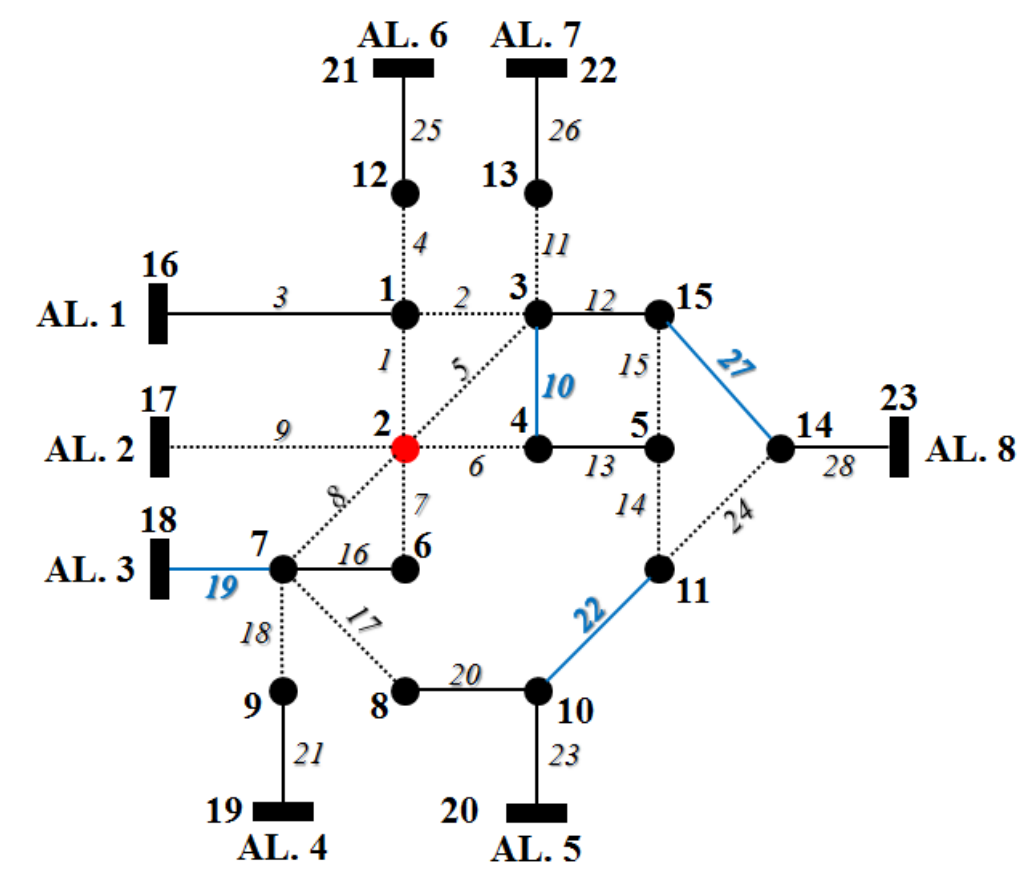

Figura 5.3: Configuração 2.

Outro exemplo de um Caso 1 é o da geração da configuração 3, apresentada na Figura 5.4, a partir da abertura da chave 22 e fechamento da chave 24 na configuração 2. Nesse caso, uma das chaves alteradas é do tipo CCR, fazendo com que tanto o contador 
Tabela 5.4: Matriz que salva o número de manobras, atualizada com a configuração 2.

\begin{tabular}{llllllll}
\hline Configuração & 1 & 2 & 3 & 4 & 5 & $\ldots$ & $g_{\max }$ \\
\hline Manobras em CCRs & 2 & 2 & & & & $\ldots$ & \\
Manobras em CCMs & 1 & 3 & & & & $\ldots$ & \\
Manobras totais & 3 & 5 & & & & $\ldots$ & \\
\hline
\end{tabular}

de manobras em CCRs, quanto o de CCMs fossem incrementados uma vez. O número de manobras em CCR e em CCM dessa configuração são apresentados na coluna 3 da matriz da Tabela 5.5 e a mesma pode ser vista na Figura 5.4.

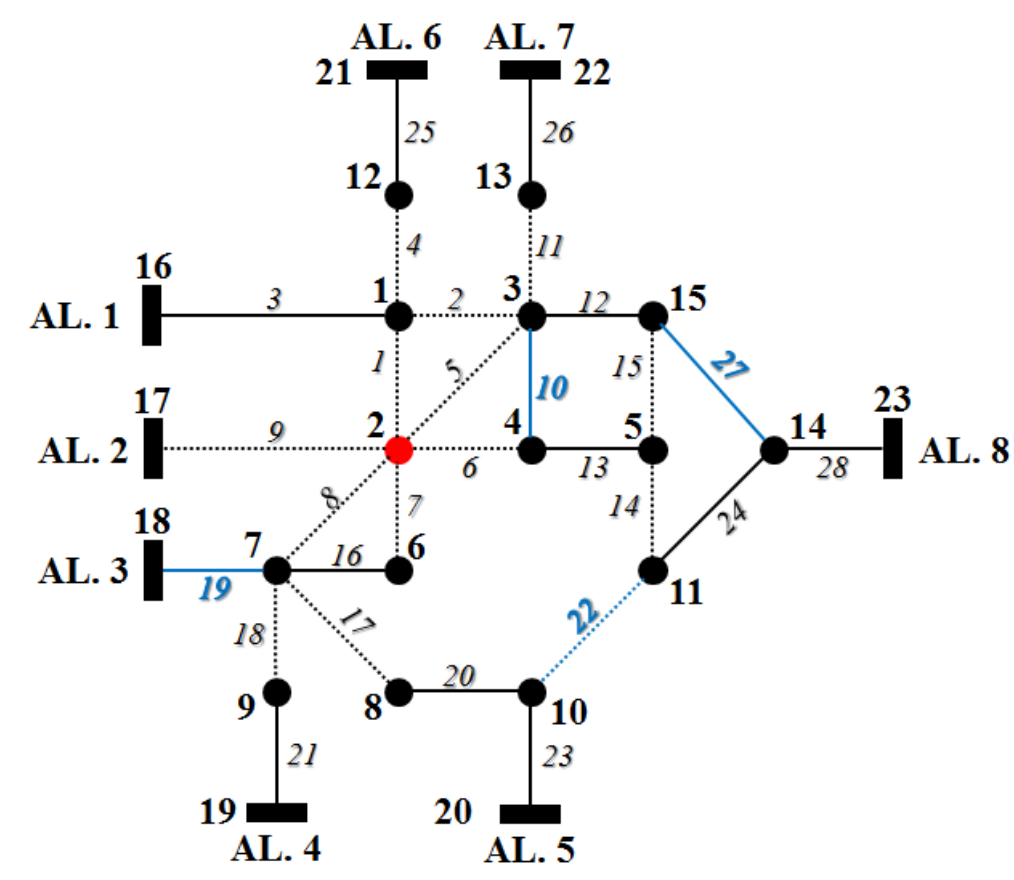

Figura 5.4: Configuração 3.

Tabela 5.5: Matriz que salva o número de manobras, atualizada com a configuração 3.

\begin{tabular}{lccccccc}
\hline Configuração & 1 & 2 & 3 & 4 & 5 & $\ldots$ & $g_{\max }$ \\
\hline Manobras em CCRs & 2 & 2 & 3 & & & $\ldots$ & \\
Manobras em CCMs & 1 & 3 & 4 & & & $\ldots$ & \\
Manobras totais & 3 & 5 & 7 & & & $\ldots$ & \\
\hline
\end{tabular}

Caso 2: o estado em $G^{y}$, das duas chaves alteradas em $G^{x}$, é igual ao estado de ambas em $G^{i}$. Portanto, o número total de chaves alteradas de $G^{y}$, em relação a $G^{i}$, será o número total de chaves alteradas de $G^{x}$ menos 2, como no Algoritmo 3. Porém, assim como no Caso 1, faz-se necessário determinar o tipo de cada chave alterada, a fim de que sejam decrementados os contadores específicos (manobras_G $G_{C C M}^{y}$ e/ou manobras_ $\left.G_{C C R}^{y}\right)$. Se ambas as chaves alteradas $\left(j\right.$ e $k$ ), que retornaram em $G^{y}$ ao seus estados em $G^{i}$, são do tipo CCR, então, manobras_ $G_{C C R}^{y}$ será decrementado duas vezes. Caso contrário, se $j$ e $k$ são do tipo CCM, então, o contador que deverá ser decrementado 
duas vezes será manobras_G $G_{C C M}^{y}$. Ou, se as chaves alteradas são uma de cada tipo, então, manobras_G $G_{C C R}^{y}$ e manobras_G $G_{C C M}^{y}$ serão, ambos, decrementados uma única vez.

Por exemplo, considere a geração de uma configuração 4 (Figura 5.5) por meio da abertura da chave 20 e do fechamento da chave 17 na configuração 3 (Figura 5.4). Conforme o Algoritmo 4, a primeira ação é salvar em manobras_G $G_{C C R}^{4}$ e em manobras_ $G_{C C M}^{4}$ o número de manobras em CCR e em CCM, respectivamente, da configuração que a gerou $G^{4}$. Tendo em vista que essa configuração foi obtida a partir de $G^{3}$, então, esses contadores assumirão, inicialmente, os seguintes valores: manobras_ $G_{C C R}^{4}=3$ e manobras_ $G_{C C M}^{4}=4$. Em seguida, compara-se o estado da primeira chave alterada com o estado da mesma em $G^{i}$. Fazendo-o observa-se que $G_{17}^{4}=G_{17}^{i}$. Logo, um dos contadores deverá ser decrementado. Analisando o vetor da Tabela 5.2 observa-se também que essa chave é do tipo CCM. Logo, manobras_G $G_{C C M}^{4}$ deverá ser um decrementado em 1, tornando-se manobras_ $G_{C C M}^{4}=3$. Fazendo o mesmo para a segunda chave alterada observa-se que $G_{20}^{4}=G_{20}^{i}$ e que esta é uma CCM. Assim, manobras_ $G_{C C M}^{4}$ deverá ser novamente decrementado. Assim sendo, ao final da execução do Algoritmo 4, para a configuração 4, ter-se-á manobras_G $G_{C C R}^{4}=3 \mathrm{e}$ manobras_ $G_{C C M}^{4}=2$, valores estes que serão salvos na quarta coluna da matriz da Tabela 5.6.

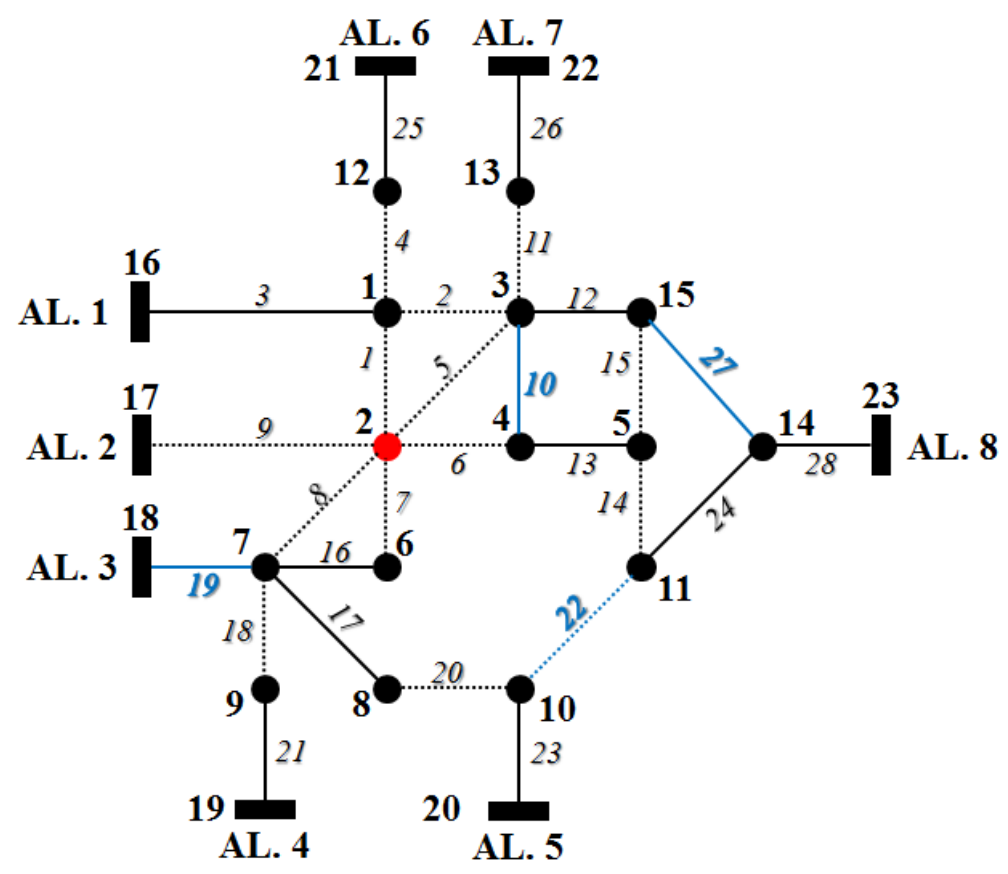

Figura 5.5: Configuração 4.

Caso 3: o estado em $G^{y}$, de uma das chaves alteradas em $G^{x}$, é igual ao seu estado em $G^{i}$, enquanto que o estado da outra chave em $G^{y}$ é diferente do seu estado em $G^{i}$. Desse modo, o número total de chaves alteradas de $G^{y}$, em relação a $G^{i}$, é igual ao número total 
Tabela 5.6: Matriz que salva o número de manobras, atualizada com a configuração 4 .

\begin{tabular}{lccccccc}
\hline Configuração & 1 & 2 & 3 & 4 & 5 & $\ldots$ & $g_{\max }$ \\
\hline Manobras em CCRs & 2 & 2 & 3 & 3 & & $\ldots$ & \\
Manobras em CCMs & 1 & 3 & 4 & 2 & & $\ldots$ & \\
Manobras totais & 3 & 5 & 7 & 5 & & $\ldots$ & \\
\hline
\end{tabular}

de chaves alteradas de $G^{x}$. No entanto, assim como nos Casos 1 e 2, deve-se verificar o tipo das chaves alteradas. Por exemplo, considere que as chaves alteradas foram uma do tipo CCR e outra do tipo CCM. Nesse caso, se a chave que retornou, em $G^{y}$, ao estado que possuía em $G^{i}$ for do tipo CCR, então, aquela que possui estados diferentes em ambas as configurações somente poderá ser do tipo CCM, e, portanto, o contador manobras_ $G_{C C R}^{y}$ deverá ser decrementado e manobras_ $G_{C C M}^{y}$ ser incrementado. Caso ambas as chaves alteradas sejam do tipo CCR, logo, manobras_ $G_{C C R}^{y}$ será primeiro incrementado e depois decrementado pelo algoritmo. Ou caso, caso sejam ambas CCM, o contador que será incrementado e posteriormente decrementado é o manobras_ $G_{C C M}^{y}$.

Para ilustrar esse terceiro caso, considere a configuração 5 apresentada na Figura 5.6, gerada a partir da configuração 3 por meio da abertura da chave 23 e do fechamento da chave 17. Segundo o Algoritmo 4 proposto, para determinar-se o número de manobras de $G^{5}$, inicialmente deve-se copiar para manobras_ $G_{C C R}^{5}$ e manobras_ $G_{C C M}^{5}$ o valor do número de manobras em CCR e em CCM, respectivamente, da configuração 3 que a gerou. Assim, esses contadores assumirão os seguintes valores, obtidos na terceira coluna da matriz que armazena número de manobras em chaves (ver Tabela 5.6): manobras_ $G_{C C R}^{5}=3$ e manobras_ $G_{C C M}^{5}=4$.

Continuando a seguir as instruções do Algoritmo 4, deve-se comparar, primeiro para a chave 23 e depois para a chave 17 , o estado das mesmas em $G^{5}$ e em $G^{i}$, e em seguida determinar se são controladas manual ou remotamente. Fazendo-o para a primeira chave, verifica-se que $G_{23}^{5} \neq G_{23}^{i}$ e que esta é uma CCM. Portanto, manobras_G $G_{C C M}^{5}$ deverá ser incrementado, e assumirá o seguinte valor: manobras_ $G_{C C M}^{5}=5$. Em relação a segunda chave, observa-se que $G_{17}^{5}=G_{17}^{i}$ e que esta também é uma CCM. Logo, manobras_ $G_{C C M}^{5}$ deverá, na sequência, ser decrementado e voltará a assumir manobras_G $G_{C C M}^{5}=4$. Desse modo, ao final da execução do algoritmo ter-se-á, separadamente, o número de manobras em CCR e em CCM da configuração 5, que serão salvos na quinta coluna da matriz da Tabela 5.7: manobras_ $G_{C C R}^{5}=3$ e manobras_ $G_{C C M}^{5}=4$.

Tabela 5.7: Matriz que salva o número de manobras, atualizada com a configuração 5.

\begin{tabular}{lccccccc}
\hline Configuração & 1 & 2 & 3 & 4 & 5 & $\ldots$ & $g_{\max }$ \\
\hline Manobras em CCRs & 2 & 2 & 3 & 3 & 3 & $\ldots$ & \\
Manobras em CCMs & 1 & 3 & 4 & 2 & 4 & $\ldots$ & \\
Manobras totais & 3 & 5 & 7 & 5 & 7 & $\ldots$ & \\
\hline
\end{tabular}




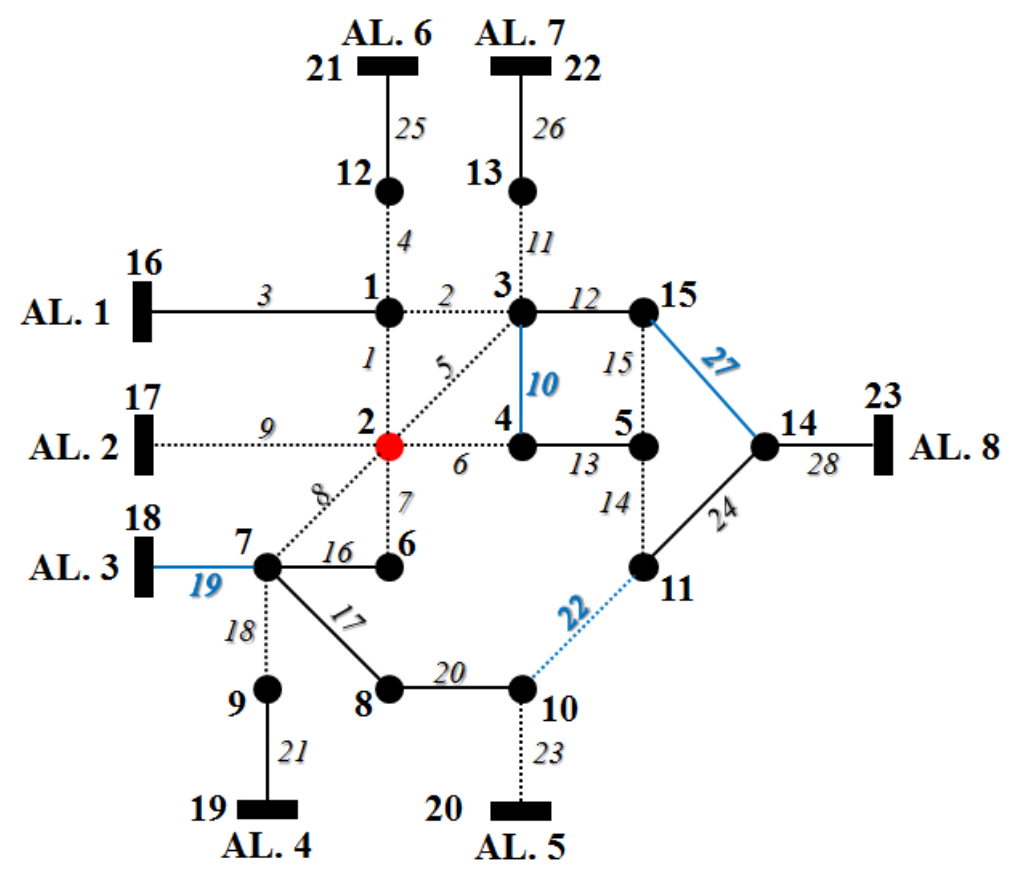

Figura 5.6: Configuração 5 .

\subsubsection{Novas Subpopulações em Tabelas}

Além de um novo contador de operações de manobras em chaves, para proporcionar uma metodologia capaz de priorizar a operação de CCRs, propõe-se novos critérios para definição dos indivíduos que serão armazenadas em tabelas. Em outras palavras, propõe-se uma modificação dos critérios que definem as soluções que serão salvas nas tabelas $P_{6}$, $P_{7}, P_{8}, P_{9}$ e $P_{10}$, tanto para o caso destas ainda estarem incompletas, antes do início do processo evolutivo, quanto para o caso das mesmas estarem completamente preenchidas, situação na qual haverá competição entre cada novo indivíduos gerado e os indivíduos presentes nas tabelas. Além disso, propõe-se a criação de uma nova subpopulação que será armazenada em uma nova tabela, chamada $P_{11}$.

Conforme dito na Seção 4.3, a metodologia base para esta pesquisa armazena nas tabelas $P_{6}, P_{7}, P_{8}, P_{9}$ e $P_{10}$ subpopulações formadas por soluções com os menores valores de perdas resistivas totais e que possuem, respectivamente, 1, 2, 3, 4 e 5 pares de manobras totais em chaves, após a isolação da falta e a reconexão das cargas sãs fora de serviço ${ }^{2}$. Assim, os critérios dessa metodologia para inserção de um indivíduo $G^{\text {new }}$ em uma tabela $P_{5+i}(\operatorname{com} 1 \leq i \leq 5)$ são (Santos et al., 2010): se $P_{5+i}$ não estiver cheia, então $G^{\text {new }}$ será inserido na mesma e nenhuma verificação adicional é realizada; caso contrário, se $P_{5+i}$ estiver completa, então, $G^{\text {new }}$ será inserido em uma tabela $P_{5+i}$ somente se tiver $i$ pares

\footnotetext{
${ }^{2}$ Após a isolação da falta e a reconexão das cargas sãs fora de serviço as manobras em chaves ocorrerão sempre em pares, como explicado na Seção 4.4.
} 
de manobras em chaves e se possuir menos perdas resistivas totais que o pior indivíduo existente em $P_{5+i}$, substituindo-o .

Para priorizar a operação de CCRs através da minimização prioritária de CCMs, como descrito no início da Seção 5.2.2, propõe-se nessa dissertação que sejam salvas nas tabelas em questão subpopulações formadas exclusivamente por soluções que possuem (após a isolação da falta e a reconexão das cargas fora de serviço):

- $P_{6}$ - zero CCMs alteradas, isto é, soluções que exigem manobras somente em CCRs;

- $P_{7}$ - de 1 até 4 CCMs alteradas;

- $P_{8}$ - de 5 até 8 CCMs alteradas;

- $P_{9}$ - de 9 até 12 CCMs alteradas;

- $P_{10}$ - de 13 até 16 CCMs alteradas.

Além disso, propõe-se que essa verificação seja feita também para inserção de um indivíduo em uma tabela $P_{5+i}$, qualquer, mesmo quando esta ainda estiver incompleta. Em testes realizados durante o desenvolvimento do AEMT++, observou-se que se essa verificação na inserção de soluções em $P_{5+i}$ não for realizada também quando cada $P_{5+i}$ ainda está incompleta, então, indivíduos não adequados aos critérios de $P_{5+i}$ poderão ser salvos. Como consequência, durante o processo de evolução das subpopulações armazenadas nessas tabelas poderão haver indivíduos inadequados presentes em $P_{8}$, por exemplo, com número de manobras em CCM menores do que 5, ou seja, indivíduos não adequados para esta tabela, mas que jamais serão substituídos.

Todavia, ao controlar o preenchimento destas tabelas, as mesmas ficarão completas em instantes diferentes, isto é, o processo de evolução da subpopulação armazenadas nestas tabelas começará em gerações diferentes. Para controlar esse processo foram criadas variáveis que salvam o número de soluções adequadamente armazenadas em cada tabela $P_{5+i}$. Assim, quando uma tabela $P_{5+i}$ qualquer, com capacidade para armazenar $S_{P_{5+i}}$ indivíduos, estiver cheia, o AEMT++ será informado de que subpopulação inicial em $P_{5+i}$ está completamente formada e que seu processo de evolução poderá iniciar-se. Vale destacar também, que a seleção em $P_{5+i}$ de um indivíduo para dar origem a uma nova solução é livre de ser realizada mesmo antes do início do processo evolutivo em $P_{5+i}$. Em relação as tabelas $P_{1}, P_{2}, P_{3}, P_{4}$ e $P_{5}$, as mesmas mantêm-se no AEMT++ como são no AEMT (ver Seção 4.3).

Após o inicio do processo de evolução das subpopulações salvas em cada tabela $P_{5+i}$, o AEMT++ irá avaliar também outros critérios toda vez que uma nova solução $G^{\text {new }}$ 
for gerada para competir com o pior indivíduo $\left(G^{P_{5+i}}\right)$ presente em uma tabela $P_{5+i}$. Em outras palavras, além de satisfazer os critérios apresentadores anteriormente, após o preenchimento completo das tabelas $P_{6}, P_{7}, P_{8}, P_{9}$ e $P_{10}$, uma solução $G^{\text {new }}$ somente será considerada melhor do que $G^{P_{5+i}}$, e assim apta para substituí-la, se uma das seguintes condições for satisfeita:

- O número de manobras em CCMs de $G^{\text {new }}$ é menor do que o número de manobras em CCMs de $G^{P_{5+i}}$ (a exceção da tabela $P_{6}$, na qual o número de manobras em CCMs já é o menor possível e igual para todas as soluções, isto é, zero);

- O número de manobras em CCMs de $G^{\text {new }}$ é igual ao número de manobras em CCMs de $G^{P_{5+i}}$, mas o número de manobras em CCRs de $G^{\text {new }}$ é menor do que o número de manobras em CCRs de $G^{P_{5+i}}$;

- O número de manobras em CCMs e em CCRs de $G^{\text {new }}$ e de $G^{P_{5+i}}$ são iguais, mas o maior valor de queda de tensão em $G^{\text {new }}$ é menor que o maior valor de queda tensão em $G^{P_{5+i}}$;

- O número de manobras em CCMs e em CCRs e o valor da maior queda de tensão em $G^{\text {new }}$ e em $G^{P_{5+i}}$ são iguais, mas o valor do maior carregamento da rede em $G^{\text {new }}$ é menor do que o valor do maior carregamento da rede em $G^{P_{5+i}}$;

- O número de manobras em CCMs e em CCRs, o valor da maior queda de tensão e do maior carregamento da rede em $G^{\text {new }}$ e em $G^{P_{5+i}}$ são iguais, mas o valor do maior carregamento de subestação em $G^{\text {new }}$ é menor do que o valor do maior carregamento de subestação em $G^{P_{5+i}}$.

Face ao exposto, percebe-se que as tabelas $P_{5+i}$ passam agora a otimizar não apenas um único, mas vários objetivos, diferentemente de outras metodologias que também são baseadas no Método de Tabelas (Benayoun et al., 1971), como, por exemplo, aquelas apresentadas por Santos et al. (2010) e por Sanches (2013). Em outras palavras, na metodologia proposta as tabelas $P_{5+i}$ minimizam, concomitantemente, os seguintes parâmetros, de acordo com uma ordem de prioridade entre eles ${ }^{3}$

- $P_{6}$ - minimiza o número de manobras em CCR, a maior queda de tensão, o maior carregamentos da rede e o maior carregamento de subestação;

- $P_{7}, P_{8}, P_{9}$ e $P_{10}$ - minimizam o número de manobras em CCMs (dentro de uma faixa específica para cada tabela), o número de manobras em CCRs, a maior queda de tensão, o maior carregamentos da rede e o maior carregamento de subestação.

\footnotetext{
${ }^{3}$ Esta ordem de prioridade é a mesma não qual estes parâmetros são listados.
} 
Por este novo procedimento de seleção mesmo que uma solução $G^{\text {new }}$ seja tão boa quanto uma solução $G^{P_{5+i}}$ em relação aos três primeiros objetivos analisados, por exemplo, se $G^{\text {new }}$ for melhor do que $G^{P_{5+i}}$ em um quarto objetivo, ainda assim esta solução será adiciona à tabela $P_{5+i}$. Desta forma, se a aptidão de uma subpopulação em uma tabela $P_{5+i}$, qualquer, tenha parado de evoluir em relação ao primeiro objetivo da tabela, a mesma passará a evoluir a aptidão da subpopulação em relação ao segundo objetivo, sem retroceder no primeiro. Quando esta população não puder mais evoluir também em relação a um segundo objetivo, este procedimento proposto permitirá que o terceiro objetivo, na lista de prioridade entre objetivos, seja otimizado, sem retroceder na aptidão dos indivíduos em relação aos dois primeiros objetivos, e assim por diante. É importante esclarecer que este procedimento de seleção não tira do AEMT++ a característica dos métodos de otimização baseados em tabelas de subpopulação de ter maior facilidade para escapar de ótimos locais. Isto ocorre porque no AEMT++, assim como nas demais metodologias baseadas em tabelas de subpopulações, indivíduos diferentes são salvos em diversas tabelas que possuem critérios diferentes para inserção de soluções, o que contribui para aumentar a diversidade da população. Além disso, o fato de uma solução $G^{\text {new }}$ ser igual a $G^{P_{5+i}}$ em três objetivos e melhor somente em um quarto objetivo, por exemplo, mas ainda assim substituir $G^{P_{5+i}}$ em uma subpopulação $P_{5+i}$, concorre para melhorar o processo de busca desse AEMO, uma vez que, no caso deste exemplo, a tendência é a de que $G^{\text {new }}$ esteja mais próximo de um valor ótimo do que $G^{P_{5+i}}$.

Além das modificações nas tabelas $P_{6}, P_{7}, P_{8}, P_{9}$ e $P_{10}$, já apresentadas, para priorizar a operação em CCRs por meio da estratégia de minimização prioritariamente da operação em CCMs optou-se também por adicionar uma nova tabela à metodologia proposta: $P_{11}$. Esta tabela tem por objetivo armazenar soluções com os menores valores de número ponderado de manobras em chaves, e assim minimizar esse parâmetro. O número ponderado de manobras em chaves de uma configuração $G^{y}$, em relação a configuração $G^{i}$, isto é, $\chi\left(G^{y}, G^{i}\right)$, pode ser determinado por meio da Equação 5.1 a seguir:

$$
\chi\left(G^{y}, G^{i}\right)=\text { manobras_ } G_{C C M}^{y}+\frac{1}{P} \text { manobras_ } G_{C C R}^{y},
$$

em que manobras_ $G_{C C M}^{y}$ e manobras_ $G_{C C R}^{y}$ representam, respetivamente, o número de CCMs e de CCR alteradas de $G^{y}$ em relação a $G^{i}$, conforme apresentado na Seção 5.2.2.1. Enquanto isso, $P$ é uma constante inteira positiva responsável por ponderar o número de operações em CCMs e em CCRs para cada configuração $G^{y}$. Fisicamente $P$ diz respeito ao número de CCRs cuja operação tem o mesmo custo e/ou trabalho de se operar uma CCM, e por isso é um parâmetro que pode variar em função das políticas de operação de cada empresa de distribuição. Por exemplo, se para uma determinada empresa efetuar 
manobras em 8 CCRs tem o mesmo custo e/ou trabalho de se operar 1 CCM, então P deverá assumir valor igual a 8. Nas simulação efetuadas para esta dissertação adotou-se $P=10$.

Em relação aos critérios de inserção de novas soluções em $P_{11}$, como não existe nenhuma restrição quanto ao número de CCMs alteradas que uma configuração $G^{\text {new }}$ deve possuir para pertencer a esta nova tabela, então, basta que $P_{11}$ esteja incompleta para receber uma nova solução. Após o seu preenchimento, uma solução $G^{\text {new }}$ somente entrará em $P_{11}$ se possuir número ponderado de manobras em chaves menor do que o número ponderado de manobras em chaves da pior solução salva em $P_{11}\left(G^{P_{11}}\right)$, isto é, se $\chi\left(G^{\text {new }}, G^{i}\right)<$ $\chi\left(G^{P_{11}}, G^{i}\right)$. Nesta tabela, não foram considerados outros objetivos, como nas tabelas $P_{6}$, $P_{7}, P_{8}, P_{9}$ e $P_{10}$ apresentadas anteriormente.

\subsection{Priorização de Fornecimento aos Consumidores Especiais}

Em SDRs de grande porte, foco desta metodologia proposta, é comum a presença de cargas elétricas que, preferencialmente, não devem ter o seu fornecimento interrompido, seja por motivos econômicos, de segurança ou de saúde pública. Dentre estas cargas pode-se citar as indústrias siderúrgicas, as indústrias que necessitam de grandes câmaras frigoríficas, os grandes hospitais, os centros de transfusão de sangue, os grandes supermercados, etc. Devido às necessidades especiais destas cargas, em relação aos demais consumidores, as mesmas podem ser chamadas de CEs.

No que tange ao fornecimento de energia aos CEs, há duas condições que devem ser satisfeitas:

1. Os CEs devem ter prioridade no restabelecimento;

2. Os CEs não podem ter o suprimento de energia elétrica interrompido, mesmo que por um curto intervalo de tempo.

Isto equivale a dizer que $(i)$ em caso de interrupção no fornecimento de energia elétrica a um grupo de cargas, dentre as quais exista um ou mais CEs, estes devem ter prioridade de restabelecimento, e precisam ter o fornecimento restaurado no menor intervalo de tempo possível; (ii) caso a localização da falta seja tal, que a interrupção de energia não tenha afetado nenhum CE, então, é necessário que a nova configuração a ser obtida para a rede não exija a transferência de CEs entre alimentadores ou, se for necessário para corrigir possíveis sobrecargas ou perfis de tensão inadequados, que permita o mínimo possível, mas apenas em ocasiões em que esta seja a única opção para se obter uma solução factível. 
Isto porque, a transferência de qualquer setor exige uma interrupção do fornecimento que, mesmo sendo momentânea, é preferível que não ocorra a um CE.

Para restaurar de forma rápida o fornecimento de CEs atingidos por uma falta, e assim, satisfazer a primeira condição enumerada e descrita acima, a estratégia adotada foi de priorizar a reconexão destas cargas por meio de CCRs. Em outras palavras, propõe-se que, se houver a possibilidade de se reconectar por meio de uma CCR um CE afetado por uma falta, que esta chave seja determinada e que a sua operação seja requerida no plano de restabelecimento obtido. Para este fim, destaca-se que o procedimento de determinação da primeira configuração factível do AEMT++, descrito na Seção 5.2.1, já é capaz de fazê-lo, satisfazendo, assim, esta primeira condição de fornecimento aos CEs. Porém, no caso da ausência de CCRs, a única possibilidade é a utilização de CCMs, e neste caso, a restauração de fornecimento de energia aos CEs afetados por uma falta não mais dependerá de uma ferramenta computacional, mas do tempo de deslocamento e ação das equipes de manutenção presentes em campo.

Após a reconexão de cargas sãs localizadas à jusante de um setor sob falta, tanto no caso em que haja um ou mais CEs desabastecidos quanto no caso da ausência de CE entre as cargas sem fornecimento, o plano de restabelecimento obtido deve possuir uma sequência de chaveamento tal, que não exija a interrupção do suprimento de energia elétrica aos CEs por meio da sua transferência de um alimentador para outro. Ou, que exija o mínimo possível em casos especiais, conforme justificado anteriormente. Para satisfazer esta segunda condição de fornecimento aos CEs, a estratégia utilizada foi prover ao AEMT++ duas novas tabelas de subpopulações, responsáveis por minimizar a transferência de CEs após a reconexão dos setores sãos sem fornecimento. Estas novas tabelas são: $P_{12}$ e $P_{13}$.

De maneira específica, na tabela $P_{12}$ são armazenadas soluções que não exigem a transferência de CEs, após a reconexão de setores sãos afetados por uma falta, e que minimizam o número ponderado de manobras. Isto quer dizer que as soluções presentes em $P_{12}$ são aquelas que possuem, concomitantemente, zero transferências de CEs com os menores valores de $\chi\left(G^{y}, G^{i}\right)$. Uma nova solução $G^{\text {new }}$ somente será armazenada em $P_{12}$ se (i) $G^{\text {new }}$ exigir zero transferências de CEs e esta tabela estiver incompleta; ou se (ii) $P_{12}$ estiver completa, $G^{\text {new }}$ exigir zero transferências de CEs e também possuir número ponderado de manobras em chaves menor do que o número ponderado de manobras da pior solução já presente em $P_{12}$, substituindo-a neste caso.

No entanto, em algumas situações, dependendo da localização da falta, dos CEs e das chaves existentes na rede, bem como das características operacionais da rede (como carregamento de alimentador e de subestação próximos da capacidade, e/ou de perfil de 


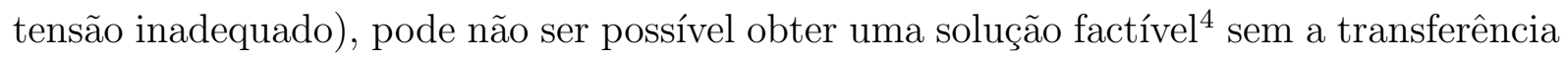
de CEs. Prevendo estes casos mais críticos, a tabela $P_{13}$ têm como objetivo primário armazenar soluções que minimizem o número de CEs transferidos após a isolação da falta e a reconexão dos setores sem fornecimento, e como objetivo secundário, adicional, minimizar o número ponderado de manobras em chaves. Isto quer dizer que esta tabela utiliza o procedimento descrito na Seção 5.2.2.2 a fim de otimizar mais de um parâmetro por meio de uma única tabela de subpopulação. Assim sendo, uma nova solução $G^{\text {new }}$ será inserida em $P_{13}$ se uma das três condições a seguir for satisfeita:

- $P_{13}$ ainda não estiver completa;

- $P_{13}$ estiver completa e o número de CEs transferidos de $G^{\text {new }}$ for menor do que o número de CEs transferidos da pior solução existente em $P_{13}$;

- $P_{13}$ estiver completa e o número de CEs transferidos de $G^{\text {new }}$ e da pior solução presente em em $P_{13}$ forem iguais e o número ponderado de manobras de $G^{\text {new }}$ $\left(\chi\left(G^{\text {new }}, G^{i}\right)\right)$ for menor que da pior solução existente em $P_{13}\left(\chi\left(G^{P_{13}}, G^{i}\right)\right)$.

\subsection{Definição de Uma Solução Final}

Com o objetivo de auxiliar o trabalho dos operadores dos SDRs, fornecendo a eles um plano adequado de restabelecimento de energia em situações de contingência, o AEMT++ foi desenvolvido com a capacidade de selecionar e informar uma solução ao final de sua execução. Observe que a metodologia base, ao contrário do AEMT++, fornece ao término do seu processo evolutivo, não uma solução, mas, um conjunto de soluções, que são os indivíduos que formam as subpopulações armazenadas nas tabelas. Além disso, deve-se destacar que essas soluções não são todas necessariamente factíveis, isto é, capazes de satisfazer todas restrições do problema (Seção 1.2.2). Por isso, além das modificações e melhorias realizadas no AEMT para alcançar os objetivos desta pesquisa, descritos na Seção 1.4, outras adicionais precisaram ser feitas para que o AEMT++ pudesse ter a capacidade de informar ao operador um plano de restabelecimento constituído por uma única solução factível com a sua respectiva sequência de chaveamento, em uma situação de contingência.

Nesse sentido, o processo de escolha de uma solução final inicia-se pela verificação da factibilidade das soluções presentes nas tabelas ao final do processo evolutivo Assim,

\footnotetext{
${ }^{4}$ Uma solução factível é uma configuração da rede na qual todas as restrições do problema (ver Seção 1.2.2) são satisfeitas, ou seja, é uma configuração radial que fornece energia a todos os setores (a exceção do setor sob falta e dos setores sãos atingidos por uma falta e cuja reconexão não é possível devido a ausência de chaves na rede), sem sobrecarga na rede e nas subestação, e com a tensão em todas as cargas dentro dos intervalos exigidos pela legislação.
} 
após o AEMT++ atingir o seu critério de parada, as subpopulações armazenadas nas tabelas $P_{6}, P_{7}, P_{8}, P_{9}$ e $P_{10}$, inicialmente, são verificadas, e somente as soluções factíveis presentes nas mesmas são extraídas e salvas em um vetor auxiliar. Este vetor tem por finalidade reunir uma subpopulação formada exclusivamente por soluções factíveis que serão, posteriormente, analisadas a fim de que seja extraída desta subpopulação factível a solução final, a ser informada no plano de restabelecimento. A verificação destas tabelas é interrompida quando esta subpopulação factível estiver completa ou quando a análise de todas estas tabelas for concluída.

Caso, ao término da verificação desta cinco tabelas, este vetor ainda não estiver completo, então, as tabelas $P_{12}, P_{13}$ e $P_{11}$, nessa sequência, serão também analisadas. É importante destacar que optou-se por verificar primeiro as tabelas relativas à priorização de operação CCRs e ao atendimento de CEs porque nestas estão armazenadas, respectivamente, as soluções com os menores valores de manobras em chaves e de CEs transferidos. Se durante o processo evolutivo, o AEMT++ conseguiu obter uma solução factível que exigirá pouquíssimas manobras para ser implementada e pouquíssima ou nenhuma transferência de CEs, então, esta solução, que é desejável, estará armazenada não apenas nas tabelas que minimizam as restrições do problema $\left(P_{1}, P_{2}, P_{3}\right.$ e $\left.P_{4}\right)$ e as perdas resistivas $\left(P_{5}\right)$, mas também em uma das tabelas que priorizam CCRs e em uma das que minimizam as interrupções em CEs. Mas, se após a verificação de mais estas três tabelas, a subpopulação factível ainda não estiver completa, então as demais tabelas são também verificadas. Caso contrário, este primeiro passo é encerrado.

Em seguida, esta subpopulação formada exclusivamente por soluções factíveis, é analisada para que seja determinado, dentre estas soluções, um subconjunto constituído pelas soluções com os menores valores de $\chi\left(G^{y}, G^{i}\right)$, ou seja, soluções que, além de serem factíveis, priorizam a operação de CCRs e exigirão menos manobras em chaves para serem implementadas. Para compor este subconjunto são consideradas a solução com o menor número ponderado de manobras $\left(\chi_{\min }\left(G^{y}, G^{i}\right)\right)$, presente nesta subpopulação, e as soluções cujo valor de $\chi\left(G^{y}, G^{i}\right)$ varia de $\chi_{\min }\left(G^{y}, G^{i}\right)$ até $\left(\chi_{\min }\left(G^{y}, G^{i}\right)+3\right)^{5}$.

Finalmente, a solução final será definida como aquela que exigirá menos transferências de CEs, dentre todas as soluções presente neste subconjunto. Caso hajam soluções com valor de CEs transferidos iguais e mínimo, ou seja, um empate, então, escolher-se-á aquela que possuir menor número de chaves que voltaram ao seu estado inicial, em $G^{i}$ (ver na Seção 5.2.2.1 os Casos 2 e 3, situações nas quais existem chaves que quando alteradas retornam ao seu estado em $G^{i}$ ), pois, esta configuração exigirá menor esforço computacional para definição de uma sequência de chaveamento.

\footnotetext{
${ }^{5}$ Essa constante (3) significa que são admissíveis, a este subconjunto, soluções que exigirão até 3 manobras em CCMs a mais do que as manobras requeridas pela solução que possui $\chi_{\min }\left(G^{y}, G^{i}\right)$.
} 
Se, num caso mais extremo, após todas as tabelas serem verificadas, não tenha sido determinada nenhuma solução factível, então, a rotina para determinação de uma solução final será reinicializada considerando a possibilidade de se compor a subpopulação, presente no vetor auxiliar, com soluções que não tenham uma sobrecarga de até $5 \%$ na rede e nas subestações. Se ainda assim nenhuma solução for obtida, então, considerar-se-á uma sobrecarga admissível de 10\%, e assim por diante, até que seja obtida uma solução final ou até que a sobrecarga tenha atingido um valor inaceitável temporariamente para a operação da rede. Caso tenha sido determinadas uma solução final, o operador será alertado pelo AEMT++ da obtenção de uma solução com sobrecarga, caso contrário, a execução da metodologia será encerrada sem encontrar uma solução final para o problema. É importante salientar que esta última situação, mais crítica, ocorre não por uma incapacidade da metodologia proposta de determinar uma solução final, mas, porque a rede não possui chaves suficientes para retirar cargas do alimentador ou subestação com sobrecarga e transferirá-las para outro alimentador ou subestação. Neste caso, o procedimento a ser adotado é o de rejeição de carga, ou seja, retirar de operação cargas menos importantes presentes no alimentador ou na subestação com excesso de cargas. Contudo, este procedimento não é contemplado pelo AEMT++.

\subsection{Definição de Sequência de Chaveamento Factível}

Um plano adequado de restabelecimento de energia deve conter, entre outras informações, a definição das chaves que precisam ser operadas para restaurar o fornecimento de energia às cargas sãs fora de serviço e para corrigir eventuais sobrecargas e tensões inadequadas, possíveis de ocorrer após a reconexão daquelas cargas atingidas pela falta. Todavia, se a operação destas chaves for realizada de forma aleatória ou sem uma sequência correta, podem ocorrer diversos distúrbios no SDR como, por exemplo, aqueles resultantes da formação de laços na rede e da conexão entre alimentadores e/ou subestações diferentes, além de aumentar o tempo sem fornecimento das cargas que necessitam ser transferidas de alimentadores. Eventos como estes comprometem a segurança operacional dos SDRs e podem causar novos danos à rede, bem como contribuem negativamente com os indicadores de continuidade. Dessa forma, além das chaves que devem ser operadas, um plano de restabelecimento deve informar também uma sequência de chaveamento factível, isto é, uma sequência por meio da qual as chaves podem ser manobradas de forma segura e eficiente.

Para possibilitar ao AEMT++ definir e informar uma sequência de chaveamento factível, diversas inserções foram realizadas naquela metodologia base. A primeira delas diz respeito ao armazenamento dos pares de chaves que são alteradas pelos operadores 
da RNP para gerar novos indivíduos. Assim, para cada nova solução $G^{\text {new }}$ é criada uma matriz, chamada de $P M_{n e w}$ ("Pares de Manobras da Configuração $G^{\text {new"), na qual são }}$ salvos todos os pares de chaves alteradas, a partir da primeira configuração factível, para se obter $G^{\text {new }}$. Sua dimensão será sempre de $N_{P M_{\text {new }}} \times 2$, em que $N_{P M_{\text {new }}}$ é o número de pares de manobras em chaves de $G^{\text {new }}$, parâmetro que varia em função do número de chaves alteradas de cada nova configuração. Na primeira coluna de $P M_{n e w}$ são salvas as chaves a serem abertas e na segunda coluna as chaves a serem fechadas, após a reconexão das cargas sãs fora de serviço na primeira configuração factível obtida.

Por exemplo, considere a configuração $3\left(G^{3}\right)$ do exemplo de aplicação do novo algoritmo para cálculo de número de manobras (Seção 5.2.2.1), apresentada na Figura 5.4. Conforme dito naquela seção, após a restauração do fornecimento de energia aos setores sãos fora de serviço (Figura 5.1(b)), foram necessários dois pares de manobras para obtenção de $G^{3}$, a saber: 17 e 20, e 22 e 24 . Assim sendo, a matriz que armazena as chaves alteradas de $G^{3}$, isto é, $P M_{3}$, pode ser expressa por aquela apresentada na Tabela 5.8. Observe na primeira coluna de $P M_{3}$ as chaves que foram abertas (17 e 22) e na segunda colunas as chaves que foram fechadas (20 e 24), enquanto que nas linhas são armazenados os pares de chaves alteradas. Já as chaves NAs que devem ser fechadas para reconectar à rede os setores sãos sem fornecimento são armazenadas em um pequeno vetor, para que sejam informadas ao operador do SDR por meio do plano de restabelecimento. No caso deste exemplo estas seriam: 27, 10 e 16.

Tabela 5.8: Conjunto de pares de chaves alteradas de $G^{3}$.

\begin{tabular}{|c|c|}
\hline \multicolumn{2}{|c|}{$\mathbf{P M}_{3}$} \\
\hline $\mathbf{A}$ & $\mathbf{F}$ \\
\hline \hline 17 & 20 \\
\hline 22 & 24 \\
\hline
\end{tabular}

Todavia, para definir uma sequência de chaveamento factível para um plano de restabelecimento não basta apenas armazenar as chaves alteradas de cada configuração gerada, deve-se também, obviamente, verificar a factibilidade da configuração definida como a solução final ${ }^{6}$. Assim, após o término do processo evolutivo do AEMT++ e da definição de uma solução final, pelo procedimento descrito na Seção 5.4, uma sequência de chaveamento será definida a partir dos pares de manobras da matriz que armazena as chaves alteradas da solução final. De tal forma que a aplicação em sequência de cada um desses pares de manobras terminará com a implantação da solução final.

Mas, deve-se destacar que a cada par de manobra executado a rede passará temporariamente por outras configurações, chamadas de configurações intermediárias,

\footnotetext{
${ }^{6}$ Para garantir eficiência computacional à metodologia, a factibilidade é verificada apenas para a configuração final.
} 
cuja factibilidade também deve ser verificada. Assim, a análise da factibilidade de uma sequência de chaveamento consiste em verificar a factibilidade de cada configuração intermediária. Em outras palavras, uma sequência de chaveamento será factível se, e somente se, todas as configurações que a rede possuirá durante a sua execução forem também factíveis ${ }^{7}$.

Já a verificação da factibilidade de uma configuração intermediária consiste em analisar se as modificações que serão produzidas pela aplicação do par de chaves, responsável pela sua obtenção, são correspondentes a aplicação de um dos operadores da $\mathrm{RNP}^{8}$. Isto porque, segundo Santos et al. (2010), a RNP e seus operadores geram exclusivamente configurações factíveis.

No entanto, a análise de factibilidade de sequências de chaveamento está diretamente relacionada com a existência de chaves alteradas que retornaram ao seu estado na primeira configuração factível obtida, ou seja, na primeira configuração da rede após a reconexão dos setores sãos sem fornecimento reconectados. Estas chaves podem ser facilmente identificadas na matriz que armazena os pares de chaves alteradas de cada nova configuração, pois, quando uma chave retorna ao seu estado anterior, a mesma aparecerá duas vezes nessa matriz, em duas linhas distintas. Assim sendo, para que a sequência de chaveamento presente no plano de restabelecimento não exija duas operações em uma mesma chave, o que equivaleria a fechá-la e depois abri-la ou a abri-la para posteriormente fechá-la, esta deverá ser localizada e excluída da matriz que o armazena. O procedimento de verificação da factibilidade de uma sequência de chaveamento é diferente na ausência de chaves repetidas, na presença de uma e de duas (Caso 2) chaves que retornaram ao seu estado anterior. Assim, para facilitar a compreensão destas três situações, as mesmas serão melhor abordadas a seguir.

\section{Verificação da Factibilidade de Sequências de Chaveamento}

\section{Na Ausência de Chaves Repetidas}

Quando uma solução final, $G^{y}$, por exemplo, é definida e a sua matriz $P M_{y}$ não possui nenhuma chave repetida, isto é, chave que retornou ao seu estado anterior na primeira configuração factível, então, a sequência de chaveamento final será a própria matriz $P M_{y}$ e nenhuma verificação adicional é necessária. Isto justifica-se pelo fato de que nesta matriz todos os pares de manobras foram gerados por meio de aplicações sucessivas dos operadores da RNP e, conforme citado anteriormente, estes operadores

\footnotetext{
${ }^{7}$ A definição de configuração factível foi apresentada na Seção 4.3, na página 34 .

${ }^{8}$ Maiores detalhes sobre a RNP e seus operadores podem ser obtidos no Apêndice A e em Delbem et al. (2004).
} 
geram exclusivamente configurações factíveis. Desse modo, saber-se-á que todas as configurações intermediárias que a rede possuirá com a execução de cada par de manobra serão factíveis. E se todas as configurações intermediárias são factíveis, logo, o conjunto de pares de chaves alteradas, na sequência em que estão presente em $P M_{y}$, constituirão uma sequência de chaveamento factível. Um exemplo desta situação é a configuração 3 (Figura 5.4), cuja matriz $P M_{3}$ foi apresentada pela Tabela 5.8.

\section{Na Presença de Uma Chave Repetida}

Quando uma solução final, $G^{y}$, por exemplo, é definida, e a sua matriz $P M_{y}$ possui uma chave que retornou ao seu estado anterior, na primeira configuração factível, então, esta chave aparecerá repetida em $P M_{y}$, isto é, em mais de uma linha. Neste caso, para que na sequência de chaveamento final não hajam manobras desnecessárias, esta chave que retornou ao seu estado anterior deverá ser localizada e excluída de $P M_{y}$. No entanto, sempre que uma chave é retirada, os dois pares de manobras aos quais ela pertencia ficarão incompletos e um novo arranjo de pares de chave deverá ser feito.

Por exemplo, considere a configuração $G^{5}$ (configuração 5), do exemplo de aplicação do novo algoritmo para cálculo de número de manobras (Seção 5.2.2.1), apresentada na Figura 5.6, bem como a sua matriz $P M_{5}$, mostrada na Tabela 5.9. Observe na primeira e na terceira linha de $P M_{5}$ que, após a reconexão dos setores sãos fora de serviço (Figura 5.1(b)), a chave 17 inicialmente foi aberta e posteriormente fechada. Desse modo, para que estas alterações que se anulam não estejam presentes na sequência de chaveamento a ser apresentada no plano de restabelecimento, a chave 17 deve ser retirada do primeiro e do terceiro par de chaves e $P M_{5}$ atualizada, como mostra a Tabela 5.10.

Tabela 5.9: Conjunto de pares de chaves alteradas de $G^{5}$.

\begin{tabular}{|c|c|}
\hline \multicolumn{2}{|c|}{$\mathbf{P M}_{5}$} \\
\hline $\mathbf{A}$ & $\mathbf{F}$ \\
\hline \hline$\underline{\mathbf{1 7}}$ & 20 \\
\hline 22 & 24 \\
\hline 23 & $\underline{\mathbf{1 7}}$ \\
\hline
\end{tabular}

Tabela 5.10: Conjunto de chaves alteradas de $G^{5}$ atualizado pela exclusão da chave 17 .

\begin{tabular}{|c|c|}
\hline \multicolumn{2}{|c|}{$\mathbf{P M}_{5}^{0}$} \\
\hline $\mathbf{A}$ & $\mathbf{F}$ \\
\hline \hline & $\mathbf{2 0}$ \\
\hline 22 & 24 \\
\hline $\mathbf{2 3}$ & \\
\hline
\end{tabular}


Contudo, observe que esse conjunto de chaves alteradas de $G^{5}$, atualizado pela retirada da chave 17, não pode formar uma sequência de pares de manobras porque as chaves 20 e 23 encontram-se agora isoladas, e também porque, devido a radialidade da rede, se uma chave NA for fechada antes da abertura de uma NF, um laço ou uma conexão entre dois alimentadores poderá formar-se na rede. Neste caso, observe na primeira configuração factível obtida, apresentada pela Figura 5.1(b) e reproduzida na Figura 5.7, se a chave 20 for fechada antes da abertura de uma chave NF os alimentadores 3 e 5 serão conectados. Portanto, um novo arranjo, composto somente por pares de chaves, deverá ser feito com as chaves resultantes.

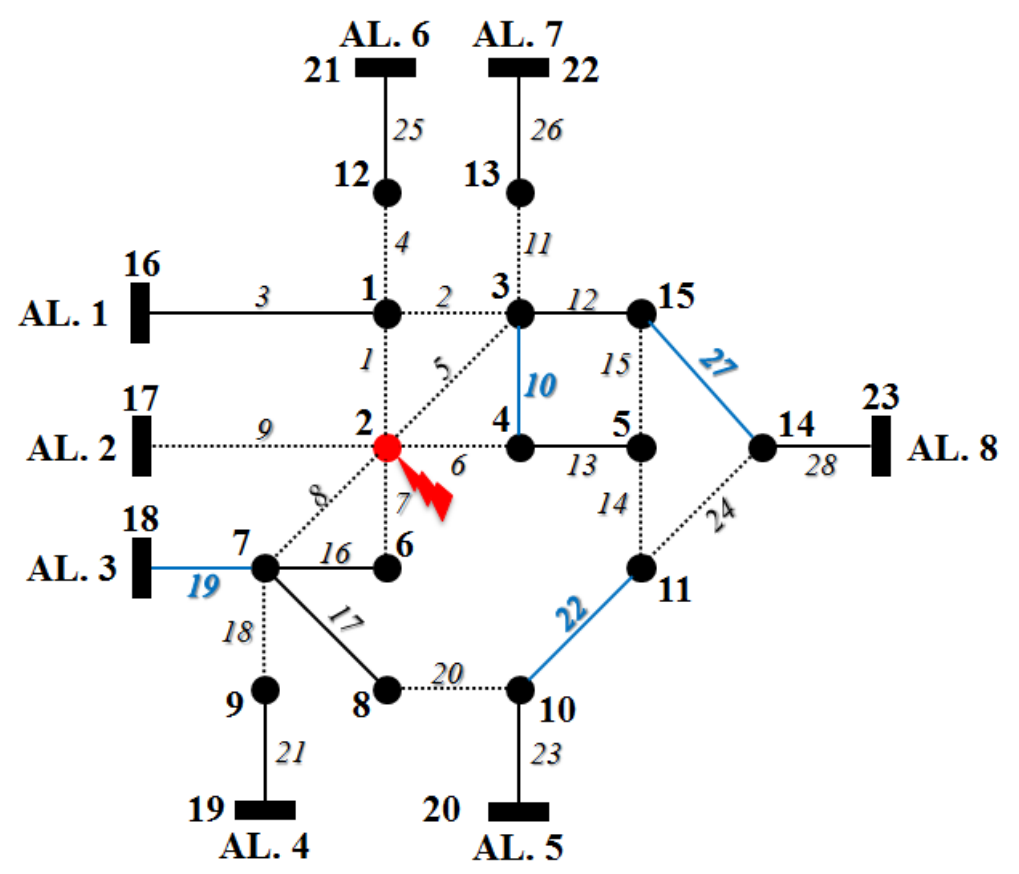

Figura 5.7: Reprodução da primeira configuração factível obtida no exemplo da Seção 5.2.1.

Para tal as chaves 23 e 20 devem ser unidas, a fim de que um novo par seja formado com as mesmas $([23,20])$. Esse novo par de chaves será chamado de par rearranjado, pois não foi criado pela aplicação de um dos operadores da RNP, mas por uma combinação de duas chaves alteradas em configurações distintas. Após a formação do par rearranjado haverão duas sequências de chaveamento possíveis de se obter e que serão verificadas a fim de determinar uma que seja factível e, portanto, que possa ser informada no plano de restabelecimento. A primeira delas, $P M_{5}^{1}$, é aquela apresentada na Tabela 5.11, na qual o par rearranjado foi inserido na primeira das duas linhas nas quais encontrava-se a chave repetida. A segunda, $P M_{5}^{2}$, é mostrada na Tabela 5.12, onde o par rearranjado foi inserido na segunda das duas linhas na qual encontrava-se a chave repetida.

Todavia, como o par rearranjado e também estas duas sequências de chaveamento foram formados por meio de recombinações de chaves e de pares de chaves, 
Tabela 5.11: Sequência de chaveamento na qual o par rearranjado encontra-se na primeira das duas linhas nas quais encontrava-se a chave 17.

\begin{tabular}{|c|c|}
\hline \multicolumn{2}{|c|}{$\mathbf{P M}_{5}^{1}$} \\
\hline $\mathbf{A}$ & $\mathbf{F}$ \\
\hline \hline $\mathbf{2 3}$ & $\mathbf{2 0}$ \\
\hline 22 & 24 \\
\hline & \\
\hline
\end{tabular}

Tabela 5.12: Sequência de chaveamento na qual o par rearranjado encontra-se na segunda das duas linhas nas quais encontrava-se a chave 17.

\begin{tabular}{|c|c|}
\hline \multicolumn{2}{|c|}{$\mathbf{P M}_{5}^{2}$} \\
\hline $\mathbf{A}$ & $\mathbf{F}$ \\
\hline \hline \hline & \\
\hline 22 & 24 \\
\hline $\mathbf{2 3}$ & $\mathbf{2 0}$ \\
\hline
\end{tabular}

respectivamente, e não através de aplicações sucessivas dos operadores da RNP, não é possível afirmar que ambas são factíveis. Nesse caso, deve-se efetuar uma verificação da factibilidade destas sequências, antes de apresentar uma delas em um plano de restabelecimento.

Começando pela primeira delas, $P M_{5}^{1}$, apresentada na Tabela 5.11, deve-se simular a aplicação de cada par de manobras presente em $P M_{5}^{1}$ e verificar se todas as configurações intermediárias que serão obtidas são factíveis. Ao aplicar o primeiro par de manobras ([23, 20]) em $P M_{5}^{1}$ na primeira configuração factível obtida, reproduzida na Figura 5.7, obter-se-á a configuração intermediária 1, mostrada na Figura 5.8, por meio de uma mudança na rede que corresponde a transferência dos setores 10 e 11 do alimentador 5 para o alimentador 3.

Note que a verificação da factibilidade de uma configuração intermediária pode ser feita de duas formas: $(i)$ a primeira, por meio de uma análise de todos os alimentadores a fim de determinar se são todos radiais e capazes de fornecer energia a todos os setores conectados à rede; (ii) a segunda, por meio da análise das mudanças ocorridas na rede pela aplicação de um par de manobras [x, y] na obtenção de uma configuração intermediária, a fim de verificar se estas mudanças correspondem a aplicação de um dos operadores da RNP, pois, segundo Santos et al. (2010), as mudanças geradas pelo operadores da RNP criam apenas configurações factíveis. Veja que o esforço computacional para a execução da primeira estratégia é diretamente proporcional ao tamanho do SDR em análise, enquanto que a segunda fará apenas duas comparações, independentemente do tamanho da rede, sendo assim computacionalmente mais eficiente que a primeira. 
As duas comparações a serem efetuadas para determinar se um par de manobras [x,y] é equivalente a aplicação do PAO ou do CAO são as seguintes: $(i)$ se a árvore origem, na qual a subárvore transferida foi podada por meio da abertura da chave ' $x$ ', é diferente da subárvore destino; e (ii) se o nó por meio do qual a subárvore foi podada é o mesmo nó por meio do qual ela foi inserida na árvore destino por meio do fechamento da chave ' $\mathrm{y}$ '. Se a resposta para as duas comparações for 'sim', então, a mudança gerada na topologia da rede por meio da aplicação do par de manobras [x, y] corresponde a uma aplicação do PAO; se a resposta para a primeira comparação for 'sim' e para a segunda for 'não', então, o par de manobras $[\mathrm{x}, \mathrm{y}]$ é equivalente a aplicação do CAO; e, por último, se a resposta para a primeira pergunta for 'não', independente da resposta da segunda comparação, esta mudança não é equivalente a aplicação de nenhum dos dois operadores da RNP, e por isso não se pode afirmar que a configuração obtida pela aplicação do par de manobras $[\mathrm{x}, \mathrm{y}]$ é factível $^{9}$.

Face ao exposto, para a configuração intermediária 1, observe que a árvore origem (alimentador 5), na qual da subárvore transferida (formada pelos nós 10 e 11) foi podada, é diferente da árvore destino (alimentador 3); e também que o nó no qual esta subárvore foi podada (nó 10) é o mesmo por meio da qual a mesma foi inserida na árvore destino. Então, pode-se afirmar que esta mudança na topologia da rede é equivalente a aplicação do PAO. Consequente, pode-se concluir que a configuração intermediária 1 é factível.

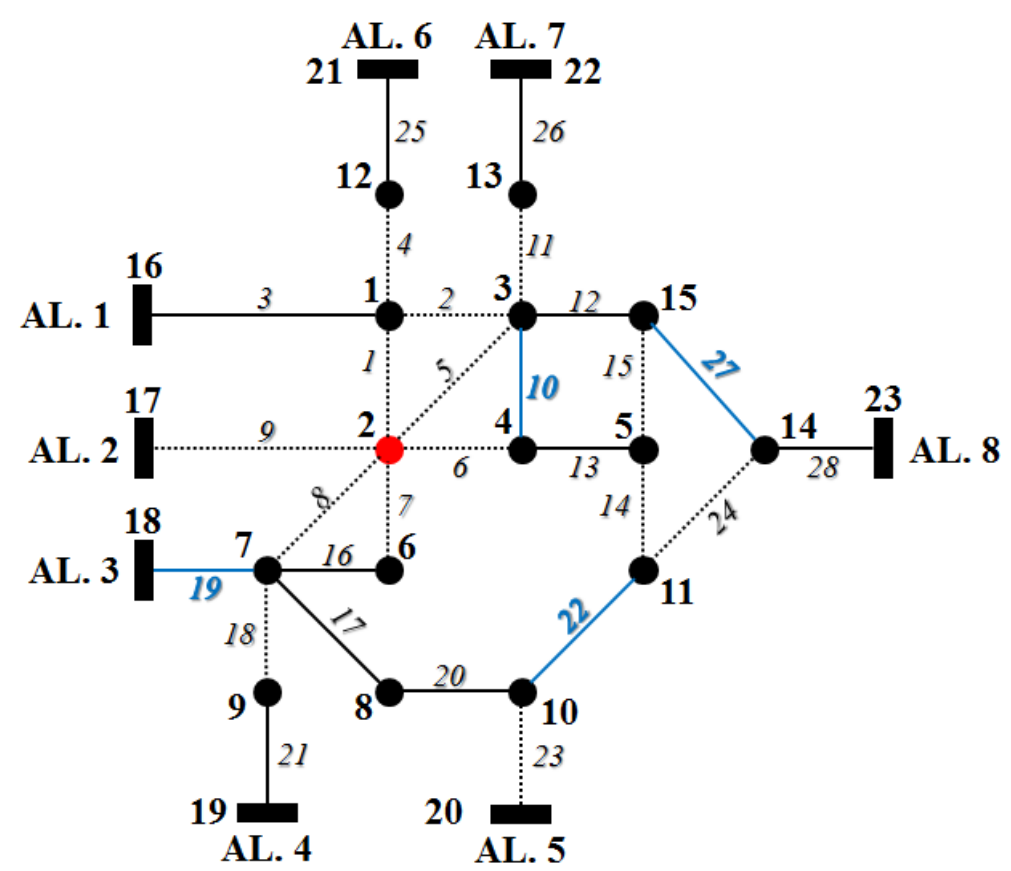

Figura 5.8: Configuração intermediária 1 de $P M_{5}^{1}$.

\footnotetext{
${ }^{9}$ Esta é a regra criada para verificar a factibilidade de configurações de uma rede, e consequentemente, a factibilidade de uma sequência de chaveamento.
} 
Aplicando o segundo e último par de manobras ([22, 24]) presente em $P M_{5}^{1}$ na configuração intermediária 1, obter-se-á a configuração da rede apresentada na Figura 5.9, por meio da transferência do setor 11 do alimentador 3 para o alimentador 8 . Neste caso, assim como no caso do par de manobras anterior, a árvore origem (alimentador 3), na qual da subárvore transferida (formada pelo nó 11) foi podada, é diferente da árvore destino (alimentador 8) e o nó no qual esta subárvore foi podada (nó 11) é o mesmo por meio da qual a mesma foi inserida na árvore destino. Logo, é correto afirmar que esta mudança na topologia da rede é equivalente a aplicação do PAO. Portanto, esta segunda configuração também é factível. E se todas as configurações obtidas pela aplicação da sequência de pares de manobras presente em $P M_{5}^{1}$ são factíveis, consequentemente, pode-se concluir que a sequência de chaveamento representada por $P M_{5}^{1}$ é factível.

Comparando a Figura 5.9 com aquela na qual é apresentada a configuração 5 (Figura 5.6), pode-se observar que ambas são iguais. Em outras palavras, a execução da sequência de chaveamento $P M_{5}^{1}$, otimizada pela exclusão de duas manobras desnecessária, foi capaz de obter para a rede a mesma topologia que seria obtida se a sequência original $P M_{5}$, com a presença da chave repetida, fosse aplicada. Desse modo, fica provado que a exclusão de chaves repetidas de uma sequência de chaveamento não compromete a obtenção da configuração final desejada, embora, as configurações intermediárias que haverão na rede sejam diferentes após a retiradas destas chaves.

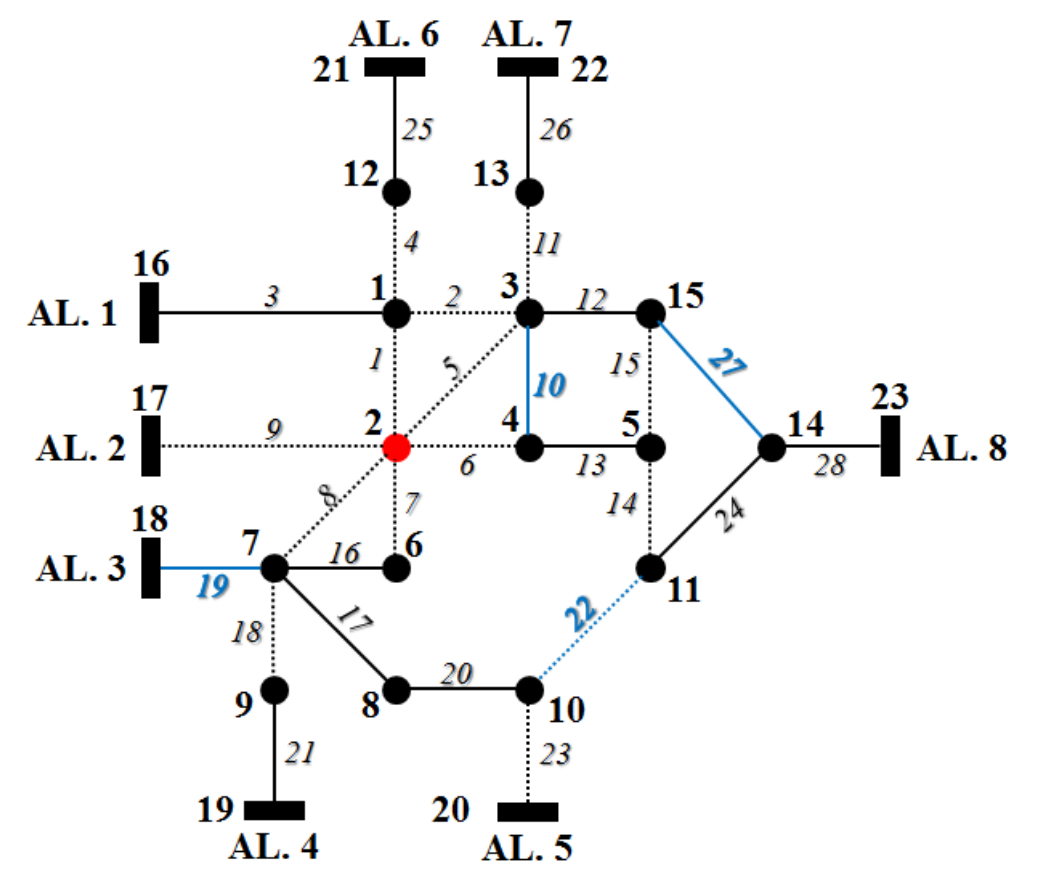

Figura 5.9: Configuração da rede obtida por meio da aplicação da sequência de chaveamento presente em $P M_{5}^{1}$.

No AEMT++, mesmo que haja mais de uma sequência possível de ser obtida após a retirada de chaves repetidas, como neste exemplo em que houvera duas, uma 
segunda sequência de pares de chaves somente terá a sua factibilidade verificada se a primeira sequência testada não for factível. Caso também a segunda sequência não seja factível, então, tomar-se-á como a sequência de chaveamento a ser informada no plano de restabelecimento aquela formada pelos pares de manobras sem a retirada da chave repetida. Isso justifica-se pelo fato de que é menos laborioso fazer e depois desfazer uma manobra em uma única chave do que escolher uma nova solução final que poderia possuir um número maior ou igual de manobras, uma vez que as ações de primeiro abrir e depois fechar uma chave ou de fecha-la e posteriormente abri-la seria executada num mesmo local, sem exigir o deslocamento de equipes. O que não aconteceria para duas manobras em duas chaves distintas em locais diferentes presentes uma nova solução final.

É importante salientar também que no caso desse exemplo as duas sequências obtidas após a exclusão da chave repetida eram exatamente as únicas possíveis de serem geradas, já que haviam restado somente dois pares de chaves. Nos casos em que o número de pares de chaves restante é maior, obviamente, o número de sequências possíveis de serem obtidas pela combinação destes pares também é maior. Contudo, mesmo nestes casos apenas duas sequências são listadas no AEMT++ para terem a factibilidade verificada, nesta situação em que apenas uma chave voltou ao seu estado anterior. São elas: 1) aquela sequência na qual o par rearranjado é inserido na primeira das duas linhas nas quais encontrava-se a chave que foi excluída, e; 2) aquela sequência na qual o par rearranjado é inserida na segunda das duas linhas nas quais encontrava-se a chave que foi retirada.

\section{Na Presença de Duas Chaves Repetidas}

Quando uma solução final, $G^{y}$, por exemplo, é definida, e a sua matriz $P M_{y}$ possui duas chaves repetidas, isto é, duas chaves que retornaram ao seu estado anterior, na primeira configuração factível, então, estas duas chaves devem ser localizadas e excluídas de $P M_{y}$ e uma sequência factível de pares de chaves, sem a presença destas chaves repetidas, deve ser obtida para ser informada no plano de restabelecimento. Por exemplo, considere a configuração $G^{4}$ (configuração 4), do exemplo de aplicação do novo algoritmo para cálculo de número de manobras (Seção 5.2.2.1), ilustrada na Figura 5.5, bem como a sua matriz $\mathrm{PM}_{4}$, mostrada na Tabela 5.13.

Tabela 5.13: Conjunto de pares de chaves alteradas de $G^{4}$.

\begin{tabular}{|c|c|}
\hline \multicolumn{2}{|c|}{$\mathbf{P M}_{4}$} \\
\hline $\mathbf{A}$ & $\mathbf{F}$ \\
\hline \hline$\underline{\mathbf{1 7}}$ & $\underline{\mathbf{2 0}}$ \\
\hline 22 & 24 \\
\hline$\underline{\mathbf{2 0}}$ & $\underline{\mathbf{1 7}}$ \\
\hline
\end{tabular}


Observe na primeira e na terceira linha de $P M_{4}$ que as chaves 17 e 20 aparecem repetidas nessa matriz. Em outras palavras, durante a obtenção de $G^{4}$, as chaves 17 e 20 foram alteradas na primeira configuração factível para dar origem a uma segunda configuração. Mas, posteriormente, para a obtenção $G^{4}$, estas duas chaves foram novamente alteradas, dessa vez na configuração $G^{3}$, desfazendo assim a primeira alteração e voltando ao estado que possuíam na primeira configuração factível. Logo, para que estas manobras que se cancelam não sejam efetuadas na implantação da solução final, ambas as chaves devem ser excluídas de $P M_{4}$. Desse modo, obter-se-á uma nova matriz $P M_{4}$, chamada $P M_{4}^{1}$, conforme mostrada na Tabela 5.14.

Tabela 5.14: Conjunto de pares de chaves alteradas de $G^{4}$, atualizado pela exclusão das chaves 17 e 20 .

\begin{tabular}{|c|c|}
\hline \multicolumn{2}{|c|}{$\mathbf{P M}_{4}^{1}$} \\
\hline $\mathbf{A}$ & $\mathbf{F}$ \\
\hline \hline \hline & \\
\hline 22 & 24 \\
\hline & \\
\hline
\end{tabular}

Apesar de não ter havido a formação de um par rearranjado neste exemplo, não é possível afirmar que essa sequência de chaveamento presente em $P M_{4}^{1}$ (Tabela 5.14) é factível. Pois, quando o par $[22,24]$ foi obtido pela aplicação de um dos operadores da RNP, a configuração tomada como base para aplicação de $[22,24]$ foi a aquela resultante da aplicação do par $[17,20]$ na primeira configuração factível. Mas, nesta nova sequência, após a exclusão do par [17, 20], o par [22, 24] será aplicado diretamente na primeira configuração factível. Por isso, para assegurar que esta ação gerará uma configuração factível, é necessário simular a aplicação de [22, 24] e verificar se a mudança ocorrida é correspondente a aplicação de um dos operadores da RNP.

Ao aplicar o par $[22,24]$ diretamente na primeira configuração factível obter-se-á para a rede aquela configuração ilustrada pela Figura 5.10. Comparando esta figura com a Figura 5.7, na qual é reproduzida a primeira configuração factível, pode-se observar que a aplicação do par $[22,24]$ foi responsável pela transferência do setor 11 do alimentador 5 para o alimentador 8. Assim, como a árvore origem (alimentador 5), na qual a subárvore transferida (formada pelo nó 11) foi podada, é diferente da árvore destino (alimentador 8) e o nó no qual esta subárvore foi podada (nó 11) é o mesmo por meio do qual a mesma foi inserida na árvores destino, então, pode-se afirmar que esta mudança na topologia da rede é equivalente a aplicação do PAO. Consequentemente, pode-se concluir que a nova configuração obtida, ilustrada na Figura 5.10, é factível. Ademais, note que a configuração obtida é exatamente igual a $G^{4}$, apresentada na Figura 5.5, o que comprova outra vez que a configuração obtida pela aplicação da sequência presente em $P M_{5}^{1}$ é factível; e também 
que a aplicação das chaves presentes em $P M_{5}^{1}$ resulta na mesma configuração que seria obtida se $P M_{5}$, com a presença das chaves repetidas, fosse aplicada.

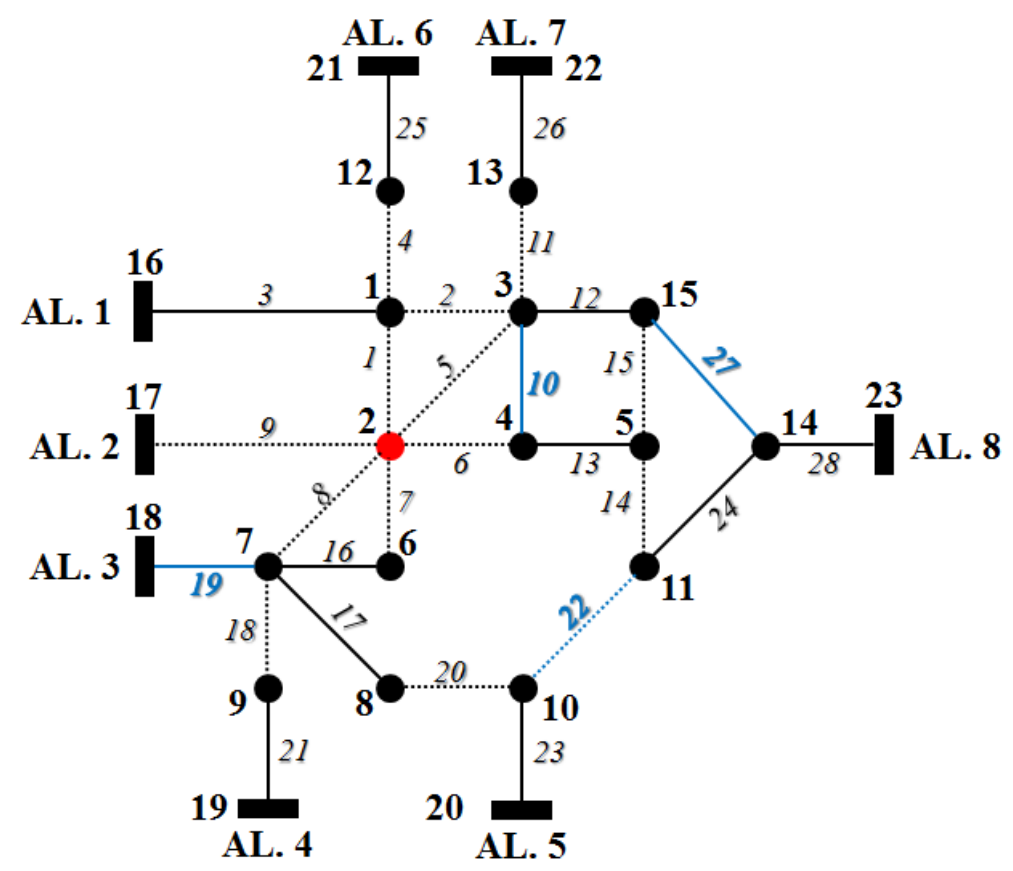

Figura 5.10: Configuração da rede obtida pela aplicação da sequência de chaveamento presente em $P M_{5}^{1}$.

Vale destacar que existem situações em que duas chaves voltam ao seu estado anterior mas que, diferentemente deste exemplo apresentado, há a formação de um par rearranjando. Neste casos, o número de sequências que serão consideradas pelo AEMT++ para terem a sua factibilidade testado é três. Por exemplo, considere os pares de chaves alteradas apresentados na Tabela 5.15 para uma configuração $15\left(G^{15}\right)$, qualquer.

Tabela 5.15: Conjunto de pares de chaves alteradas de $G^{15}$.

\begin{tabular}{|c|c|}
\hline \multicolumn{2}{|c|}{$\mathbf{P M}_{15}$} \\
\hline $\mathbf{A}$ & $\mathbf{F}$ \\
\hline \hline 17 & 20 \\
\hline$\underline{\mathbf{3}}$ & 4 \\
\hline 13 & 14 \\
\hline 25 & $\underline{\mathbf{2}}$ \\
\hline 21 & 18 \\
\hline$\underline{\mathbf{2}}$ & $\underline{\mathbf{3}}$ \\
\hline
\end{tabular}

Perceba que as chaves 2 e 3 ao serem alteradas para obtenção de $G^{15}$ retornaram ao seu estado anterior. Todavia, estas haviam sido alteradas pela primeira vez em pares de manobras diferentes: a chave 2 no par de manobras da quarta linha de $P M_{15}$ e a chave 3 no par de manobras da segunda linha de $P M_{15}$. Assim, ao excluí-las, como mostrado 
em $P M_{15}^{0}$ pela Tabela 5.16, as chaves 25 e 4 ficarão isoladas e deverão ser unidas a fim de formarem um novo par de manobras, isto é, um par rearranjado: [25, 4]. Quando o número de chaves que retornaram ao seu estado anterior é dois e há a formação de um par rearranjado, três são as sequências de pares de manobras que terão a sua factibilidade verificada: a primeira é aquela presente em $P M_{15}^{1}$ e apresentada na Tabela 5.17, na qual o para rearranjado é inserido na primeira das três linhas nas quais haviam chaves repetidas; a segunda é a sequência presente em $P M_{15}^{2}$ e apresentada na Tabela 5.18, na qual o para rearranjado é inserido na segunda das três linhas nas quais haviam chaves repetidas; e a terceira é aquela presente em $P M_{15}^{3}$ e apresentada na Tabela 5.19, na qual o para rearranjado é inserido na terceira das três linhas nas quais haviam chaves repetidas. Obviamente outras sequências poderiam ser geradas com estes pares de manobras. Mas, o $\mathrm{AEMT}++$ considerará a verificação apenas dessas três sequências citadas, na ocorrência de duas chaves repetidas com formação de um par rearranjado. Mas, deve-se dizer que a segunda sequência somente será verificada se a primeira for testada e a sua factibilidade não for comprovada. Da mesma forma que a terceira sequência será analisada somente se a segunda for verificada e a sua factibilidade não for assegurada. Caso não seja possível obter nenhuma sequência de chaveamento factível, então, o AEMT++ informará no plano de restabelecimento aquela sequência sem a retirada das chaves repetidas, pelo motivo já informado anteriormente.

Tabela 5.16: Conjunto de pares de chaves alteradas de $G^{15}$, atualizado pela retiradas das chaves 2 e 3 .

\begin{tabular}{|c|c|}
\hline \multicolumn{2}{|c|}{$\mathbf{P M}_{15}^{0}$} \\
\hline $\mathbf{A}$ & $\mathbf{F}$ \\
\hline \hline 17 & 20 \\
\hline & $\mathbf{4}$ \\
\hline 13 & 14 \\
\hline $\mathbf{2 5}$ & \\
\hline 21 & 18 \\
\hline & \\
\hline
\end{tabular}

Esta é, por sinal, uma das limitações desse procedimento proposto para definição de uma sequência de chaveamento factível, pois, ao invés de retomar e informar a sequência que possui os pares de chaves repetidas, seria adequado analisar outras sequências de pares de chaves, formadas pela inserção do par rearranjado em outras linhas diferentes daquelas já testadas ou por combinações diferentes dos pares de manobras existentes. Isto se justifica pelo fato de que dentre estas outras sequências é possível que haja uma que seja factível. Da mesma maneira, quando é informada uma sequência de chaveamento factível não se pode afirmar que não existam outras sequências também factíveis. Contudo, apesar 
Tabela 5.17: Sequência de chaveamento na qual o par rearranjado [25, 4] encontra-se inserido na primeira das três linhas nas quais haviam chaves repetidas.

\begin{tabular}{|c|c|}
\hline \multicolumn{2}{|c|}{$\mathbf{P M}_{15}^{1}$} \\
\hline $\mathbf{A}$ & $\mathbf{F}$ \\
\hline \hline 17 & 20 \\
\hline $\mathbf{2 5}$ & $\mathbf{4}$ \\
\hline 13 & 14 \\
\hline & \\
\hline 21 & 18 \\
\hline & \\
\hline
\end{tabular}

Tabela 5.18: Sequência de chaveamento na qual o par rearranjado [25, 4] encontra-se inserido na segunda das três linhas nas quais haviam chaves repetidas.

\begin{tabular}{|c|c|}
\hline \multicolumn{2}{|c|}{$\mathbf{P M}_{15}^{2}$} \\
\hline $\mathbf{A}$ & $\mathbf{F}$ \\
\hline \hline 17 & 20 \\
\hline & \\
\hline 13 & 14 \\
\hline $\mathbf{2 5}$ & $\mathbf{4}$ \\
\hline 21 & 18 \\
\hline & \\
\hline
\end{tabular}

Tabela 5.19: Sequência de chaveamento na qual o par rearranjado [25, 4] encontra-se inserido na terceira das três linhas nas quais haviam chaves repetidas.

\begin{tabular}{|c|c|}
\hline \multicolumn{2}{|c|}{$\mathbf{P M}_{15}^{3}$} \\
\hline $\mathbf{A}$ & $\mathbf{F}$ \\
\hline \hline 17 & 20 \\
\hline & \\
\hline 13 & 14 \\
\hline & \\
\hline 21 & 18 \\
\hline $\mathbf{2 5}$ & $\mathbf{4}$ \\
\hline
\end{tabular}


desta limitação, durante o desenvolvimento deste procedimento pode-se perceber que são raríssimas as vezes em que nenhuma das três sequências testadas seja factível.

Outra limitação deste procedimento de definição de uma sequência de chaveamento factível é o fato de que o mesmo considera como referência, para comparação de estados de chaves, a primeira configuração factível obtida e não $G^{i}$ (configuração inicial). Em outras palavras, caso uma das chaves que foi fechada em $G^{i}$, na obtenção da primeira configuração factível, seja aberta, isto é, retorne ao seu estado em $G^{i}$, este procedimento não conseguirá identificá-la nem verificar a factibilidade de sequências com a sua exclusão. Isto decorre do fato de que a matriz que armazena os pares de chaves alteradas o faz somente para as chaves que são alteradas após a obtenção da primeira configuração factível, quando as manobras passam a ocorrer em pares.

Além disso, este procedimento não verifica para as configurações que a rede terá temporariamente, durante a execução da sequência de chaveamento, outras restrições do problema, como queda de tensão e carregamento da rede e de subestação. Porém, ao contrário da restrição de radialidade, isto é, de ausência de laços e de conexão entre alimentadores e/ou subestações, que é verificada pelo procedimento proposto, a inadequação a estas restrições citadas podem ser aceita por um curto período de tempo.

\subsection{Considerações Finais}

Neste capítulo foi apresentada a metodologia proposta nesta dissertação: o AEMT++. Esta metodologia possui como diferencial, em relação àquelas existentes na literatura, a capacidade de fornecer planos de restabelecimento de energia em situações de contingência em SDRs de grande porte, considerando a presença dos CEs e de CCRs, bem como a necessidade de se informar ao operador da rede uma sequência de chaveamento factível. Sequência esta que deverá ser seguida para implementar com segurança a configuração obtida para rede. Para isso, foi proposto e apresentado também um procedimento para determinação de uma solução final, isto é, da configuração que será informada no plano de restabelecimento. 
CAPÍTULO 5. METODOLOGIA PROPOSTA 


\subsection{Considerações Iniciais}

Neste capítulo serão apresentados os resultados experimentais obtidos pela metodologia proposta para diversas simulações computacionais. Estas foram realizadas no SDR real da cidade de São Carlos-SP (SDR-SC) em operação no ano de 1994, que é constituído por 3.860 barras, 532 setores, 631 chaves, 23 alimentadores e 3 subestações. A primeira subestação, chamada de Paraíso, é constituída por um único transformador de 25 MVA, enquanto que as demais, Bela Vista e São Carlos, possuem, cada uma, 2 transformadores também de 25 MVA. Todos estes dados foram representados computacionalmente sem simplificações por meio da utilização da RNP na codificação dos alimentadores e dos setores da rede. Para verificar a variação do desempenho do AEMT++ com o aumento do tamanho do SDR, foram realizadas simulações também em outros três SDRs, que correspondem ao SDR-SC aumentado em duas, quatro e oito vezes ${ }^{1}$.

Contudo, para estes quatro SDRs não se dispunha das informações relativas à quantidade e à localização dos CEs e das CCRs. Desse modo, foram criados dois pequenos programas para gerarem de forma artificial estes dados, e, assim, tornar possível a realização destas simulações. O primeiro destes programas auxiliares é responsável por especificar um conjunto de CCRs a partir das chaves existentes no SDR, através de um

\footnotetext{
${ }^{1}$ Maiores detalhes sobre o procedimento de obtenção destes SDRs a partir do SDR-SC podem ser obtidos em (Santos, 2009).
} 
procedimento que visa definir como CCR, prioritariamente aquelas chaves localizadas à montante dos setores com maior número de setores adjacentes, e por meio das quais há maiores fluxos de corrente em relação às demais chaves. Enquanto isso, o segundo programa, desenvolvido em parceria com o aluno de iniciação científica Douglas Henrique Pereira, tem a função de alocar de forma aleatória e fictícia CEs.

Deste modo foram definidos aproximadamente 5\% dos setores do SDR-SC para receberem $1 \mathrm{CE}$ cada. A partir disso, estes dados foram replicados em duas, quatro e oito vezes para os demais SDRs. Em relação às CCRs, foram selecionadas para cada SDR aproximadamente $7 \%$ das chaves para serem definidas como CCRs ${ }^{2}$. Assim, os quatros sistemas utilizados nos testes apresentam as seguintes características:

- Sistema 1 (SDR-SC) - 3.860 barras, 532 setores, 631 chaves (509 NF e 122 NA), das quais, 43 são CCRs e 588 são CCMs, 25 CEs (sendo um por setor), 23 alimentadores e 3 subestações;

- Sistema 2 - 7.720 barras, 1.064 setores, 1.275 chaves (1.018 NF e 257 NA), das quais, 86 são CCRs e 1.889 são CCMs, 50 CEs (sendo um por setor), 46 alimentadores e 6 subestações;

- Sistema 3 - 15.440 barras, 2.128 setores, 2.573 chaves (2.036 NF e 537 NA), das quais, 168 são CCRs e 2.405 são CCMs, 100 CEs (sendo um por setor), 92 alimentadores e 12 subestações;

- Sistema 4 - 30.880 barras, 4.256 setores, 5.158 chaves (4.072 NF e 1.086 NA), das quais, 337 são CCRs e 4.821 são CCMs, 200 CEs (sendo um por setor), 184 alimentadores e 24 subestações.

Para efetuar estas simulações foi utilizado um computador pessoal com processador I7 3,4GHZ, 32 Gigabytes de memória RAM e sistema operacional Linux Ubuntu versão 12.04. A metodologia foi desenvolvida em linguagem $\mathrm{C}$ e o compilador utilizado foi o GCC-4.7.

Com objetivo de analisar o comportamento do AEMT++ e a sua capacidade de fornecer planos adequados de restabelecimento de energia em situações de contingência distintas, foram realizadas simulações nos 4 SDRs descritos anteriormente considerando a ocorrência tanto de uma única falta quanto de múltiplas faltas simultâneas. Em todos estes testes foram utilizados os seguintes parâmetros de entrada:

- Número máximo de indivíduos gerados $\left(g_{\max }\right)=15.000$;

\footnotetext{
${ }^{2}$ Esse número foi adotado tendo como base a informação de uma rede real que possui aproximadamente $5 \%$ de CCRs.
} 
- Tamanho das subpopulações armazenadas em tabelas $\left(S_{P_{1}}, \ldots, P_{13}\right)=5$.

Os pesos $w_{x}, w_{s}$ e $w_{v}$, definidos na Seção 4.3 (página 33) e mantidos na metodologia proposta, foram definidos da seguinte forma:

$$
\begin{gathered}
w_{x}=\left\{\begin{array}{l}
100, \text { se } X(G)>1 \\
0, \text { caso contrário; }
\end{array}\right. \\
w_{b}=\left\{\begin{array}{l}
100, \text { se } B(G)>1 \\
0, \text { caso contrário } ;
\end{array}\right. \\
w_{v}=\left\{\begin{array}{l}
100, \text { se } V(G)>0,1 \\
0, \text { caso contrário. }
\end{array}\right.
\end{gathered}
$$

Com a finalidade de avaliar o desempenho da metodologia proposta, foram definidos quatros critérios para auxiliar na análise dos resultados experimentais obtida pelas simulações, a saber: ( $i$ ) capacidade de otimização, isto é, de alcançar os objetivos do problema considerando-se as suas restrições; (ii) capacidade de priorização de CCRs; (iii) capacidade de definição de uma sequência de chaveamento sem a presença de chaves que retornaram ao seu estado anterior; e $(i v)$ capacidade de priorização de fornecimento aos CEs. Será ilustrado também, ao final da Seção 6.2, a evolução das subpopulações armazenadas nas tabelas propostas.

É importante destacar que todos os resultados apresentados neste capítulo são relativos à solução final, determinada pelo AEMT++ ao término de seu processo evolutivo, segundo o procedimento descrito na Seção 5.4 .

\subsection{Simulações para Uma Única Falta}

Para avaliar a viabilidade da aplicação do AEMT++ em situações de contingência correspondentes a ocorrência de uma única falta em SDRs de grande porte, foram realizados 100 testes em cada um dos sistemas descritos anteriormente, totalizando 400 execuções da metodologia proposta. Em todos os sistemas de teste, foi considerada a existência de uma falta no setor 504, no alimentador 23, ilustrado na Figura 6.1 para o Sistema 1, responsável por retirar o fornecimento de energia às cargas de um alimentador inteiro (o alimentador 23).

Conforme descrito no Capítulo 5, o AEMT++ começa a sua execução por meio da determinação de uma primeira configuração factível para a rede, isto é, uma primeira configuração na qual os setores sem fornecimento já estão reconectados à rede e o setor 

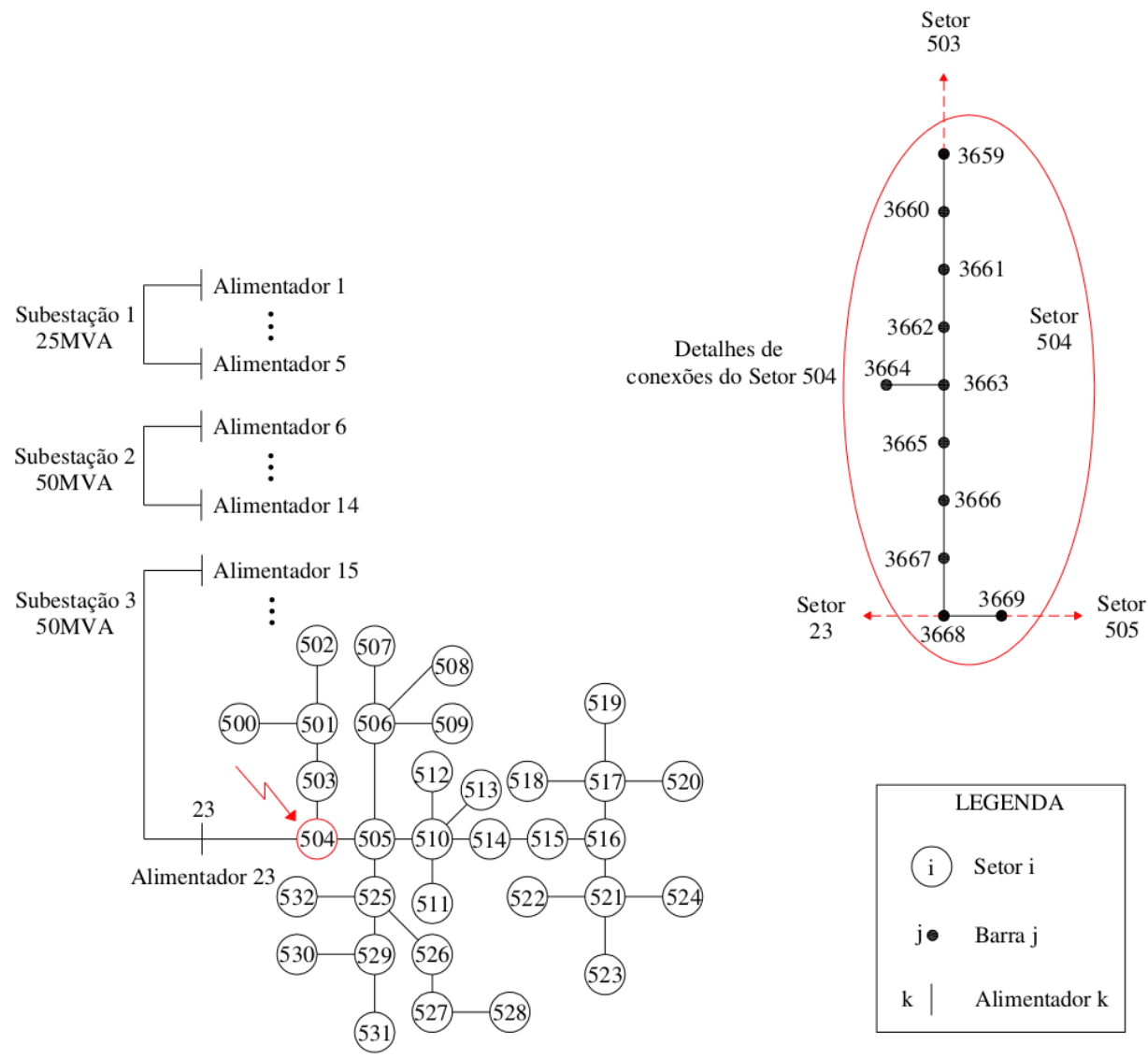

Figura 6.1: Alimentador 23 do Sistema 1, com destaque para o setor 504 sob falta (Santos, 2009).

em falta encontra-se isolado. Ao fazê-lo para os Sistemas 1, 2, 3 e 4, foram determinadas diversas configurações, cujas características estão resumidas e apresentadas na Tabela 6.1. Observe pelos valores médio e máximo, que, nos quatro sistemas, a primeira configuração factível determinada é, para a maioria das simulações executadas, imprópria para operação destes SDRs, pois possui carregamento superior ao que é suportado pela rede, a exceção de poucas configurações obtidas para os Sistemas 3 e 4, como pode ser visto na coluna de valores mínimos.

Perceba na Figura 6.1 que, ao isolar o setor sob falta, os setores fora de serviço estarão divididos em dois grandes grupos. O primeiro, que possui como nó raiz o setor 503, e o segundo, que tem como nó raiz o setor 505. Devido a quantidade e a localização das chaves NAs existentes nestes quatro SDRs sob testes, há uma única possibilidade de restabelecer o fornecimento de energia ao primeiro grupo de setores, isto é, por meio do fechamento da CCM NA existente entre os setores 501 e 449, e consequente conexão dos mesmos com o alimentador 22. Enquanto isso, para o segundo grupo de setores fora de serviço, há 6 chaves NAs que permitem reconectá-lo também ao alimentador 22 (somente a este), sendo todas do tipo CCM. Porém, para testar o procedimento proposto na Seção 5.2.1, 
para priorização de operação de CCRs na obtenção da primeira configuração factível, definiu-se como CCR, para os Sistemas 1 e 2, uma destas 6 chaves NA. No caso do Sistema 1 a chave escolhida para ser definida como CCR foi aquela entre os setores 514 e 491, e no Sistema 2, escolheu-se a chave entre 531 e 486. Em ambos os caso, estas CCRs permitirão reconectar o grupo de setores ao alimentador 22 e também restabelecer em um curto intervalo de tempo o CEs presente no setor 525 .

Tabela 6.1: Valores das restrições operacionais e perdas ôhmicas totais para a primeira configuração factível obtida para os Sistemas 1, 2, 3 e 4 considerando-se a ocorrência de uma única falta.

\begin{tabular}{|c|c|c|c|c|c|}
\hline & & Mínima & Médio & Máximo & $\overline{\overline{\mathrm{DP}^{*}}}$ \\
\hline \multirow{4}{*}{ Sistema 1} & Queda de Tensão (\%) & 4,8 & 4,8 & 4,8 & 0,0 \\
\hline & Carreg. da Rede (\%) & 139,6 & 139,6 & 139,6 & 0,0 \\
\hline & Carreg. de Subestação (\%) & 52,7 & 52,7 & 52,7 & 0,0 \\
\hline & Perdas Ôhmicas (kW) & 403,9 & 403,9 & 403,9 & 0,0 \\
\hline \multirow{4}{*}{ Sistema 2} & Queda de Tensão (\%) & 5,4 & 5,4 & 5,4 & 0,0 \\
\hline & Carreg. da Rede (\%) & 139,6 & 139,6 & 139,6 & 0,0 \\
\hline & Carreg. de Subestação (\%) & 53,3 & 53,3 & 53,3 & 0,0 \\
\hline & Perdas Ôhmicas (kW) & 690,5 & 690,5 & 690,5 & 0,0 \\
\hline \multirow{4}{*}{ Sistema 3} & Queda de Tensão (\%) & 4,1 & 5 & 5,5 & 0,4 \\
\hline & Carreg. da Rede (\%) & 80,6 & 129,6 & 139,6 & 22,3 \\
\hline & Carreg. de Subestação (\%) & 53,3 & 54,1 & 57,9 & 1,7 \\
\hline & Perdas Ôhmicas $(\mathrm{kW})$ & 1218,6 & 1243,1 & 1259,1 & 12,4 \\
\hline \multirow{4}{*}{ Sistema 4} & Queda de Tensão (\%) & 4,1 & 4,9 & 5,5 & 0,4 \\
\hline & Carreg. da Rede (\%) & 80,0 & 131,3 & 139,6 & 20,5 \\
\hline & Carreg. de Subestação (\%) & 53,3 & 54,0 & 57,9 & 1,6 \\
\hline & Perdas Ôhmicas (kW) & 2344,0 & 2370,3 & 2384,4 & 13,0 \\
\hline
\end{tabular}

* Desvio Padrão

Face ao exposto, perceba na Tabela 6.1 que, para os Sistemas 1 e 2, o desvio padrão é nulo. Isto significa, que em todas as 100 execuções do AEMT++ para estes dois sistemas foi obtida a mesma primeira configuração factível em ambos, o que pode ser comprovado também pela igualdade entre os valores mínimo, médio e máximo das restrições operacionais (queda máxima de tensão, carregamento máximo da rede e carregamento máximo de subestação) e das perdas ôhmicas totais, apresentadas. Na prática, isto quer dizer que em todas as execuções sempre as mesmas chaves NAs foram requisitadas para restabelecer as cargas fora de serviço, e, em todos os casos, as simulações provaram que uma destas chaves foi sempre a CCR inserida para reconectar o segundo grupo de setores, comprovando assim que, sempre que houver no mínimo uma CCR que permita reconectar as cargas fora de serviço o AEMT++ será capaz de encontrá-la e requerer a sua operação. 


\section{Avaliação da Capacidade de Otimização}

Ao final de cada execução da metodologia proposta, foi determinada uma única solução final, cujos valores das restrições operacionais e das perdas ôhmicas totais foram extraídas a fim de serem apresentadas de forma sucinta na Tabela 6.2, juntamente com o tempo de processamento. Ao comparar os valores de queda de tensão, de carregamento da rede, de carregamento de subestação e de perdas ôhmicas totais obtidos ao final das execuções do $\mathrm{AEMT}++$, com os valores dos mesmos parâmetros na primeira configuração factível, que marca o início do processo evolutivo (Tabela 6.1), percebe-se que a metodologia proposta foi capaz de minimizá-los, sem exceção. Considere também o tempo de processamento da metodologia proposta. Observe que, mesmo para o Sistema 4, que possui 30.880 barras, o AEMT++ é compatível com a exigência do problema de soluções em curto intervalo de tempo.

Tabela 6.2: Valores das restrições operacionais e das perdas ôhmicas totais para as soluções finais obtidas e tempo de processamento considerando-se a ocorrência de uma única falta nos Sistemas 1, 2, 3 e 4.

\begin{tabular}{l|l|cccc}
\hline \hline \multicolumn{1}{c}{} & Mínimo & Médio & Máximo & DP* \\
\hline \multirow{5}{*}{ Sistema 1 } & Queda de Tensão (\%) & 3,1 & 3,7 & 4,7 & 0,7 \\
& Carreg. da Rede (\%) & 62,2 & 75,0 & 99,5 & 8,5 \\
& Carreg. de Subestação (\%) & 47,1 & 52,9 & 59,0 & 3,1 \\
& Perdas Ôhmicas (kW) & 242,8 & 355,6 & 463,4 & 56,8 \\
& Tempo de Processamento (s) & 1,4 & 1,6 & 1,7 & 0,1 \\
\hline \multirow{5}{*}{ Sistema 2} & Queda de Tensão (\%) & 3,2 & 3,4 & 5,7 & 0,5 \\
& Carreg. da Rede (\%) & 62,2 & 73 & 98,7 & 9,2 \\
& Carreg. de Subestação (\%) & 52,6 & 53,4 & 55,0 & 0,3 \\
& Perdas Ôhmicas (kW) & 524,6 & 609,0 & 731,1 & 45,0 \\
& Tempo de Processamento (s) & 1,5 & 1,6 & 1,8 & 0,1 \\
\hline \multirow{5}{*}{ Sistema 33 3} & Queda de Tensão (\%) & 3,2 & 5,2 & 5,5 & 0,6 \\
& Carreg. da Rede (\%) & 67,1 & 80,2 & 90,2 & 1,1 \\
& Carreg. de Subestação (\%) & 53,3 & 57,5 & 57,8 & 1,1 \\
& Perdas Ôhmicas (kW) & 1088,9 & 1228,2 & 1298,9 & 35,7 \\
& Tempo de Processamento (s) & 1,6 & 1,8 & 1,9 & 0,1 \\
\hline \multirow{5}{*}{ Sistema 4} & Queda de Tensão (\%) & 3,2 & 5,2 & 5,5 & 0,7 \\
& Carreg. da Rede (\%) & 67,1 & 79,7 & 93,0 & 4,1 \\
& Carreg. de Subestação (\%) & 53,3 & 57,4 & 57,8 & 1,2 \\
& Perdas Ôhmicas (kW) & 2212,8 & 2348,2 & 2356,7 & 26,9 \\
& Tempo de Processamento (s) & 1,9 & 2,1 & 2,3 & 0,1 \\
\hline \hline
\end{tabular}

* Desvio Padrão

Conforme fora dito na Seção 1.2.2, além da reconexão das cargas sãs fora de serviço, da minimização das restrições operacionais e das perdas ôhmicas, assim como da 
determinação de uma solução em tempo real, o problema de restabelecimento de energia exige a minimização do número de manobras em chaves necessários para implantação da nova solução. Assim, é apresentada na Tabela 6.3, para os Sistemas 1, 2, 3 e 4, o número mínimo, médio e máximo de manobras em CCRs e em CCMs das soluções finais obtidas pelo AEMT++. Perceba que, apesar de em alguns casos terem sido alteradas até 20 ou 24 chaves no total, em média, para os Sistemas 1 e 2, o número total de manobras em chaves manteve-se em torno de 12 operações. No caso dos Sistemas 3 e 4, estes valores foram ainda menores: 2,7 e 2,8, respectivamente. Observe também que em todas as soluções finais determinadas para os Sistemas 2 e 3 havia no mínimo uma CCR presente.

Tabela 6.3: Número de manobras em chaves obtidas pelo AEMT++ para a solução final considerando-se a ocorrência de uma única falta nos Sistemas 1, 2, 3 e 4.

\begin{tabular}{|c|c|c|c|c|c|}
\hline & & $\overline{\text { Mínimo }}$ & Médio & $\overline{\overline{\text { Máximo }}}$ & $\overline{\overline{\mathrm{DP}^{*}}}$ \\
\hline \multirow{3}{*}{ Sistema 1} & Manobras em CCRs & 0 & 1,6 & 4 & 0,6 \\
\hline & Manobras em CCMs & 3 & 9,8 & 19 & 4,2 \\
\hline & Manobras Totais & 4 & 11,4 & 20 & 4,2 \\
\hline \multirow{3}{*}{ Sistema 2} & Manobras em CCRs & 1 & 2,2 & 4 & $\overline{0,7}$ \\
\hline & Manobras em CCMs & 3 & 10,1 & 21 & 4,3 \\
\hline & Manobras Totais & 6 & 12,4 & 24 & 4,7 \\
\hline \multirow{3}{*}{ Sistema 3} & Manobras em CCRs & 1 & 1,3 & 4 & 0,7 \\
\hline & Manobras em CCMs & 1 & 1,4 & 14 & 1,6 \\
\hline & Manobras Totais & 2 & 2,7 & 18 & 2,0 \\
\hline \multirow{3}{*}{ Sistema 4} & Manobras em CCRs & 0 & 0,1 & 1 & $\overline{0,3}$ \\
\hline & Manobras em CCMs & 2 & 2,8 & 17 & 2,4 \\
\hline & Manobras Totais & 2 & 2,8 & 18 & 2,6 \\
\hline
\end{tabular}

Com base nestes primeiros resultados apresentados, pode-se concluir que a metodologia proposta obteve um desempenho satisfatório no critério relativo à capacidade de otimização dos objetivos do problema, obtendo, inclusive, diversas soluções viáveis para implementação. Deve-se ressaltar ainda que a qualidade das soluções finais obtidas reflete não apenas a capacidade de minimização do $\mathrm{AEMT}++$, mas também que o procedimento de definição de uma solução final, proposto na Seção 5.4, foi capaz de alcançar o seu objetivo de selecionar e informar uma boa solução para o problema, dentre todas as soluções armazenadas nas tabelas ao final do processo evolutivo.

\section{Avaliação da Capacidade de Priorização de Manobras em CCRs}

Para avaliar a capacidade da metodologia proposta em priorizar a operação de CCRs, foi determinada a razão entre o número de manobras em CCRs e o número total de manobras em chaves para a solução final de cada simulação realizada nos Sistemas 1, 2, 3 e 4, isto é, a 
porcentagem de CCRs presente no plano de restabelecimento obtido em cada simulação. Assim, quanto maior for esta razão, poder-se-á afirmar que maior é a capacidade do AEMT ++ em priorizar manobras em CCRs. A Tabela 6.4 mostra resumidamente estes dados por meio da apresentação dos valores mínimo, médios e máximos, e do desvio padrão, da porcentagem de CCRs na solução final.

Sabendo que o número percentual de CCRs existentes em cada um destes quatro sistemas é relativamente baixo, de aproximadamente $7 \%$, pode observar que o desempenho da metodologia proposta foi considerada satisfatória para três dos quatros sistemas analisados. Tanto para os Sistemas 1 quanto para o Sistema 2 as soluções obtidas possuem em média mais de 15\% de manobras em CCRs. No caso do Sistema 3 o desempenho foi melhor ainda, ao passo que soluções obtidas possuíam em média 50,5\% de de CCRs e no mínimo $22,2 \%$ desse tipo de chave no plano final de restabelecimento. Contudo, para o Sistema 4 este desempenho caiu vertiginosamente, uma vez que, em média, apenas 1,1\% de CCRs foi obtido.

Tabela 6.4: Percentual de manobras em CCRs presentes na solução final, em relação ao número total de manobras em chaves.

\begin{tabular}{l|l|c}
\hline \hline & Mínimo & $0,0 \%$ \\
Sistema 1 & Médio & $15,3 \%$ \\
& Máximo & $25,0 \%$ \\
& DP* & 6,7 \\
\hline \multirow{4}{*}{ Sistema 2 } & Mínimo & $10,0 \%$ \\
& Médio & $19,2 \%$ \\
& Máximo & $50,0 \%$ \\
& DP* & 7,1 \\
\hline \multirow{5}{*}{ Sistema 3 3} & Mínimo & $22,2 \%$ \\
& Médio & $50,5 \%$ \\
& Máximo & $75,0 \%$ \\
& DP* & 9,5 \\
\hline \multirow{3}{*}{ Sistema 4 4} & Mínimo & $0,0 \%$ \\
& Médio & $1,1 \%$ \\
& Máximo & $25,0 \%$ \\
& DP* & 4,4 \\
\hline \hline
\end{tabular}

Para complementar esta avaliação, considere o gráfico apresentado na Figura 6.2. Ele mostra o número percentual de vezes em que o percentual de CCRs presentes na solução final, determinada como descrito anteriormente, foi superior a 15\%, isto é, pouco maior que o dobro de CCRs existentes nos quatro SDRs simulados. Esta análise também é importante porque ela relaciona a razão de CCRs selecionadas para operação com a quantidade existente deste tipo de chave. 
Veja na Figura 6.2 que, para os Sistemas 1 e 2, em mais de $50 \%$ das simulações o plano de restabelecimento obtido possuía número de operações em CCRs em quantidade percentual superior ao dobro da quantidade percentual de CCRs existente. Já no Sistema 3, em $100 \%$ das simulações realizadas o plano obtido possuía mais de $15 \%$ de CCRs, confirmando os dados apresentados pela Tabela 6.4. Enquanto isso, veja que, para o Sistema 4, o desempenho do AEMT++ não foi adequado.

Contudo, deve-se observar que a capacidade de uma metodologia qualquer em priorizar operações em CCRs pode ser influenciada pela localização destas chaves e também da falta no SDR. Isto ocorre porque, quando os setores sãos fora de serviço são reconectados à rede, normalmente apenas os alimentadores que receberam estas cargas ficam com sobrecargas ou perfis de tensão inadequados. Assim, para não realizar manobras em excesso, a ação de transferência de cargas para adequação das restrições operacionais deve ser focada na região com sobrecargas ou subtensões. No caso da metodologia proposta, esta função é desempenhada pela heurística proposta por Sanches (2013) e inserida ao AEMT++, apresentada na Seção 4.5. Todavia, quando as ações de transferência de cargas priorizam as regiões mais críticas dos SDR pode ocorrer que nestas regiões não haja CCRs ou haja em número muitíssimo baixo, dificultando, portanto, a priorização de operação nestas chaves.

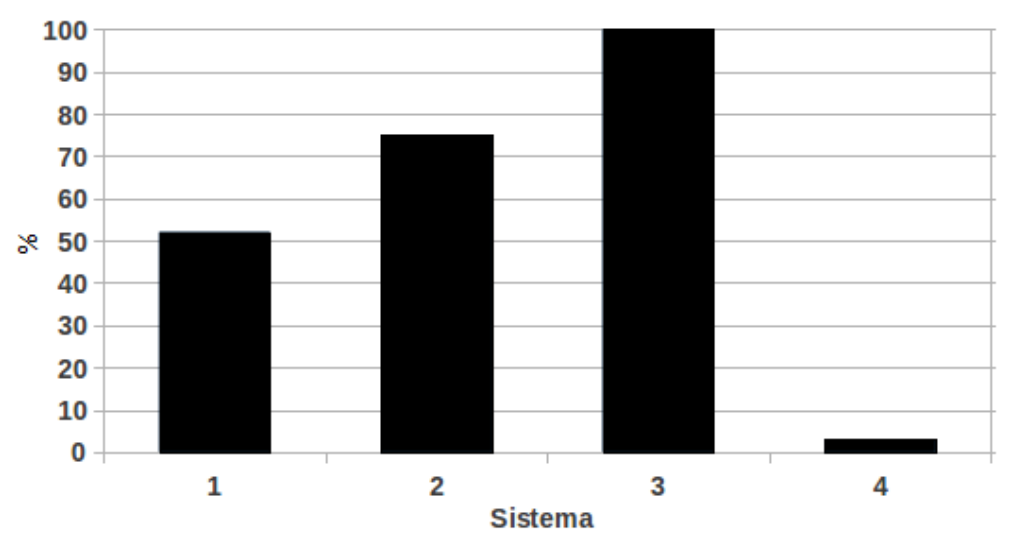

Figura 6.2: Número percentual de vezes em que o percentual de manobras em CCRs da solução final, em relação ao número total de manobras em chaves, foi igual ou superior a $15 \%$ (aproximadamente o dobro da quantidade percentual de CCRs existentes nos Sistemas 1, 2, 3 e 4).

Além disso, deve-se recordar que, para estas simulações, não se dispunha de nenhuma informação relativa à localização das CCRs nos SDRs sob teste, e que os critérios utilizados neste trabalho para esta definição não são exatamente aqueles utilizados pela empresas de distribuição na alocação deste tipo de chave. Assim, em redes reais é possível mapear os locais nos quais ocorrem faltas com maior frequência e instalar CCRs nestas regiões, minimizando a limitação descrita no parágrafo anterior. 
Face ao exposto, pode-se concluir que o AEMT++ possui capacidade para priorizar a operação de CCRs, mesmo quando o número percentual destas chaves não é tão grande quanto em redes em processo para automação do restabelecimento, nas quais a quantidade deste tipo de chave costuma ser bem superior a 7\%. Além disso, que esta capacidade é demonstrada tanto pela quantidade de CCRs presentes em cada solução final obtida, quanto pelo número de soluções finais que possuem quantidade satisfatória de CCRs. Porém, pôde ser visto também que esta capacidade pode ser influenciada pela localização das CCRs e também da falta.

\section{Avaliação da Capacidade de Definição de uma Sequência de Chaveamento Factível sem a Presença de Chaves Repetidas}

Conforme provado na Seção 5.5, toda sequência de chaveamento fornecida pelo AEMT++ em um plano de restabelecimento é comprovadamente factível, uma vez que, antes de ser disponibilizada, toda sequência de pares de chaves é analisada a fim de certificar que é correspondente à uma aplicação sequencial dos operadores da RNP. Além disso, como fora dito também na Seção 5.5, dado um conjunto de pares de manobras, o AEMT++ analisará a factibilidade somente de algumas sequências possíveis se obter com o conjunto de pares de manobras: $(i)$ no caso em que apenas uma das chaves retornou ao seu estado anterior, duas são as sequências verificadas; (ii) quando duas chaves retornam ao seu estado anterior e há formação de um par rearranjado, o número de sequências analisadas é três; e (iii) quando duas chaves retornam ao seu estado anterior e não há formação de um par rearranjado, então, uma única sequência é verificada. Caso, nenhuma destas sequências verificadas seja factível, logo, a metodologia proposta informará a sequência sem a retiradas das chaves repetidas, isto é, das chaves que retornaram ao seu estado na primeira configuração factível.

Sabendo que todas as sequências de chaves disponibilizadas pelo AEMT++ são factíveis, analisar-se-á, por meio da simulações computacionais realizadas, não a capacidade da metodologia proposta em definir sequências de chaveamento factíveis, mas a sua aptidão em definir uma sequência sem a presença de chaves repetidas. Em outras palavras, verificar-se-á a capacidade do AEMT++ em fornecer sequências de chaveamento quando somente algumas das sequências possíveis de serem definidas com um conjunto de pares de manobras são analisadas.

Para tal, foi determinado, para todas as simulações realizadas nos quatro sistemas de teste, o número total de chaves repetidas informadas no plano de restabelecimento disponibilizado. E, com base nestas informações, foi construído o gráfico ilustrado na Figura 6.3. Este gráfico apresenta a varição, em função do sistema simulado, do número 
percentual de vezes que o AEMT++ informou uma sequência de chaveamento na qual todas as chaves repetidas foram excluídas. Como pode ser visto, independentemente do tamanho do sistema simulado, em mais de $75 \%$ dos planos de restabelecimento disponibilizados a sequência de chaveamento informada foi de boa qualidade, isto é, não exigiu nenhuma manobra na mesma chave. Além disso, deve-se destacar que, para os três primeiros sistemas simulados, esta capacidade demonstrou-se diretamente proporcional ao tamanho da rede, ao passo que para o Sistema 3, 100\% das sequências disponibilizadas não possuía chaves repetidas, conforme ilustrado pelo gráfico da Figura 6.3. Por outro lado, pode-se observar que para o Sistema 4, este desempenho começou a diminuir.

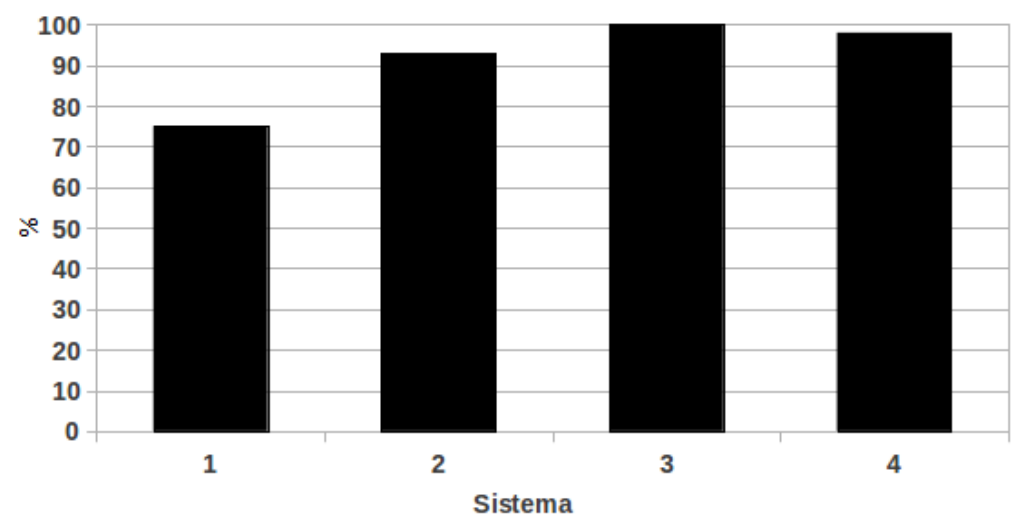

Figura 6.3: Número percentual de vezes em que foi definida uma sequência de chaveamento sem a presença de chaves que retornaram ao seu estado anterior, considerando-se a ocorrência de uma única falta.

Com base nestes resultados, pode-se concluir que, mesmo não verificando a factibilidade de todas as sequências de chaveamento possíveis de serem obtidas com um conjunto de pares de manobras, a metodologia proposta obteve um ótimo rendimento ao ser capaz de determinar, em média para os quatros SDRs simulados, mais de $90 \%$ de planos de restabelecimento sem a presença de chaves repetidas. Além disso, é importante ressaltar que, para as 400 simulações realizadas com estes quatro SDRs, o maior número de chaves repetidas disponibilizadas foi 7 , tendo ocorrido uma única vez.

\section{Avaliação da Capacidade de Priorização de Fornecimento aos CEs}

Para analisar a capacidade da metodologia proposta em priorizar o fornecimento de energia aos CEs na ocorrência de uma única falta, considere as informações apresentadas na Tabela 6.5 e no gráfico da Figura 6.4. A Tabela 6.5 informa o número de CEs localizados à jusante do setor 504 sob falta e que, por isso, tiveram o seu fornecimento de energia interrompidos; assim como, mostra também os valores mínimo, médio e máximo, e de 
desvio padrão, do número de CEs transferidos após a reconexão das todas as cargas sãs fora de serviço nas 100 simulações realizadas para cada sistema de teste.

Tabela 6.5: Número de CEs desligados pela ocorrência da falta e de CEs transferidos para implementação das soluções finais obtidas para os Sistemas 1, 2, 3 e 4 na ocorrência de uma única falta.

\begin{tabular}{|c|c|c|c|c|c|}
\hline & & Mínimo & Médio & Máximo & $\mathrm{DP}^{*}$ \\
\hline \multirow{2}{*}{ Sistema 1} & Desligados & 4 & 4,0 & 4 & 0,0 \\
\hline & Transferidos & 0 & 4,7 & 6 & 2,3 \\
\hline \multirow{2}{*}{ Sistema 2} & Desligados & 4 & 4,0 & 4 & 0,0 \\
\hline & Transferidos & 0 & 2,5 & 6 & 1,5 \\
\hline \multirow{2}{*}{ Sistema 3} & Desligados & 4 & 4,0 & 4 & 0,0 \\
\hline & Transferidos & 0 & 5,6 & 6 & 1,2 \\
\hline \multirow{2}{*}{ Sistema 4} & Desligados & 4 & 4,0 & 4 & 0,0 \\
\hline & Transferidos & 0 & 3,4 & 4 & 1,0 \\
\hline
\end{tabular}

* Desvio Padrão

Perceba nesta tabela, na coluna de valores máximo, que em todas as 400 simulações realizadas não foi exigida a transferência de um número maior do que 6 CEs. Considerando que idealmente nenhum CE deve ser transferido após a reconexão das cargas e dos CEs fora de serviço, este número não é considerado bom. Contudo, deve ser observado que, em alguns sistemas, como é o caso destes quatro, o número de chaves disponíveis para transferência de cargas e correção de sobrecargas e tensões inadequadas, pode ser tal baixo que dificulte muito ao AE obter soluções que possibilitem a retiradas de cargas de um alimentador sobrecarregado sem que haja a transferência de alguns CEs existentes. Nos casos em que, entre não transferir CEs e deixar inadequado os valores de carregamento e/ou tensão, e transferir CEs e corrigir as sobrecargas e/ou perfis de tensão ruins o AEMT ++ optará pela segunda opção. Obviamente, a transferência de CEs é influenciada também pela localização destes consumidores e da falta ocorrida.

Para auxiliar na avaliação da metodologia proposta em relação ao critério em questão, considere também o gráfico ilustrado pela Figura 6.4. Ele apresenta o número percentual de vezes em que a solução final determinada pelo AEMT++ não exigiu a transferência de nenhum CEs. Como pode ser visto, para o Sistema 1, somente $30 \%$ dos planos de restabelecimento obtidos para este sistema não exigia a transferência de CEs. Isso acena para uma pequena inconsistência da metodologia proposta, pois, se em algumas das simulações para este sistema foi possível obter soluções sem CEs transferidos, é porque havia esta possibilidade. E se esta possibilidade existia, era de se esperar que a metodologia proposta tivesse obtido-a em um número maior vezes. Contudo, observe que para os sistemas maiores, no caso os Sistemas 3 e 4, mais de $95 \%$ dos planos de restabelecimento determinados não exigia que CEs fossem transferidos. Isso demostra 
que, apesar da limitação descrita anteriormente, a metodologia proposta é, de uma forma geral, capaz de priorizar o fornecimento de energia aos CEs em SDR de grande porte. É importante destacar que, apesar de no caso Sistema 1 ter havido a transferência de CEs na maioria dos planos obtidos, o número de CEs definidos para estes sistemas de teste ( $5 \%$ do número total de setores, sendo um CE por setor) é relativamente grande em comparação com a quantidade destes consumidores em SDRs reais. Existem SDRs reais de grande porte em que o número de CEs existentes não é superior a $1 \%$ do número de setores.

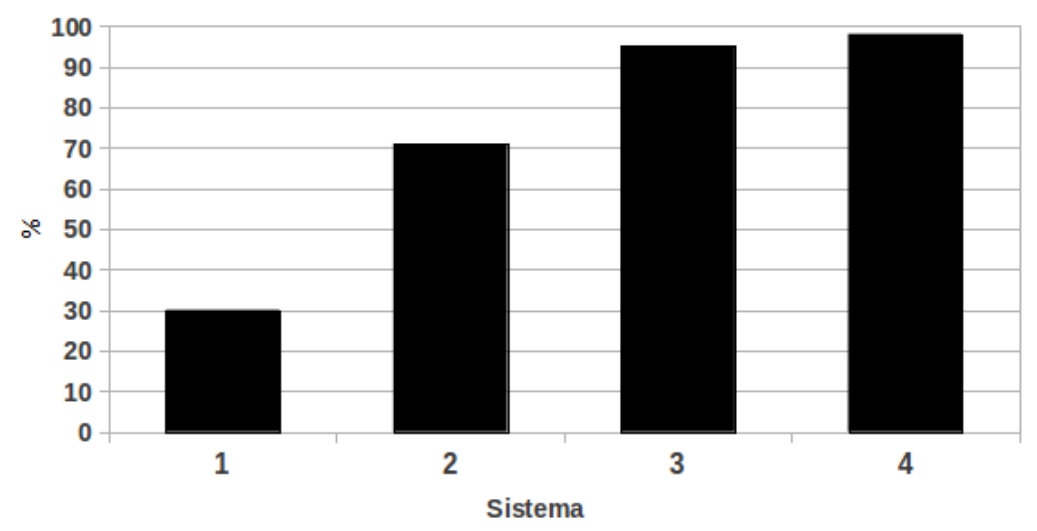

Figura 6.4: Número percentual de vezes em que a solução final definida não exigiu a transferência de CEs, considerando-se a ocorrência de uma única falta nos Sistemas 1, 2, 3 e 4 .

\subsection{Simulações para Múltiplas Faltas}

Com a finalidade de avaliar o comportamento da metodologia proposta para o problema de restabelecimento de energia na ocorrência de várias faltas simultâneas, diversas simulações computacionais foram realizadas nos Sistemas 1, 2, 3 e 4. Para tal, foi considerada a ocorrência, concomitantemente, de uma falta em três setores diferentes destes SDRs. O primeiro deles é o próprio setor 504, pertencente ao $23^{\circ}$ alimentador de cada sistema de testes e mostrado na Figura 6.1 para o Sistema 1. Os outros dois são o setor 464, pertencente ao alimentador 22, e o setor 189, suprido pelo alimentador 6. As Figuras 6.5 e 6.6, ilustram estes dois últimos setores na configuração pré-falta do Sistema 1.

Para a obtenção dos resultados experimentais e avaliação do desempenho do AEMT++ na ocorrência de múltiplas faltas, 100 simulações foram realizadas em cada um dos quatro sistemas de testes, totalizando 400 execuções da metodologia proposta. Também neste caso de ocorrência de múltiplas faltas simultâneas, o desempenho da metodologia proposta será avaliado com base nos quatro critérios definidos na Seção 6.1 e já explorados anteriormente para o caso de ocorrência de uma única falta. 


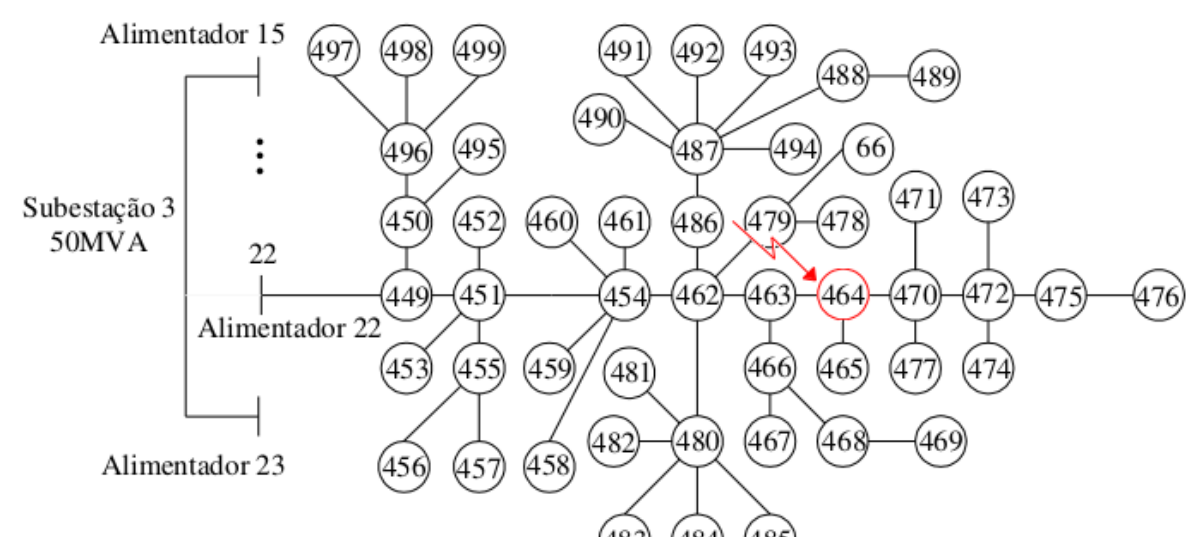

(483) (484) (485)

Figura 6.5: Alimentador 22 do Sistema 1, com destaque para o setor 464 sob falta (Modificado de Santos (2009)).

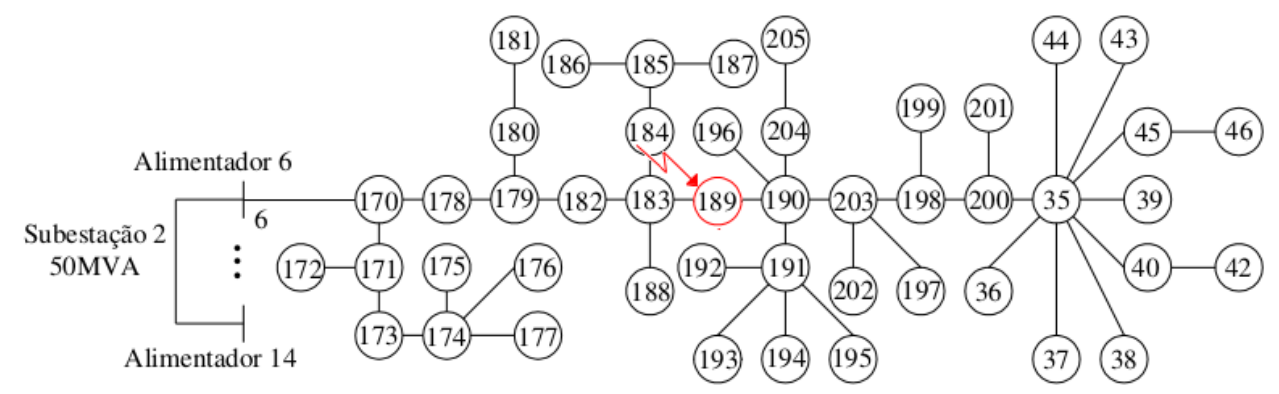

Figura 6.6: Alimentador 6 do Sistema 1, com destaque para o setor 189 sob falta (Modificado de Santos (2009)).

Inicialmente, considere os dados apresentados pela Tabela 6.6. Eles dizem respeito às restrições operacionais e as perdas ôhmicas totais da primeira configuração factível obtida pelo AEMT++ para cada um dos quatro sistemas simulados. Observe que, tanto para os Sistemas 1 e 2, quanto para os Sistemas 3 e 4, para a maioria das simulações, esta primeira configuração é infactível, devido à sobrecargas na rede. Contudo, veja também na coluna de valores mínimos que, em algumas das simulações realizadas nos Sistemas 3 e 4, esta primeira configuração factível obtida já era um configuração que atendia as restrições operacionais, isto é, uma solução factível, e que por isso permitiria o SDR operar de forma segura.

É importante destacar que todas as vezes em que a primeira configuração factível obtida era uma solução factível, esta fora selecionada pelo AEMT++ como a solução final a ser fornecida no plano de restabelecimento. Isto comprova a habilidade do procedimento existente na metodologia proposta para definição de uma solução final (ver Seção 5.4), uma vez que toda primeira configuração factível, se for também uma solução factível, não exigirá nenhuma manobra para transferência de cargas, apenas aquelas para reconectar os setores sãos fora de serviço, o que concorre também para que nenhum CE seja transferido. 
Tabela 6.6: Valores das restrições operacionais e das perdas ôhmicas totais para a primeira configuração factível obtida para os Sistemas 1, 2, 3 e 4 considerando-se a ocorrência de múltiplas faltas simultâneas.

\begin{tabular}{l|l|cccc}
\hline \hline \multicolumn{1}{c}{} & \multicolumn{1}{c}{ Mínimo } & Médio & Máximo & DP* \\
\hline \multirow{5}{*}{ Sistema 1 } & Queda de Tensão (\%) & 4,5 & 4,5 & 4,5 & 0,0 \\
& Carreg. da Rede (\%) & 120,1 & 120,1 & 120,1 & 0,0 \\
& Carreg. de Subestação (\%) & 52,6 & 52,8 & 52,85 & 0,1 \\
& Perdas Ôhmicas (kW) & 408,9 & 409,5 & 409,7 & 0,3 \\
\hline \multirow{5}{*}{ Sistema } & Queda de Tensão (\%) & 5,1 & 5,1 & 5,1 & 0,0 \\
& Carreg. da Rede (\%) & 120,1 & 120,1 & 120,1 & 0,0 \\
& Carreg. de Subestação (\%) & 53,3 & 53,3 & 53,3 & 0,0 \\
& Perdas Ôhmicas (kW) & 710,5 & 710,5 & 710,5 & 0,0 \\
\hline \multirow{5}{*}{ Sistema 3 3} & Queda de Tensão (\%) & 3,8 & 4,7 & 5,5 & 0,5 \\
& Carreg. da Rede (\%) & 80,6 & 114,8 & 120,1 & 12,9 \\
& Carreg. de Subestação (\%) & 53,3 & 54,5 & 57,9 & 0,5 \\
& Perdas Ôhmicas (kW) & 1204,9 & 1254,0 & 1285,5 & 16,8 \\
\hline \multirow{5}{*}{ Sistema 4 4} & Queda de Tensão (\%) & 3,8 & 4,7 & 5,5 & 0,5 \\
& Carreg. da Rede (\%) & 80,6 & 115,8 & 120,1 & 11,4 \\
& Carreg. de Subestação (\%) & 53,3 & 54,4 & 57,9 & 1,5 \\
& Perdas Ôhmicas (kW) & 2330,2 & 2379,2 & 2410,7 & 16,8 \\
\hline \hline
\end{tabular}

* Desvio Padrão

\section{Avaliação da Capacidade de Otimização}

Conforme mencionado anteriormente, ao término de cada execução da metodologia proposta, é definida uma solução final a ser apresentada em um plano de restabelecimento. E, para cada simulação computacional em cada um dos quatro sistemas de teste foram extraídos os valores das restrições operacionais e das perdas ôhmicas totais destas soluções finais, que são apresentados sucintamente na Tabela 6.7, juntamente com o tempo de processamento para cada sistema simulado.

Comparando os valores apresentados nesta tabela com aqueles mostrados pela Tabela 6.6 pode-se comprovar, também para situações de múltiplas faltas simultâneas, a capacidade da metodologia proposta em minimizar as restrições operacionais e as quedas de tensão. Por meio da Tabela 6.7 pode observar ainda a compatibilidade do tempo de processamento da metodologia proposta com a necessidade do problema de soluções em tempo real.

Além disso, outra exigência do problema de restabelecimento, conforme mencionado na Seção 1.2.2, é a de minimização do número de manobras em chaves da solução final. Desse modo, considere Tabela 6.8. Nela são mostrados os valores mínimos, médios e máximos do número de manobras em CCRs e em CCM para as simulações nos quatros sistemas de teste. Como pode ser visto, nesse objetivo, a metodologia proposta obteve 
Tabela 6.7: Valores das restrições operacionais e das perdas ôhmicas totais para as soluções finais obtidas e tempo de processamento considerando-se a ocorrência de múltiplas faltas simultâneas nos Sistemas 1, 2, 3 e 4.

\begin{tabular}{l|l|cccc}
\hline \hline \multicolumn{1}{l|}{} & Mínimo & Médio & Máximo & DP* \\
\hline \multirow{5}{*}{ Sistema 1 } & Queda de Tensão (\%) & 3,2 & 3,9 & 4,7 & 4,1 \\
& Carreg. da Rede (\%) & 63,8 & 76,9 & 95,4 & 6,6 \\
& Carreg. de Subestação (\%) & 50,7 & 59,5 & 63,3 & 4,1 \\
& Perdas Ôhmicas (kW) & 268,3 & 374,2 & 446,9 & 54,8 \\
& Tempo de Processamento (s) & 1,5 & 1,6 & 1,8 & 0,1 \\
\hline \multirow{5}{*}{ Sistema 2} & Queda de Tensão (\%) & 3,2 & 3,4 & 4,7 & 0,3 \\
& Carreg. da Rede (\%) & 77,3 & 79,4 & 86,6 & 1,2 \\
& Carreg. de Subestação (\%) & 52,7 & 53,6 & 56,8 & 0,9 \\
& Perdas Ôhmicas (kW) & 572,6 & 635,7 & 719,9 & 44,2 \\
& Tempo de Processamento (s) & 1,4 & 1,6 & 1,7 & 0,1 \\
\hline \multirow{5}{*}{ Sistema 33 3} & Queda de Tensão (\%) & 3,2 & 5,3 & 5,7 & 0,5 \\
& Carreg. da Rede (\%) & 79,1 & 85,9 & 92,5 & 6,0 \\
& Carreg. de Subestação (\%) & 53,3 & 57,7 & 60,3 & 1,0 \\
& Perdas Ôhmicas (kW) & 1130,3 & 1247,2 & 1296,9 & 28,0 \\
& Tempo de Processamento (s) & 1,6 & 1,8 & 2,0 & 0,1 \\
\hline \multirow{5}{*}{ Sistema 4} & Queda de Tensão (\%) & 3,2 & 5,2 & 5,5 & 0,6 \\
& Carreg. da Rede (\%) & 79,1 & 85,4 & 99,1 & 6,1 \\
& Carreg. de Subestação (\%) & 53,3 & 57,7 & 62,9 & 1,2 \\
& Perdas Ôhmicas (kW) & 2248,5 & 2373,2 & 2417,5 & 23,6 \\
& Tempo de Processamento (s) & 2,0 & 2,1 & 2,4 & 0,1 \\
\hline \hline
\end{tabular}

* Desvio Padrão

melhor desempenho para os Sistemas 3 e 4. Todavia, também para os Sistemas 1 e 2 foram informadas soluções com número de manobras adequados, possíveis de serem implementadas. Deve ser destacado também, por meio desta tabela, que em todas as simulações realizadas, para todos os sistemas de teste, houve pelo menos uma CCR presente no plano de restabelecimento obtido.

Com base nestes resultados, pode-se concluir que também na ocorrência de três faltas simultâneas a capacidade de otimização do AEMT++ pode ser considerada satisfatória, uma vez que os valores das restrições operacionais, das perdas ôhmicas totais, do número de manobras em chaves e de tempo de processamento obtidos nas soluções finais informadas pela metodologia proposta são compatíveis com as necessidades do problema. Além disso, esta foi capaz de obter soluções com a presença de CCRs em todas as simulações. 
Tabela 6.8: Número de manobras em chaves obtidas pelo AEMT++ para a solução final considerando-se a ocorrência de múltiplas faltas nos Sistemas 1, 2, 3 e 4.

\begin{tabular}{l|l|cccc}
\hline \hline \multicolumn{2}{c}{} & Mínimo & Médio & Máximo & DP* \\
\hline \multirow{3}{*}{ Sistema } & Manobras em CCRs & 1 & 2,3 & 3 & 0,5 \\
& Manobras em CCMs & 7 & 10,7 & 19 & 3,1 \\
& Manobras Totais & 9 & 13,0 & 21 & 3,1 \\
\hline \multirow{3}{*}{ Sistema 2} & Manobras em CCRs & 3 & 3,9 & 5 & 0,5 \\
& Manobras em CCMs & 5 & 9,0 & 18 & 3,2 \\
& Manobras Totais & 9 & 12,7 & 23 & 3,5 \\
\hline \multirow{3}{*}{ Sistema 3 3} & Manobras em CCRs & 2 & 2,1 & 4 & 0,3 \\
& Manobras em CCMs & 3 & 3,1 & 8 & 0,6 \\
& Manobras Totais & 5 & 5,2 & 11 & 0,9 \\
\hline \multirow{3}{*}{ Sistema 4} & Manobras em CCRs & 1 & 1,1 & 2 & 0,3 \\
& Manobras em CCMs & 4 & 4,9 & 21 & 2,6 \\
& Manobras Totais & 5 & 6,0 & 23 & 2,8 \\
\hline \hline
\end{tabular}

* Desvio Padrão

\section{Avaliação da Capacidade de Priorização de Manobras em CCRs}

Para completar esta avaliação da capacidade do AEMT++ em priorizar a operação de CCRs, considere a Tabela 6.9, apresentada a seguir. Nela é mostrado o percentual de CCRs, em relação ao número total de manobras em chaves, existentes nas soluções finais informadas para o situação de três faltas em pontos diferentes da rede.

Tabela 6.9: Percentual de CCRs presentes na solução final, em relação ao número total de manobras em chaves.

\begin{tabular}{l|l|c}
\hline \hline \multirow{3}{*}{ Sistema 1 } & Mínimo & $7,7 \%$ \\
& Médio & $18,7 \%$ \\
& Máximo & $27,3 \%$ \\
& DP* & 5,8 \\
\hline \multirow{4}{*}{ Sistema 2 } & Mínimo & $17,6 \%$ \\
& Médio & $31,7 \%$ \\
& Máximo & $45,4 \%$ \\
& DP* & 6,6 \\
\hline \multirow{5}{*}{ Sistema 3 } & Mínimo & $27,3 \%$ \\
& Médio & $40,0 \%$ \\
& Máximo & $57,1 \%$ \\
& DP* & 2,6 \\
\hline \multirow{3}{*}{ Sistema 4 4} & Mínimo & $8,7 \%$ \\
& Médio & $19,2 \%$ \\
& Máximo & $28,6 \%$ \\
& DP* & 3,2 \\
\hline \hline
\end{tabular}


Como pode ser visto nesta tabela, nos planos de restabelecimento obtidos o número de mínimo de CCRs presentes variou entre 7,7\% (Sistema 1) e 40,0\% (Sistema 3). Considerando o percentual total de CCRs existentes em cada um dos quatro sistemas de teste não é superior a 7\%, esses valores podem ser considerados satisfatórios, e demonstram que a metodologia proposta foi capaz atingir também objetivo do problema.

Para complementar esta análise considere também o gráfico da Figura 6.7. Nele é ilustrado o número percentual de vezes em que a quantidade percentual de CCRs presentes no plano de restabelecimento foi igual ou superior a $15 \%$, isto é, maior que o dobro do número percentual de chaves existentes em cada um dos sistemas simulados. Conforme dito na seção anterior, esta análise é importante porque ela relaciona a capacidade de priorização de CCRs, da metodologia proposta, com a quantidade de CCRs existentes nos sistemas simulados.

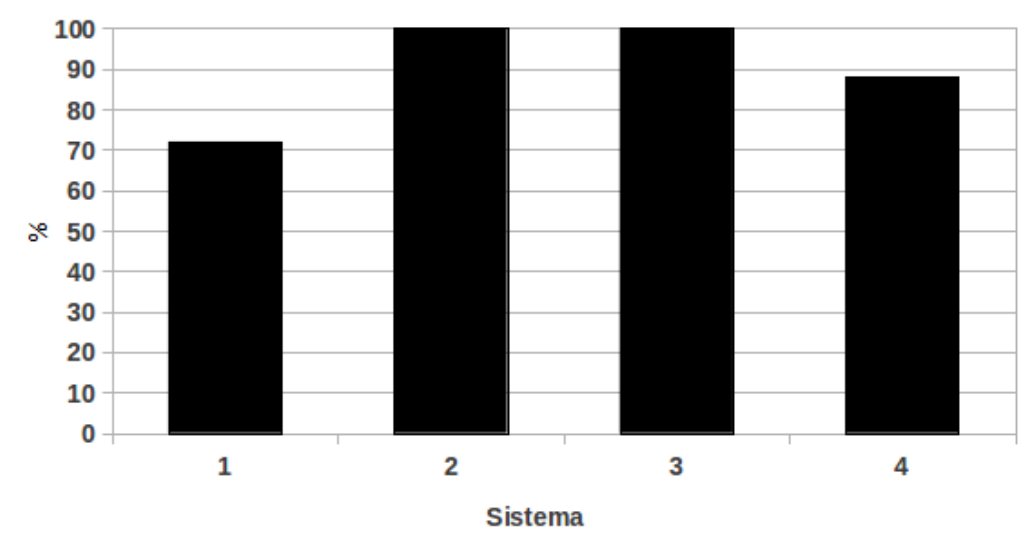

Figura 6.7: Número percentual de vezes em que o percentual de CCRs presentes na solução final, em relação ao número de total de manobras em chaves, foi igual ou superior a 15\% (aproximadamente o dobro da quantidade percentual de CCRs existentes nos Sistemas 1, 2, 3 e 4).

Como pode ser observado na Figura 6.7, na ocorrência de três faltas simultâneas, em mais de $70 \%$ das simulações, para os quatro sistemas de teste, o AEMT ++ foi capaz de obter planos de restabelecimento com mais de $15 \%$ de CCRs. No caso dos Sistemas 2 e 3 , isto ocorreu para todas as simulações realizadas. Sabendo que a quantidade percentual de CCRs em cada uma destas rede é de aproximadamente 7\%, estes números podem ser considerados satisfatórios e comprovam a capacidade da metodologia proposta em priorizar a operação de CCRs. 


\section{Avaliação da Capacidade de Definição de uma Sequência de Chaveamento Factível sem a Presença de Chaves Repetidas}

Para avaliar a capacidade do AEMT ++ em definir sequências de chaveamento factíveis sem a presença de chaves repetidas, na ocorrência de múltiplas faltas, é apresentada a Figura 6.8. Nela, o gráfico ilustrado mostra, para os Sistemas 1, 2, 3 e 4, o número percentual de vezes em que foram obtidas sequências de chaveamento sem a presença de chaves que retornaram ao seu estado anterior, na primeira configuração fatível.

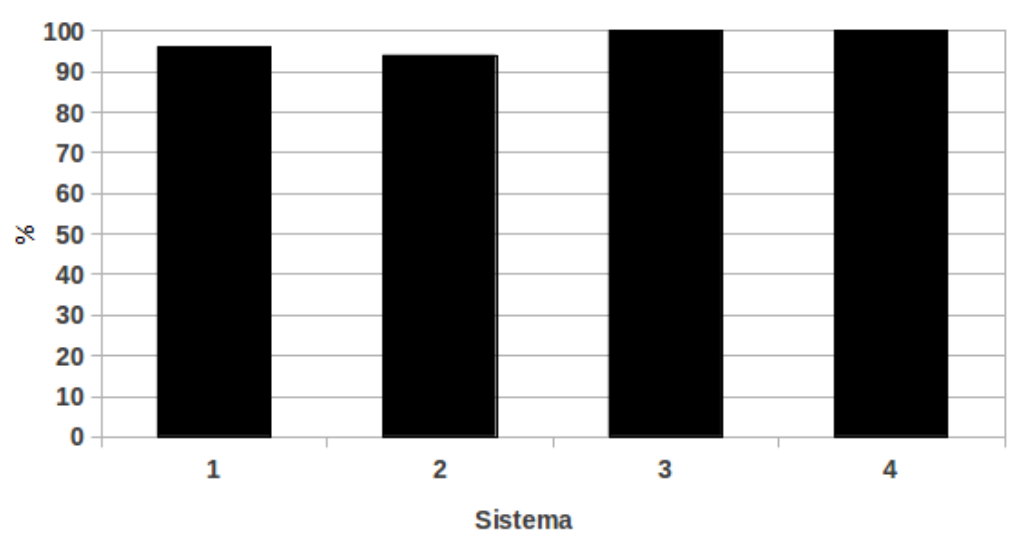

Figura 6.8: Número percentual de vezes em que foi definida uma sequência de chaveamento sem a presença de chaves que retornaram ao seu estado anterior, considerando-se a ocorrência de múltiplas faltas.

Como pode ser visto, para os Sistemas 3 e 4, em 100\% das sequências de chaveamento definidas não haviam manobras desnecessárias em chaves. Enquanto isso, para os Sistemas 1 e 2, $96 \%$ e $94 \%$, respectivamente, das sequências definidas eram de boa qualidade, isto é, não exigiam manobras adicionais em chaves.

Assim, conclui-se que, apesar de a metodologia proposta não avaliar todas as sequências possíveis de serem obtidas a partir de um determinado conjunto de pares de manobras, como dito na seção anterior e também no Capítulo 5, ela mostrou-se apta a fornecer sequências de chaveamento factíveis sem a presença de chaves repetidas. E, desse modo, capaz de fornecer planos de restabelecimento de energia com sequências de pares de chaves que minimizam o trabalho adicional de se operar duas vezes a mesma chave.

\section{Avaliação da Capacidade de Priorização do Fornecimento aos CEs}

Para avaliar a capacidade do AEMT++ em priorizar o fornecimento de energia aos CEs na ocorrência de múltiplas faltas, considere a Tabela 6.10 e também o gráfico mostrado pela Figura 6.9. Na Tabela 6.10 é apresentado o número mínimo, médio e máximo de CEs transferidos nas simulações realizadas para os Sistemas 1, 2, 3 e 4. Já na Figura 6.9 
é ilustrado o número percentual de vezes em que a solução final obtida não exigiu a transferência de nenhum CE.

Tabela 6.10: Número de CEs desligados pela ocorrência de múltiplas faltas e de CEs transferidos para implementação das soluções finais obtidas para os Sistemas 1, 2, 3 e 4 na ocorrência de múltiplas faltas.

\begin{tabular}{l|l|cccc}
\hline \hline \multicolumn{2}{c}{} & Mínimo & Médio & Máximo & DP* \\
\hline \multirow{2}{*}{ Sistema 1 } & Desligados & 4 & 4,0 & 4 & 0,0 \\
& Transferidos & 0 & 4,8 & 7 & 2,4 \\
\hline \multirow{2}{*}{ Sistema 2 } & Desligados & 4 & 4,0 & 4 & 0,0 \\
& Transferidos & 0 & 1,8 & 4 & 1,1 \\
\hline \multirow{2}{*}{ Sistema 3 3} & Desligados & 4 & 4,0 & 4 & 0,0 \\
& Transferidos & 0 & 4,0 & 4 & 0,4 \\
\hline \multirow{2}{*}{ Sistema 44 4 Tesligados } & 4 & 4,0 & 4 & 0,0 \\
& Transferidos & 0 & 4,3 & 9 & 1,8 \\
\hline \hline
\end{tabular}

* Desvio Padrão

Analisando esta tabela pode-se observar que em todos sistemas simulados, em média, mais de quatro CEs tiveram que ser transferidos. Contudo, percebe-se também que para todos os sistemas de teste foram determinadas soluções sem a transferência de CEs.

Para auxiliar nesta avaliação, considere o gráfico da Figura 6.9. Nele, é possível verificar que para o Sistema 1 apenas 36\% das soluções finais determinadas não exigiam a transferência de nenhum CEs, enquanto que para os demais sistemas esse número manteve-se superior a 70\%. Apesar deste mal rendimento da metodologia proposta para o Sistema 1, é importante dizer que foi possível verificar nas simulações computacionais que a maioria dos CEs transferidos são exatamente aqueles que foram desligados pela ocorrência da falta. Isso significa que, apesar de os planos de restabelecimento obtidos preverem uma segunda interrupção nos CEs desligados, baixo é o número de CEs adicionais que terão o seu fornecimento interrompido para transferência de alimentador. Ademais, deve-se recordar que o número de CEs definidos para estes testes é relativamente grande em comparação com a quantidade destes consumidores em SDR reais de grande porte.

\subsection{Evolução das Subpopulações Armazenadas nas Tabelas Propostas}

A fim de ilustrar o funcionamento das tabelas propostas e o processo de evolução das subpopulações armazenadas nas mesmas, foi selecionada uma das simulação computacional dentre todas as 800 realizas no $\mathrm{AEMT}++$, mas especificamente, uma das simulações para o Sistema 3 considerando a ocorrência de uma única falta. E nesta 


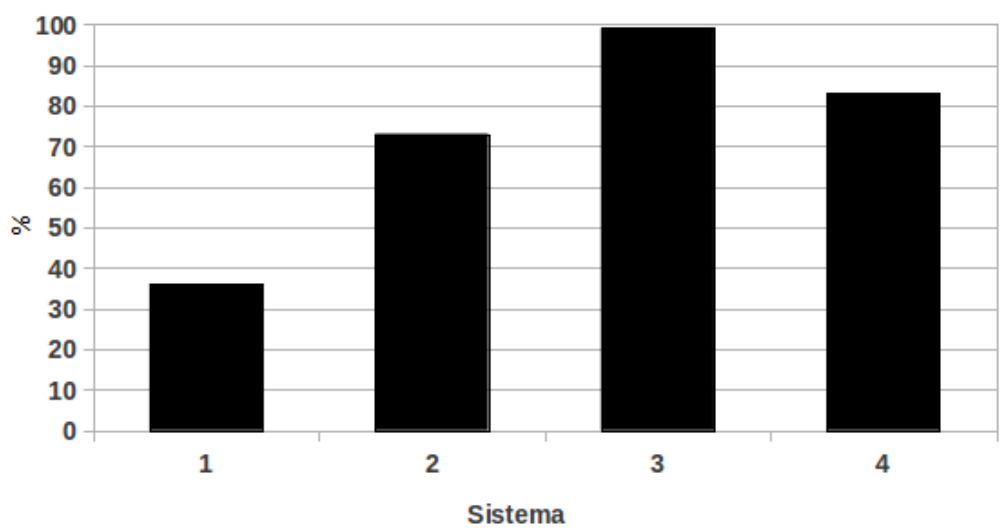

Figura 6.9: Número percentual de vezes em que a solução final definida não exigiu a transferência de CEs, considerando-se a ocorrência de múltiplas faltas nos Sistemas 1, 2, 3 e 4 .

simulação foi extraída, a cada nova solução gerada, a média da aptidão de todos os indivíduos armazenados em cada tabela $P_{i}$, para $6 \leq i \leq 13$, cujas informações encontram-se apresentadas nas Figuras 6.10 a 6.17 . Como as Tabelas $P_{1}, P_{2}, P_{3}, P_{4}$ e $P_{5}$, presentes no AEMT++, não foram alteradas em relação à metodologia base, não será apresentado a seguir o processo de evolução das subpopulações armazenadas nas mesmas. Maiores informações sobre estas tabelas podem ser obtidas em (Santos et al., 2010) e em (Santos, 2009).

Nas Figuras 6.10 a 6.15 é mostrado o processo de evolução das subpopulações armazenadas nas tabelas inseridas para priorização de manobras em CCRs. Enquanto isso, nas Figuras 6.16 e 6.17 é ilustrada, a cada novo indivíduo gerado, a aptidão das subpopulações armazenadas para priorizar o fornecimento de energia aos CEs.

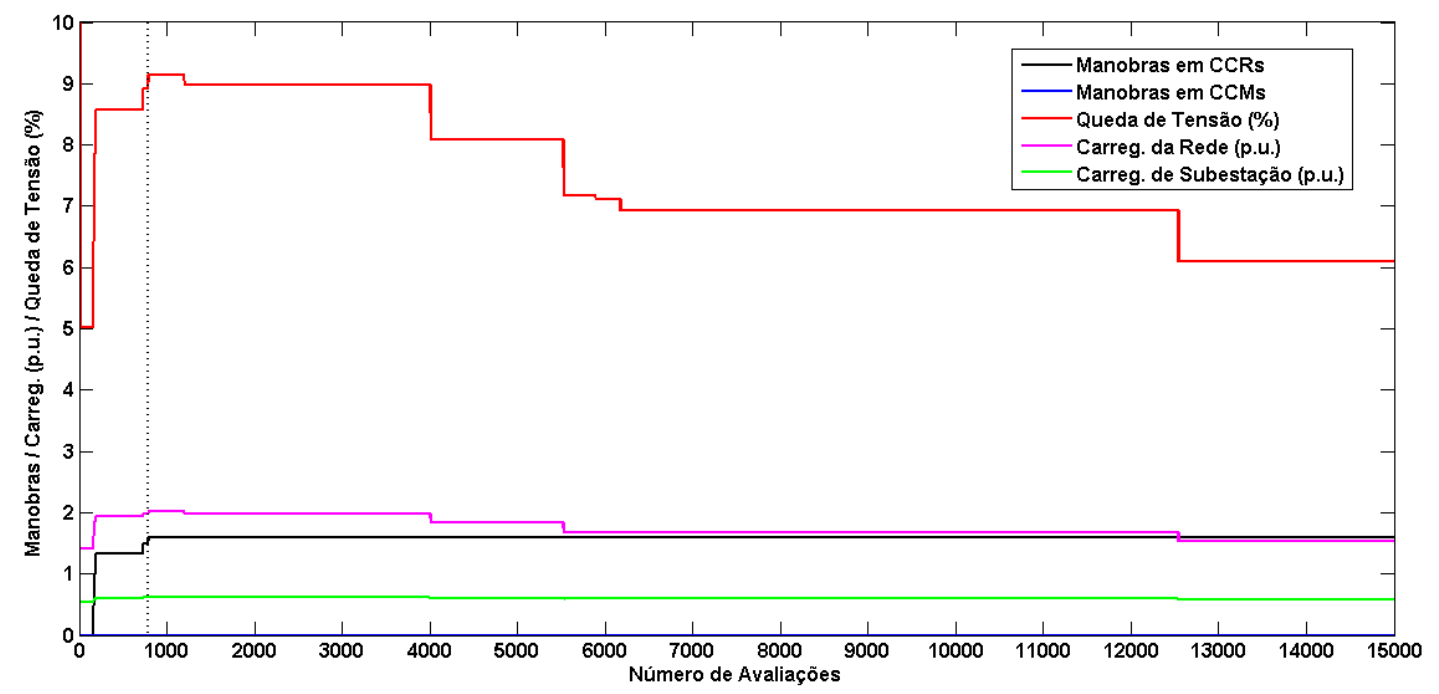

Figura 6.10: Evolução da média da aptidão dos indivíduos que compõem a subpopulação armazenada na tabela $P_{6}$. 
Conforme explicado na Seção 5.2.2.2, as tabelas de subpopulação $P_{6}, P_{7}, P_{8}, P_{9}, P_{10}$ e $P_{13}$, presentes no AEMT ++ , apresentam um novo conceito de tabelas de subpopulação, que possuem como diferencial a capacidade de otimizar em uma única tabela dois ou mais parâmetros, isto é, de utilizar uma tabela no tratamento de mais de um objetivo. Para ilustrar o funcionamento deste procedimento considere a Figura 6.10, na qual é ilustrada a evolução da média da aptidão dos indivíduos que compõe a subpopulação armazenada na tabela $P_{6}$. No caso desta tabela, são salvos indivíduos que possuem zero manobras em CCMs e que minimizam quatro parâmetros distintos, a saber: manobras em CCRs, queda de tensão, carregamento da rede e carregamento de subestação. Estes objetivos são ordenados seguindo um grau de prioridade de otimização entre eles, ao passo que, em $P_{6}$, minimizar manobras CCRs tem prioridade superior a minimização de quedas de tensão e assim sucessivamente, de acordo com a ordem em que forem listados anteriormente.

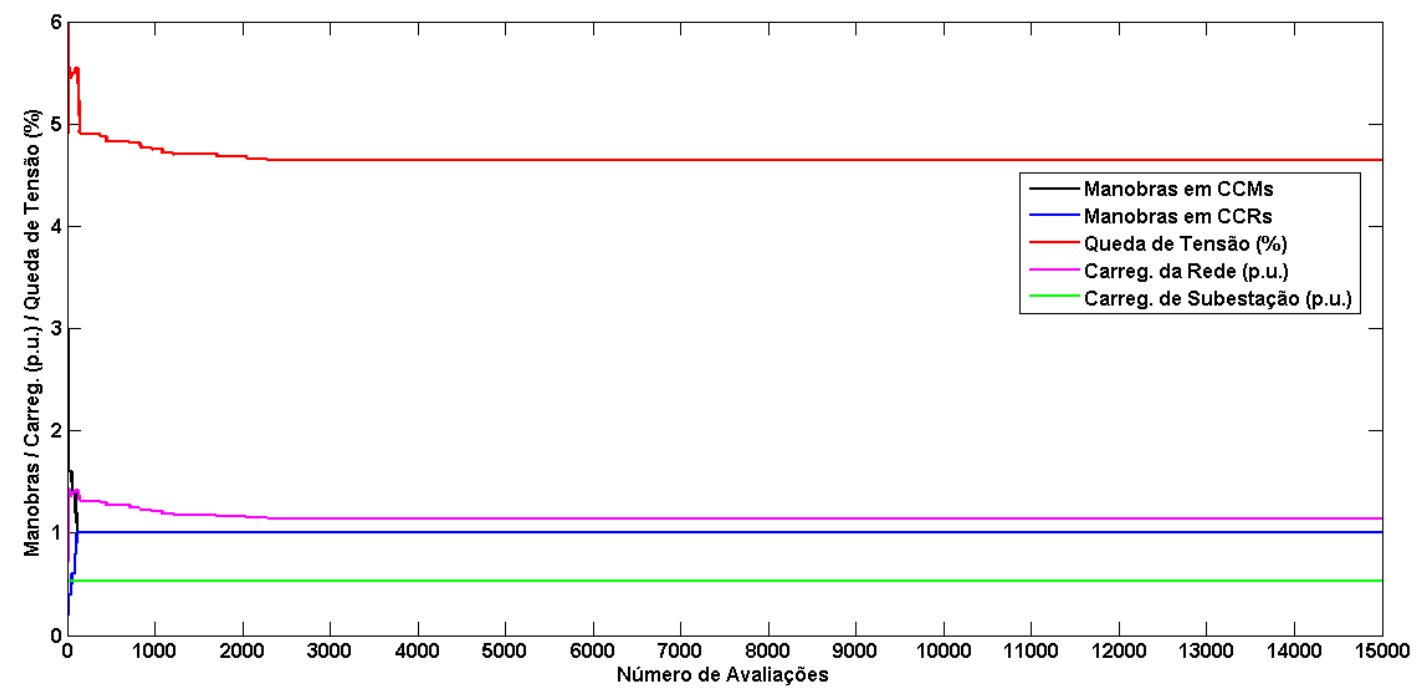

Figura 6.11: Evolução da média da aptidão dos indivíduos que compõem a subpopulação armazenada na tabela $P_{7}$.

Face ao exposto, observe na Figura 6.10 dois comportamentos distintos para aptidão média dos indivíduos em relação aos parâmetros minimizados por essa tabela. Inicialmente, entre a geração do primeiro indivíduos pelo AEMT++ e a avaliação do $791^{\circ}$ indivíduo gerado, marcado pela linha vertical tracejada, o valor da aptidão média dos indivíduo para cada parâmetro cresce continuamente, e posteriormente, eles começam a diminuir. Isto ocorre porque, num primeiro momento, $P_{6}$ ainda não estava completa. Mas, após o preenchimento desta subpopulação, com o $791^{\circ}$ indivíduo gerado e avaliado, é iniciado o seu processo de evolução.

Perceba na Figura 6.10 que quando o número de manobras em CCRs não pode mais ser minimizado, outros parâmetros com prioridade inferior, como queda de tensão e carregamento da rede, continuam a evoluir. Isto significa que a tabela permitiu que fossem 


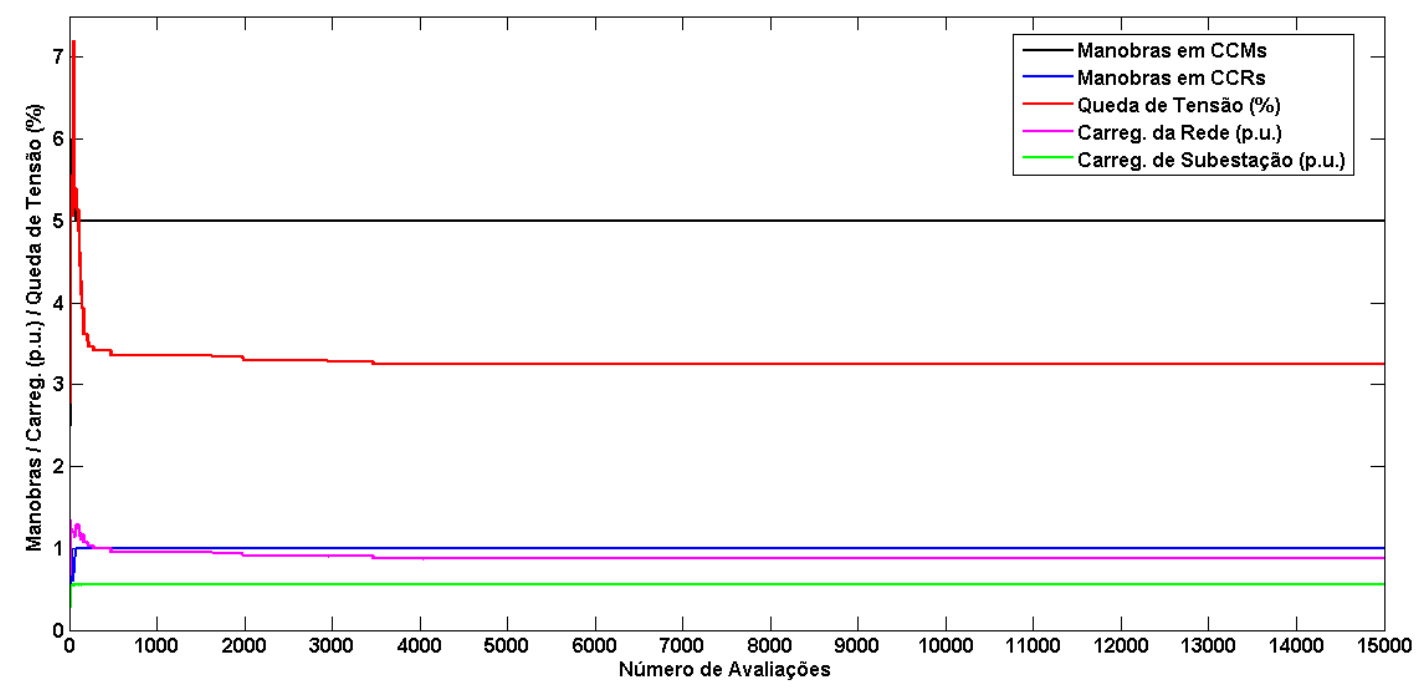

Figura 6.12: Evolução da média da aptidão dos indivíduos que compõem a subpopulação armazenada na tabela $P_{8}$.

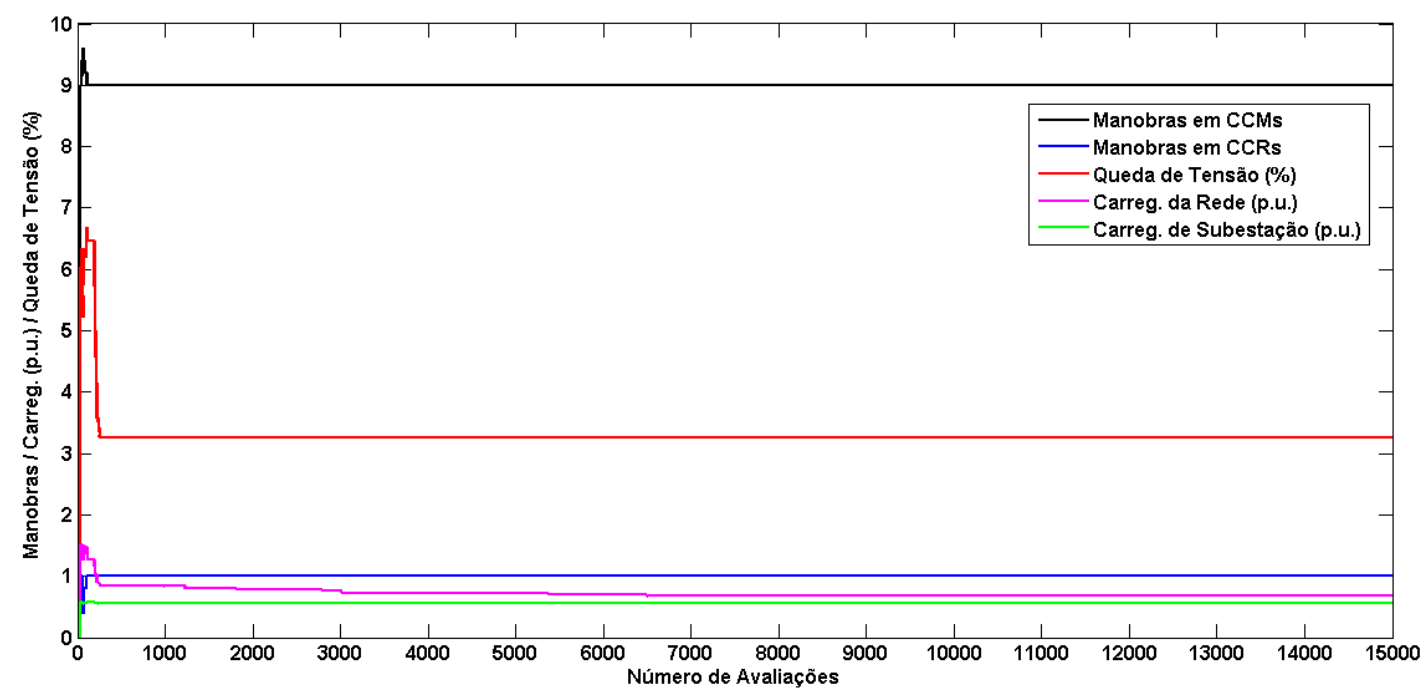

Figura 6.13: Evolução da média da aptidão dos indivíduos que compõem a subpopulação armazenada na tabela $P_{9}$.

inseridos indivíduos que possuem menores valores de queda de tensão e carregamento da rede, mas que com valor de manobras em CCRs igual ao valor mínimo já obtido, ou seja, indivíduos melhores do que aqueles existentes na tabela quando manobras em CCRs deixou de evoluir. O número de manobras em CCMs é mostrado nesta figura apenas para ilustrar que todas as soluções presentes em $P_{6}$ não exigem manobras em CCMs após a reconexão das cargas sãs fora de serviço, isto é, possuem número de manobras em CCM nulo. As Figuras 6.11 a 6.15 ilustram o processo evolutivo nas demais tabelas para priorização de manobras em CCRs. A prioridade entre os cinco parâmetros minimizados em cada uma delas é correspondente a ordem em que eles estão dispostos na legenda de 
cada figura. Na Figura 6.15 é ilustrada a evolução da média da aptidão dos indivíduos salvos na tabela $P_{11}$.

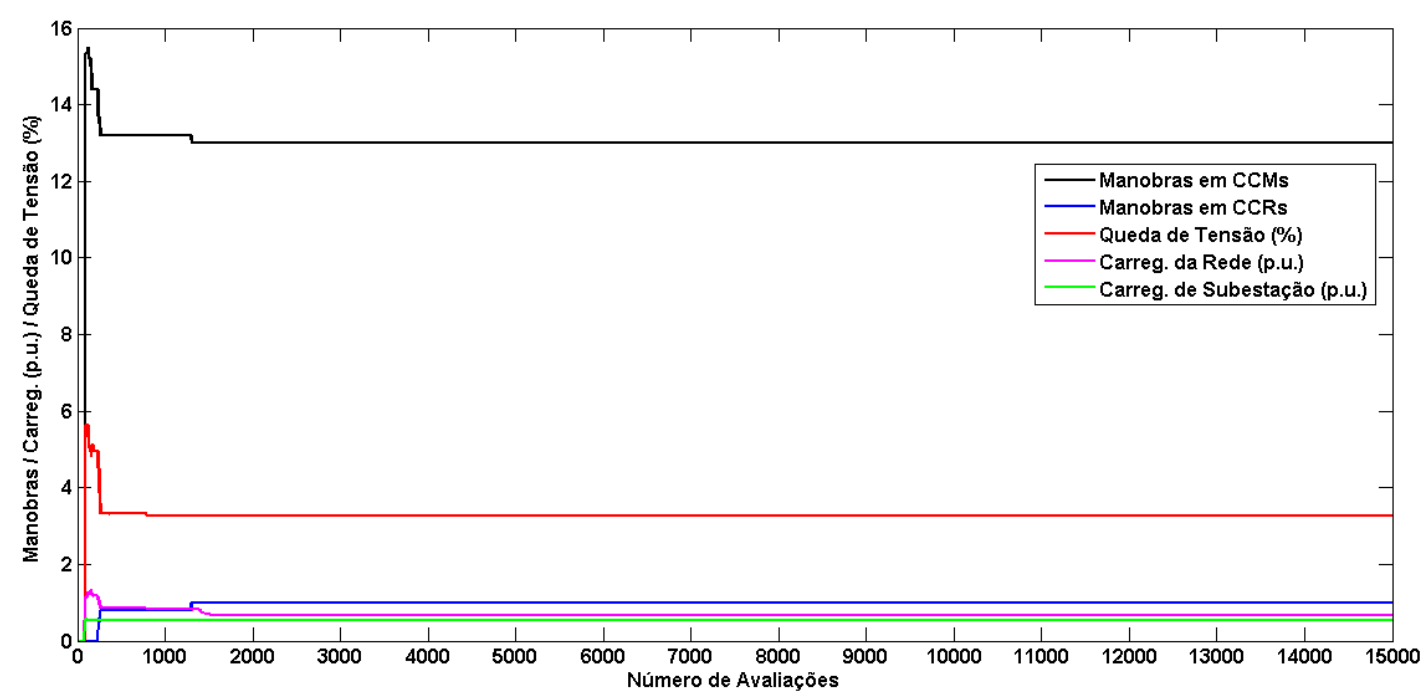

Figura 6.14: Evolução da média da aptidão dos indivíduos que compõem a subpopulação armazenada na tabela $P_{10}$.

A Figura 6.14 ilustra um comportamento destas novas tabelas de múltiplos objetivos que vale a pena ser apresentado. Perceba que, entre o $1000^{\circ}$ e o $2000^{\circ}$ indivíduo avaliado, uma nova solução, com menor número de manobras em CCMs, foi inserida, e que neste instante, o número médio de manobras em CCRs da subpopulação aumentou. Isto ocorreu porque a otimização de múltiplos objetivos em uma única tabela segue, como mencionado anteriormente, uma ordem de prioridade entre eles, de modo que neste caso, apesar de o indivíduo inserido ter maximizado o número médio de manobras em CCRs das soluções presentes nesta tabela, ele minimizou um parâmetro que possui grau de prioridade de otimização superior à minimização de CCRs, isto é, minimização de manobras em CCMs.

Em relação a Figura 6.16, relativa ao processo de evolução da subpopulação armazenada na tabela $P_{12}$, é importante dizer que, apesar desta tabela minimizar o número ponderado de manobras, o número de CEs transferidos é apresentado para mostrar que nesta tabela são aceitos somente indivíduos que não exigem a transferência de CEs, após a reconexão daqueles fora de serviço. Já na Figura 6.17 é ilustrada evolução da aptidão dos indivíduos que compõe a tabela $P_{13}$, responsável por minimizar concomitantemente o número de CEs transferidos e o número ponderado de manobras, dando prioridade à otimização do primeiro. Perceba nesta figura que, como o objetivo prioritário, isto é, número de CEs transferidos, manteve-se inalterado, o segundo objetivo foi, então, otimizado. 


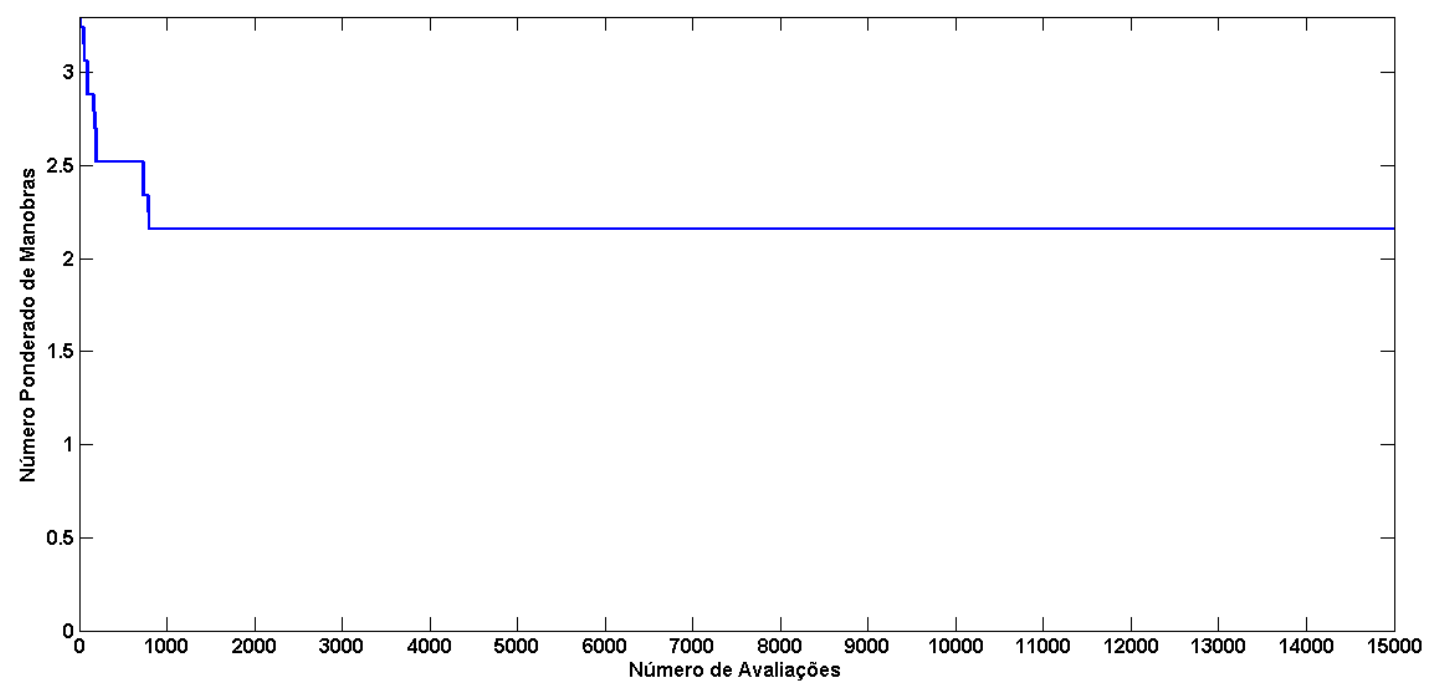

Figura 6.15: Evolução da média da aptidão dos indivíduos que compõem a subpopulação armazenada na tabela $P_{11}$.

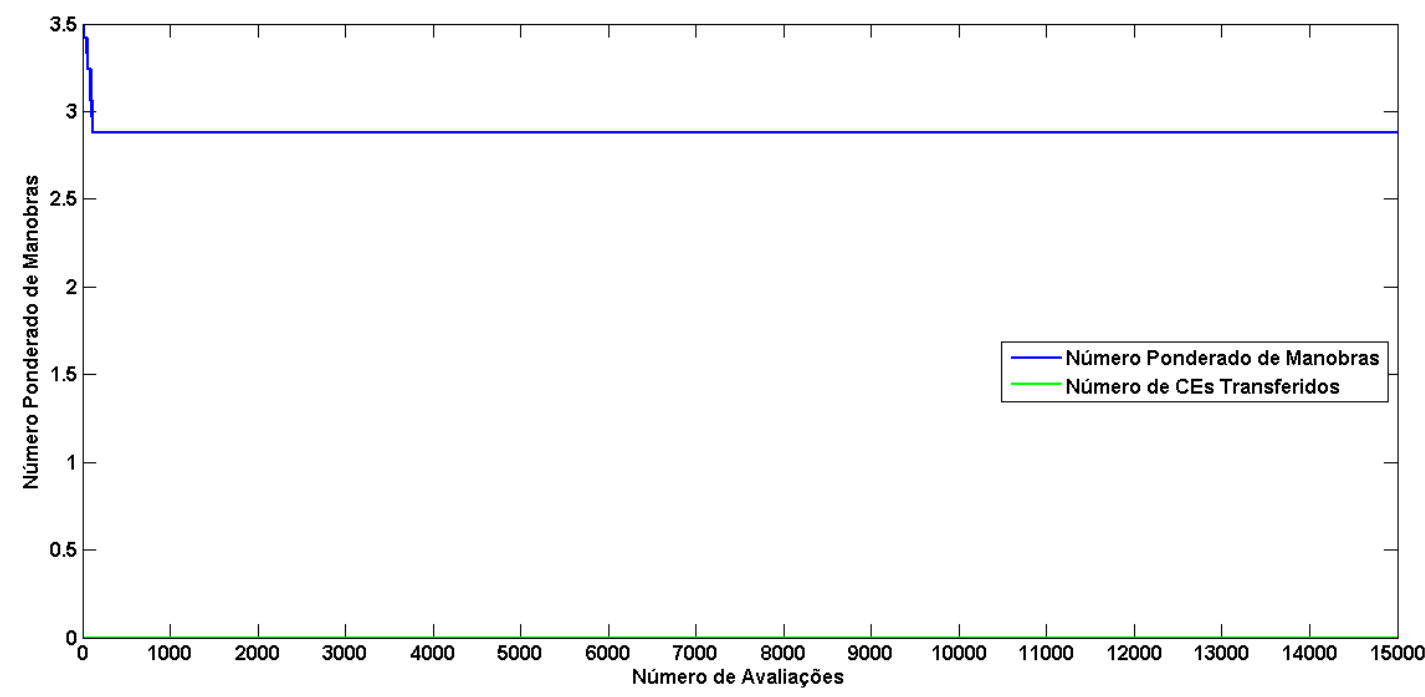

Figura 6.16: Evolução da média da aptidão dos indivíduos que compõem a subpopulação armazenada na tabela $P_{12}$.

\subsection{Considerações Finais}

Considerando todas as simulações computacionais realizadas e os resultados experimentais apresentados, pode-se concluir que a metodologia proposta demonstrou ser capaz de fornecer planos adequados de restabelecimento de energia em SDRs de grande porte. Tanto na ocorrência de uma, quanto de múltiplas faltas, foi possível observar a capacidade de otimização satisfatória desta metodologia, bem como a sua habilidade para priorizar a operação de CCRs, o fornecimento de CEs, e de informar sequências de chaveamento factíveis sem manobras repetidas em chaves. 


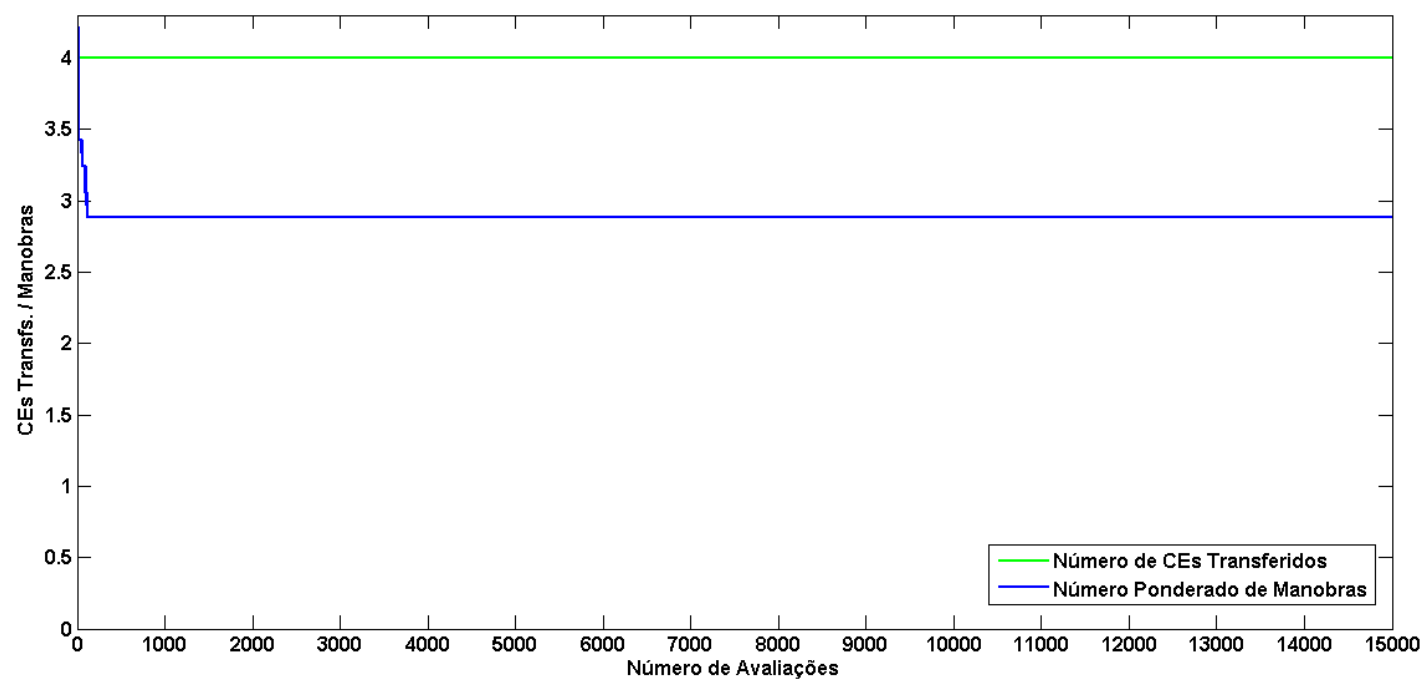

Figura 6.17: Evolução da média da aptidão dos indivíduos que compõem a subpopulação armazenada na tabela $P_{13}$.

Para proporcioná-la estas características, foram incluídas 8 novas tabelas de subpopulação, cujo funcionamento foi ilustrado por meio de figuras que mostram o processo de evolução destas subpopulações na ocorrência de uma única falta no Sistema 3. Além disso, pôde-se comprovar a eficiência do procedimento proposto para seleção e definição de uma solução final, dentre todas as soluções armazenas nas tabelas ao término do processo evolutivo. 


\section{Conclusões, Contribuições e Trabalhos}

Futuros

\subsection{Conclusões}

Nesta dissertação foi proposta uma metodologia para tratar do problema de restabelecimento de energia em SDRs de grande porte, e assim auxiliar as atividades dos engenheiros e operadores de sistemas de distribuição de energia elétrica. Esta ferramenta computacional possui como principal diferencial, em relação às metodologias existentes, a capacidade de considerar a presença e priorizar a operação de CCRs e o fornecimento de energia aos CEs. Além disso, a mesma é capaz de fornecer planos de restabelecimento de energia que possuem uma sequência factível para operação de chaves e consequente implementação da nova configuração obtida para a rede.

Conforme fora dito, inicialmente, devido as suas necessidades, o problema de restabelecimento de energia pode ser classificado como um problema de otimização multi-objetivo, sujeito a várias restrições e que exige soluções em tempo real. Assim, para tratá-lo, diversos métodos de otimização têm sido propostos na literatura, com destaque para os AEs que, quanto comparados a outras técnicas, têm se mostrado mais flexíveis, mais simples de serem compreendidos e implementados, apresentado resultados satisfatórios. 
Desse modo, foram apresentados os principais conceitos relacionados aos AEs e os principais AEs existentes na literatura para tratamento de problemas multi-objetivo, como é o caso do problema de restabelecimento de energia. Dentre os AEMOs apresentados, foi dado maior destaque ao AEMT, tomado como base para o desenvolvimento da metodologia proposta. Devido a sua importância para esta dissertação, o AEMT teve o seu funcionamento explicado em detalhes, dando enfoque as suas características e elementos que o diferenciam das demais metodologias existentes: codificação de dados utilizada para representar computacionalmente alimentadores e setores da rede (RNP), operadores de mutação que geram exclusivamente configurações factíveis (PAO e CAO), algoritmo eficiente para cálculo de número de manobras em chaves e subpopulações armazenadas em tabelas.

Com base nestas informações iniciais foi, em seguida, apresentada a metodologia proposta, denominada AEMT++. Assim como o AEMT, esta metodologia faz uso da RNP para representar os SDRs sem simplificações, isto é, com todas as suas barras, linhas e chaves, bem como utiliza os operadores PAO e CAO da RNP para a geração de novas configurações factíveis. Para priorizar a operação de CCRs foi proposto um novo procedimento para determinação da primeira configuração factível, a partir da configuração da rede com o setor em falta isolado e os setores sãos desconectados. Além disso, para tratar deste primeiro objetivo de pesquisa, foram propostas seis novas tabelas de subpopulações, sendo uma para minimização do número ponderado de manobras em chaves e outras cinco para minimizar concomitantemente vários objetivos do problema por meio de um novo conceito proposto de tabelas de subpopulação. Para determinar corretamente o número de manobras em CCMs e em CCRs de cada configuração gerada pelos operadores da RNP, foi proposto também um novo algoritmo para cálculo de número de manobras em chaves, baseado naquele presente no AEMT, mas com a capacidade de distinguir entre operações em CCR e em CCMs.

Na priorização de fornecimento de energia aos CEs, comumente existentes em SDRs de grande porte, foram apresentadas duas novas tabelas de subpopulação, responsáveis por minimizar o número de CEs transferidos e obter para o problema, se possível, soluções que não exijam o desligamento destes tipos de consumidores, mesmo que temporário. Além disso, foi desenvolvido e apresentado um modo para seleção e definição de uma única solução final, dentre todos os indivíduos presentes nas tabelas de subpopulação ao final do processo evolutivo.

Por último, foi apresentado um procedimento que visa definir uma sequência de chaveamento factível a ser informada em planos de restabelecimento de energia. Esta sequência permite a implementação na rede da solução final obtida e selecionada, de 
forma segura, sem a formação de laços ou conexão entre alimentadores e/ou subestações diferentes.

Com a finalidade de avaliar a metodologia proposta, foram realizadas diversas simulações computacionais em quatro SDRs de grande porte, que correspondem ao SDR da cidade de São Carlos, em operação no ano de 1994, e as suas versões duplicada, quadruplicada e octuplicada. Como situação de contingência foi considerada a ocorrência tanto de uma única quanto de múltiplas faltas simultâneas em cada um dos quatros SDRs. Para auxiliar na análise dos resultados das 800 simulações realizadas, foram definidos quatro critérios, que permitiram concluir que o AEMT ++ é apto a fornecer planos adequados de restabelecimento de energia, com um baixo de processamento, minimizando os objetivos gerais do problema, dando prioridade à operação de CCRs e ao fornecimento de CEs, e informando uma sequência de chaveamento capaz de implementar de forma eficiente a solução final, e deste modo, atingindo o objetivo desta dissertação. Todavia, pôde-se verificar também algumas limitações da metodologia proposta, que, contudo, não inviabilizam a sua aplicação como ferramenta computacional de auxilio às atividades dos engenheiros e operadores de SDRs.

\subsection{Contribuições}

Em relação às principais contribuições deste trabalho, elas podem ser sintetizadas como a seguir:

1. Desenvolvimento de uma metodologia para o problema de restabelecimento de energia em SDRs de grande porte capaz de priorizar a operação de CCRs e o fornecimento de CEs, assim como de informar planos de restabelecimento com definição de uma sequência de chaveamento factível;

2. Desenvolvimento de um procedimento para verificação da factibilidade de sequências de chaveamento;

3. Proposição de um novo conceito de tabelas de subpopulação, que permite a otimização de mais de um objetivo por meio de uma única tabela;

4. Desenvolvimento de uma metodologia eficiente para calcular separadamente o número de manobras em CCRs e em CCMs de cada configuração gerada;

5. Desenvolvimento de um procedimento para seleção e definição de uma única solução final, a partir de todos os indivíduos armazenados nas tabelas ao término do processo evolutivo. 


\subsection{Trabalhos Futuros}

Como perspectivas de trabalhos futuros é possível citar:

1. Melhorar a capacidade da metodologia proposta em obter soluções que não exijam a transferência de CEs;

2. Priorizar o atendimento de CEs segundo o grau de prioridade específica de cada carga. Observe, por exemplo, que a prioridade de fornecimento de energia de um hospital deve ser maior que a de um grande supermercado;

3. Melhorar o procedimento proposto para verificação da factibilidade de sequências de chaveamento, a fim de que o mesmo considere também o retorno ao estado anterior de chaves alteradas para reconexão de cargas sãs fora de serviço. Em outras palavras, fazer com que o procedimento proposto utilize como referência, na comparação do estado das chaves, a configuração inicial, ao invés da primeira configuração factível obtida. Além disso, considerar, na verificação da factibilidade, as demais restrições do problema;

4. Considerar a possibilidade de rejeição de cargas em alimentadores sobrecarregados na ausência de chaves que possibilitem a transferência das mesmas.

\subsection{Publicações Originadas desta Pesquisa}

1. Marques, L. T.; Pereira, D. H.; Sanches, D. S.; Delbem, A. C. B.; London Jr., J. B. A. Metodologias para Restabelecimento de Energia com Priorização de Consumidores Especiais em Sistemas de Distribuição de Grande Porte. No XI Simpósio Brasileiro de Automação Inteligente, 2013, Fortaleza-CE. (Submetido).

2. Sanches, D. S.; Marques, L. T.; Borges, H. P.; Delbem, A. C. B.; London Jr., J. B. A.; Análise Comparativa entre Algoritmos Evolutivos Multi-objetivos Aplicados ao Problema de Redução de Perdas em Sistemas de Distribuição de Grande Porte. No XIX Congresso Brasileiro de Automática, 2012, Campina Grande-PB. Anais. 


\section{Referências Bibliográficas}

Augugliaro, A.; Dusonchet, L.; Sanseverino, E. R. Service restoration in compensated distribution networks using a hybrid genetic algorithm. Electric Power Systems Research, v. 46, n. 1, p. 59 - 66, 1998.

Augugliaro, A.; Dusonchet, L.; Sanseverino, E. R. Multiobjective service restoration in distribution networks using an evolutionary approach and fuzzy sets. International Journal of Electrical Power \& Energy Systems, v. 22, p. 103-110, 2000.

Baran, M.; Wu, F. Optimal sizing of capacitors placed on a radial distribution system. Power Delivery, IEEE Transactions on, v. 4, n. 1, p. 735-743, 1989.

Benayoun, R.; de Montgolfier, J.; Tergny, J.; Laritchev, O. Linear programming with multiple objective functions: Step method (stem). Mathematical Programming, v. 1, p. $366-375,1971$.

Botea, A.; Rintanen, J.; Banerjee, D. Optimal reconfiguration for supply restoration with informed a ${ }^{\text {ast }}$ search. Smart Grid, IEEE Transactions on, v. 3, n. 2, p. $583-593$, 2012 .

Carreno, E. M.; Romero, R.; Padilha-Feltrin, A. An efficient codification to solve distribution network reconfiguration for loss reduction problem. Power Systems, IEEE Transactions on, v. 23, n. 4, p. $1542-1551,2008$.

Cormen, T. H. Algoritmos: Teoria e prática. Campus, 2002.

Curcic, S.; Szveren, C.; Crowe, L.; Lo, P. Electric power distribution network restoration: a survey of papers and a review of the restoration problem. Electric Power Systems Research, v. 35, n. 2, p. 73-86, 1995. 
Deb, K. Multi-objective optimization using evolutionary altorithms. New York: Wiley, 2001.

Deb, K.; Agrawal, S.; Pratap, A.; Meyarivan, T. A fast elitist non-dominated sorting genetic algorithm for multi-objective optimization: Nsga-ii. Springer, 2000, p. 849-858.

Delbem, A. C. B. Restabelecimento de energia em sistemas de distribuição por algoritmo evolucionário associado a cadeias de grafos. 2002.

Delbem, A. C. B.; de Carvalho, A. A forest representation for evolutionary algorithms applied to network design. In: GECCO'03: Proceedings of the 2003 international conference on Genetic and evolutionary computation, Berlin, Heidelberg: Springer-Verlag, 2003, p. 634-635.

Delbem, A. C. B.; de Carvalho, A. C. P. L. F.; Bretas, N. G. Main chain representation for evolutionary algorithms applied to distribution system reconfiguration. Power Systems, IEEE Transactions on, v. 20, n. 1, p. 425-436, 2005.

Delbem, A. C. B.; de Carvalho, A. C. P. L. F.; Policastro, C. A.; Pinto, A. K.; Honda, K.; Garcia, A. C. Node-depth encoding for evolutionary algorithms applied to network design. GECCO (1), 2004, p. 678-687.

Eiben, A. E.; Smith, J. E. Introduction to evolutionay computing. Springer, 2003.

Fantin, C. A.; Sanches, D. S.; London Jr., J. A.; A.C.B, D.; Santos, A. C. Reconfiguração de redes para melhoria do perfil de tensão e redução de perdas em sistemas de distribuição de grande porte. IX Conferência Brasileira sobre Qualidade da Energias Elétrica, Cuiabá-MT, 2011.

Ferreira, F. A. L. Metodologia para reconfiguração de redes de distribuição trifísica assimétrica e não balanceadas com geração distribuída. Dissertação de Mestrado, PUCRS, 2010.

Gabriel, P. H. R.; Delbem, A. C. B. Fundamentos de algoritmos evolutivos. Material didático do ICMC - USP., 2008.

Gomes, F. V.; Carneiro, S., J.; Pereira, J. L. R.; Vinagre, M. P.; Garcia, P. A. N.; Oliveira, E. J.; Araujo, L. R. A new distribution system reconfiguration approach using optimal power flow technique and sensitivity analysis for loss reduction. Power Engineering Society General Meeting, 2005. IEEE, p. 897-901 Vol. 1, 2005. 
Hart, P.E., N. N.; Raphael, B. A formal basis for the heuristic determination of minimum cost paths. Systems Science and Cybernetics, IEEE Transactions on, v. 4, n. 2, p. 100 $-107,1968$.

Jong, K. A. D. Evolutionary computation: a unified aproach. The MIT Press, 2006.

Kagan, N. Configuração de redes de distribuição através de algoritmos genéticos e tomada de decisão fuzzy. 1999.

Kagan, N.; de Oliveira, C. C. B.; Robba, E. J. Introdução aos sistemas de distribuição de energia elétrica. São Paulo: Edgard Blucher, 2005.

Kumar, Y.; Das, B.; Sharma, J. Multiobjective, multiconstraint service restoration of electric power distribution system with priority customers. Power Delivery, IEEE Transactions on, v. 23, n. 1, p. 261-270, 2008.

Lima, T. W.; Delbem, A. C. B. Estruturas de dados eficientes para algoritmos evolutivos aplicados ao projeto de redes. Relatório Técnico 301, ICMC-USP, 2007.

Mansour, M. R. Algoritmo para obtenção de planos de restabelecimento para sistemas de distribuição de grande porte. Dissertação de Mestrado, Engenharia Elétrica, EESC/USP, São Carlos/SP - Brasil, 2009.

Mansour, M. R.; Santos, A. C.; London Jr, J. B. A.; Delbem, A. C. B.; Bretas, N. G. Energy restoration in distribution systems using multi-objective evolutionary algorithm and an efficient data structure. PowerTech, IEEE Bucharest, p. 1 -7, 2009.

Mansour, M. R.; Santos, A. C.; London Jr., J. B. A.; Delbem, A. C. B.; Bretas, N. G. Representação nó-profundidade e algoritmos evolutivos aplicados ao problema de restabelecimento de energia em sistemas de distribuição de energia. Congresso Brasileiro de Automática, p. 1 -7, 2010.

Merlin, A.; Back, H. Search for a minimal-loss operating spanning tree configuration in an urban power distribution system. In: Proc. 5th Power System Computation Conference, 1975, p. 1-18.

Pelikan, M.; Goldberg, D. E.; Lobo, F. A survey of optmization by building and using probabilistic models. Computational Optmization and Applications, v. 21, n. 1, p. 5-20, 2002.

Prasad, P. V.; Sivanagaraju, S.; Sreenivasulu, N. Network reconfiguration for load balancing in radial distribution systems using genetic algorithm. Electric Power Components and Systems, v. 36, p. 63-72, 2008. 
Sanches, D. S. Algoritmo evolutivo multiobjetivo para reconfiguração de redes em sistemas de distribuição de energia elétrica. Texto do exame de qualificação de doutorado em Engenharia Elétrica/EESC/USP, 2012.

Sanches, D. S. Algoritmos evolutivos multi-objetivo para reconfiguração de redes em sistemas de distribuição de energia elétrica. Tese de Doutoramento, Engenharia Elétrica - EESC/USP., São Carlos/SP, Brasil, 2013.

Sanches, D. S.; London, J.; Delbem, A. C. B.; Santos, A. Integrating relevant aspects of moeas applied to service restoration in distribution systems. In: Power and Energy Society General Meeting, 2012 IEEE, 2012, p. 1-8.

Sanches, D. S.; Mansour, M. R.; London Jr., J. B. A.; Delbem, A. C. B.; Santos, A. C. Integrating relevant aspects of moeas to solve loss reduction problem in large-scale distribution systems. In: PowerTech, 2011 IEEE Trondheim, 2011, p. 1 -6.

Santos, A.; Delbem, A.; London, J.; Bretas, N. Node-depth encoding and multiobjective evolutionary algorithm applied to large-scale distribution system reconfiguration. Power Systems, IEEE Transactions on, v. 25, n. 3, p. 1254-1265, 2010.

Santos, A. C. Algoritmo evolutivo computacionalmente eficiente para reconfiguração de sistemas de distribuição. Tese de Doutoramento, Engenharia Elétrica, EESC/USP, São Carlos/SP - Brasil, 2009.

Santos, A. C.; Delbem, A.; Bretas, N. G. Energy restoration for large-scale distribution system using ea and a new data structure. Power and Energy Society General Meeting - Conversion and Delivery of Electrical Energy in the 21st Century, 2008 IEEE, p. 1-8, 2008.

Schaffer, J. D. Multiple objective optimization with vector evaluated genetic algorithms. In: Proceedings of the 1st International Conference on Genetic Algorithms, Hillsdale, NJ, USA: L. Erlbaum Associates Inc., 1985, p. 93-100.

Shirmohammadi, D.; Hong, H.; Semlyen, A.; Luo, G. A compensation-based power flow method for weakly meshed distribution and transmission networks. Power Systems, IEEE Transactions on, v. 3, n. 2, p. 753-762, 1988.

Srinivas, N.; Deb, K. Multiobjective optimization using nondominated sorting in genetic algorithms. Evolutionary Computation, v. 2, n. 3, p. 221-248, 1994.

Zitzler, E.; Laumanns, M.; Thiele, L. Spea2: Improving the strength pareto evolutionary algorithm. Relatório Técnico, 2001. 


\section{Representação Nó-Profundidade e Seus}

\section{Operadores}

\section{A.1 Considerações Iniciais}

Segundo Delbem et al. (2005), a estrutura de dados utilizada para representar um SDR é um fator crítico para o desempenho de AEs aplicados à reconfiguração de redes. Nesse contexto, foi proposto em (Delbem et al., 2004) uma nova codificação de árvores de grafos para ser aplicada a AE que visam solucionar o problema de reconfiguração de redes em SDRs, tendo em vista que as redes de distribuição de energia elétrica podem ser representadas por meio de grafos. Essa codificação, denominada RNP (Representação Nó-Profundidade), será apresentada com maiores detalhes neste apêndice, juntamente com os seus operadores, após uma revisão de alguns conceitos da teoria de grafos.

\section{A.2 Conceitos Básicos da Teoria de Grafos}

Um grafo $G$ consiste de um conjunto finito de pontos, denominados de nós $(\mathrm{N}(\mathrm{G})$ ), interligados ou não por linhas, denominadas de arestas $(\mathrm{E}(\mathrm{G}))$, sendo representado matematicamente por $G=(N, E)$. O número de nós de um grafo $\mathrm{G}$ determina a sua ordem, e o número de arestas de G indica o seu tamanho. Desse modo, a ordem do 
grafo da Figura A.1 é igual a 6 e o seu tamanho é igual a 7. O grau de um nó é dado pelo número de arestas que lhe são incidentes, por exemplo, os nós 1, 2 e 6 da Figura A.1 possuem grau, respectivamente, igual a 2,3 e 1.

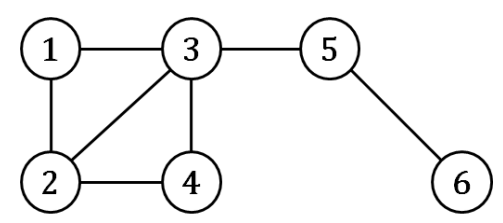

Figura A.1: Exemplo de um grafo.

Em um grafo G qualquer, caminho é uma sequência de nós, tal que, de cada um dos nós exista uma única aresta distinta para o nó seguinte (Mansour, 2009). Além disso, se os nós inicial e final desse caminho são iguais, então esse caminho é chamado de ciclo. Do contrário, se todos os nós do caminho são distintos então esse caminho é chamado de cadeia ou caminho simples (Mansour, 2009). Por exemplo, na Figura A.1 a sequência de nós $5,3,2,4$ e as arestas $\{5,3\},\{3,2\}$ e $\{2,4\}$ formam uma cadeia ou caminho simples, enquanto que a sequência dos nós 1, 3, 5, 6 unidos pelas arestas $\{1,3\},\{3,5\},\{5,6\}$ formam uma cadeia; já a sequência de nós 1, 3, 2, 1 conectados pelas arestas $\{1,3\},\{3,2\},\{2,1\}$ formam um ciclo.

Um par conexo é um par de nós com pelo menos um caminho entre eles. Da mesma forma, um grafo conexo é um grafo no qual todos os pares de nós são um par conexo. Um subgrafo de um grafo G é um grafo formado por alguns dos nós e arestas de G. Um grafo acíclico é um grafo sem ciclos. Uma árvore é um grafo acíclico e conexo. Uma subárvore é um subgrafo de uma árvore. Uma floresta é um grafo formado por um conjuntos de árvores. Nó raiz é um nó de uma árvore tomado como referência e que pode ter grau maior ou igual a um. Nós terminais são os nós de uma árvore que possuem grau igual a um, exceto se for o no raiz. Profundidade de um nó em uma árvore é o número de arestas do caminho formado entre este nó e o nó raiz.

\section{A.3 RNP Aplicada a Problemas de Reconfiguração de Redes}

A RNP, proposta por Delbem et al. (2004), baseia-se nos conceitos de caminho e profundidade de nó em uma árvore de grafo. Conforme dito no Capítulo 4, ela consiste basicamente de uma lista linear contendo os nós da árvore e suas respectivas profundidades, formando pares do tipo $\left(n_{x} ; p_{x}\right)$, sendo $n_{x}$ o nó da árvore e $p_{x}$ a profundidade do nó (Delbem et al., 2004; Mansour, 2009). 
Para ilustrar o modo como uma árvore é armazenada pela RNP, considere a floresta $F$ apresentada na Figura A.2, composta por três árvores. Conforme apresentado na Seção 4.2.1, essa floresta pode ser vista como um SDR com três alimentadores, sendo as árvores, os nós do grafo e as arestas correspondentes, respectivamente, aos alimentadores, setores e chaves seccionadoras. As arestas em linhas cheias representam chaves NF e as arestas em linha tracejada representam chaves NA. Por meio da RNP, cada árvore dessa floresta pode ser codificada e armazenada através das matrizes $T_{1}, T_{2}$, e $T_{3}$, conforme apresentado na Figura A.3 (Santos et al., 2010). É importante destacar que os índices ilustrados nessa figura não fazem parte da RNP. Eles servem apenas como identificadores de cada nó presente na árvore. A codificação para uma floresta é composta pela união das codificações de todas as árvores da mesma ( A.3). Assim, a estrutura de dados da floresta pode ser implementada utilizando uma lista de ponteiros, onde cada ponteiro indica a RNP de uma árvore da floresta (Mansour, 2009).

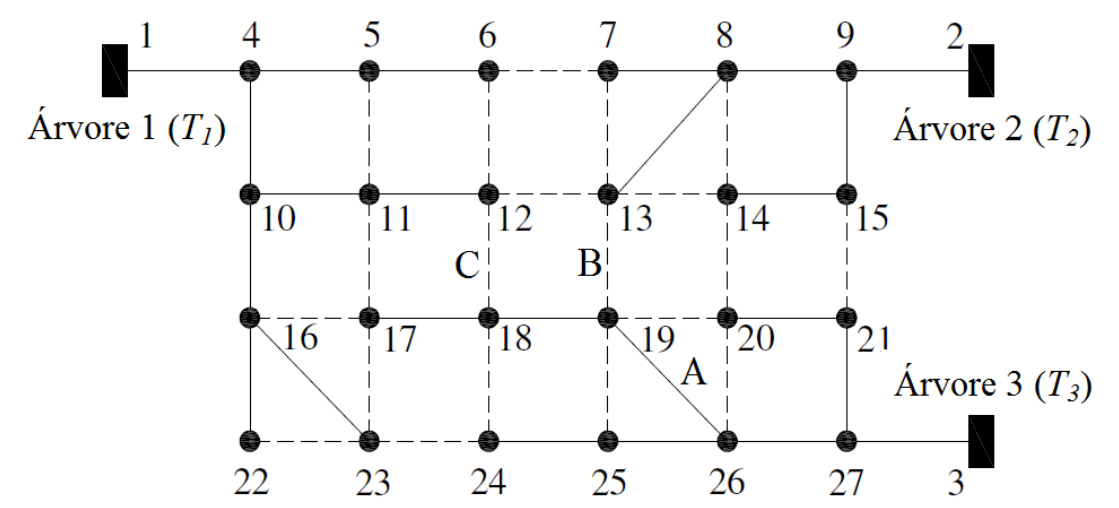

Figura A.2: Grafo representando um SDR com três alimentadores (Santos et al., 2010).

$$
\begin{aligned}
& T_{1}=\left|\begin{array}{c}
\text { índice } \\
\text { prof. } \\
\text { nó }
\end{array}\right|=\left|\begin{array}{cccccccccc}
1 & 2 & 3 & 4 & 5 & 6 & 7 & 8 & 9 & 10 \\
0 & 1 & 2 & 3 & 2 & 3 & 4 & 3 & 4 & 4 \\
1 & 4 & 5 & 6 & 10 & 11 & 12 & 16 & 22 & 23
\end{array}\right| \\
& T_{2}=\left|\begin{array}{c}
\text { índice } \\
\text { prof. } \\
\text { nó }
\end{array}\right|=\left|\begin{array}{ccccccc}
1 & 2 & 3 & 4 & 5 & 6 & 7 \\
0 & 1 & 2 & 3 & 2 & 3 & 3 \\
2 & 9 & 15 & 14 & 8 & 7 & 13
\end{array}\right| \\
& T_{3}=\left|\begin{array}{c}
\text { índice } \\
\text { prof. } \\
\text { nó }
\end{array}\right|=\left|\begin{array}{cccccccccc}
1 & 2 & 3 & 4 & 5 & 6 & 7 & 8 & 9 & 10 \\
0 & 1 & 2 & 3 & 2 & 3 & 4 & 5 & 3 & 4 \\
3 & 27 & 21 & 20 & 26 & 19 & 18 & 17 & 25 & 24
\end{array}\right|
\end{aligned}
$$

Figura A.3: RNP das três árvores da Figura A.2 (Santos et al., 2010).

Para facilitar a manipulação da floresta armazenada em RNPs, com baixo tempo de processamento computacional, foram criados dois operadores: o PAO (Preserve Ancestor Operator) e o CAO (Change Ancestor Operator) (Delbem et al., 2004). Em um AE esses 
operadores tem por finalidade a geração de indivíduos para uma nova geração, ou seja, gerar novos indivíduos candidatos a solução do problema.

De forma sucinta, ambos os operadores transferem uma subárvore (parte podada) de uma árvore $T_{d e}$ (árvore origem) para uma árvore $T_{\text {para }}$ (árvore destino). Entretanto, para o operador PAO a raiz da subárvore podada será a raiz dessa subárvore na nova árvore $T_{\text {para }}$, enquanto que no operador CAO um novo nó, diferente da raiz, é escolhido para ser a nova raiz da subárvore em $T_{\text {para }}$ (Delbem et al., 2004). O operador PAO requer a definição prévia de dois nós: o nó de poda $p$, que indica a raiz da subárvore que será podada; e o nó adjacente $a$, que indica onde a subárvore será inserida na árvore $T_{\text {para }}$. Além desses dois nós, o operador CAO requer ainda o nó $r$, que será a nova raiz da subárvore que será transferida (Delbem et al., 2004; Mansour, 2009).

A fim de facilitar a compreensão acerca do funcionamentos desses dois operadores e de como eles manipulam árvores de grafo, ambos serão apresentados na sequência por meio do desenvolvimento, passo-a-passo, de um exemplo no qual o PAO e o CAO serão aplicados à floresta da Figura A.2, armazenada em 3 RNPs conforme ilustrado na Figura A.3. Para tal, considere a Lista de Adjacências do SDR em questão apresentada na Tabela A.1. No entanto, para melhor compreender a ação desses operadores sobre uma floresta é necessário primeiramente entender como é feita a localização de um nó na RNP de uma floresta. Desse modo, na próxima subseção será ilustrado esse procedimento e nas subseções seguintes a aplicação do PAO e do CAO.

\section{A.3.1 Localização de um nó na RNP}

A posição de um nó $x$ em uma floresta $F$ codificada pela RNP pode ser determinada por meio das matrizes $\Pi_{x}$ e do array $\pi$. Cada nó $x$ de um grafo $G$ possui uma matriz $\Pi_{x}$, que armazena as informações desse nó $x$. Por exemplo, considere que, na floresta inicial $F_{0}$, o nó $x$ pertence a uma árvore $T_{i_{0}}$, e que nessa árvore $x$ possui índice igual a $j_{0}$ e profundidade $k_{0}$. Assim sendo, a matriz $\Pi_{x}$ será dada por:

$$
\Pi_{x}=\left[\begin{array}{c}
0 \\
i_{0} \\
j_{0} \\
k_{0}
\end{array}\right]
$$

Agora suponha que uma nova floresta $F_{\text {posterior }}$ tenha sido gerada a partir de uma floresta $F_{\text {anterior }}$ por meio da transferência de uma subárvore da árvore $T_{i_{\text {anterior }}}$ dando origem a árvore $T_{i_{\text {posteior }}}$ em $F_{\text {posteior }}$, e que o nó $x$ pertença a essa subárvore transferida. Assim, a matriz $\Pi_{x}$ resultará em: 


\begin{tabular}{c|l}
\hline Nó & Nós Adjacentes \\
\hline 1 & 4 \\
2 & 9 \\
3 & 27 \\
4 & $1,5,10$ \\
5 & $4,6,11$ \\
6 & $5,7,12$ \\
7 & $6,8,13$ \\
8 & $7,9,13,14$ \\
9 & $2,8,15$ \\
10 & $4,11,16$ \\
11 & $5,1012,17$ \\
12 & $6,11,13,18$ \\
13 & $7,8,12,14,19$ \\
14 & $8,13,15,20$ \\
15 & $9,14,21$ \\
16 & $10,17,22,23$ \\
17 & $11,16,18,23$ \\
18 & $12,17,19,24$ \\
$\mathbf{1 9}$ & $\mathbf{1 3}, \mathbf{1 8}, \mathbf{2 0}, \mathbf{2 5}, \mathbf{2 6}$ \\
20 & $14,19,21,26$ \\
21 & $15,20,27$ \\
22 & 16,23 \\
23 & $16,17,22,24$ \\
24 & $18,23,25$ \\
25 & $19,24,26$ \\
26 & $19,20,25,27$ \\
27 & $3,21,26$ \\
\hline
\end{tabular}

Tabela A.1: Lista de adjacências para os nós do grafo da Figura A.2 (Santos, 2009).

$$
\Pi_{x}=\left[\begin{array}{cccc}
0 & \ldots & \text { anterior } & \text { posterior } \\
i_{0} & \ldots & i_{\text {anterior }} & i_{\text {posterior }} \\
j_{0} & \ldots & j_{\text {anterior }} & j_{\text {posterior }} \\
k_{0} & \ldots & k_{\text {anterior }} & k_{\text {posterior }}
\end{array}\right]
$$

Assim, toda vez que um nó $x$ qualquer muda de posição em um grafo $G$ por meio da sua transferência de uma árvore para outra, então, é adicionada uma nova coluna em $\Pi_{x}$, a fim de armazenar a atualização dos dados desse nó. Essa atualização deve ser efetuada para todos os nós pertencentes a subárvore transferida (Santos, 2009).

Já o array $\pi$ é um vetor que armazena a relação de ancestralidade entre as florestas (Delbem et al., 2004). Assim, para localizar a posição de um nó $x$ na floresta $F_{i}$, primeiro busca-se, em $\Pi_{x}$, se $F_{i}$ existe em $\Pi_{x}$. Caso contrário, localiza-se em $\pi \mathrm{o}$ 
predecessor de $F_{i}$, chamado de $F_{k}$, com $k<i$, e em seguida busca-se $F_{k}$ em $\Pi_{x}$. Se a busca novamente retornar um valor nulo, o processo recomeça buscando o predecessor de $F_{k}$ até que seja encontrada em $\Pi_{x}$ uma coluna para $x$ em alguma floresta.

\section{A.3.2 Aplicação do Operador PAO}

\section{Etapa 1: definição dos nós $p$ e $a$.}

Passo 1: Selecionar aleatoriamente um índice de uma árvore na floresta $F$ e, nessa árvore, selecionar aleatoriamente o índice de um nó que não seja o nó raiz. A árvore selecionada será chamada de árvore origem, ou $T_{d e}$, e o nó selecionado na mesma será chamado de nó de poda, ou, nó $p$, identificado pelo índice $i_{p}$.

\section{Exemplo 1:}

- Índice de árvore selecionado: 3 (árvore $T_{3}$ );

- Índice de um nó selecionado nessa árvore: 6 ( nó 19).

Assim, $T_{d e}=T_{3}$ e $p=19$ (Figura A.4).

Passo 2: Selecionar aleatoriamente um nó adjacente a $p$ na lista de adjacência ( A.1), e chamá-lo de nó $a$. Se o nó a não pertencer a árvore que contém o nó $p$, então determine a posição de $a$ na floresta $F$ utilizando o array $\pi$ e a matriz $\Pi_{a}$; caso contrário, selecione aleatoriamente outro nó a ou retorne para o Passo 1.

\section{Continuação do exemplo 1:}

- Nó selecionado: 25

- Teste: o nó $a(25)$ pertence a $T_{3}$ ?

Sim! Logo, deve-se selecionar outro nó.

- Novo nó selecionado: 13

- Teste: o nó a $(13)$ pertence a $T_{3}$ ?

Não! Logo, deve-se determinar a qual árvore pertence esse nó a selecionado, bem como a sua profundidade nessa árvore, e o seu índice. Para tal, conforme apresentado na subseção A.3.1, deve-se utilizar a matriz $\Pi_{a}$ e o array $\pi$. Suponha que a floresta atual seja a $F_{1}$ e que a matriz $\Pi_{x}$ no nó $13\left(\Pi_{13}\right)$ seja dada por:

$$
\Pi_{13}=\left[\begin{array}{ll}
0 & 1 \\
1 & 2 \\
8 & 7 \\
5 & 3
\end{array}\right]
$$


Analisando-a observa-se que $F_{1}$ existe em $\Pi_{13}$. Logo, é necessário apenas ler os índices de 13 armazenados na última coluna. Assim, observa-se que, na floresta atual $\left(F_{1}\right)$, esse nó pertence a árvore $T_{2}$, e que seu índice e sua profundidade nessa árvore são, respectivamente, 7 e 3 . A matriz $\Pi_{13}$ permite observar ainda que na floresta $F_{0}$ o nó 13 pertencia a outra árvore $T_{1}$.

Desse modo, para o exemplo em questão, foram selecionados: a árvore 3 como árvore origem $\left(T_{d e}=T_{3}\right.$, ) e o nó 19 como nó de poda $(p=19)$, sendo $i_{p}=6$ (Figura A.4); a árvore 2 como árvore destino $\left(T_{\text {para }}=T 2\right)$ e o nó 13 como nó a $(a=13)$, sendo $i_{a}=7$ (Figura A.5).

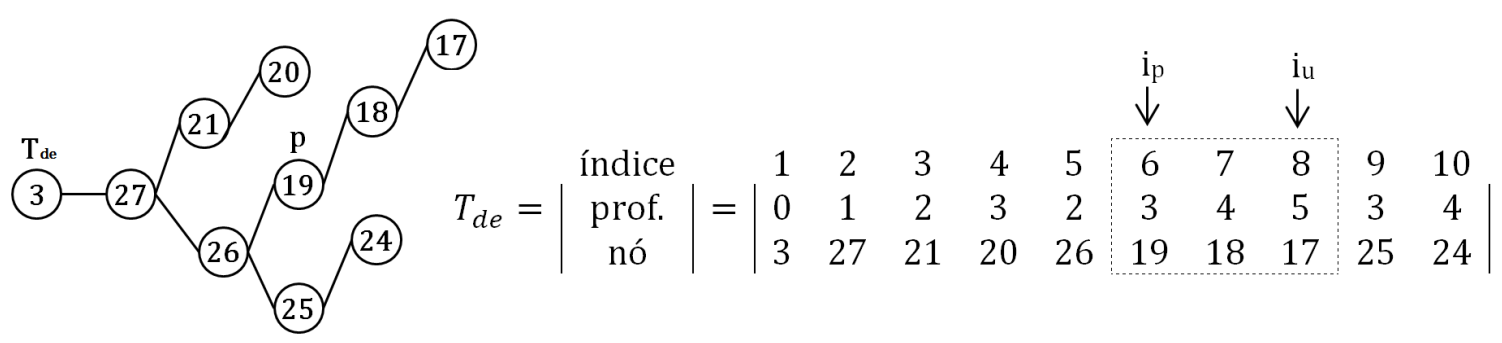

Figura A.4: Árvore $T_{d e}$ e sua RNP, para aplicação do operador PAO.

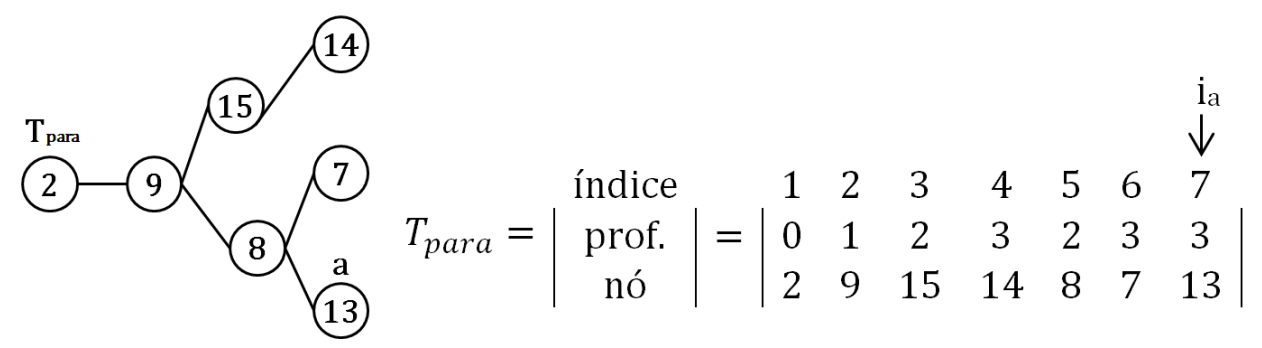

Figura A.5: Árvore $T_{\text {para }}$ e sua RNP, para aplicação do operador PAO.

\section{Etapa 2: aplicação propriamente dita do operador PAO}

Definidos os nós $p$ e $a$, os seus índices $i_{p}$ e $i_{a}$, e as árvores $T_{d e}$ e $T_{\text {para }}$, pode-se aplicar o operador PAO da RNP.

Passo 1: Determinar a subárvore que será podada em $T_{d e}$ (essa subárvore é aquela que possui o nó $p$ como raiz). Para tal, deve-se determinar o intervalo $i_{p}-i_{u}$, onde $i_{p}$ é o índice do nó $p$, em $T_{d e}$, e $i_{u}$ é o índice do último nó folha $u$ que tem o nó $p$ como 'raiz', em $T_{d e}$. Como $i_{p}$ já é conhecido, faz-se necessário obter apenas $i_{u}$. Para determiná-lo parte-se do pressuposto de que o conjunto de nós no intervalo $i_{p}-i_{u}$ corresponde ao nó $p$ em $i_{p}$ e aos consecutivos nós $x$ na árvore $T_{d e}$ de tal forma que $i_{x}>i_{p}$ e $p_{x}>p_{p}\left(p_{x}\right.$ é a profundidade do nó $x, p_{p}$ é a profundidade do nó $p$ ). Ou seja, esse conjunto é formado pelo nó $p$ e por todos os nós que o possuem como 'raiz' ou antecessor comum.

\section{Continuação do exemplo 1:}


No exemplo em questão $i_{19}<i_{18}<i_{17}<i_{25} \ldots$ e $p_{19}<p_{18}<p_{17}>p_{25}$, logo $u=17$ e, portanto, $i_{u}=8$. Ou seja, a subárvore que será podada em $T_{d e}$ é formada pelos nós 19 , 18 e 17 (retângulo tracejado na Figura A.4).

Passo 2: Copiar os dados dos nós contido no intervalo $i_{p}-i_{u}$ de $T_{d e}$ para uma matriz temporária $T_{t m p}$ (subárvore podada), e atualizar a profundidade de cada nó $x$ presente nesse intervalo por meio da equação $p_{x}=p_{x}-p_{p}+p_{a}+1$.

\section{Continuação do exemplo 1:}

Sendo $p_{a}=3$ e $p_{p}=3$, a subárvore podada $T_{t m p}$, com a profundidade de cada nó atualizada, é ilustrada pela Figura A.6.

$$
T_{t m p}=\left|\begin{array}{c}
\text { prof. } \\
\text { nó }
\end{array}\right|=\left|\begin{array}{ccc}
4 & 5 & 6 \\
19 & 18 & 17
\end{array}\right|
$$

Figura A.6: Subárvore podada $T_{t m p}$ e sua RNP, na aplicação do operador PAO.

Passo 3: Criar uma matriz $T_{\text {para }}^{\prime}$ que contenha os dados de $T_{\text {para }}$ mais os dados de $T_{t m p}$, sendo que estes últimos devem ser inseridos em $T_{\text {para }}$ a partir da posição definida pelo índice $i_{a}$. Posteriormente, os índices de $T_{\text {para }}$ devem ser atualizados em $T_{\text {para }}^{\prime}$.

\section{Continuação do exemplo 1:}

Sendo $i_{a}=7$, a árvore $T_{\text {para }}^{\prime}$ e a sua codificação em matriz são apresentadas na Figura A.7.

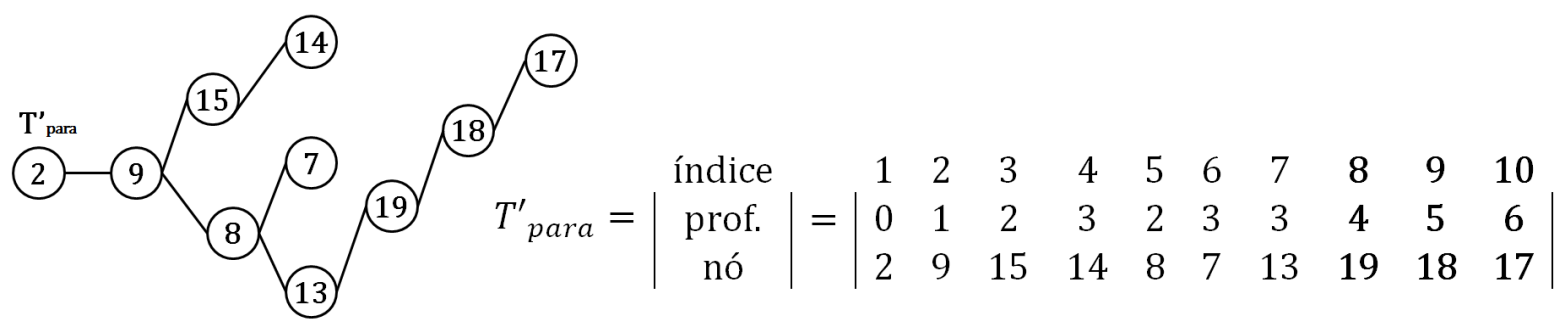

Figura A.7: Árvore $T_{\text {para }}^{\prime}$ e sua RNP após a aplicação do operador PAO.

Passo 4: Construir a matriz $T_{d e}^{\prime}$ compreendendo os nós de $T_{d e}$ sem os nós de $T_{t m p}$, ou seja, sem os nós da subárvore podada, e atualizar os índices de $T_{d e}$ em $T_{d e}^{\prime}$.

\section{Continuação do exemplo 1:}

Passo 5: Copiar a estrutura de ponteiros de $F$ para $F^{\prime}$, trocando o ponteiro de $T_{d e}$ para $T_{d e}^{\prime}$ e o de $T_{\text {para }}$ para $T_{\text {para }}^{\prime}$.

\section{Continuação do exemplo 1:}

Desse modo, a árvore $T_{3}\left(T_{d e}\right)$ se transformará em $T_{3}^{\prime}$ e $T_{2}\left(T_{\text {para }}\right)$, e a floresta $F^{\prime}$ será dada pelas RNPs apresentadas na Figura A.9. 


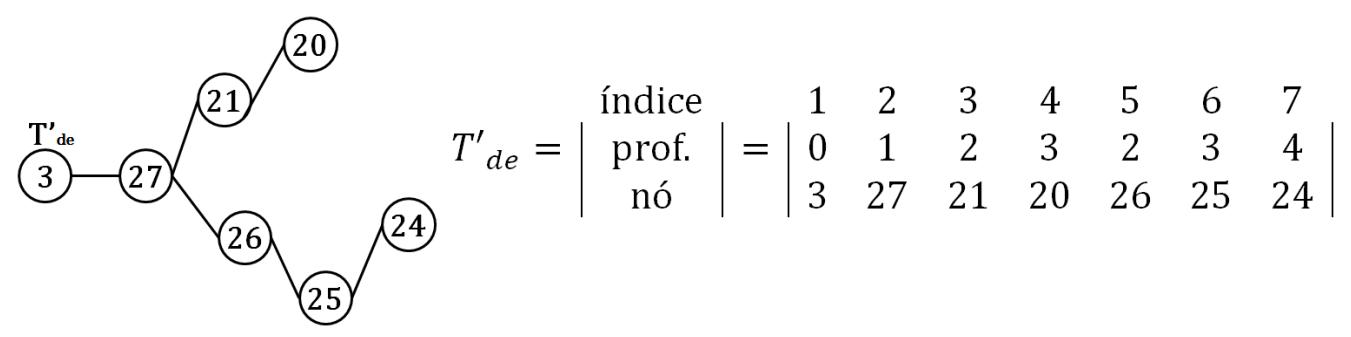

Figura A.8: Árvore $T_{d e}^{\prime}$ e sua RNP após a aplicação do operador PAO.

$$
\begin{aligned}
T_{1}=\left|\begin{array}{c}
\text { índice } \\
\text { prof. } \\
\text { nó }
\end{array}\right|=\left|\begin{array}{llllllllll}
1 & 2 & 3 & 4 & 5 & 6 & 7 & 8 & 9 & 10 \\
0 & 1 & 2 & 3 & 2 & 3 & 4 & 3 & 4 & 4 \\
1 & 4 & 5 & 6 & 10 & 11 & 12 & 16 & 22 & 23
\end{array}\right| \\
T_{2}^{\prime}=\left|\begin{array}{c}
\text { índice } \\
\text { prof. } \\
\text { nó }
\end{array}\right|=\left|\begin{array}{cccccccccc}
1 & 2 & 3 & 4 & 5 & 6 & 7 & 8 & 9 & 10 \\
0 & 1 & 2 & 3 & 2 & 3 & 3 & 4 & 5 & 6 \\
2 & 9 & 15 & 14 & 8 & 7 & 13 & 19 & 18 & 17
\end{array}\right| \\
T_{3}^{\prime}=\left|\begin{array}{cccccccc}
\text { índice } \\
\text { prof. } \\
\text { nó }
\end{array}\right|=\left|\begin{array}{ccccccc}
1 & 2 & 3 & 4 & 5 & 6 & 7 \\
0 & 1 & 2 & 3 & 2 & 3 & 4 \\
3 & 27 & 21 & 20 & 26 & 25 & 24
\end{array}\right|
\end{aligned}
$$

Figura A.9: RNP da floresta $F^{\prime}$ obtida pela aplicação do operador PAO.

Sob a ótica da engenharia a aplicação do operador PAO no SDR da Figura A.2 consistiu na transferência dos setores 17, 18 e 19 do alimentador 3 para o alimentador 2. Na prática isso significa a abertura da chave A e fechamento da chave B (Figura A.2) e consequentemente a manutenção do sentido do fluxo do potência através dos setores transferidos.

\section{A.3.3 Aplicação do Operador CAO}

Etapa 1: definição dos nós $p, r$ e $a$

Passo 1: Selecionar aleatoriamente um índice de uma árvore da floresta $F$ e para essa árvore, selecionar aleatoriamente o índice de um nó que não seja o nó raiz $\left(i_{p}\right)$. A árvore selecionada será a árvore $T_{d e}$, e nó selecionado na mesma será o nó $p$.

\section{Exemplo 2:}

- Índice de árvore selecionado: 3 (árvore $T_{3}$ );

- Índice de um nó selecionado nessa árvore: 6 (nó 19).

Assim, $T_{d e}=T_{3}, p=19$ e $i_{p}=6$.

Passo 2: Determinar o conjunto de nós que tem o nó $p$ como 'raiz', ou antecessor comum, (conjunto formado pelos nós pertencentes ao intervalo $i_{p}-i_{u}$ ), ou seja, determinar 
a subárvore que será podada e transferida. Em seguida escolher aleatoriamente um índice de nó nesse conjunto e chamar esse nó de $r$, que será o novo nó raiz da subárvore podada.

\section{Continuação do exemplo 2:}

- Para esse caso, o conjunto dos nós pertencentes ao intervalo $i_{p}-i_{u}$ é o mesmo determinado no passo 1 da etapa 2 do exemplo 1, ou seja, nós 19, 18 e 17 que possuem profundidade igual a 3,4 e 5 e índices iguais a 6,7 e 8 , respectivamente;

- Índice escolhido aleatoriamente dentro desse conjunto: 7 (nó 18). Portanto, $i_{r}=7$ e $r=18$.

Passo 3: Selecionar aleatoriamente um nó adjacente a $r$, na lista de adjacências, e chamá-lo de nó adjacente $a$. Se o nó a não pertencer a árvore que contém o nó $p$, então determine a sua posição na floresta $F$ utilizando o array $\pi$ e a matriz $\Pi_{a}$; caso contrário, selecione aleatoriamente outro nó a ou retorne para o passo 1.

\section{Continuação do exemplo 2:}

- Nó a (adjacente a $r$ ) selecionado: 12;

- Teste: o nó a pertence a $T_{3}$ ?

Não! Logo, deve-se determinar a sua posição em $F$, ou seja, a qual árvore o nó selecionado pertence, bem como seu índice e profundidade nesse nó. Suponha que a matriz $\Pi_{a}$ desse nó seja dada por:

$$
\Pi_{12}=\left[\begin{array}{l}
0 \\
1 \\
7 \\
4
\end{array}\right]
$$

Por meio de $\Pi_{12}$ observa-se que o nó 12 da floresta $F$ pertence a árvore $T_{1}$, possui índice $i_{a}$ igual a 7 e profundidade igual a 4 . Vê-se ainda que esse nó sempre pertenceu a essa árvore.

Desse modo, para o exemplo em questão, foram selecionados: a árvore 3 como árvore origem $\left(T_{d e}=T_{3},\right)$ o nó 19 como nó de poda $(p=19)$ e o nó 18 como novo nó raiz $(r=18)$, sendo $i_{p}=6$ e $i_{r}=7$; (Figura A.10); a árvore 1 como árvore destino( $T_{\text {para }}=T 1$ ) e o nó 12 como nó a $(a=12)$, sendo $i_{a}=7$ (Figura A.11).

\section{Etapa 2: aplicação propriamente dita do operador CAO}

Passo 1: Igual ao passo 1 do operador PAO.

Continuação do Exemplo 2: 


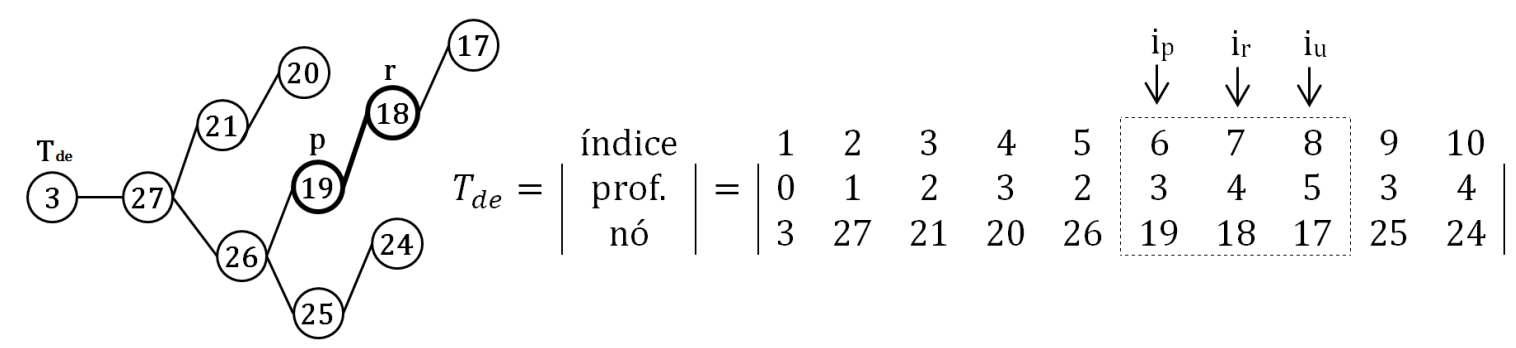

Figura A.10: Árvore $T_{d e}$ e sua RNP, para aplicação do operador CAO.

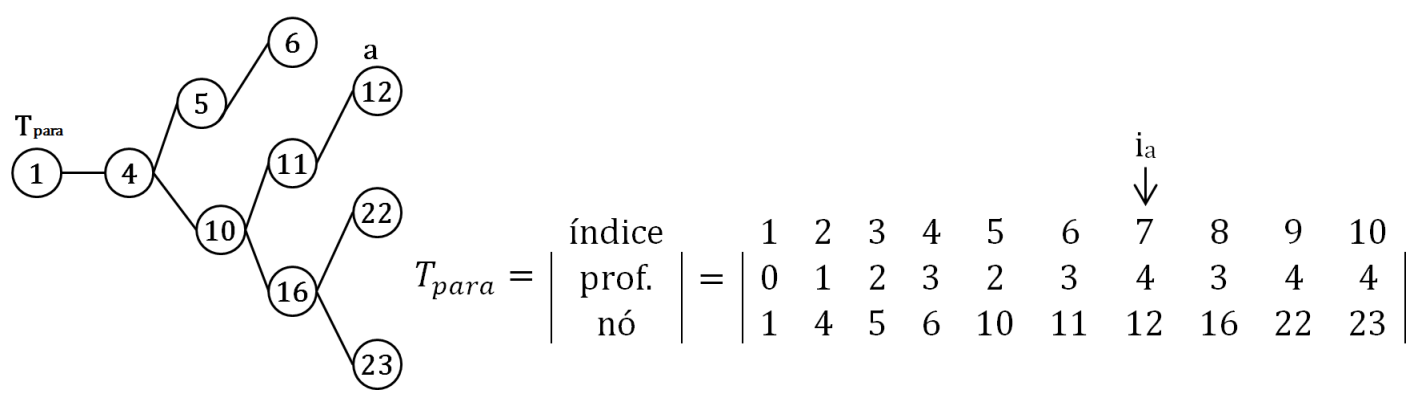

Figura A.11: Árvore $T_{\text {para }}$ e sua RNP, para aplicação do operador CAO.

A subárvore que será podada em $T_{d e}$ corresponde aos nós presentes no retângulo tracejado da Figura A.10.

Passo 2: No operador CAO o passo 2 é dividido em dois subpassos (2.1 e 2.2).

Passo 2.1: Copiar os dados dos nós presentes no intervalo $i_{r}-i_{u}$, em $T_{d e}$, para um vetor temporário $T_{t m p}$, e atualizar a profundidade de cada nó por meio da equação $p_{x}=p_{x}-p_{r}+p_{a}+1$ (igual ao passo 2 do operador 1 , trocando apenas $i_{p}$ por $i_{u}$ ).

\section{Continuação do exemplo 2:}

Sendo $p_{r}=4$ e $p_{a}=4$, a subárvore podada $T_{t m p}$, com a profundidade de cada nó atualizada, é apresentada na Figura A.13.

Passo 2.2: Percorrer o caminho entre os nós $r$ e $p$, isto é, $r_{0}, r_{1}, r_{2}, \ldots, r_{n}$, onde $r_{0}=r$ e $r_{n}=p$, e considerar cada nó desse caminho como raízes de subárvores (ver nós destacados na Figura A.10). Em seguida copiar cada subárvore enraizada em $r_{i}(i=01,2, \ldots, n)$, sem a subárvore enraizada em $r_{i-1}$ e com as profundidades atualizadas, para uma matriz temporária $T_{t m p}$, que corresponde a árvore que será inserida em $T_{\text {para }}$.

\section{Continuação do exemplo 2:}

Nesse caso o caminho entre os nós $r$ e $p$ é formado apenas pelos próprios nó $r$ e $p$. Logo, as subárvores enraizadas nestes nós são aquelas apresentadas pela Figura A.12 e a matriz temporária $T_{t m p}$, correspondendo a subárvore podada com profundidades atualizadas, é ilustrada na Figura A.13.

Passo 3: Igual ao passo 3 do operador PAO.

Continuação do Exemplo 2: 


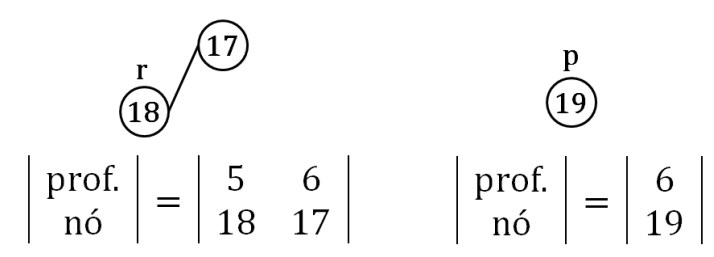

Figura A.12: Subárvores enraizadas nos nós do caminho de $r$ a $p$.

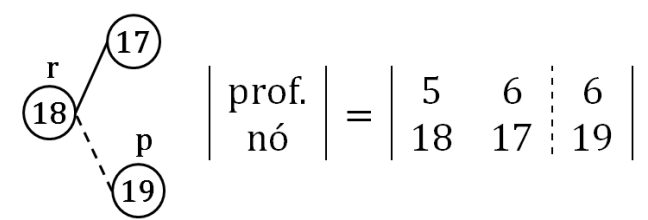

Figura A.13: Subárvore $T_{t m p}$ e sua RNP na aplicação do operador CAO.

A árvore $T_{\text {para }}^{\prime}$ contendo os dados de $T_{\text {para }}$ mais os dados de $T_{t m p}$ bem como a sua RNP pode ser vista na Figura A.14.

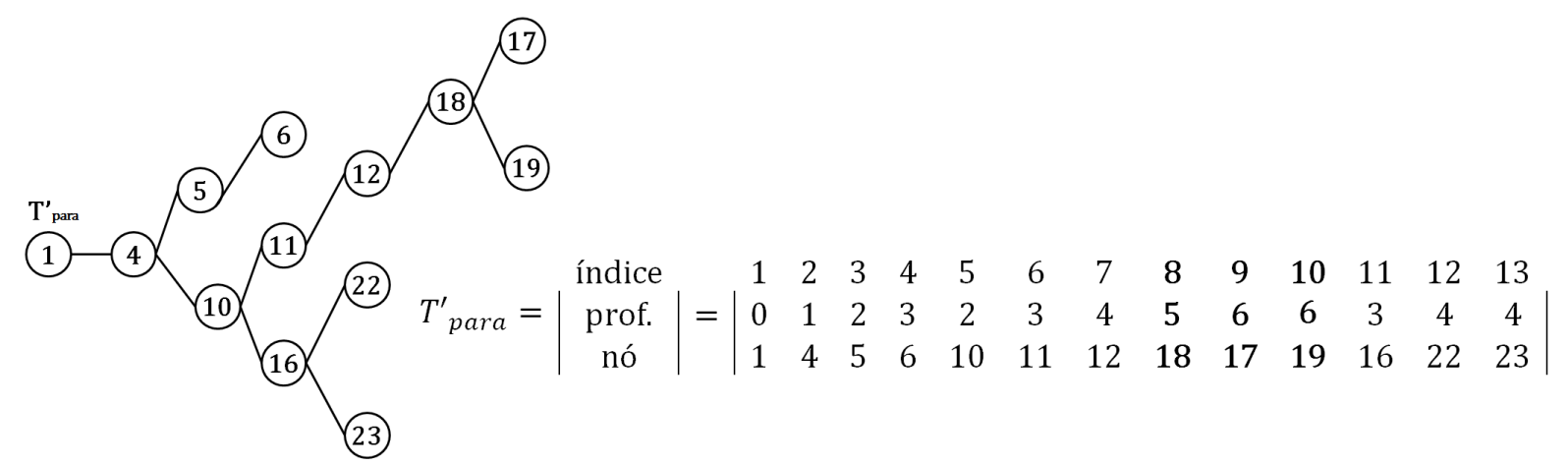

Figura A.14: Árvore $T_{\text {para }}^{\prime}$ e sua RNP após a aplicação do operador CAO.

Passo 4: Igual ao passo 4 do operador PAO.

Continuação do Exemplo 2:

A árvore $T_{d e}^{\prime}$ resultante e sua RNP é a mesma do exemplo anterior, sendo esta apresentada na Figura A.8.

Passo 5: Igual ao passo 5 do operador PAO.

Continuação do Exemplo 2:

A floresta $F^{\prime}$, produto da aplicação do operador CAO na floresta da Figura A.2, é aquela ilustrada pela Figura A.15.

Sob a ótica da engenharia a aplicação do operador CAO no SDR da Figura A.2 consistiu na transferência dos setores 17, 18 e 19 do alimentador 3 para o alimentador 1 por meio da abertura da chave A e fechamento da chave C. E, por possibilitar a reconexão da rede por meio de qualquer setor da rede em transferência, o operador CAO faz com que o fluxo de potência mude de direção em alguns trechos da rede transferida de alimentador. 


$$
\begin{aligned}
T_{1}^{\prime} & =\left|\begin{array}{c}
\text { índice } \\
\text { prof. } \\
\text { nó }
\end{array}\right|=\left|\begin{array}{ccccccccccccc}
1 & 2 & 3 & 4 & 5 & 6 & 7 & 8 & 9 & 10 & 11 & 12 & 13 \\
0 & 1 & 2 & 3 & 2 & 3 & 4 & 5 & 6 & 6 & 3 & 4 & 4 \\
1 & 4 & 5 & 6 & 10 & 11 & 12 & 18 & 17 & 19 & 16 & 22 & 23
\end{array}\right| \\
T_{2} & =\left|\begin{array}{c}
\text { índice } \\
\text { prof. } \\
\text { nó }
\end{array}\right|=\left|\begin{array}{cccccccc}
1 & 2 & 3 & 4 & 5 & 6 & 7 \\
0 & 1 & 2 & 3 & 2 & 3 & 3 \\
2 & 9 & 15 & 14 & 8 & 7 & 13
\end{array}\right| \\
T_{3}^{\prime} & =\left|\begin{array}{c}
\text { índice } \\
\text { prof. } \\
\text { nó }
\end{array}\right|=\left|\begin{array}{cccccccc}
1 & 2 & 3 & 4 & 5 & 6 & 7 \\
0 & 1 & 2 & 3 & 2 & 3 & 4 \\
3 & 27 & 21 & 20 & 26 & 25 & 24
\end{array}\right|
\end{aligned}
$$

Figura A.15: RNP da floresta $F^{\prime}$ gerado pela a aplicação do operador CAO.

\section{A.4 Considerações Finais}

A RNP é uma nova estrutura de dados capaz de representar computacionalmente SDRs de forma eficiente, sem simplificações e manipulá-lo de maneira simples por meio dos seus operadores PAO e CAO. Por sua importância no desenvolvimento desse trabalho, a RNP e seus operadores foram apresentadas nesse apêndice de forma detalhada por meio de um exemplo relacionado a problemas de reconfiguração de redes, de uma forma geral. Ademais, para complementar essas informações, foi detalhado o procedimento de localização de um nó em uma floresta codificada pela RNP, necessário para aplicação dos operadores. 